\title{
Radiopaque bioactive microspheres as injectable biomaterials
}

Citation for published version (APA):

Saralidze, K. (2008). Radiopaque bioactive microspheres as injectable biomaterials. [Doctoral Thesis, Maastricht University]. Datawyse / Universitaire Pers Maastricht. https://doi.org/10.26481/dis.20080214ks

Document status and date:

Published: 01/01/2008

DOI:

$10.26481 / \mathrm{dis} .20080214 \mathrm{ks}$

Document Version:

Publisher's PDF, also known as Version of record

\section{Please check the document version of this publication:}

- A submitted manuscript is the version of the article upon submission and before peer-review. There can be important differences between the submitted version and the official published version of record.

People interested in the research are advised to contact the author for the final version of the publication, or visit the DOI to the publisher's website.

- The final author version and the galley proof are versions of the publication after peer review.

- The final published version features the final layout of the paper including the volume, issue and page numbers.

Link to publication

\footnotetext{
General rights rights.

- You may freely distribute the URL identifying the publication in the public portal. please follow below link for the End User Agreement:

www.umlib.nl/taverne-license

Take down policy

If you believe that this document breaches copyright please contact us at:

repository@maastrichtuniversity.nl

providing details and we will investigate your claim.
}

Copyright and moral rights for the publications made accessible in the public portal are retained by the authors and/or other copyright owners and it is a condition of accessing publications that users recognise and abide by the legal requirements associated with these

- Users may download and print one copy of any publication from the public portal for the purpose of private study or research.

- You may not further distribute the material or use it for any profit-making activity or commercial gain

If the publication is distributed under the terms of Article $25 \mathrm{fa}$ of the Dutch Copyright Act, indicated by the "Taverne" license above, 
Radiopaque Bioactive Microspheres as Injectable Biomaterials 
Radiopaque Bioactive Microspheres as Injectable Biomaterials ISBN 9789052786995

Printed by Datawyse / Universitaire Pers Maastricht Copyright (C K. Saralidze, Maastricht 2008 


\title{
Radiopaque Bioactive Microspheres as Injectable Biomaterials
}

\author{
PROEFSCHRIFT
}

ter verkrijging van de graad van doctor aan de Universiteit Maastricht, op gezag van de Rector Magnificus, Prof. Mr. G.P.M.F. Mols, volgens het besluit van het College van Decanen, in het openbaar te verdedigen op donderdag 14 februari 2008 om 14.00 uur

door

Ketie Saralidze

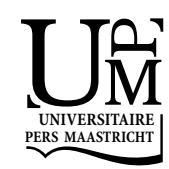




\section{Promotor}

Prof. dr. ir. L.H. Koole

\section{Copromotores}

Dr. M.L.W. Knetsch

Dr. ir. C.S.J. van Hooy-Corstjens

\section{Beoordelingscommissie}

Prof. dr. Ph. Van Kerrebroeck (voorzitter)

Prof. dr. H. ten Cate

Dr. M. De Haan

Prof. dr. C. Jérôme (Université de Liège)

Prof. dr. D. Klee (Rheinisch-Westfälische-Technische-Hochschule Aachen)

This thesis-project was funded by Graduiertenkolleg 1035 "BioInterface - Detektion und Steuerung grenzflächen-induzierter biomolekularer und zellulärer Funktionen" in which the Rheinisch Westfälische Technische Hochschule Aachen, and the Universities of Liège and Maastricht cooperate.

The research in this thesis was also supported by the Technology Foundation STW, project 0.6777 entitled "Intrinsic radiopacity for embolic microspheres".

Financial support for the printing of this thesis by the Dutch Society for Biomaterials and Tissue Engineering is greatly acknowledged. 
To my parents

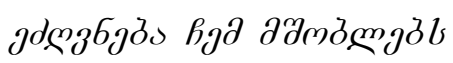





\section{CONTENTS}

$\begin{array}{lll}\text { Chapter } 1 \quad \text { General Introduction. } & 9\end{array}$

Chapter 2 Injectable Polymeric Microspheres with X-ray visibility.

Preparation, properties, and potential utility as new traceable bulking agents.

Chapter 3 Development of new injectable bulking agents: biocompatibility of radiopaque polymeric microspheres studied in a mouse model.

Chapter 4 Radio-opaque and surface-functionalized polymer microparticles: potentially safer biomaterials for different injection therapies.

Chapter 5 New acrylic microspheres for arterial embolization:

combining radiopacity for precise localization with immobilized thrombin to trigger local blood coagulation.

Chapter 6 Radiopaque microspheres containing acrolein for protein attachment to improve cell adhesion.

Chapter $7 \quad$ New intrinsically radiopaque hydrophilic microspheres for embolization: synthesis and characterization.

Summary

Samenvatting

Краткое обозрение

дмз

List of publications

Acknowledgements

Curriculum Vitae 


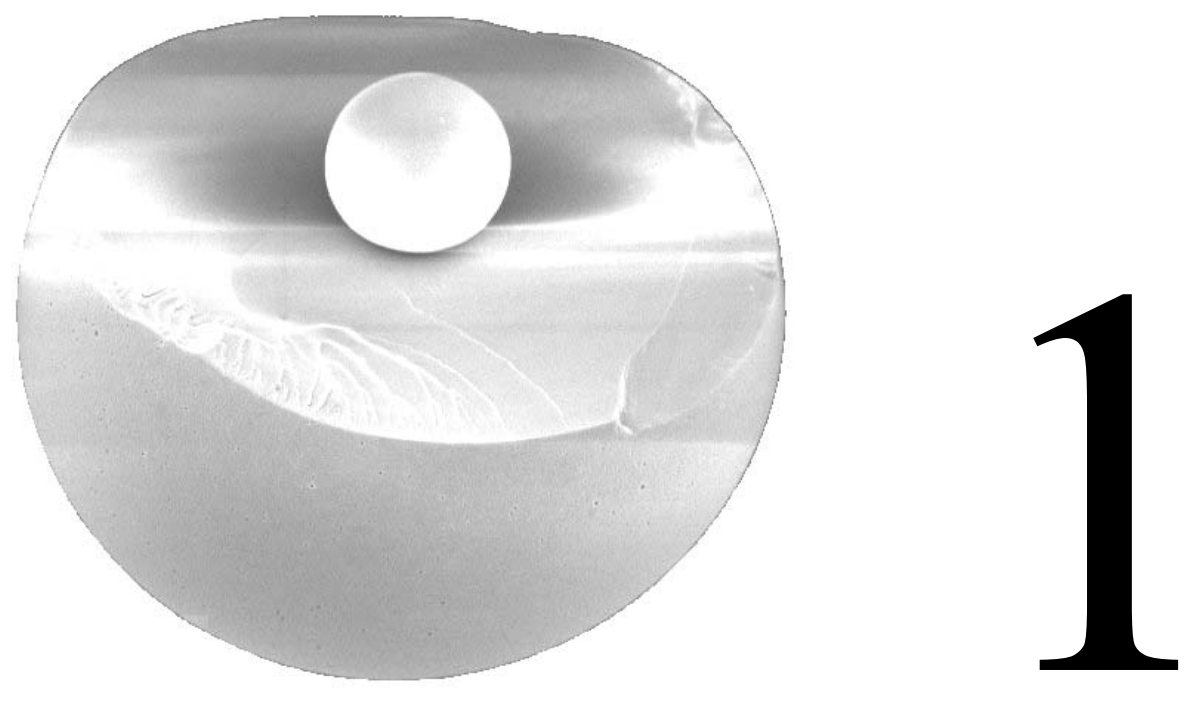

General Introduction 


\section{Chapter 1}

\section{Preface}

The number of applications of synthetic biomaterials continues to expand. One particularly interesting new development concerns the use of injectable polymeric biomaterials, e.g., to correct wrinkles and lips, to treat lipoatrophy in AIDS patients, or to treat acne scars. Injection of synthetic biomaterials is also used to treat stress urinary incontinence, or vesicoureteral reflux, for vocal cord augmentation, and in various embolization strategies, such as those aimed at blockage of tumor-feeding arteries, or uterine fibroids. The increase in use of injectable biomaterials has coincided with improved imaging techniques, so that minimally invasive treatment of patients has become more reliable and safe. Imaging of the injected biomaterials is important to control the treatment procedure in real time, to avoid complications and to assess therapeutic success. Minimally invasive approaches have set new standards for the physico-chemical characteristics of the injectable materials, in so far that they have to be easily detectable by clinically available imaging techniques, like X-ray or magnetic resonance imaging (MRI). The standard polymeric biomaterials that have been used for injection purposes are dominated by inert materials that are poorly visible with standard imaging techniques.

This thesis focuses in particular on the development of new injectable biomaterials that combine intrinsic X-ray visibility with a biofunctionality.

\section{Stress Urinary Incontinence}

In 2003, the International Continence Society committee on terminology presented a well-considered set of definitions for lower urinary tract functions and dysfunctions. The committee defined stress urinary incontinence as follows:

Stress urinary incontinence (SUI) is the complaint of involuntary leakage on effort or exertion, or sneezing or coughing [1].

Incontinence, i.e., the complaint of involuntary leakage of urine, has been known as long as written records are being made. Already in the $2^{\text {nd }}$ millennium $\mathrm{BC}$, the Egyptians described a series of recipes and treatments for incontinence $[2,3]$. Nowadays, more than 200 million people worldwide live with incontinence. A major subset of these patients, approximately 35\%, suffers from so-called stress urinary 
incontinence. SUI is a bladder storage problem in which the strength of the muscles (urethral sphincter) that help to control urination is reduced. The sphincter is not able to prevent urine flow when there is increased pressure from the abdomen. The disease is usually caused by weakening of the pelvic floor muscles that support the bladder and urethra or because of malfunction of the urethral sphincter (intrinsic sphincter deficiency). The weakness may be caused by prior injury to the urethral area, child birth, neurological injury, medications, or after surgery.
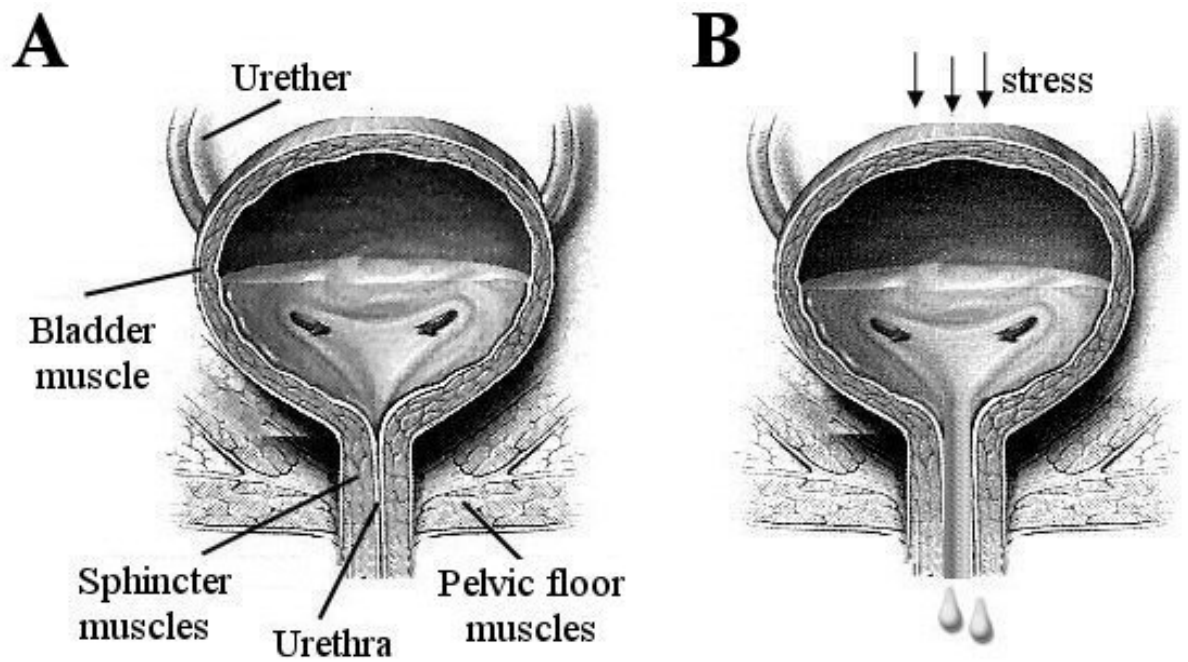

Figure 1. Front view of bladder. a) Strong sphincter and pelvic muscles keep the urethra closed. b) Weak muscles result in urine leakage.

SUI is the most common type of urinary incontinence in women. Studies have shown about $50 \%$ of all women have occasional urinary incontinence. At least $10 \%$ have frequent incontinence, and approximately $20 \%$ of women over age 75 experience daily urinary incontinence. One has to realize that these data represent only the portion of women who chose to discuss their symptoms. Owing to embarrassment and other factors, fewer than half of the women seek treatment or talk to a physician [4].

Therefore, SUI is an important medical and societal problem. More than $65 \%$ of the treatment-seeking SUI patients in 14 European countries reported that they were moderately to extremely bothered by the symptoms [5]. For instance, the impact of SUI 


\section{Chapter 1}

on sexual activity in women is considerable, since the disease can lead to sexual anxiety [6,7]. Furthermore, numerous women avoid sport activities [8].

The etiology of SUI is well investigated. The most important risks are: being female, age [9-11], childbirth, smoking, obesity, and chronic coughing (e.g., as a result of bronchitis and asthma). SUI is most prevalent in white Caucasian women [12,13]. Childbirth increases the risk of SUI drastically. The prevalence of SUI in parous women is much higher than in nulliparous women, since pelvic floor injuries are common during vaginal delivery $[14,15]$. Menopause is associated with aging of patients, and it has been shown that postmenopausal women have higher frequency of SUI, compared to peri- and pre-menopausal women $[16,17]$. Also, women whose mothers and older sisters are incontinent have an increased risk of acquiring SUI themselves $[18,19]$. Smoking, which is associated with decreased collagen synthesis, is believed to cause weakening of the pelvic floor's supportive muscles [20]. The association between SUI and obesity is probably a consequence of the fact that excess weight places extra pressure on the pelvic floor, compromising the outlet [21].

It seems logical to suppose, that physically fit woman have a strong pelvic floor as a result of their regular training, thus have less chance of obtaining urinary incontinence problems. But this does not correspond to the facts. Sports involving high impact activities such as gymnastics, track and field, and some ball games also pose a significant risk to develop urinary incontinence problems [22,23]. Tea drinkers are at slightly higher risk for all types of incontinence. A decrease of fluid intake can result in improvement of SUI. Intake of caffeine containing beverages has no important effect on SUI [24]. Diabetic and pre-diabetic woman have twice the prevalence of stress urinary incontinence, compared with healthy woman [25].

\section{Treatment of SUI}

In 1948 Arnold Kegel introduced pelvic floor muscle training (PFMT) for management of SUI [26]. The aim of these exercises, which may actually root in Chinese Taoism, is to strengthen the muscles which support the urethra, bladder sphincter muscles, via permanent elevation of the levator plate into a higher location inside the pelvis, increased muscle volume, strengthened connective tissue in the muscles, strengthened bony connections, and more effective recruiting of motor neurons [27]. Long-term results of PFMT program are unclear. Symptoms tend to worsen on the long run and 
women then prefer alternative treatments [28]. Another considerable argument against this method is the conviction that PFMT must be done permanently. But because of the lack of risk and relatively small cost, PFMT is recommended by health professionals as a first-line therapy [29].

Pharmacological treatment of SUI has been attempted, but with moderate success. The mixed serotonin/noradrenaline reuptake inhibitor Duloxetine was used. Duloxetine was believed to increase the strength of urethral sphincter contraction and to increase bladder outlet resistance, thereby, prevent accidental urine leakage. However, Duloxetine has a wide spectrum of severe side effects, which led to denial of approval by the US Food and Drug administration [30-35].

There are also surgical interventions, which have been practiced for decades. In 1996 Ulmstein first introduced tension-free vaginal tape (TVT), used as a sling [36]. This procedure is performed through a small vaginal and two small abdominal incisions. TVT involves placing a narrow strip of synthetic material around the middle of the urethra. Surgical intervention of SUI has been associated with some serious complications like perforation of the bladder [37], excessive bleeding [38], erosion of the sling into the vagina or urinary tract [39-41], and infection. Urethral erosion is dependent on the biomechanical and mesh properties of the tape, as well as on surgical technique. Complications result in pain and worsening of SUI symptoms [42-45]. When the implanted biomaterial meshes extrude from the tissue, infection is almost unavoidable and the sling has to be removed. Furthermore, bone anchors used in SUI surgery can be associated with pubic osteomyelitis and osteitis pubis. In such cases, surgical removal and aggressive treatment with long-term antibiotics is required [46,47].

\section{Modern minimally invasive therapies for SUI}

During the last two decades, less invasive procedures, aimed at achieving high longterm cure rates for SUI, have been developed. Most successful are peri-urethral injections of a so-called bulking agent. This technique led to very good results, especially for the elderly patients, for women who have undergone multiple failed procedures, or after radiotherapy where the urethra may have become fixed and scarred. From the perspective of biomaterials science, these developments are particularly interesting. A variety of different bulking agents have been used; the most commonly used materials are cross-linked bovine collagen (Contigen), polydimethylsiloxane 


\section{Chapter 1}

(PDMS, Macroplastique), ethylene vinyl alcohol copolymer (Tegress), polytetrafluoroethylene (PTFE, Urethrin), carbon-coated zirconiumdioxide beads (Durasphere), calcium hydroxylapatite (Coaptite), and dextranomer/hyaluronic acid copolymer. Bulking agents are injected carefully in the periurethral tissue. The goal is urethral coaptation during the storage of urine, maintenance of that coaptation during periods of increased abdominal pressure, and improving sphincter closure.

A

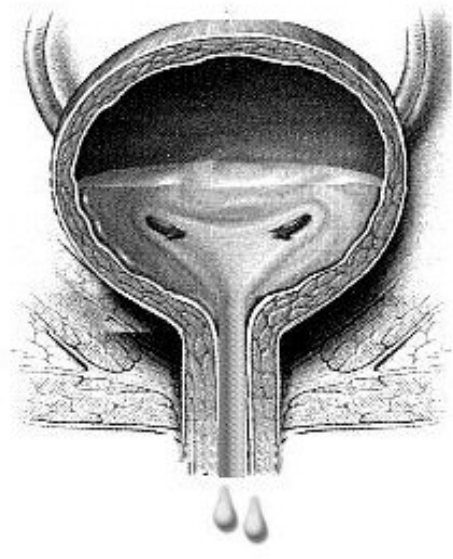

B

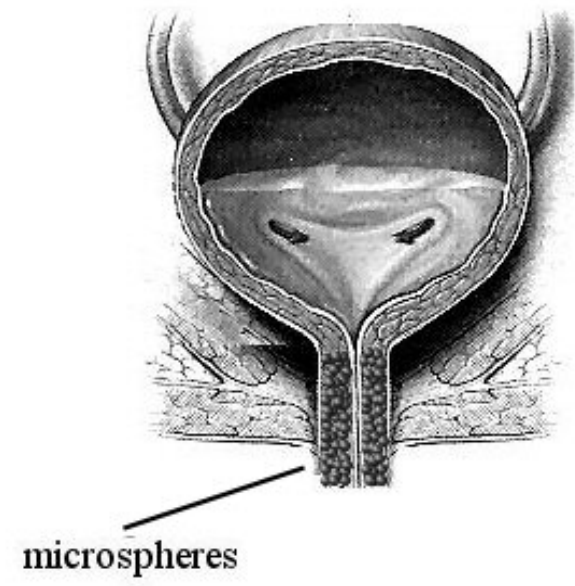

Figure 2. Front view of bladder. a) Urethra with weak muscles results in urine leakage. b) Complete coaptation of the urethra, which is achieved by injection of the bulking agent around the urethra.

Degradable bulking agents such as autologous fat tend to relieve symptoms, but have comparatively low efficiency and disappointing long-term results. In addition, some side-effects were reported, such as granuloma formation, obstructive mass formation, urine retention and fat embolism [48-55].

Ethylene vinyl alcohol copolymer suspended in DMSO (Tegress) was evaluated as embolic agent, but was also approved as a bulking agent for treatment of SUI. Recent studies not only demonstrated that Tegress may be less efficacious than reported in FDA trials, but also that a significant percentage of patients experienced serious complications like urethral erosion [56,57]. Injection of solid polydimethylsiloxane 
(silicone rubber) particles proved to have moderate success, with approximately half of the patients being cured after 24 months [58-60]. Furthermore, the misplacement or injection of too many silicon particles leads to complications, caused by the invisibility of the particles $[61,62]$.

Polytetrafluoroethylene paste is a resin with very high molecular weight and high viscosity. The material is composed of small particles and has been used to treat SUI since 1964. In spite of this, PTFE is not approved in the United States for treatment of incontinence, because of dangerous complications, such as distant migration, periurethral abscess, urethral diverticulum, urethral granuloma formation, and even increased tumor risk [63-66].

Durasphere ${ }^{\circledR}$ is composed pyrolitic carbon-coated zirconium oxide beads suspended in water-based carrier gel containing beta-glucan. Pyrolytic carbon is inert and biocompatible, and is used in implantable medical devices, including replacement heart valves [67]. One of the potential advantages is its very low immunogenicity. Durasphere $^{\circledR}$ particles are relatively large, $200-500 \mu \mathrm{m}$, and radiopaque, which is useful for tracing after injection. Durasphere ${ }^{\circledR}$ is non-degradable, therefore concerns were raised over long-term durability [68]. In spite of promising clinical data, Durasphere ${ }^{\circledR}$ demonstrated some serious complications, among which migration from implantation site is the most dangerous one. The obvious dislocation from the implantation site was shown in animal studies [69]. Six months after injection of carbon coated beads with diameter of 251 to $300 \mu \mathrm{m}$, significant migration of these beads was observed into local and distant lymph nodes, as well as into the urethral mucosa. The exact reason for bead migration remains unclear [70]. Durasphere ${ }^{\circledR}$ injection may result in long-term outlet obstruction, which can cause voiding dysfunction, permanent urinary retention and periurethral mass formation [71-73]. Urethral prolapse is an uncommon condition, but some cases have been described [74]. The long-term efficacy of Durasphere ${ }^{\circledR}$ injection is low. At 18 months follow up in 70 patients only $13 \%$ of patients considered themselves cured, 52.2\% improved and 34.7\% failed [75]. Another study demonstrated that Durasphere ${ }^{\circledR}$ remained effective in $35 \%, 33 \%$, and $21 \%$ of patients at 12,24 , and 36 months respectively [76].

Synthetic calcium hydroxylapatite $(\mathrm{CaHa})$ spheres suspended in a water-based gel carrier is a sterile, radiopaque, non-pyrogenic, semi-solid, cohesive implant. It is known as Coaptite and Radiesse. Coaptite is used for treatment of SUI and Radiasse is used for 


\section{Chapter 1}

the correction of facial lypoatrophy in HIV patients [77,78]. They differ in size range of the microspheres.

Theoretically, injected CaHa spheres have to form a scaffold for developing soft tissue that will gradually replace the gel carrier. For integration in the surrounding tissue, fibroblasts have to attach and grow on the surface of the spheres, resulting in anchoring at the injection site. Coaptite had promising results beforehand [79]. Nevertheless, the implant also has shortcomings. The histology of injected $\mathrm{CaHa}$ microspheres demonstrated, that microspheres become deformed, appearing irregular, and start being adsorbed at 9 months, likely because of enzymatic breakdown of the calcium hydroxylapatite [80]. Furthermore, it looks as if $\mathrm{CaHa}$ microspheres migrate away from the injection site. This migration may result in periureteral fibrosis, ureteric obstruction and subsequent renal loss [81]. Moreover, granulomatous reaction can lead to urethral prolapse, as early as 3 months after the transurethral injection of calcium hydroxylapatite [82].

\section{Embolization therapy}

Embolization is defined as "therapeutic introduction of various substances into the circulation to occlude vessels, either to arrest or prevent hemorrhaging, to devitalize a structure, tumor, or organ by occluding its blood supply, or to reduce blood flow to an arteriovenous malformation" [83].

Closure of a target artery can be achieved by use of different embolic agents such as synthetic microparticles, pellets, glues, or platinum coils [84,85]. This technique, also known as embolotherapy, leads to obstruction of arterial blood flow. Injected particles act in the same way as thrombotic emboli [86-90].

The field of interventional radiology routinely uses artificial microparticles and liveimaging techniques to specifically block arteries and starve targeted tissues from oxygen and nutrients. For this, a catheter is inserted and maneuvered to the target vessel that has to be embolized, i.e., blocked. Subsequently, the embolic particles are injected into the flowing blood and become stuck in the vessel, blocking the blood flow to the downstream tissue.

Embolotherapy is used in a variety of treatments of: (i) tumors, varicoceles, and organ ablation; (ii) hemorrhages, e.g., pelvic, posttraumatic, epistaxis, and hemoptysis; (iii) vascular anomalies, e.g., venous, lymphatic, arteriovenous malformations. Also the 
treatment of inoperable tumors is among the applications of embolotherapy. Tumors that lie deep in the brain are an obvious target for embolotherapy although one has to keep in mind that such interventions are often more palliative.

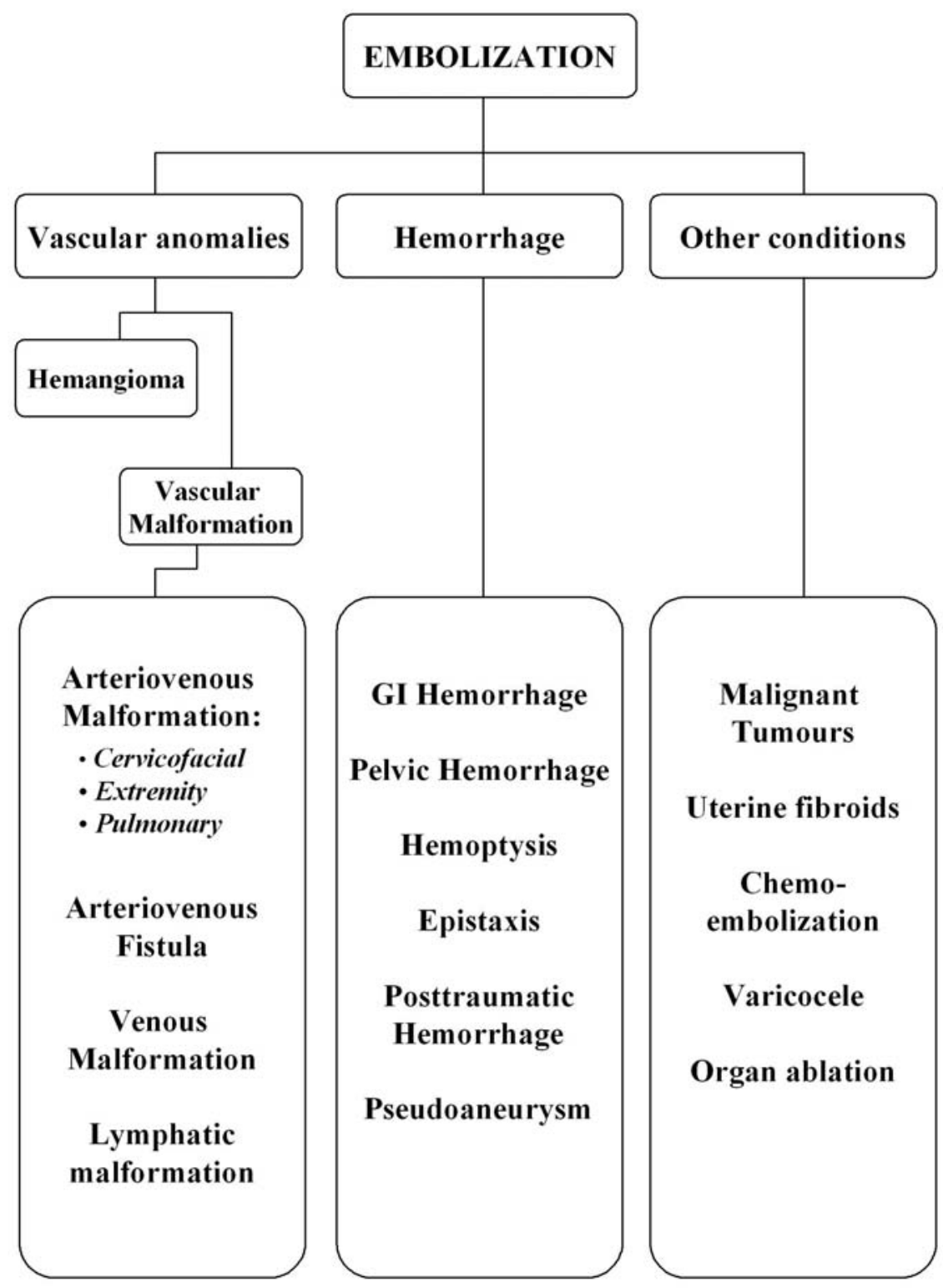

Figure 3. Overview of different applications of embolization therapy. 


\section{Chapter 1}

Furthermore, benign tumors like uterine fibroids can be treated by embolizing the feeding artery as an alternative to the common hysterectomy. So in this case embolotherapy is a minimally invasive alternative to surgery. Another application of embolic particles is the treatment of hemoptysis, i.e., severe bleeding because of trauma or of infections in the lungs, e.g., pneumonia can cause heavy bleeding. Embolization in such cases is used to stop lethal blood loss of the patient [85, 91-98].

\section{Embolization of tumors}

Embolotherapy is a new minimally invasive technique for the treatment of solid tumors. The embolization is performed pre-operatively, to shrink the tumor and prevent excessive blood-loss, or as a palliative treatment of unoperable tumors. The benign uterus tumors in women, called uterine fibroids (UF), will be discussed to explain tumor embolization in further detail.

UF consist mainly of smooth muscles and large amounts of extracellular matrix containing collagen, fibronectin, and proteoglycan. UF are also called fibromyomas, leiomyomas or myomas. They are very common and clinically apparent in about $25 \%$ of women, but because many commonly used imaging techniques lack resolution, the true prevalence may be as high as $77 \%$ [99].
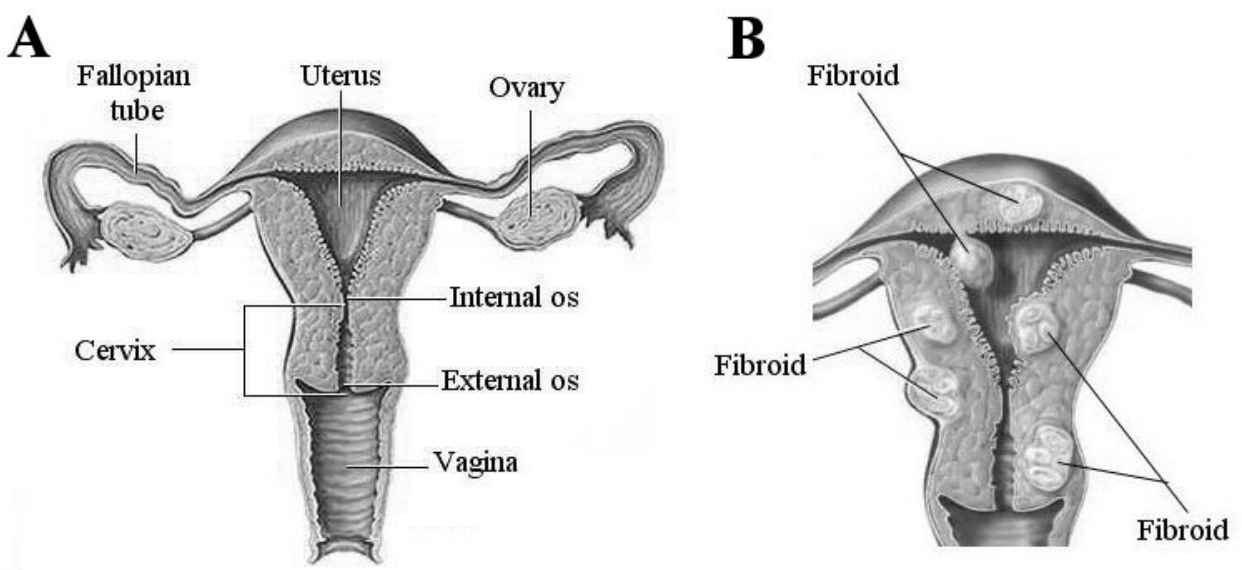

Figure 4. Front view of uterus: a) healthy uterus; b) uterus with fibroids. 
UF can cause abnormal uterine bleeding, resulting in iron-deficiency anemia, dysmenorrhea and non-cyclic pelvic pain [100-103]. The enlarging pelvic mass contributes to urinary problems and constipation [104-106]. UF are also associated with an increased risk of complications during pregnancy, and with infertility [107,108]. In other words UF have significant impact on the quality of life of women [109].

Even there are no systematic estimates of the total healthcare and productivity-loss costs attributable to uterine fibroid, the high cost of procedures used to treat (up $\$ 11,839$ per procedure) was reported [110].

Interestingly, race is an important risk factor for UF. Black women are more likely than white women to have uterine fibroids, are more likely to have multiple fibroid tumors too. Black women are also younger at diagnosis than white $[111,112]$.

The prevalence of UF definitely increases with age with a peak around the menopause and decreases after menopause. However, UF are present in the sixth, seventh, and even the eighth decade $[113,114]$. First-degree relatives of women with UF have a 2.5 times increased risk of developing myomas. Furthermore, cytogenetic, molecular and epidemiological data strongly suggest a genetic component in the etiology of fibroids $[115,116]$. Body mass index and weight gain exhibit a complex relation with risk of UF. This can be supposed that women with greater upper body obesity have decreased sex hormone-binding globulin levels, altered estrogen metabolism and some other such factors, which may promote tumor development [117].

There are also several factors that surprisingly decrease the risk for UF among which are smoking, pregnancy, and exercise [99]. This does not mean that smoking is an advised therapy in the prevention of UF, or can be used as an excuse for smoking.

Treatment of UF is relatively crude; surgical removal of the uterus, hysterectomy, is the most common method. In the US only, approximately 600,000 hysterectomies are performed annually, with uterine fibroids accounting for approximately $40 \%$ of all hysterectomies [118]. Especially for younger women, hysterectomy means that the possibility for child birth is gone and this may have serious psychological effects. Also, hysterectomy often does not relieve symptoms in several women, and some women reported new symptoms, such as hot flashes, weight gain, and depression $[119,120]$.

Myomectomy is the surgical removal of uterine fibroids with preservation of the uterus. This is an invasive surgical technique, which can be performed in several different ways depending upon the size, number and location of the UF. There are three approaches to 


\section{Chapter 1}

myomectomy: abdominal, laparoscopic, and hysteroscopic. Despite preserving fertility, myomectomy has complications. Most common complications of myomectomy are damage and infections of surrounding organs; damage, weakening and scaring of womb, which can lead to complications during the pregnancy such as rupturing the womb wall; bleeding, that can lead to full hysterectomy [121-123].

Medications for uterine fibroids do not eliminate fibroids, but may shrink them. Target hormones regulate menstrual cycle, treating symptoms such as heavy menstrual bleeding and pelvic pressure. The most commonly reported adverse effects of progesterone receptor modulators were headache, abdominal pain, nausea, dizziness, and metrorrhagia [124]. Side effects such as muscle cramps, acne, fluid retention, unwanted hair growth, weight gain, and deeper voice can occur during androgen therapy [125].

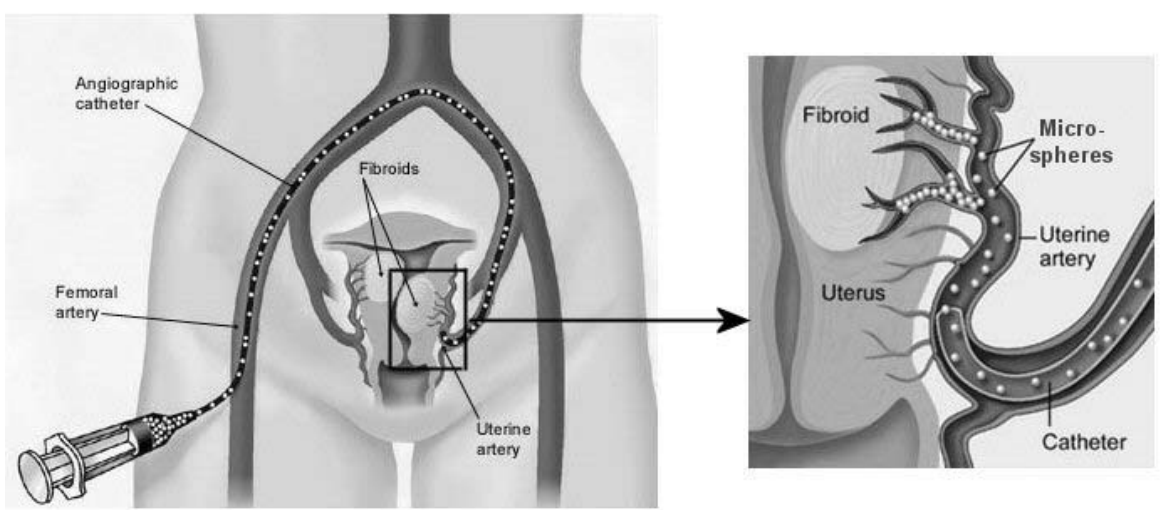

Figure 5. Angiographic catheter is introduced into the femoral artery through the small opening in the groin. Microspheres are injected into the artery that is supplying the fibroids and block these arteries.

An alternative treatment of uterine fibroids is called embolotherapy. This means that the feeding arteries to the fibroids are blocked by localized injection of microparticles. As a consequence, the fibroids will become devoid of oxygen and nutrients. The mass of the UF will diminish over time and the symptoms will thus be reduced. The interventional radiologist has the choice of a number of synthetic microparticles that can be used for the embolotherapy. 
These particles are however not ideal because: i) they are not visible under standard clinical conditions (X-ray); ii) they are irregular in shape and size; iii) they are inert and the interaction with the surrounding tissue is unpredictable. The lack of radiopacity, i.e., $\mathrm{X}$-ray visibility forces the interventional radiologist to guess how much particles have been injected and where these end up. Therefore the currently used microparticles are mixed with liquid contrast agent to at least get some idea of where the injected particles end up. Also, in this way reverse flow, and unwanted embolization distant from the intended site, can be avoided. The current embolization-microparticles are irregular in shape. This may lead to obstruction in the catheter and incomplete embolization, leaking blood to the down-stream tissues. In practice microspheres are the ideal embolic particles. After embolization the microparticles induce a reaction from the surrounding tissue. Severe inflammatory reactions are in general undesirable, and also angiogenesis, formation of collateral vessels is surely not wanted. The preferred tissue reaction would be inertia, leaving the down-stream tissues devoid of oxygen and nutrients.

\section{Aim of thesis}

The research described in this thesis set out to achieve improvements over the injectable polymeric biomaterials that are currently in clinical use. Most of the commercially available particulate injectables are composed of inert polymers. These materials are radiolucent, i.e., the particles are invisible on X-ray images. Obviously, this hampers their retrieval once they have been injected in the body. Note that other imaging techniques, notably magnetic resonance imaging, are also of limited use for localization of small polymer particles. Some commercially available injectable particles are radiopaque; the most important example is DuraSphere ${ }^{\circledR}$. These particles consist of $\mathrm{ZrO}_{2}$. For DuraSphere ${ }^{\circledR}$, however, the advantage of the $\mathrm{X}$-ray visibility is counterbalanced by the fact that the particles have a high density (around $6 \mathrm{~g} / \mathrm{cm}^{3}$ ). Presumably, the high density of DuraSphere ${ }^{\circledR}$ particles is responsible for the fact that these particles have a tendency to migrate from the site of injection [70]. Our key hypothesis was that methacrylate copolymers that contain covalently bound iodine would offer a promising approach to injectable particles that uniquely combine: adequate radiopacity, spherical shape, a high level of biocompatibility and a density which is comparable to the density of soft tissues. This approach is a logical extension 


\section{Chapter 1}

of previous work from the laboratory on polymeric biomaterials featuring intrinsic radiopacity, on the basis of incorporation of covalently bound iodine $[126,127,128]$.

We chose to focus on poly(methacrylate) copolymers, since these already find widespread use as implant biomaterials. Radiopacity was introduced through either monomer 2-[4,-iodobenzoyloxy] ethyl methacrylate (4-IEMA), or monomer 2[2',3',5',-triiodobenzoyloxy] ethyl methacrylate (2,3,5-TIEMA), shown in Figure 6 and 7 , respectively. Note that these monomers have a reactive methacrylate group on one side, and an iodine-bearing aromatic ring on the other side. Both monomers were copolymerized with methyl methacrylate, 2-hydroxy ethyl methacrylate or $\mathrm{N}$ vinylpyrrollidinone, always in temperature-controlled free-radical polymerization reactions.<smiles>C=C(C)C(=O)OCCOC(=O)c1ccc(I)cc1</smiles>

Figure 6. 4IEMA

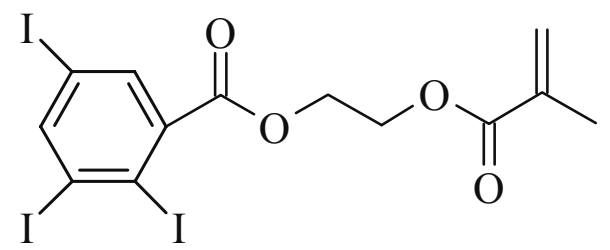

Figure 7. 2,3,5-TIEMA.

We have become familiar with the copolymer materials that are produced in such reactions. For instance, an animal study demonstrated that these radiopaque materials are stable in vivo over a long period of time (2 years) [129]. In one case, an official CEcertification for an implant medical device that was based on an iodine-containing copolymer was awarded. Through the use of different co-monomers, it proved possible to manipulate the properties of the resulting copolymers. This is especially valuable with regard to hydrophilicity an aqueous swelling. Completely new hydrogel biomaterials, which combine radiopacity and controlled uptake of water, biocompatibility, and surprisingly high resistance to fatigue, emerged form this work. 
Preparation of microspheres with the desired properties proved to be possible. Two routes of preparation were explored: solvent evaporation and suspension polymerization; each proved effective after careful optimization of several essential parameters. We further investigated the biocompatibility of these particles, both in vitro and in vivo. Finally, we added and additional functionality through chemical modification of the surface of the radiopaque spheres. A method was explored to attach proteins, such as thrombin and collagen. In the case of thrombin, we found that the enzyme retains its activity, at least partially, after immobilization.

Chapter 2 describes the first production of small microspheres using the 2,3,5-TIEMA monomer. For this, copolymer was produced in bulk, dissolved in an organic solvent, and dripped slowly in a stirred aqueous solution containing a stabilizing agent to obtain small droplets. Upon evaporation of the solvent, small microspheres were obtained that are visible under standard clinical X-ray conditions (mammography). A prerequisite for all injectable biomaterials is their biocompatibility. The iodine-containing microspheres were shown to be devoid of any cytotoxicity in vitro.

Biocompatibility was further investigated in Chapter 3 where we studied the behavior of the microspheres in rats over a period of 3 months. Both subcutaneous and intramuscular injection of the microspheres, suspended in collagen, demonstrated the microspheres to be nicely biocompatible.

Chapter 4 describes a different method of obtaining X-ray visible microspheres. Suspension polymerization results in microspheres that are more uniform and the control over size and shape are improved. Furthermore, the problem of the inert surface of the microspheres is tackled in this chapter. Heating of the microspheres in strong alkaline environment results in the formation of carboxylic groups on the surface, which can be used to anchor active protein. The addition of protein on the surface may be of importance to anchor the spheres more strongly in the tissue, preventing the problem of microsphere migration.

In Chapter 5 this biofunctionalization is improved by addition of methacrylic acid in the suspension polymerization, resulting in microspheres with surface carboxylic groups. This method is more controllable than the one described in Chapter 4. As an example, active thrombin, the key enzyme in blood coagulation, was coupled to the spheres in order to enhance embolization therapy. The clotting of blood upon mechanical closure 


\section{Chapter 1}

of e.g., a tumor-feeding artery or a severely bleeding artery, may lead to faster and more stable closure of the blood vessel.

In Chapter 6 biofunctionalization was achieved by the synthesis of microspheres with surface aldehyde groups. Coupling of collagen should result in improved adhesion of cells and ultimately better anchoring of microspheres in surrounding tissue.

In Chapter 7, the synthesis of a different sort of microspheres is described. The X-ray visible microspheres are designed to slowly swell in aqueous environment. This has several advantages for embolotherapy. First of all these microspheres are compressible, which can avoid microspheres getting stuck in the catheter. Also the microspheres could potentially anchor themselves tightly in the artery by swelling in situ and blocking blood-flow completely.

\section{References}

1. Abrams P, Cardozo L, Fall M, Griffiths D, Rosier P, Ulmsten U, Van Kerrebroeck P, Victor A, Wein A. Standardisation Sub-Committee of the International Continence Society. The standardisation of terminology in lower urinary tract function: report from the standardisation sub-committee of the International Continence Society. Urology. 2003;61(1):37-49.

2. Breasted JH: Edwin Smith surgical papyrus in facsimile and hieroglyphic transliteration with translation and commentary. Chicago, University of Chicago Oriental Institute. 1930.

3. Joachim H: Papyrus Ebers, Berlin, G.Reimer.1890.

4. Shaw C, Tansey R, Jackson C, Hyde C, Allan R. Barriers to help seeking in people with urinary symptoms. Fam Pract. 2001;18(1):48-52.

5. Monz B, Pons ME, Hampel C, Hunskaar S, Quail D, Samsioe G, Sykes D, Wagg A, Papanicolaou S. Patient-reported impact of urinary incontinence--results from treatment seeking women in 14 European countries. Maturitas. 2005;52 Suppl 2:S24-34.

6. Salonia A, Zanni G, Nappi RE, Briganti A, Deho F, Fabbri F, Colombo R, Guazzoni G, Di Girolamo V, Rigatti P, Montorsi F. Sexual dysfunction is common in women with lower urinary tract symptoms and urinary incontinence: results of a cross-sectional study. Eur Urol. 2004;45(5):642-8.

7. Barber MD, Dowsett SA, Mullen KJ, Viktrup L. The impact of stress urinary incontinence on sexual activity in women. Cleve Clin J Med. 2005;72(3):225-32.

8. Brown WJ, Miller YD. Too wet to exercise? Leaking urine as a barrier to physical activity in women. J Sci Med Sport. 2001;4(4):373-8.

9. Hannestad YS, Rortveit G, Hunskaar S. Help-seeking and associated factors in female urinary incontinence. The Norwegian EPINCONT Study. Epidemiology of Incontinence in the County of Nord-Trondelag. Scand J Prim Health Care. 2002;20(2):102-7.

10. Hunskaar S, Burgio K, Diokno A, Herzog AR, Hjalmas K, Lapitan MC. Epidemiology and natural history of urinary incontinence in women. Urology. 2003;62(4 Suppl 1):16-23.

11. Danforth KN, Townsend MK, Lifford K, Curhan GC, Resnick NM, Grodstein F. Risk factors for urinary incontinence among middle-aged women. Am J Obstet Gynecol. 2006;194(2):339-45.

12. Sze EH, Jones WP, Ferguson JL, Barker CD, Dolezal JM. Prevalence of urinary incontinence symptoms among black, white, and Hispanic women. Obstet Gynecol. 2002;99(4):572-5. 
13. Thom DH, van den Eeden SK, Ragins AI, Wassel-Fyr C, Vittinghof E, Subak LL, Brown JS. Differences in prevalence of urinary incontinence by race/ethnicity. J Urol. 2006;175(1):259-64.

14. Williams A, Herron-Marx S, Knibb R. The prevalence of enduring postnatal perineal morbidity and its relationship to type of birth and birth risk factors. J Clin Nurs. 2007;16(3):549-61.

15. Chin HY, Chen MC, Liu YH, Wang KH. Postpartum urinary incontinence: a comparison of vaginal delivery, elective, and emergent cesarean section. Int Urogynecol J Pelvic Floor Dysfunct. 2006;17(6):631-5.

16. Jackson SL, Scholes D, Boyko EJ, Abraham L, Fihn SD. Predictors of urinary incontinence in a prospective cohort of postmenopausal women. Obstet Gynecol. 2006;108(4):855-62.

17. Steinauer JE, Waetjen LE, Vittinghoff E, Subak LL, Hulley SB, Grady D, Lin F, Brown JS. Postmenopausal hormone therapy: does it cause incontinence? Obstet Gynecol. 2005;106(5 Pt 1):940-5.

18. Hannestad YS, Lie RT, Rortveit G, Hunskaar S. Familial risk of urinary incontinence in women: population based cross sectional study. BMJ. 2004;329(7471):889-91.

19. Ertunc D, Tok EC, Pata O, Dilek U, Ozdemir G, Dilek S. Is stress urinary incontinence a familial condition? Acta Obstet Gynecol Scand. 2004;83(10):912-6.

20. Hannestad YS, Rortveit G, Daltveit AK, Hunskaar S. Are smoking and other lifestyle factors associated with female urinary incontinence? The Norwegian EPINCONT Study. BJOG. 2003;110(3):247-54.

21. Subak LL, Whitcomb E, Shen H, Saxton J, Vittinghoff E, Brown JS. Weight loss: a novel and effective treatment for urinary incontinence. J Urol. 2005;174(1):190-5.

22. Caylet N, Fabbro-Peray P, Mares P, Dauzat M, Prat-Pradal D, Corcos J. Prevalence and occurrence of stress urinary incontinence in elite women athletes. Can J Urol. 2006;13(4):3174-9.

23. Bo K. Urinary incontinence, pelvic floor dysfunction, exercise and sport. Sports Med. 2004;34(7):451-64.

24. Swithinbank L, Hashim H, Abrams P. The effect of fluid intake on urinary symptoms in women. $J$ Urol. 2005;174(1):187-9.

25. Brown JS, Vittinghoff E, Lin F, Nyberg LM, Kusek JW, Kanaya AM. Prevalence and risk factors for urinary incontinence in women with type 2 diabetes and impaired fasting glucose: findings from the National Health and Nutrition Examination Survey (NHANES) 2001-2002. Diabetes Care. 2006;29(6):1307-12.

26. Kegel AH. Progressive resistance exercise in the functional restoration of the perineal muscles. American Journal of Obstetrics and Gynecology. 1948;56:238-48.

27. Cammu H, Van Nylen M, Amy J. A ten-year follow-up after Kegel pelvic floor muscle exercises for genuine stress incontinence. BJU Int. 2000;85:655-658

28. Hay-Smith EJ, Dumoulin C. Pelvic floor muscle training versus no treatment, or inactive control treatments, for urinary incontinence in women. Cochrane Database Syst Rev. 2006;25;(1):CD005654.

29. Bo K. Pelvic floor muscle training is effective in treatment of female stress urinary incontinence, but how does it work? Int Urogynecol J Pelvic Floor Dysfunct. 2004;15(2):76-84.

30. Oelke M, Roovers JP, Michel MC. Safety and tolerability of duloxetine in women with stress urinary incontinence. BJOG. 2006;113 Suppl 1:22-6.

31. Guay DR. Duloxetine for management of stress urinary incontinence. Am J Geriatr Pharmacother. 2005;3(1):25-38.

32. Mariappan P, Ballantyne Z, N'Dow JM, Alhasso AA. Serotonin and noradrenaline reuptake inhibitors (SNRI) for stress urinary incontinence in adults. Cochrane Database Syst Rev. 2005;(3):CD004742. 


\section{Chapter 1}

33. Mariappan P, Alhasso A, Ballantyne Z, Grant A, N'Dow J. Duloxetine, a serotonin and noradrenaline reuptake inhibitor (SNRI) for the treatment of stress urinary incontinence: a systematic review. Eur Urol. 2007;51(1):67-74.

34. van Kerrebroeck P, Abrams P, Lange R, Slack M, Wyndaele JJ, Yalcin I, Bump RC; Duloxetine Urinary Incontinence Study Group. Duloxetine versus placebo in the treatment of European and Canadian women with stress urinary incontinence. BJOG. 2004;111(3):249-57.

35. Lenzer J. FDA warns that antidepressants may increase suicidality in adults. $B M J$. 2005;331(7508):70.

36. Ulmsten U, Henriksson L, Johnson P, Varhos G. An ambulatory surgical procedure under local anesthesia for treatment of female urinary incontinence. Int Urogynecol J Pelvic Floor Dysfunct. 1996;7(2):81-5.

37. Comiter CV. Surgery insight: management of failed sling surgery for female stress urinary incontinence. Nat Clin Pract Urol. 2006;3(12):666-74.

38. Flock F, Reich A, Muche R, Kreienberg R, Reister F. Hemorrhagic complications associated with tension-free vaginal tape procedure. Obstet Gynecol. 2004;104(5 Pt 1):989-94.

39. Amundsen CL, Flynn BJ, Webster GD Urethral erosion after synthetic and nonsynthetic pubovaginal slings: differences in management and continence outcome. J Urol. 2003;170(1):134-7.

40. Madjar S, Tchetgen MB, Van Antwerp A, Abdelmalak J, Rackley RR. Urethral erosion of tensionfree vaginal tape. Urology. 2002;59(4):601

41. Abdel-Fattah M, Sivanesan K, Ramsay I, Pringle S, Bjornsson S. How common are tape erosions? A comparison of two versions of the transobturator tension-free vaginal tape procedure. BJU Int. 2006;98(3):594-8.

42. Yamada BS, Govier FE, Stefanovic KB, Kobashi KC. High rate of vaginal erosions associated with the mentor ObTape. J Urol. 2006;176(2):651-4.

43. Siegel AL. Vaginal mesh extrusion associated with use of Mentor transobturator sling. Urology. 2005;66(5):995-9.

44. Comiter CV, Colegrove PM. High rate of vaginal extrusion of silicone-coated polyester sling. Urology. 2004;63(6):1066-70.

45. Govier FE, Kobashi KC, Kuznetsov DD, Comiter C, Jones P, Dakil SE, James R Jr. Complications of transvaginal silicone-coated polyester synthetic mesh sling. Urology. 2005;66(4):741-5.

46. Frederick RW, Carey JM, Leach GE. Osseous complications after transvaginal bone anchor fixation in female pelvic reconstructive surgery: report from single largest prospective series and literature review. Urology. 2004;64(4):669-74.

47. Goldberg RP, Tchetgen MB, Sand PK, Koduri S, Rackley R, Appell R, Culligan PJ. Incidence of pubic osteomyelitis after bladder neck suspension using bone anchors. Urology. 2004;63(4):704-8.

48. Mayer RD, Dmochowski RR, Appell RA, Sand PK, Klimberg IW, Jacoby K, Graham CW, Snyder JA, Nitti VW, Winters JC Multicenter prospective randomized 52-week trial of calcium hydroxylapatite versus bovine dermal collagen for treatment of stress urinary incontinence. Urology. 2007;69(5):876-80.

49. Chapple CR, Haab F, Cervigni M, Dannecker C, Fianu-Jonasson A, Sultan AH. An open, multicentre study of NASHA/Dx Gel (Zuidex) for the treatment of stress urinary incontinence. Eur Urol. 2005;48(3):488-94.

50. van Kerrebroeck P, ter Meulen F, Larsson G, Farrelly E, Edwall L, Fianu-Jonasson A. Efficacy and safety of a novel system (NASHA/Dx copolymer using the Implacer device) for treatment of stress urinary incontinence. Urology. 2004;64(2):276-81. 
51. Abdelwahab HA, Ghoniem GM. Obstructive suburethral mass after transurethral injection of dextranomer/hyaluronic acid copolymer. Int Urogynecol J Pelvic Floor Dysfunct. 2007;18(11):137980 .

52. Castillo-Vico MT, Checa-Vizcaíno MA, Payà-Panadés A, Rueda-García C, Carreras-Collado R. Periurethral granuloma following injection with dextranomer/hyaluronic acid copolymer for stress urinary incontinence. Int Urogynecol J Pelvic Floor Dysfunct. 2007;18(1):95-7.

53. Lee PE, Kung RC, Drutz HP. Periurethral autologous fat injection as treatment for female stress urinary incontinence: a randomized double-blind controlled trial. J Urol. 2001;165(1):153-8.

54. Andersen RC. Long-term follow-up comparison of durasphere and contigen in the treatment of stress urinary incontinence. J Low Genit Tract Dis. 2002;6(4):239-43.

55. Chrouser KL, Fick F, Goel A, Itano NB, Sweat SD, Lightner DJ. Carbon coated zirconium beads in beta-glucan gel and bovine glutaraldehyde cross-linked collagen injections for intrinsic sphincter deficiency: continence and satisfaction after extended followup. J Urol. 2004;171(3):1152-5.

56. Hurtado E, McCrery R, Appell R. The safety and efficacy of ethylene vinyl alcohol copolymer as an intra-urethral bulking agent in women with intrinsic urethral deficiency. Int Urogynecol J Pelvic Floor Dysfunct. 2007;18(8):869-73.

57. Erekson EA, Sung VW, Rardin CR, Myers DL. Ethylene vinyl alcohol copolymer erosions after use as a urethral bulking agent. Obstet Gynecol. 2007;109(2 Pt2):490-2.

58. Maher CF, O'Reilly BA, Dwyer PL, Carey MP, Cornish A, Schluter P. Pubovaginal sling versus transurethral Macroplastique for stress urinary incontinence and intrinsic sphincter deficiency: a prospective randomised controlled trial. BJOG. 2005;112(6):797-801.

59. Radley SC, Chapple CR, Mitsogiannis IC, Glass KS. Transurethral implantation of macroplastique for the treatment of female stress urinary incontinence secondary to urethral sphincter deficiency. Eur Urol. 2001;39(4):383-9.

60. Tamanini JT, D'Ancona CA, Netto NR. Treatment of intrinsic sphincter deficiency using the Macroplastique Implantation System: two-year follow-up. J Endourol. 2004;18(9):906-11.

61. Kulkarni S, Davies AJ, Treurnicht K, Dudderidge TJ, Al-Akraa M. Misplaced Macroplastique injection presenting as a vaginal nodule and a bladder mass. Int J Clin Pract Suppl. 2005;(147):85-6.

62. Peeker R, Edlund C, Wennberg AL, Fall M. The treatment of sphincter incontinence with periurethral silicone implants (macroplastique). Scand J Urol Nephrol. 2002;36(3):194-8.

63. Malizia AA, Reiman HM, Myers RP, Sande JR, Barham SS, Benson RC, Dewanjee MK, Utz WJ. Migration and granulomatous reaction after periurethral injection of polytef (Teflon). JAMA. 1984;251(24):3277-81.

64. Kiilholma PJ, Chancellor MB, Makinen J, Hirsch IH, Klemi PJ. Complications of Teflon injection for stress urinary incontinence. Neurourol Urodyn. 1993;12(2):131-7.

65. Dewan PA, Owen AJ, Byard RW. Long-term histological response to subcutaneously injected Polytef and Bioplastique in a rat model. Br J Urol. 1995;76(2):161-4.

66. Dewan PA. Is injected polytetrafluoroethylene (Polytef) carcinogenic? Br J Urol. 1992;69(1):29-33.

67. Beavan A. Material properties and applications of Pyrolite ${ }^{\mathrm{TM}}$ Carbon. Materials Engineering. 1990;77:39-41.

68. Lightner D, Calvosa C, Andersen R, Klimberg I, Brito CG, Snyder J, Gleason D, Killion D, Macdonald J, Khan AU, Diokno A, Sirls LT, Saltzstein D. A new injectable bulking agent for treatment of stress urinary incontinence: results of a multicenter, randomized, controlled, doubleblind study of Durasphere. Urology. 2001;58(1):12-5.

69. Lemperle G, Morhenn VB, Pestonjamasp V, Gallo RL. Migration studies and histology of injectable microspheres of different sizes in mice. Plast Reconstr Surg. 2004;113(5):1380-90. 


\section{Chapter 1}

70. Pannek J, Brands FH, Senge T. Particle migration after transurethral injection of carbon coated beads for stress urinary incontinence. J Urol. 2001;166(4):1350-3.

71. Hartanto VH, Lightner DJ, Nitti VW. Endoscopic evacuation of Durasphere. Urology. 2003;62(1):135-7.

72. US Food and Drug Administration, Center for Devices and Radiological Health: Summary of safety and effectiveness data: Durasphere ${ }^{\mathrm{TM}}$ injectable bulking agent, 1999. Available at: .www.fda.gov/cdrh/pdf/p980053.html. Accessed April 17, 2007.

73. Madjar S, Sharma AK, Waltzer WC, Frischer Z, Secrest CL. Periurethral mass formations following bulking agent injection for the treatment of urinary incontinence. J Urol. 2006;175(4):1408-10.

74. Ghoniem GM, Khater U. Urethral prolapse after durasphere injection. Int Urogynecol J Pelvic Floor Dysfunct. 2006;17(3):297-8.

75. Madjar S, Covington-Nichols C, Secrest CL. New periurethral bulking agent for stress urinary incontinence: modified technique and early results. J Urol. 2003;170(6 Pt 1):2327-9.

76. Chrouser KL, Fick F, Goel A, Itano NB, Sweat SD, Lightner DJ. Carbon coated zirconium beads in beta-glucan gel and bovine glutaraldehyde cross-linked collagen injections for intrinsic sphincter deficiency: continence and satisfaction after extended followup. J Urol. 2004;171(3):1152-5.

77. Food and Drug Administration, Center for Devices and Radiological Health: Summary of safety and effectiveness data: Coaptite $^{\circledR}$, injectable implant for soft tissue augmentation, November 10, 2005. Available at: http://www.fda.gov/cdrh/PDF4/p040047b.pdf Accessed April 17, 2007.

78. Food and Drug Administration, Center for Devices and Radiological Health: Summary of safety and effectiveness data: Radiesse ${ }^{\circledR}$, injectable dermal filler, December 22, 2006. Available at: http://www.fda.gov/cdrh/pdf5/p050037.html Accessed April 18, 2007.

79. Mayer R, Lightfoot M, Jung I. Preliminary evaluation of calcium hydroxylapatite as a transurethral bulking agent for stress urinary incontinence. Urology. 2001;57(3):434-8.

80. Lemperle G, Morhenn V, Charrier U. Human histology and persistence of various injectable filler substances for soft tissue augmentation. Aesthetic Plast Surg. 2003;27(5):354-66.

81. Onol FF, Tarcan T, Tinay I, Kotiloglu E, Simsek F. Kidney loss due to periureteral fibrosis and ureteral obstruction secondary to migration of subureterically injected calcium hydroxylapatite. $J$ Pediat Urol. 2006;2:503-508.

82. Palma PC, Riccetto CL, Martins MH, Herrmann V, de Fraga R, Billis A, Netto NR Jr. Massive prolapse of the urethral mucosa following periurethral injection of calcium hydroxylapatite for stress urinary incontinence. Int Urogynecol J Pelvic Floor Dysfunct. 2006;17(6):670-1.

83. Stedman T. Stedman's medical dictionary. $27^{\text {th }}$ ed. Lippincott Williams \& Wilkins. 2000.

84. Coldwell DM, Stokes KR, Yakes WF. Embolotherapy: agents, clinical applications, and techniques. Radiographics. 1994;14(3):623-43.

85. Ramsey DE, Geschwind JF. New interventions for liver tumors. Semin Roentgenol. 2002;37(4):30311.

86. Agnelli G, Becattini C. Venous thromboembolism and atherosclerosis: common denominators or different diseases? J Thromb Haemost. 2006;4(9):1886-90.

87. Eliasson A, Bergqvist D, Björck M, Acosta S, Sternby NH, Ogren M. Incidence and risk of venous thromboembolism in patients with verified arterial thrombosis: a population study based on 23,796 consecutive autopsies. J Thromb Haemost. 2006;4(9):1897-902.

88. Prandoni P, Ghirarduzzi A, Prins MH, Pengo V, Davidson BL, Sørensen H, Pesavento R, Iotti M, Casiglia E, Iliceto S, Pagnan A, Lensing AW. Venous thromboembolism and the risk of subsequent symptomatic atherosclerosis. J Thromb Haemost. 2006;4(9):1891-6.

89. Turpie AG. Preventing thromboembolism in patients with prosthetic heart valves. Cardiol Clin. 1994;12(3):487-93. 
90. Al-Mubarak N, Roubin GS, Vitek JJ, Iyer SS. Microembolization during carotid stenting with the distal-balloon antiemboli system. Int Angiol. 2002;21(4):344-8.

91. Liapi E, Geschwind JF. Transcatheter and ablative therapeutic approaches for solid malignancies. $J$ Clin Oncol. 2007;25(8):978-86.

92. Lupattelli T, Basile A, Garaci FG, Simonetti G. Percutaneous uterine artery embolization for the treatment of symptomatic fibroids: current status. Eur J Radiol. 2005;54(1):136-47.

93. Helmberger TK, Jakobs TF, Reiser MF. Embolization of uterine fibroids. Abdom Imaging. 2004;29(2):267-77.

94. Yoon W. Embolic agents used for bronchial artery embolization in massive haemoptysis., Expert Opin Pharmacother. 2004;5(2):361-7.

95. Funaki B. Superselective embolization of lower gastrointestinal hemorrhage: a new paradigm. Abdom Imaging. 2004;29(4):434-8.

96. Hsu AA. Thoracic embolotherapy for life-threatening haemoptysis: a pulmonologist's perspective. Respirology. 2005;10(2):138-43.

97. Enting D, van der Werf TS, Prins TR, Zijlstra JG, Ligtenberg JJ, Tulleken JE. Massive haemoptysis: primary care, diagnosis and treatment. Ned Tijdschr Geneeskd. 2004;148(32):1582-6.

98. Abe Y, Nakamura M, Suzuki K, Hashizume T, Tanigaki T, Saito T, Fujino T, Kikuchi K. Massive hemoptysis due to Mycobacterium fortuitum infection controlled with bronchial artery embolization a case report. Clin Imaging. 1999;23(6):361-3.

99. Parker WH. Etiology, symptomatology, and diagnosis of uterine myomas. Fertil Steril. 2007;87(4):725-36.

100. Munro MG, Lukes AS; Abnormal Uterine Bleeding and Underlying Hemostatic Disorders Consensus Group. Abnormal uterine bleeding and underlying hemostatic disorders: report of a consensus process. Fertil Steril. 2005;84(5):1335-7.

101. Wegienka G, Baird DD, Hertz-Picciotto I, Harlow SD, Steege JF, Hill MC, Schectman JM, Hartmann KE. Self-reported heavy bleeding associated with uterine leiomyomata. Obstet Gynecol. 2003;101(3):431-7.

102. Lippman SA, Warner M, Samuels S, Olive D, Vercellini P, Eskenazi B. Uterine fibroids and gynecologic pain symptoms in a population-based study. Fertil Steril. 2003;80(6):1488-94.

103. Dick ML. Chronic pelvic pain in women: assessment and management. Aust Fam Physician. 2004;33(12):971-6.

104. Hosokawa Y, Kishino T, Ono T, Oyama N, Momose H. Two cases of female acute urinary retention caused by an impacted pelvic mass. Int J Urol. 2005;12(12):1069-70.

105. Barnacle S, Muir T. Intermittent urinary retention secondary to a uterine leiomyoma. Int Urogynecol J Pelvic Floor Dysfunct. 2007;18(3):339-41.

106. Iavazzo C, Myriokefalitaki E, Vorgias G, Akrivos T, Lekka I, Katsoulis M. Giant solid abdominal mass with cystic lesions: a case report and diaphorodiagnostic approach. Bratisl Lek Listy. 2006;107(11-12):445-7.

107. Vilos GA. Uterine fibroids: relationships to reproduction. Minerva Ginecol. 2003;55(5):417-23.

108. Casini ML, Rossi F, Agostini R, Unfer V. Effects of the position of fibroids on fertility. Gynecol Endocrinol. 2006;22(2):106-9.

109. Williams VS, Jones G, Mauskopf J, Spalding J, DuChane J. Uterine fibroids: a review of healthrelated quality of life assessment. J Womens Health (Larchmt). 2006;15(7):818-29.

110. Mauskopf J, Flynn M, Thieda P, Spalding J, Duchane J. The economic impact of uterine fibroids in the United States: a summary of published estimates. J Womens Health (Larchmt). 2005;14(8):692703. 


\section{Chapter 1}

111. Day Baird D, Dunson DB, Hill MC, Cousins D, Schectman JM. High cumulative incidence of uterine leiomyoma in black and white women: ultrasound evidence. Am J Obstet Gynecol. 2003;188(1):1007.

112. Wise LA, Palmer JR, Stewart EA, Rosenberg L. Age-specific incidence rates for self-reported uterine leiomyomata in the Black Women's Health Study. Obstet Gynecol. 2005;105(3):563-8.

113. Borgfeldt C, Andolf E. Transvaginal ultrasonographic findings in the uterus and the endometrium: low prevalence of leiomyoma in a random sample of women age 25-40 years. Acta Obstet Gynecol Scand. 2000;79(3):202-7.

114. Lurie S, Piper I, Woliovitch I, Glezerman M. Age-related prevalence of sonographicaly confirmed uterine myomas. J Obstet Gynaecol. 2005;25(1):42-4.

115. Schwartz SM, Marshall LM, Baird DD. Epidemiologic contributions to understanding the etiology of uterine leiomyomata. Environ Health Perspect. 2000;108 Suppl 5:821-7.

116. Ligon AH, Morton CC. Leiomyomata: heritability and cytogenetic studies. Hum Reprod Update. 2001;7(1):8-14.

117. Wise LA, Palmer JR, Spiegelman D, Harlow BL, Stewart EA, Adams-Campbell LL, Rosenberg L. Influence of body size and body fat distribution on risk of uterine leiomyomata in U.S. black women. Epidemiology. 2005;16(3):346-54.

118. Myers ER, Barber MD, Gustilo-Ashby T, Couchman G, Matchar DB, McCrory DC. Management of uterine leiomyomata: what do we really know? Obstet Gynecol. 2002;100(1):8-17.

119. Kjerulff KH, Langenberg PW, Rhodes JC, Harvey LA, Guzinski GM, Stolley PD. Effectiveness of hysterectomy. Obstet Gynecol. 2000;95(3):319-26.

120. Hartmann KE, Ma C, Lamvu GM, Langenberg PW, Steege JF, Kjerulff KH. Quality of life and sexual function after hysterectomy in women with preoperative pain and depression. Obstet Gynecol. 2004;104(4):701-9.

121. West S, Ruiz R, Parker WH. Abdominal myomectomy in women with very large uterine size. Fertil Steril. 2006;85(1):36-9.

122. Muñoz JL, Jiménez JS, Hernández C, Vaquero G, Pérez Sagaseta C, Noguero R, Miranda P, Hernández JM, De la Fuente P. Hysteroscopic myomectomy: our experience and review. JSLS. 2003;7(1):39-48.

123. Hurst BS, Matthews ML, Marshburn PB. Laparoscopic myomectomy for symptomatic uterine myomas. Fertil Steril. 2005;83(1):1-23.

124. Chwalisz K, Perez MC, Demanno D, Winkel C, Schubert G, Elger W. Selective progesterone receptor modulator development and use in the treatment of leiomyomata and endometriosis. Endocr Rev. 2005;26(3):423-38.

125. Chavez NF, Stewart EA. Medical treatment of uterine fibroids. Clin Obstet Gynecol. 2001;44(2):37284.

126. Boelen EJ, van Hooy-Corstjens CS, Bulstra SK, van Ooij A, van Rhijn LW, Koole LH. Intrinsically radiopaque hydrogels for nucleus pulposus replacement. Biomaterials. 2005;26(33):6674-83.

127. van Hooy-Corstjens CS, Govaert LE, Spoelstra AB, Bulstra SK, Wetzels GM, Koole LH. Mechanical behaviour of new acrylic radiopaque iodine-containing bone cement. Biomaterials. 2004;25(13):2657-67.

128. Kruft MA, Benzina A, Blezer R, Koole LH. Studies on radio-opaque polymeric biomaterials with potential applications to endovascular prostheses. Biomaterials. 1996;17(18):1803-12.

129. Aldenhoff YB, Kruft MA, Pijpers AP, van der Veen FH, Bulstra SK, Kuijer R, Koole LH. Stability of radiopaque iodine-containing biomaterials. Biomaterials. 2002;23(3):881-6 

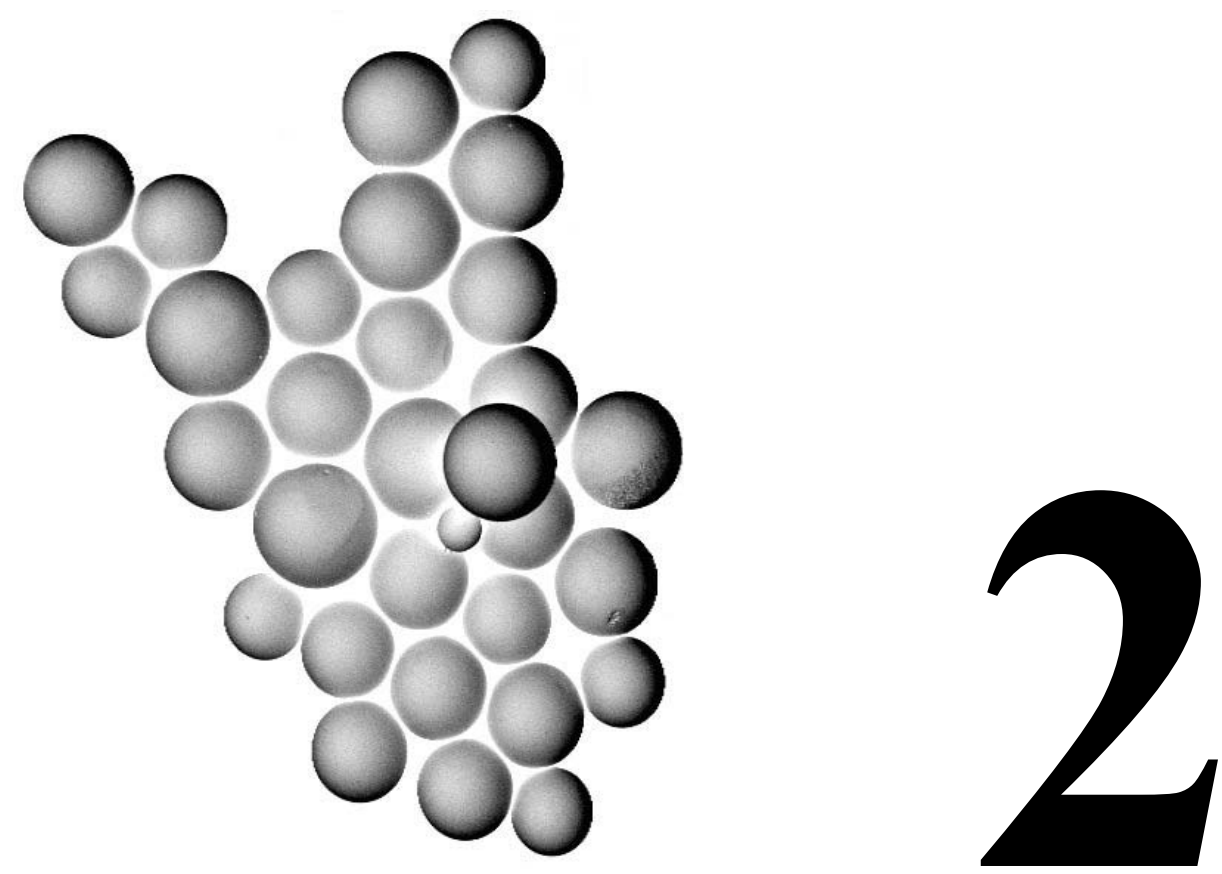

Injectable Polymeric Micropsheres with X-ray visibility. Preparation, Properties, and potential utility as New Traceable Bulking Agents

Ketie Saralidze, Yvette B.J. Aldenhoff, Menno L.W. Knetsch, and Leo H. Koole

Biomacromolecules 4 (2003), 793-798 


\title{
Chapter 2
}

\begin{abstract}
The copolymer of methyl methacrylate (MMA) and 2-[2',3',5'-triiodobenzoyl]oxoethyl methacrylate (1), ratio 3:1 (mass/mass) was prepared via a free-radical polymerization in bulk. The copolymer $(M w=97.9 \mathrm{kD}$ and $M n=41.5 \mathrm{kD})$ was dissolved in chloroform and subsequently transformed into beads with a diameter in the micrometer range, using a solvent evaporation technique. The resulting microbeads were characterized by different techniques, including NMR spectroscopy, differential scanning calorimetry, gel permeation chromatography, and scanning electron microscopy. The latter technique was used as the basis for statistical analysis of the bead size. Typically, an average diameter of $96 \mu \mathrm{m}$ and a standard deviation of $21 \mu \mathrm{m}$ were obtained. The beads were also subjected to some preliminary test regarding cytotoxicity. The copolymer of MMA and 1 contains covalently bound iodine. Therefore, the material is intrinsically radiopaque, i.e., capable of adsorbing X-radiation while no contrast additive is needed. Our interest in these microspheres stems primarily from their possible utility as injectable and afterward traceable (radiopaque) bulking agents, e.g., for use in urology for the treatment of female stress incontinence due to sphincter deficiency. As a first test into this direction, a sample of the microbeads was mixed with ethylene glycol, and the resulting suspension was studied with respect to injectability and radiopacity. The results suggest that the radiopaque microbeads may provide access to improved bulking agents. Further modification of the surface may be necessary in order to suppress the migratory aptitude of the radiopaque polymeric microspheres in vivo.
\end{abstract}

\section{Introduction}

Polymeric beads with a diameter in the micrometer range find use in various medical applications, such as bone dements (powder fraction) [1], in local delivery of drugs [2], and in treatment of female stress urinary incontinence [3,4]. Medical microspheres usually consist of poly(methyl methacrylate) (PMMA), poly(lactic acid-co-glycolic acid), poly(tetrafluoroethylene) (PTFE), or silicone rubbers. A particularly important application of microspheres relates to their use as so-called bulking agents; the microspheres are injected via a syringe, usually as a suspension in a collagen solution. It is known that injected microspheres have a tendency to migrate, depending on their size. It is believed that beads with a diameter $>80 \mu \mathrm{m}$ are unlikely to migrate [5], but it 
remains unclear how other factors (such as the exact site of the injection) might influence their migratory aptitude.

Herein, we report the preparation of new polymeric microspheres with clear X-ray visibility (radiopacity). In principle, this feature offers the advantage that injected beads can be detected through X-ray fluoroscopy, not only shortly after the injection but also on the long term [6]. Microspheres consisting of PMMA, PTFE, or silicon rubbers are radiolucent, i.e., invisible on the X-ray image. The practical utility of microspheres with $\mathrm{X}$-ray visibility lies in the fact that the clinician can assess possible migration in a direct manner. This information may provide guidance in cases where a second injection of bulking agent is necessary (repeated treatment).

The microspheres which are described in this work are made out of a polymer that belongs to the poly(methacrylate) family. A copolymer of methyl methacrylate (MMA) and a methacrylate that contains covalently bound iodine in the side chain was used. The copolymer features intrinsic radiopacity; i.e., it has the capacity to absorb Xradiation while no radiopaque additive is used. Biomaterials of this type have proven biocompatibility and stability in vivo [6], which may explain the increased interest in these biomaterials over the last years [7]. The copolymer used in this work was synthesized from MMA and 2-[2',3',5'-triiodobenzoyl] oxoethyl methacrylate (1), via a free-radical polymerization in bulk. We report synthesis and physicochemical analysis of the copolymer with ratio MMA:1 = 3:1 (mass:mass).

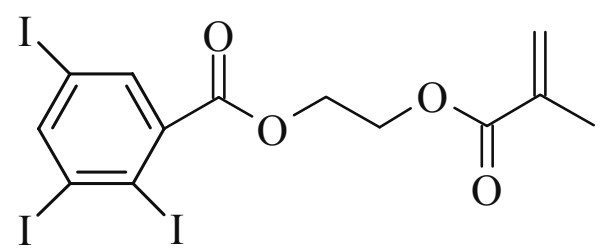

1

Furthermore, we describe a reproducible procedure, based on a solvent evaporation, for transformation of the crude materials into microspheres with a mean diameter of approximately $96 \mu \mathrm{m}$ and a standard deviation of $21 \mu \mathrm{m}$. Size and size distribution could be varied, and the most important process parameters to accomplish this were identified. In addition, it is shown that the microspheres have clear X-ray visibility after injection in a realistic model system. Furthermore, the microspheres were tested with 


\section{Chapter 2}

respect to their biocompatibility in vitro. Finally, it is discussed that these microspheres are potentially useful as bulking agents which can be traced by X-ray fluoroscopy, after their implantation, e.g., for treatment of stress urinary incontinence.

\section{Materials and Methods}

\section{Materials}

All materials were purchased from Sigma/Aldrich/Fluka chemicals, Acros Organics, and Invitrogen. MMA was distilled at atmospheric pressure and stored at $-20{ }^{\circ} \mathrm{C}$. 2Hydroxyethyl methacrylate (HEMA) was distilled under reduced pressure (13 mbar) and stored at $-20^{\circ} \mathrm{C}$. Tetrahydrofuran (THF), dichloromethane, and triethylamine (TEA) were distilled from calcium hydride and stored over either $3 \AA$ molecular sieves (THF, dichloromethane) or potassiumhydroxide pellets (TEA).

\section{Synthesis of 2-[2',3',5'-triiodobenzoyl]oxoethyl methacrylate (1)}

At room temperature, thionyl chloride $(19.00 \mathrm{~g}, 159,70 \mathrm{mmol})$ was added dropwise to a magnetically stirred solution of 2,3,5-triiodobenzoic acid (40.00 g, $80.13 \mathrm{mmol})$ in 300 $\mathrm{mL}$ of anhydrous THF. After completion of the addition, the reaction mixture was heated, refluxed (30 $\mathrm{min}$ ), and then allowed to cool to ambient temperature. All volatiles were removed under reduced pressure (stench!). The residue, 2,3,5-triiodobenzoyl chloride, was dissolved in $450 \mathrm{~mL}$ of anhydrous dichloromethane. The solution was magnetically stirred and cooled to $-5^{\circ} \mathrm{C}$, and a solution of HEMA $(11.47 \mathrm{~g}, 88.14$ mmol) and TEA (32.43 g, $320.52 \mathrm{mmol})$ in $50 \mathrm{~mL}$ of anhydrous dichloromethane was added dropwise. After the addition was completed, the ice bath was removed, and stirring was continued for $1 \mathrm{~h}$ at room temperature. Then, the reaction mixture was again cooled $-5{ }^{\circ} \mathrm{C}$, and water (approximately $150 \mathrm{~mL}$ ) was added carefully. The reaction mixture was transferred into a separatory funnel, and the organic layer was separated. The organic layer was washed with $0.1 \mathrm{M}$ sodium bicarbonate (once) and with brine (twice), dried over $\mathrm{MgSO}_{4}$, filtered, and concentrated. The crude product was recrystallized from hexane/ethanol to afford 1 as a white solid in $77 \%$ yield, mp $95.5^{\circ} \mathrm{C}$. ${ }^{1} \mathrm{H}$ NMR $\left(\mathrm{CDCl}_{3}\right): \delta 1.95\left(\mathrm{~s}, 3 \mathrm{H}, \mathrm{CH}_{3}\right), 4.48$ (d, 2H, $\left.\mathrm{CH}_{2} \mathrm{CH}_{2}\right), 4.57$ (d, 2H, $\mathrm{CH}_{2} \mathrm{CH}_{2}$ ), $5.61\left(\mathrm{~s}, 1 \mathrm{H}, \mathrm{CH}_{2}=\mathrm{C}\right), 6.16\left(\mathrm{~s}, 1 \mathrm{H}, \mathrm{CH}_{2}=\mathrm{C}\right), 7.73(\mathrm{~s}, 1 \mathrm{H}$, arom $), 8.29$ (s, $1 \mathrm{H}$ arom) ${ }^{13} \mathrm{C}$ NMR $\left(\mathrm{CDCl}_{3}\right): \delta 18.67,62.24,64.23,94.02,106.96,113.78,126.75,135.99,137.44$, 141.15, 149.13, 165.85, 167.24. ${ }^{1} \mathrm{H}$ and ${ }^{13} \mathrm{C}$ NMR spectra were recorded at 399.6 and 
100.6 MHz, respectively, on a Varian Unity-Plus spectrometer using deuterated chloroform as the solvent. Tetramethylsilane was used as the internal standard $(\delta=0.00$ ppm).

\section{Polymerization}

A $500 \mathrm{~mL}$ round-bottom flask was charged with 1 (10.00 g, $16.34 \mathrm{mmol})$ and MMA (30.00 g, $299.64 \mathrm{mmol}$ ), dibenzoyl peroxide (BPO, $1.2 \mathrm{~mol} \%, 0.92 \mathrm{~g}, 3.80 \mathrm{mmol}$ ) as initiator, and $N, N$-dimethyl-p-toluidine $(0.13 \mathrm{~mL}, 0.91 \mathrm{mmol})$ as accelerator. Monomers 1 and MMA were miscible at room temperature in the mass:mass ratio 1:3; further increase of the content of $\mathbf{1}$ resulted in a inhomogeneous mixture and, hence, a nonhomogeneous copolymer. The flask was placed in a thermostated oil bath, equipped with a programmable time-temperature control system (PM LAUDA, Könogshausen, Germany). The temperature profile as show in table 1 was run. The procedure afforded the copolymer as an amber-like solid. The procedure involves relatively slow polymerization at $60{ }^{\circ} \mathrm{C}$, and subsequent thermal treatment at 80 and $100{ }^{\circ} \mathrm{C}$. It is our experience that this temperature profile results in high conversions (typically $>95 \%$ ). Presently, a conversion of approximately $96 \%$ was achieved, as judged by ${ }^{1} \mathrm{H}$ NMR of the crude polymer. Remnants of unreacted MMA and 1 were still present, vide infra.

Table 1. Temperature Profile for the Polymerization

\begin{tabular}{llll}
\hline temperature $\left({ }^{\circ} \mathrm{C}\right)$ & time $(\mathrm{h})$ & temperature $\left({ }^{\circ} \mathrm{C}\right)$ & time $(\mathrm{h})$ \\
\hline 1) heat to 60 & 0.5 & 5) heat to 100 & 1.0 \\
2) maintain at 60 & 8.0 & 6) maintain at 100 & 4.0 \\
3) heat to 80 & 1.0 & 7) cool down to 40 & 2.0 \\
4) maintain at 80 & 4.0 & & \\
\hline
\end{tabular}

\section{Preparation of microspheres}

The copolymer was dissolved in chloroform $(150 \mathrm{mg} / \mathrm{mL})$. The solution was added dropwise to a mechanically stirred $(500 \mathrm{rpm})$ solution of $12 \mathrm{~g}$ of detergent (Dubro, Proctor \& Gamble) in $2 \mathrm{~L}$ of distilled water. Other detergents tried were Triton, Tween (both nonionic detergents) and sodium dodecyl sulfate (anionic). 


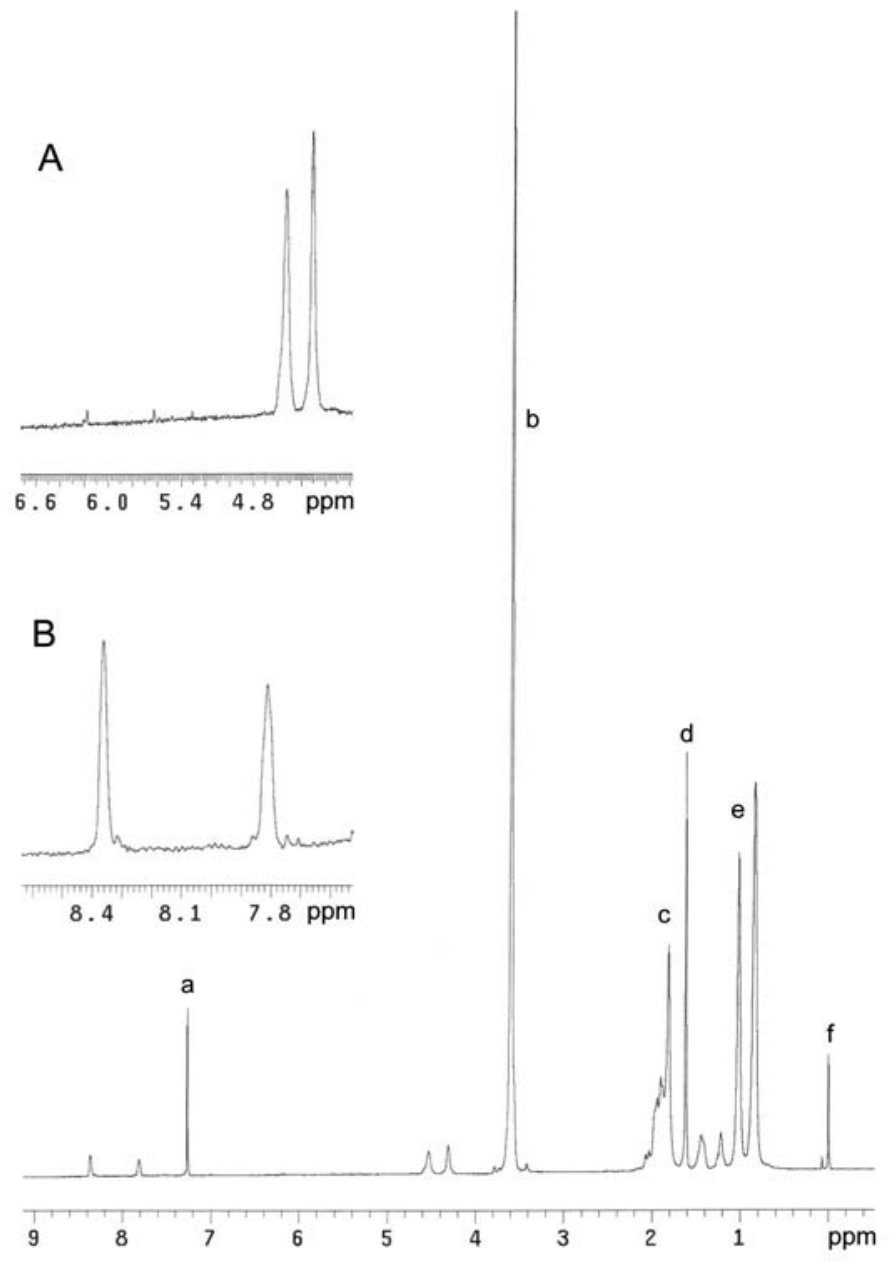

Figure 1. Overall proton NMR spectrum ( $\delta 9.0$ to $-0.5 \mathrm{ppm})$ of a sample of the radiopaque microspheres, after redissolution in deuterated chloroform. The spectrum provides evidence for the composition and purity of the material. $A$ and $B$ are expansions of the spectral regions $\delta 6.65$ 4.20 and 8.65-7.55 ppm. The two broadened singlet peaks in A correspond with the methylene protons of iodine-containing elements in the polymer chain. The two broadened singlet peaks in $B$ correspond with the aromatic protons in the same elements. Assignments of the resonances in the overall spectra are as follows: a, sharp singlet of $\mathrm{CHCl}_{3}$ traces in the solvent; $b$, pendant $\mathrm{OCH}_{3}$ groups; $c$, methylene protons in the polymer chain; $d$, singlet due to trace of water in the solvent; e, pendant $\mathrm{CH}_{3}$ groups; $f$, tetramethylsilane (reference, $\delta=0$ ppm). 
No microspheres were obtained with Triton $\mathrm{X}-100$ (poly-(oxyehtylene)(10)isooctylhexyl ether (CAS \# 92046-34-9), 4- $\left(\mathrm{C}_{8} \mathrm{H}_{17}\right) \mathrm{C}_{6} \mathrm{H}_{4} \mathrm{C}_{6} \mathrm{H}_{10}\left(\mathrm{OCH}_{2} \mathrm{CH}_{2}\right)_{n} \mathrm{OH}(\mathrm{n}=$ 10)), or Tween 20 (poly(oxyethylene)(20) sorbitan monolaureate (CAS \# 9005-64-5)), and sodium dodecyl sulfate performed less satisfactorily, as compared to Dubro. Stirring was continued overnight at room temperature to remove the chloroform (fume hood). Then, stirring was stopped and the microspheres were allowed to precipitate. The microspheres were thoroughly washed with water (2x), ethanol (3x) and water (3x). The microspheres were transferred into a $100-\mathrm{mL}$ round-bottom flask and dried by lyophilization. Yield: 76\%. 1H NMR $\left(\mathrm{CDCl}_{3}\right): \delta$ 0.71-2.10 (aliphatic $\left.\mathrm{H}\right), 3.59(\mathrm{OMe})$, 5.30 and 4.52 (methylene H), 7,81 and 8.36 (aromatic $\mathrm{H}$ ) see Figure 1.

\section{Scanning Electron Microscopy (SEM)}

Morphology and size of the microspheres were characterized using SEM (RJ Lee PSEM75, Goffin Meyvis, Etten Leur, The Netherlands). The microspheres were stuck on an aluminum stub with double-face adhesive carbon tape. The stubs were coated under vacuum for $2 \mathrm{~min}$ with a thin layer of gold and examined at an accelerating voltage of $20 \mathrm{kV}$. Three different windows of view were chosen, and approximately 300 spheres were included in each determination of average size and size distribution.

\section{Differential Scanning Calorimetry (DSC)}

Samples (approximately $14 \mathrm{mg}$ ) placed in aluminum pans were analyzed with a PerkinElmer-DSC-7 instrument at a heating rate of $10 \mathrm{deg} / \mathrm{min}$. Each sample was heated beyond the glass transition temperature, cooled rapidly, and heated again. The data presented were collected during the second heating scan. The glass transition temperature was taken as the midpoint of the heat capacity change. Indium and gallium were used as standards for temperature calibration.

\section{Gel Permeation Chromatography (GPC)}

GPC was performed using a Water Wisp autoinjection apparatus (Millipore Corp., Milford, MA), equipped with $10^{5}, 10^{4}$, and $10^{3} \mu$-Styragel (Alltech, Deerfield, IL). THF was used as the mobile phase at a flow rate of $1.0 \mathrm{~mL} / \mathrm{min}$. Detection was based on UV (UV 440, ambient conditions) at $254 \mathrm{~nm}$ and reflective index (RI 410, $40{ }^{\circ} \mathrm{C}$ ). Calibration was against a series of polystyrene standards $\left(580\right.$ to $\left.6 \times 10^{6} \mathrm{Da}\right)$. We realize 


\section{Chapter 2}

that use of these standards does not provide an accurate measure of $M_{\mathrm{W}}$ and $M_{\mathrm{N}}$ of our copolymer, which will have a different "molecular density" as compared to polystyrene (i.e., different Mark-Houwink constant). Nonetheless, the experiment values for $M_{\mathrm{W}}$ and $M_{\mathrm{N}}$, as derived from the GP chromatograms and using the polystyrene standards, allow us to conclude that the copolymer was a mixture of genuine macromolecules (vide infra).

\section{X-ray Visibility}

The radiopacity of the microspheres was tested in a realistic model, under routine hospital conditions. First, a suspension of microspheres in ethylene glycol was made (500 mg of microspheres/1.00 mL of ethylene glycol). The suspension was transferred into a 2-mL syringe. A chicken leg, purchased in a local supermarket, was used as a model. The microsphere suspension was injected into the soft tissue, and the model was examined with a Philips Optimus Z75C radiodiagnostic system.

\section{Cytotoxicity}

Microspheres were sterilized with UV light for $15 \mathrm{~min}$ and subsequently incubated for $48 \mathrm{~h}$ in culture medium at $37^{\circ} \mathrm{C}$. Culture medium used was Dulbecco's modification of eagle medium/F-12 nutrient mix containing Glutamax-I and supplemented with 10\% fetal bovine serum and antibiotic/antimycotic solution (1x). Mouse 3T3 fibroblasts were inoculated into a 96-well tissue culture plate (TCP) at a density of approximately $10^{3}$ cells/well. The cells were cultured to semi-confluence, in an incubator at $37{ }^{\circ} \mathrm{C}$ and $5 \%$ $\mathrm{CO}_{2}$ at high (near 100\%) humidity for 3 days. The incubated microspheres were placed in the wells in such a way that estimated $15-20 \%$ coverage of the total area by the spheres was achieved. The remaining extract medium, $100 \mu \mathrm{L}$, was separately added to the cells. TCP was used as a negative control, and latex was used as a positive control. Cells were cultured for another 3 days. Then, the medium was removed and replaced with culture medium containing thiazolyl blue (MTT, $0.5 \mathrm{mg} / \mathrm{mL}$ ). The cells were cultured for 1-2 $\mathrm{h}$, the medium was removed, and the formed precipitated formazan was dissolved in dimethyl sulfoxide (DMSO). The absorbance of the samples was determined using a microtiter plate reader at $550 \mathrm{~nm}$. 


\section{Direct Cell Contact Assay}

Mouse 3 T3 cells were inoculated into a 24-well TCP at a density of approximately $25 \mathrm{x}$ $10^{3}$ cells/well. The same culture medium as described above was used. The cells were incubated at $37{ }^{\circ} \mathrm{C}$ and $5 \% \mathrm{CO}_{2}$ overnight. When the cells were semi-confluent, a suspension of the microspheres in culture medium $(50 \mu \mathrm{g} / \mathrm{mL})$ was added to the cells. Cells were cultured for another 4 days and examined with light microscopy. Pictures were taken. Light microscopy was performed on a Leica DM-IL inverted microscope equipped with a Sony DSC-70 digital camera.

\section{Results and Discussion}

The two-step synthesis of 1, starting from 2,3,5-triiodobenzoic acid and HEMA, proceeded smoothly and with satisfactory overall yield (77\%). The subsequent freeradical copolymerization of $\mathbf{1}$ and MMA was run in bulk, using dibenzoyl peroxide and $N, N$-dimethyl- $p$-toluidine as radical initiator and accelerator, respectively. ${ }^{1} \mathrm{H}$ NMR analysis of the crude product revealed that the conversion was approximately $95 \%$. Both unreacted MMA and $\mathbf{1}$ were present, as judged by four singlet resonances in the spectral region $\delta 6.2-5.5 \mathrm{ppm}$.

The key step in the preparation of the microspheres was the dropwise addition of the copolymer-in-chloroform solution to the stirred solution of detergent in water. Upon falling in the turbulent aqueous medium, each drop of the copolymer solution is split into numerous smaller droplets. These are stabilized by the detergent. Continuous stirring results in evaporation of the chloroform. Several experimental parameters were found to influence the average size and the size distribution of the microspheres. The concentration of the polymer-in-chloroform solution was set at $15 \mathrm{~g} / 100 \mathrm{~mL}$. This resulted in microspheres with average diameter of $96 \mu \mathrm{m}$, and a standard deviation of 21 $\mu \mathrm{m}$ (vide infra). At lower concentrations, the average diameter became smaller (e.g., 25 $\mu \mathrm{m}(6 \mu \mathrm{m}$ standard deviation) at $5 \mathrm{~g} / 100 \mathrm{~mL})$. At higher concentrations, the procedure failed in most cases; a clump of polymer then attached to the rotor blade. Another important parameter, although less sensitive, was the speed of stirring. The optimal speed was found to be $500 \mathrm{rpm}$. Slower stirring resulted in broader size distributions, whereas faster stirring was practically impossible. A third important parameter was the height from which each drop fell into the detergent solution: this height was fixed at approximately $10 \mathrm{~cm}$. With respect to the detergent, it was found that the most 


\section{Chapter 2}

satisfactory results were obtained with the commercial household detergent Dubro, at a concentration of $6 \mathrm{~g} / \mathrm{L}$. After a series of test experiments, the other experimental parameters were chosen as follows: 2 L of detergent solution in a 4-L conical glass vessel, addition of $100 \mathrm{~mL}$ of the copolymer solution, time of addition $30 \mathrm{~min}$.

The microspheres precipitated readily when stirring was stopped (typically $18 \mathrm{~h}$ after the addition). Workup consisted of several washing steps, including three washings with alcohol to remove monomer remnants, and lyophilization. ${ }^{1} \mathrm{H}$ NMR analysis of the microspheres showed the absence of free monomer (Figure 1). GPC analysis showed that the microspheres consist of genuine macromolecular structures with $M_{\mathrm{W}}=97.8 \mathrm{kD}$ and $M_{\mathrm{N}}=41.5 \mathrm{kD}$, i.e., polydispersity $=2.4$. We realize that these numbers must be treated with caution, as a series of polystyrenes was used for GPC calibration, and the Mark-Houwink constants for our copolymer and polystyrene are most likely different.

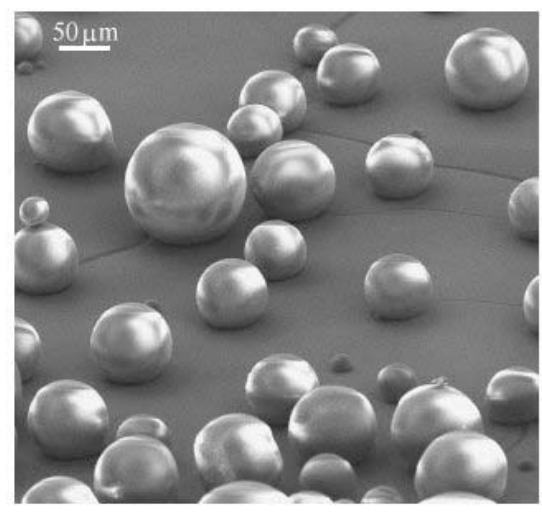

Figure 2. Typical scanning electron micrograph of microspheres as obtained by the solvent evaporation technique.

Nonetheless, we can safely conclude that the copolymer consists of a mixture of genuine macromolecules with a relatively small polydispersity. DSC showed a clear glass transition at $104{ }^{\circ} \mathrm{C}$. Figure 2 shows a SEM micrograph of a typical batch of microspheres. Size distributions of all different batches were derived from the SEM pictures, by measuring all microspheres in several arbitrarily chosen windows of view. Approximately 300 microspheres were incorporated in each analysis. The data were sorted into $10 \mu \mathrm{m}$ intervals. Figure 3 shows a histogram that compiles the results of a 


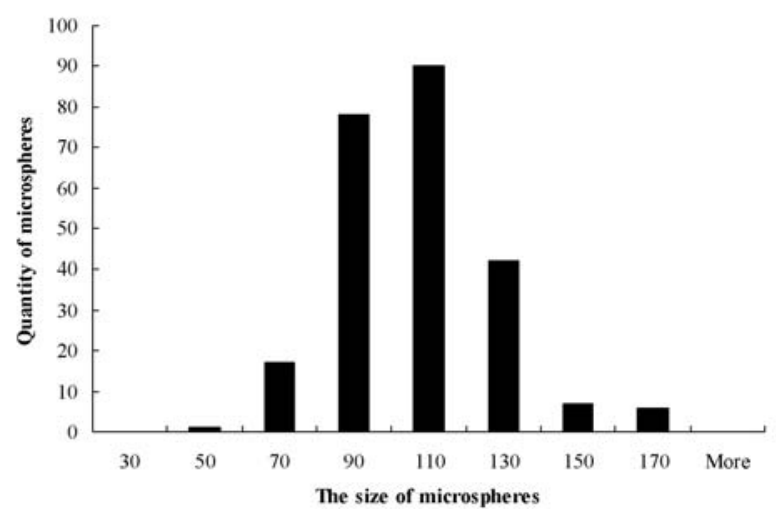

Figure 3. Size distribution, as measured for a typical batch of microspheres. The data were derived from several independent scanning electron micrographs of the same synthetic batch

typical size analysis, showing an average diameter of $96 \mu \mathrm{m}$, and a standard deviation of $21 \mu \mathrm{m}$.

A pilot experiment was conducted in order to check whether the microspheres have adequate radiopacity. A suspension of microspheres $(500 \mathrm{mg})$ in ethylene glycol (1.0 $\mathrm{mL}$ ) was made and transferred into a 2-mL syringe.

A

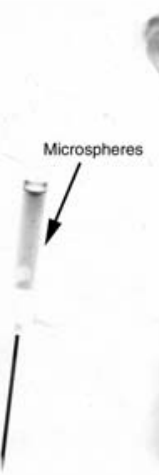

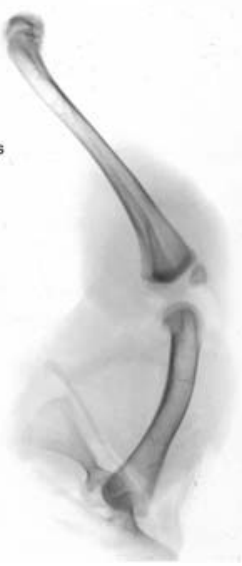

B

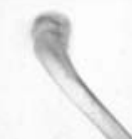

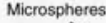

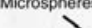

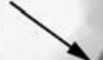

4

Figure 4. Demonstration of the X-ray visibility of injected microspheres, in a representative model, a chicken leg as purchased in a local supermarket: (A) X-ray image before the injection (filled syringe); (B) X-ray image after the injection. Note that the injected suspension is imaged as clearly as the femur and tibia. 


\section{Chapter 2}

A fresh chicken leg, purchased in a local supermarket, was used as a realistic model which allowed us to compare the X-ray visibility of (i) the microspheres after injection in the soft tissue, and (ii) the chicken femur and tibia. Figure 4 shows the X-ray images of the chicken leg before (left) and after (right) injection of the microspheres. The images of Figure 4 were recorded under normal clinical conditions in equipment that is routinely used for the detection of breast tumors.

The injected microspheres show excellent visibility, as judged by an experienced radiologist. It was also established that comparable microspheres of PTFE, PMMA, or silicone rubber are practically invisible under the same experimental conditions.

Two different experiments were done in order to investigate the in vitro biocompatibility of the microspheres.

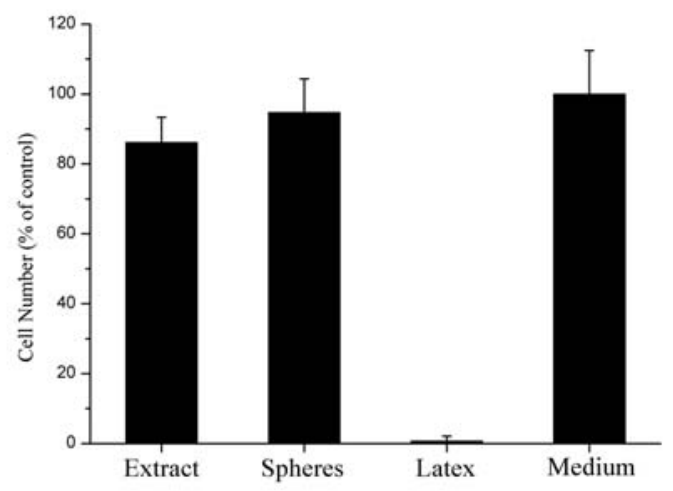

Figure 5. Survival percentage of the mouse $3 T 3$ fibroblast cells in the MTT test.

First, the MTT test was performed, using mouse 3T3 fibroblast cells. Defining adhered cell density onto tissue-culture-polystyrene as $100 \%$, it was found that the adhered cell density is $88 \%$ and $95 \%$, in contrast with the extract and microspheres, respectively (Figure 5).

Second, the growth of mouse $3 \mathrm{~T} 3$ cells in direct contact with microspheres was monitored. After 4 days, the cells formed a confluent layer on the bottom of the well, as is shown in Figure 6. Moreover, cells appear to cover parts of the surface of the microspheres (arrows), which may be interpreted as additional proof for the noncytotoxicity of the material. 


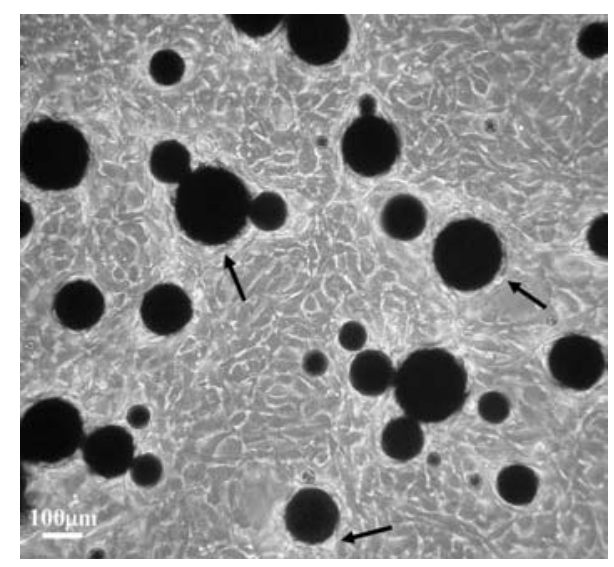

Figure 6. Light microscopic image of microspheres, after 4 days of incubation with $3 T 3$ mouse fibroblast cells. The cells adhere not only to the bottom of the well (polystyrene) but also to some of the microspheres, indicating that the material is not cytotoxic.

In 1992, Jayakrishnan and Thanoo already described polymeric iodine-containing radiopaque microspheres which are similar to ours [7a,b]. They reported on copolymers of (i), the HEMA-ester of iothalamic acid (IEH) and HEMA, and (ii), triiodophenyl methacrylate (TIPM) and HEMA [7a]. These copolymers were converted into beads with large diameter (mostly $>1 \mathrm{~mm}$ ), also through the solvent evaporation method. The monomer IEH has a bulky side chain, which was held responsible for the observation that copolymerization of IEH and MMA did not produce a high-molecular-weight copolymer. The monomer TIPM has its iodine-containing aromatic ring very close to the reactive double bond, which may explain why the copolymerization TIPM + MMA also failed. It is for this reason, that Jayakrishnan and Thanoo restricted themselves to copolymers based on HEMA [7a]. These microspheres have a slightly hydrophilic nature, and it must be assumed that they will absorb some water and become softer after implantation. This is undesirable as far as the application as a bulking agent is concerned. While Jayakrishnan and Thanoo observed that copolymerization of IEH or TIPM with MMA is troublesome, we have now found that the copolymerization MMA $+\mathbf{1}$ proceeds smoothly. The resulting microspheres consist of hydrophobic building blocks exclusively. Therefore, they will retain their hardness after implantation. 


\section{Chapter 2}

We anticipate that the present microspheres can be helpful in the search for an improved treatment of female stress urinary incontinence, caused by intrinsic sphincter deficiency. Several injectable bulking agents have been developed specifically for this purpose, but their use is still associated with significant drawbacks and complications. Microparticles of PTFE, formulated in a paste, have been used with reasonable success, but the safety of this material is uncertain for two reasons: (i) the tendency of PTFE microbeads to migrate away from the implantation site to lymph nodes, lungs, and brain [8] and (ii) the risk for granuloma formation (sometimes called "Teflonoma") [9]. Silicone rubber particles, suspended in hydrogel, appear to work better than PTFE. Distant migration was found, but only for particles smaller than $70 \mu \mathrm{m}[5,10]$. The long-term risks of silicone microbeads are unknown [3a]. Biological materials, such as cross-linked bovine collagen or autologous fat, are biodegradable, and therefore the initial bulking effect is usually lost on the long-term. A very promising new injectable bulking agent, consisting of biocompatible and non-immunogenic zirconium dioxide beads with a coating of pyrolytic carbon $\left(\right.$ Durasphere $\left.^{\circledR}\right)$ was introduced recently [3b,11]. However, clear evidence of their migration was found [12]. This is a puzzling observation, since Durasphere ${ }^{\circledR}$ beads have a large diameter (ranging from 251 to $300 \mu \mathrm{m}$ ); this diameter is at least three times larger than the reported threshold for particle size migration $(80 \mu \mathrm{m})$ [5]. A factor that may be responsible in part for the apparent migratory aptitude of Durasphere in vivo is the density of the bulk material (zirconium dioxide, $5.89 \mathrm{~g} / \mathrm{cm}^{3}$ density), which is much higher than the density of the surrounding soft tissue (approximately $1 \mathrm{~g} / \mathrm{cm}^{3}$ ) [13]. It must be noted that migration of Durasphere ${ }^{\circledR}$ particles could be monitored in a straightforward manner, due to their excellent X-ray visibility [3b]. Migration of the other polymeric beads (PTFE, silicone) is much more difficult to assess, since these polymers are radiolucent. Our new polymeric microspheres share the advantage of having clear X-ray visibility with Durasphere ${ }^{\circledR}$. We envisage two additional advantages of the new radiopaque microbeads: (i) a better match of the density of the microbeads (approximately $1.35 \mathrm{~g} / \mathrm{cm}^{3}$ ) with the surrounding soft tissue and (ii) the possibility for further modification of the surface, e.g., to promote anchoring in the surrounding tissue in order to minimize the risk of migration. We have started to work on this type of surface engineering of radiopaque polymeric microspheres, combined with testing of biocompatibility, functionality, and migratory aptitude in vivo. 


\section{Conclusion}

The microbeads described in this work are potentially useful as injectable and afterward traceable bulking agents. This expectation is based on (i) the combined physical properties of the copolymer and the beads, (ii) their non-cytotoxicity, and (iii) their cell friendliness, at least with respect to fibroblasts in vitro. With respect to clinical utility, it is mandatory that migration of the microbeads, after injection, is prevented. In vivo animal experiments to test this point are ongoing. It is of interest that surface modification of the microbeads may be required in order to achieve sufficient anchoring in the soft tissues of the implantation site.

\section{References}

1. (a) Lewis GJ. Biomed. Mater. Res. 1997;38:155-182. (b) Artola A, Goni I, Ginebra P, Manero JM, Gurruchaga MJ. Biomed. Mater. Res. 2003;64:44-55. (c) Jang JS, Lee SH, Jung SK. Spine 2002;27:416-418. (d) Espehaug B, Fumes O, Havelin LI, Engesaeter LB, Vollset SE. J. Bone Jt. Surg. Br. 2002;84:832-838. (d) Lewis GJ. Biomed. Mater. Res. 2002;63:455-466.

2. (a) Tsapis N, Bennett D, Jackson B, Weitz DA, Edwards DA. Proc. Natl. Acad. Sci. U.S.A. 2002;99:12001-12005. (b) Brandau T. Int. J. Pharm. 2002;242:197-201. (c) Hickey T, Kreutzer D, Burgess DJ, Moussy F. Biomaterials 2002;23:1649-1656. (d) Stenekes RJ, de Smedt SC, Demeester J, Sun G, Zhang Z, Hennink WE. Biomacromolecules 2002;1:696-703. (e) Kim HD, Valentini RF. Biomaterials 1997;18:1175-1181. (f) Emerich DF, Snodgrass P, Lafreniere D, Dean RL, Salzberg H, Marsh J, Perdomo B, Arastu M, Winn SR, Bartus RT. Pharm. Res. 2002;19:1052-1060. (g) Du J, Jasti B, Vasavada RC. J. Controlled Release 1997;43:223-230.

3. (a) Herschorn S. Can. J. Urol. 2001;8:1281-1289. (b) Dmochowski RR, Appell RA. Urology 2000;56:328-340. (c) Dmochowski RR, Appell RA. Tech. Urol. 2001;2;110-117. (d) Lightner D, Calvosa C, Andersen R, Klimberg I, Brito CG, Snyder J, Gleason D, Killion D, Macdonald J, Khan AU, Diokno A, Sirls LT, Saltzstein D. Urology 2001;58:12-15. (e) Barranger E, Fritel X, Kadoch O, Liou Y, Pigne A. J. Urol. 2000;164:1619-1622. (f) Bidmead J, Cardozo L. Lancet 2000;355:21832184.

4. (a) Peeker R, Edlund C, Wennberg AL, Fall M. Scand. J. Urol. Nephrol. 2002;36:194-198. (b) Duckett JRA. Br. J. Obstet Gynecol. 1998;105:390-396. (b) Herschorn S, Glazer AA. J. Urol. 2000;163:1838-1842.

5. (a) Malizia AA Jr, Reiman HM, Myers RP, Sande JR, Barham SS, Benson RC Jr, Dewanjee MK, Utz WJ. JAMA, J. Am. Med. Assoc. 1984;251:3277-3281. (b) Henly DR, Barrett DM, Weiland TL, O’Connor MK, Malizia AA, Wein AJ. J. Urol. 1995;153:2039-2043.

6. Aldenhoff YBJ, Kruft MAB, Pijpers AP, van der Veen FH, Bulstra SK, Kuijer R, Koole LH. Biomaterials 2002;23:881-886.

7. (a) Jayakrishnan A, Thanoo BC. J. Appl. Polym. Sci. 1992;44:743-748. (b) Jayakrishnan A, Thanoo BC, Rathinam K, Mohanty M. J. Biomed. Mater. Res. 1990;24:993-1000. (c) Davy KWM, Anseau MR, Odlyha M, Foster GM. Polym. Int. 1997;43:143-154. (d) Moszner N, Salz U, Klester AM, Rheinberger V. Angew. Makromol. Chem. 1995;224:115-123. (e) Kruft MAB, Benzina A Ba" $r$ FHMW, van der Veen FH, Bastiaansen CWM, Blezer R, Lindhout T, Koole LH. J. Biomed. Mater. Res. 1994;28:1259-1265, and 1996;32:459-466. (f) Kruft MAB, Benzina A, Blezer R, Koole LH. 


\section{Chapter 2}

Biomaterials 1996;17:1803-1810. (g) Davy KWM, Anseau MR, Berry C. J. Dent. 1997;25:499-505. (h) Horak D, Metalova M, Rypacek F. J. Biomed. Mater. Res. 1997;34:183-188. (i) Kruft MAB, van der Veen FH, Koole LH. Biomaterials 1997;18:31-38. (j) Koole LH, Kruft MAB, Aldenhoff YBJ, van't Oost NE, van Kroonenburgh MJPG, van der Veen FH. Nat. Biotechnol. 1998;16:172-176. (k) Mottu F, Rufenacht DA, Doelker E. InVest. Radiol. 1999;5:323-335. (1) Ginebra MP, Aparicio C, Albuixech L, Fernandez-Barragan E, Gil F J, Planell JA, Morelon L, Vazquez B, San Roman J. J. Mater. Sci., Mater. Med. 1999;10:733-737.

8. (a) Aaronson IA, Rames RA, Greene WB, Walsh LG, Hasal UA, Garen PD. Eur. J. Urol. 1993;23:394-399. (b) Rames RA, Aaronson IA. Ped. Surg. Int. 1991;6:239-240.

9. (a) Aragona F, Artibani W. Eur. Urol. 1995;4:146-151. (b) Kiiholma P, Makinen J. Eur. J. Urol. 1991;20:197-199.

10. Harriss DR, Iacovou JW, Lemberger RJ. Br. J. Urol. 1996;78:722-728.

11. Lightner D, Calvosa C, Andersen R, Klimberg I, Gilberto Brito C, Snyder J, Gleason D, Killion D, MacDonald J, Khan AU, Diokno A, Sirls LT, Saltzstein D. Urology 2001;58:12-15.

12. Pannek J, Brands FH, Senge Th. J. Urol. 2001;166:1350-1353.

13. Handbook of Chemistry and Physics, 70th ed.; CRC Press: Boca Raton, FL, 1989; p B-145. 


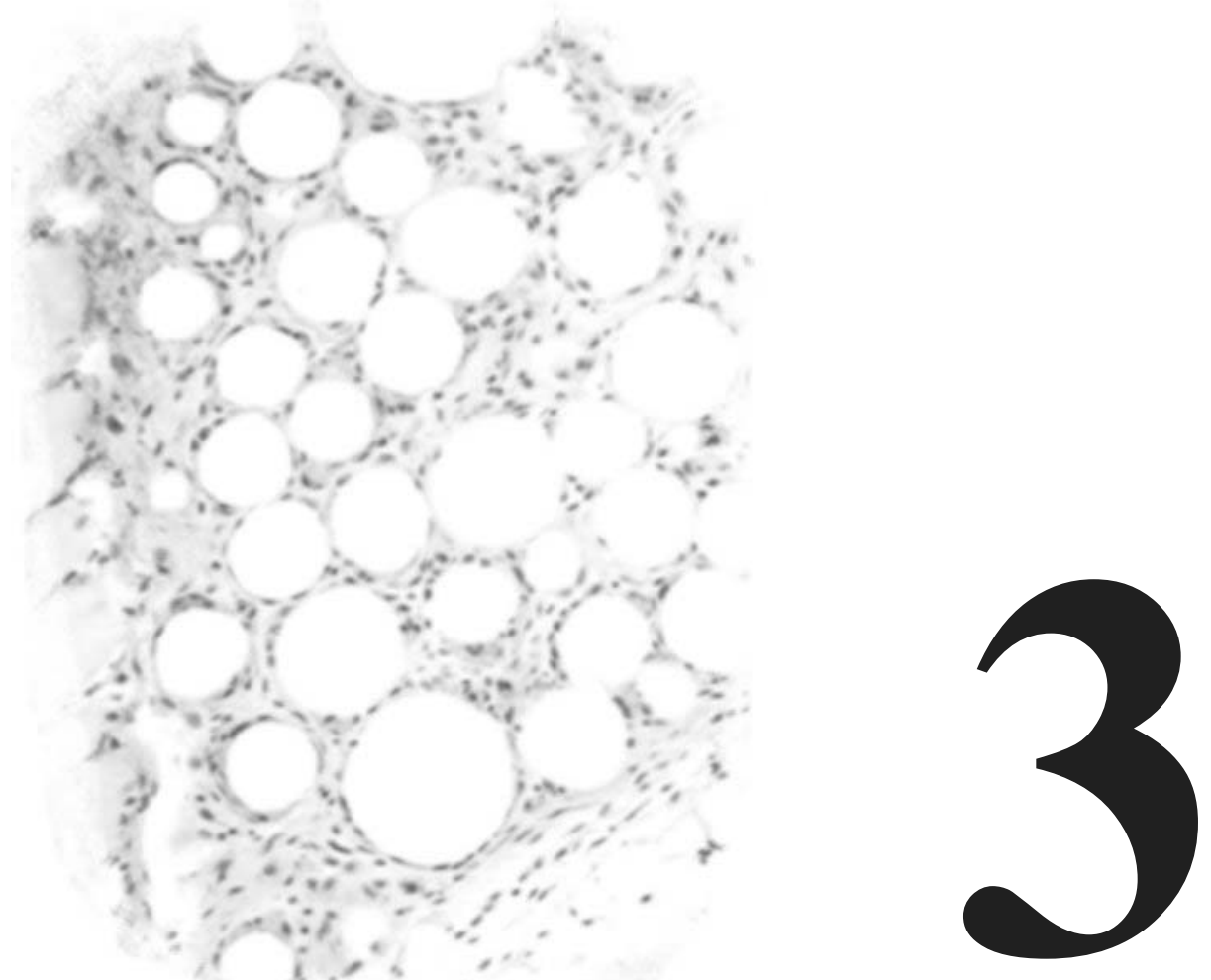

Development of new injectable bulking agents: Biocompatibility of radiopaque polymeric microspheres studied in a mouse model

Pieter J. Emans, Ketie Saralidze, Menno L. W. Knetsch, Marion J. J. Gijbels, Roel Kuijer and Leo H. Koole Journal of Biomedical Materials Research 73A (2005), 430-436 


\title{
Chapter3
}

\begin{abstract}
Radiopaque polymeric microspheres have a potential as new bulking agents for treatment of stress urinary incontinence (SUI). The advantage over existing bulking agents lies in their X-ray visibility in situ; other polymeric bulking agents (e.g., PTFE or silicone rubbers) are practically radiolucent (i.e., incapable of absorbing X-radiation). Radiopacity is useful in practice because of the high spatial accuracy of X-ray imaging. For instance, X-ray fluoroscopy can be used to assess possible migration of the bulking agent over time or to provide guidance in cases in which a second injection of a bulking agent is necessary (repeated treatment of SUI). Biocompatibility of injected radiopaque microspheres was investigated in vivo by using the mouse as a model. Microspheres were injected subcutaneously ( 9 animals) or intramuscularly ( 9 animals), and follow-up was 8 days or 3 months. X-ray fluoroscopy gave clear images of the microspheres as an ensemble, and it was found that no migration occurred during 3 months. Histopathology confirmed that all microspheres stayed close to the site of the injection. The microspheres appeared to be well tolerated; only a few giant cells, manifesting a mild inflammatory reaction, were encountered. At 3 months, capillary blood vessels were observed throughout the microsphere beds, and macrophages and fibroblast cells were seen in between the microspheres. This is encouraging with respect to the intended application, although it must be acknowledged that the data refer merely to a mouse model. Further experiments with larger, more representative models (rabbit and goat) are in progress.
\end{abstract}

\section{Introduction}

Polymeric spheres with a diameter in the micrometer range find use in several therapeutic strategies. Degradable polymer microspheres can be applied as vehicles for controlled local administration of drugs. This principle is used in numerous drug delivery strategies:

1. oral administration of low-molecular-weight heparin $[1,2]$,

2. development of better delivery systems in antisense therapy[3],

3. controlled local release of cytostatic agents [4,5],

4. treatment of Heliobacter pylori through mucoadhesive gastric retention [6,7],

5. oral delivery of insulin [8],

6. production of systemic and mucosal antibodies in mice [9], and 
7. sustained release of drugs (gancyclovir) to the vitreous body of the eye [10].

Nondegradable polymeric microspheres find use in totally different applications; two examples may serve to illustrate this. First, microspheres of poly(methylmethacrylate) (PMMA) suspended in collagen or dextran microbeads suspended in hyaluronic acid gels are used by plastic surgeons and ophthalmologists as soft tissue fillers for facial rejuvenation [11]. These materials provide reduction of wrinkles, volume augmentation, and contour improvement when injected into lines and furrows. Second, stable polymeric microspheres play a role in an emerging technique to treat recurrent stress urinary incontinence (SUI) in women [12-14]. We focus in this article on new polymeric microspheres that are potentially useful for SUI treatment. SUI is a complicated phenomenon that is associated with weakening of the soft tissue around the bladder neck. This may result from local denervation after childbearing, estrogen deficiency, and/or congenital factors. Periurethral injection of microspheres is a promising therapeutic option [12]; the microparticles are believed to provide more stiffness to the soft tissue, thus compensating deficiency of the sphincter muscle. Periurethral injection therapy for SUI was first described in 1938 by Murless, who used sodium morrhuate [15]. The first use of polymer microspheres in SUI treatment dates back to 1973 when Berg used poly(tetrafluoroethylene) (PTFE) [16]. Clinical experience showed, however, that PTFE is by no means the ideal biomaterial for SUI treatment. It is stable, biocompatible, and nonantigenic, but it induces granuloma formation [17]. Moreover, PTFE microparticles tend to migrate away from the injection site [18], even to distant sites (e.g., lungs, brain, kidneys, and choroids plexus). Other biomaterials did not provide an adequate solution, so far. Poly(dimethylsiloxane) microspheres were also found to migrate, and collagen-based agents rapidly lost their augmenting effect due to degradation in situ [20]. Durasphere ${ }^{\circledR}$, a new agent consisting of microspheres of zirconium dioxide with a coating of pyrolytic carbon, was also found to migrate, despite the relatively large diameter of the microbeads (251-300 $\mu \mathrm{m})$ [21]. We recently described the preparation, properties, and biocompatibility in vitro of new polymeric microspheres, consisting of a copolymer of methyl methacrylate (MMA) and a methacrylate monomer that contains covalently bound iodine [22]. We advocated that these microspheres are potentially useful for SUI treatment; they offer an important advantage over the existing polymeric agents. Our microspheres can be detected and 


\section{Chapter3}

visualized directly through X-ray fluoroscopy, not only shortly after the injection but also on the long term. In this way, the clinician can assess possible migration in a direct manner. This information may be very useful in cases in which a second injection of bulking agent is necessary (repeated treatment). Here, we report a study on the in vivo biocompatibility of the new radiopaque microspheres by using a mouse model. Sterile suspensions of the new microspheres in collagen were injected subcutaneously or intramuscularly. The animals were sacrificed after 8 days or 3 months.

\section{Materials and Methods}

\section{Materials}

All chemicals were purchased from Sigma/Aldrich/Fluka or Acros Organics. MMA was distilled at atmospheric pressure and stored for a maximum of $24 \mathrm{~h}$ at $-20^{\circ} \mathrm{C}$. The iodine-containing monomer, 2-[2',3',5'-triiodobenzoyl]oxoethyl methacrylate (1) was synthesized as described previously [22].

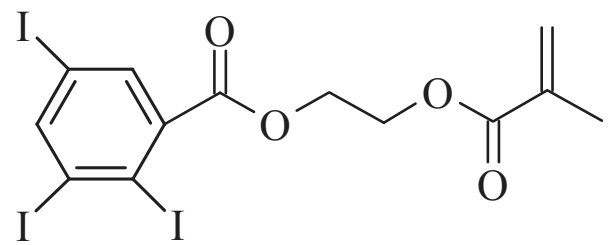

\section{1}

\section{Analytical methods}

${ }^{1} \mathrm{H}$ and ${ }^{13} \mathrm{C}$ NMR spectra were recorded at 400 and $100.6 \mathrm{MHz}$, respectively, on a Varian Unity-Plus spectrometer using deuterated chloroform as the solvent. Tetramethyl silane (TMS) was used as the internal chemical shift reference $(\delta=0.00 \mathrm{ppm})$. Morphology and size of the microspheres were characterized by scanning electron microscopy (SEM) with use of an RJ Lee Personal SEM75 system (Goffin Meyvis, Etten-Leur, The Netherlands).

Differential scanning calorimetry (DSC) was performed with a PerkinElmer DSC-7 instrument. Samples $(\sim 14 \mathrm{mg})$ were placed in aluminum pans. The heating rate was 10 degrees/min. Each sample was heated beyond the glass transition, cooled rapidly, and heated again. The glass transition temperature was measured during the second heating scan and taken as the midpoint of the heat capacity change. Indium and gallium were 
used as the standards for temperature calibration. Gel permeation chromatography (GPC) was performed on a Waters Wisp autoinjection apparatus (Millipore Corp., Milford, MA), equipped with $10^{5}, 10^{4}$, and $10^{3} \mu$-Styragel columns (Alltech, Deerfield, IL). Tetrahydrofuran was used as the mobile phase (flow rate $1.0 \mathrm{~mL} / \mathrm{min}$ ). Detection was based on Ultraviolet absorption at $260 \mathrm{~nm}$ and refractive index. Calibration was against polystyrene standards $\left(580-6 \times 10^{6} \mathrm{Da}\right) \mathrm{X}$-ray images were recorded with a Philips Diagnost 88 system $(40 \mathrm{kV})$ or with a Bennet-Trex Medical system $(24 \mathrm{kV})$ using a protocol for mammography. Both systems are in use in the Department of Radiology of the Academic Hospital, Maastricht.

\section{Polymerization}

A 500-mL round bottom flask was charged with 1 (10.00 g, $16.34 \mathrm{mmol})$ and MMA (30.00 g, $299.64 \mathrm{mmol}$ ), dibenzoyl peroxide (BPO; $1.2 \mathrm{~mol} \%, 0.92 \mathrm{~g}, 3.8 \mathrm{mmol}$ ) as the source of free radicals, and N,N-dimethyl-p-toluidine $(0.13 \mathrm{~mL}, 0.91 \mathrm{mmol})$ as the accelerator.

Table 1. Time-Temperature Profile for the Polymerization

\begin{tabular}{clcccc}
\hline Step No. & Temperature & Time (h) & Step No. & Temperature & Time (h) \\
\hline 1 & heat to $60^{\circ} \mathrm{C}$ & 0.5 & 5 & heat to $100^{\circ} \mathrm{C}$ & 1.0 \\
2 & maintain at $60^{\circ} \mathrm{C}$ & 8.0 & 6 & maintain at $100^{\circ} \mathrm{C}$ & 4.0 \\
3 & heat to $80^{\circ} \mathrm{C}$ & 1.0 & 7 & cool down to $40^{\circ} \mathrm{C}$ & 2.0 \\
4 & maintain at $80^{\circ} \mathrm{C}$ & 4.0 & & & \\
\hline
\end{tabular}

The flask was shaken until homogenization of the contents was achieved and placed in an oil bath, which was interfaced with a time-temperature control system (PM Lauda, Köningshofen, Germany). The time-temperature profile as outlined in Table 1 was then run. This procedure resulted in the desired copolymer as an amber like solid. A conversion of approximately $95 \%$ was achieved, as judged by ${ }^{1} \mathrm{H}$ NMR of the crude material. The NMR spectra showed the presence of traces of unreacted 1 and MMA, vide infra. 


\section{Chapter3}

\section{Preparation of microspheres}

The copolymer was dissolved in chloroform by overnight mechanical stirring (concentration $150 \mathrm{mg} / \mathrm{mL}$ ). This solution was added dropwise (in the fume hood) to a bowl containing $2 \mathrm{~L}$ of distilled water and $12 \mathrm{~g}$ of detergent. The contents of the bowl were mechanically stirred at $500 \mathrm{rpm}$. Stirring was continued overnight, which allowed the chloroform to evaporate. Stirring was stopped in the morning, and the microspheres were seen to precipitate readily. They were thoroughly washed with water (2 times), ethanol (3 times), and water (3 times) and transferred into a $100-\mathrm{mL}$ round bottom flask and dried by lyophilization. Yield was $84 \%$. ${ }^{1} \mathrm{H}$ NMR $\left(\mathrm{CDCl}_{3}\right): \delta 0.71-2.10$ (aliphatic $\mathrm{H}), 3.59$ (OMe), 4.30 and 4.52 (methylene $\mathrm{H}$ ), and 7.81 and 8.36 (aromatic H). No signals corresponding to unreacted residual monomers (MMA, 1) could be found in these NMR spectra; indicating that these were effectively removed during the solvent evaporation and the subsequent wash steps. Radiopaque microspheres $(3.00 \mathrm{~g})$ were mixed with a solution of bovine collagen $(10.0 \mathrm{~mL}, 20 \%)$, and this suspension was transferred into 10 1-mL syringes. Samples were sterilized with gas (ethylene oxide). The formulation stayed homogeneous for $>12$ months and proved to be easily injectable (23-gauge needle, blue).

\section{Scanning Electron Microscopy}

Microspheres were stuck on an aluminum stub with use of double-faced carbon tape. The samples were sputter-coated with gold and examined at an accelerating voltage of $20 \mathrm{kV}$. Three different windows of view were chosen, and $\sim 300$ spheres were included in each determination of average size and size distribution.

\section{Biocompatibility in vitro}

The microspheres passed tests for cytotoxicity and cell friendliness in vitro. These experiments (MTT assay, culturing of mouse 3T3 fibroblast cells in direct contact with the microspheres) were described previously [22].

\section{Animal experiments}

This study comprised 18 Adult Swiss mice. All experiments were approved by the Maastricht University Animal Experimental Committee. European and Dutch laws on animal experimentation were followed strictly. The animals were anesthetized through 
an intraperitoneal injection with pentabarbital (Nebutal; Ceva, Maassluis, The Netherlands). Dose was $100 \mu \mathrm{g} / \mathrm{g}$ body weight.

Injections were performed as follows: 1) $100 \mu \mathrm{L}$ of the microsphere/collagen suspension were injected underneath the subcutus (9 animals); 2) $50 \mu \mathrm{L}$ of the microsphere/collagen suspension was injected intramuscularly (in the hamstrings, 9 animals); 3) as controls, only the collagen suspension was injected on the contra-lateral side. Sterile 23-gauge needles were used. All animals were subjected to X-ray fluoroscopy at two time points: immediately after the injection and just prior to sacrificing. Comparing the X-ray images per animal provided information about possible migration of the microspheres. None of the animals showed unusual behavior, and no premature deaths occurred. Nine animals were sacrificed after 8 days (4 with microspheres in the subcutaneous tissue and 5 with microspheres injected intramuscularly). The other animals were sacrificed after 3 months. The X-ray images provided a convenient guidance during harvesting of tissue parts that contained the microspheres. Animals were anesthetized by inhalation of $\mathrm{CO}_{2}$, followed by cervical dislocation. Microspheres with surrounding tissue were excised, and the explants were immediately immersed in 10\% neutral buffered formalin for fixation and left for $24 \mathrm{~h}$ at least. After rinsing in distilled water and dehydration in an alcohol series (50, 70, 96, and $100 \%$ ), explants were embedded in glycidyl methacrylate (Technovit 7100; Heraeus Kulzer, Darmstadt, Germany). Sections $(5 \mu \mathrm{m})$ were cut and stained with hematoxylin and eosin to be used in histopathological evaluations using light microscopy.

\section{Results and Discussion}

Figure 1 represents an SEM micrograph of the microspheres; their average size was 63 $\pm 18 \mu \mathrm{m}$. High resolution ${ }^{1} \mathrm{H}$ NMR spectroscopy of these microspheres, redissolved in deuterated chloroform, revealed the absence of unreacted 1 and MMA.

Apparently, these impurities were removed effectively during microsphere workup. This is essential because remnants of unreacted monomer would render the microspheres cytotoxic. In the literature, it is generally assumed that the migratory aptitude of microspheres is related to their diameter.

Migration is generally believed to be unlikely when the diameter is larger than $80 \mu \mathrm{m}$ $[23,24]$. Recent studies have shown, however, that particle migration can also occur for much larger diameters $(251-300 \mu \mathrm{m})$ [21]. This may be explained by the fact that these 


\section{Chapter3}

particles (which are composed of carbon-coated zirconium dioxide) have a significantly higher density than the surrounding soft tissue.

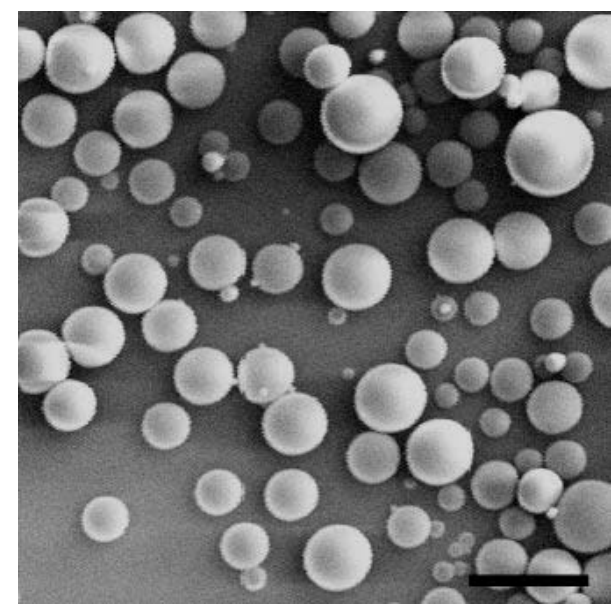

Figure 1. Scanning electron micrograph showing the microspheres used in this study. Scale bar $=100 \mu \mathrm{m}$.

We made numerous attempts to enlarge our microspheres further, but this proved to be very difficult, whereas increasing the concentration of the copolymer-in-chloroform solution leads to high viscosity, which precludes the formation of droplets before immersion in the aqueous detergent solution. Mixing of the microspheres with the solution of bovine collagen, subsequent transfer to $1-\mathrm{mL}$ syringes, and gas sterilization proceeded without difficulties. Several mice were injected from the same syringe; each injection was only $50 \mu \mathrm{L}$ (intramuscular) or $100 \mu \mathrm{L}$ (subcutaneous). Each injection was done with a new sterile needle.

Figure 2 shows representative X-ray images of mice after subcutaneous (A) or intramuscular (B) injection. Note the clear visibility of the microspheres in all cases. The X-ray images indicated that all microspheres resided closely packed at the site of the injection; no evidence of any particle migration could be inferred from the X-ray images. The same conclusion could be drawn from histology. Macroscopically, there were no differences between the two time points ( 8 days and 3 months) and no difference between the two sites of injection (subcutaneous and intramuscular). 

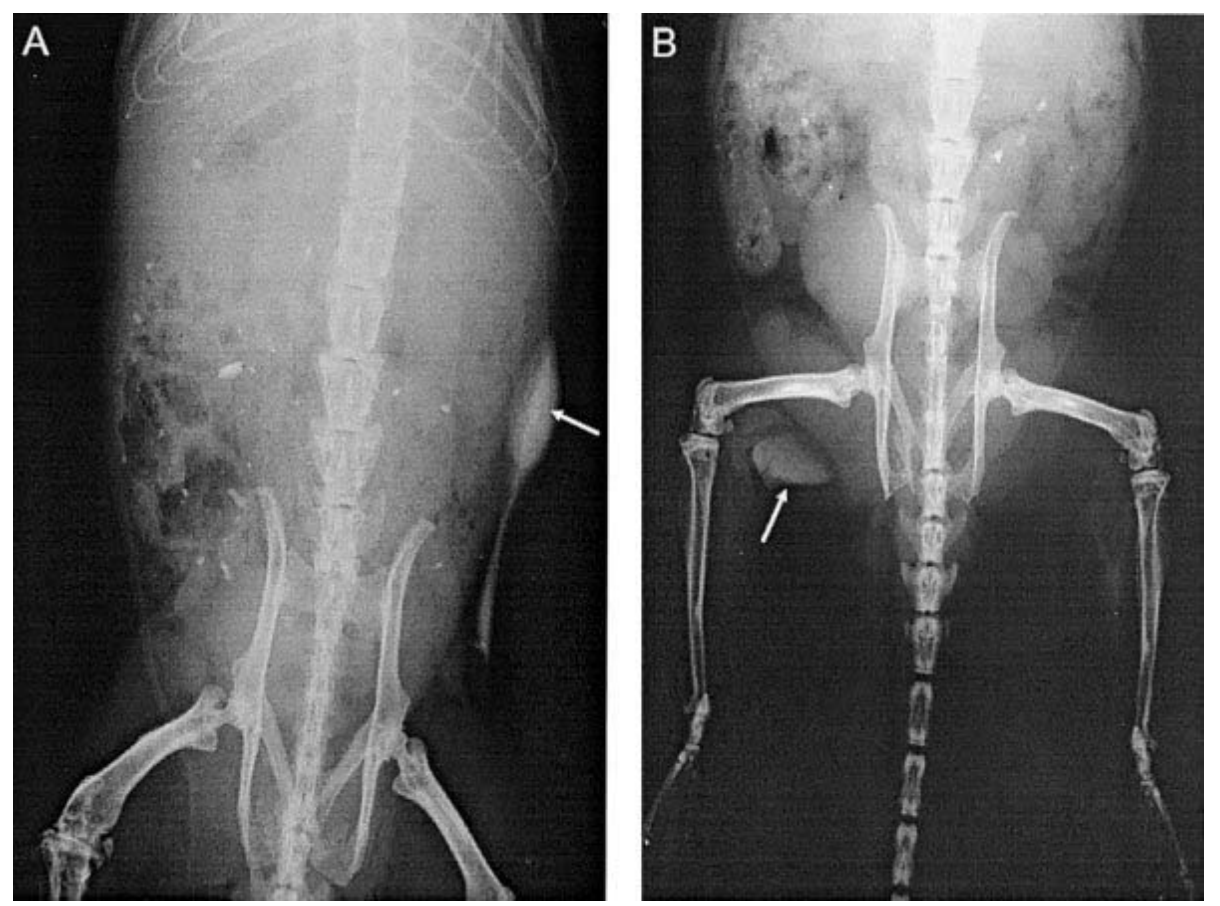

Figure 2. X-ray images of two mice before sacrificing at 3 months. Microspheres are indicated by a small white arrow. (A) Subcutaneous microspheres. (B) Microspheres located in the hamstrings (intramuscular).

Microspheres were retrieved as closely packed ensembles in all cases. Microscopically, we also noted similarity between 8 days and 3 months follow-up. The microspheres were well tolerated, irrespective of the site of injection. After 8 days, some inflammatory cells invaded the microsphere beds; these were mostly macrophages and granulocytes. Most of the macrophages were isolated; in some cases, they fused to form a giant cell.

Figure 3 shows two representative light micrographs of microspheres that resided in the subcutaneous tissue for 3 months. Figure 3(A) (low magnification) is an overview of the skin with some subcutaneous fat, a thin muscle layer, and the bed of microspheres underneath. The microspheres are closely packed, and there is no evidence of any particle migration. Figure 3(B) shows a part of the microsphere bed at a larger magnification. 


\section{Chapter3}
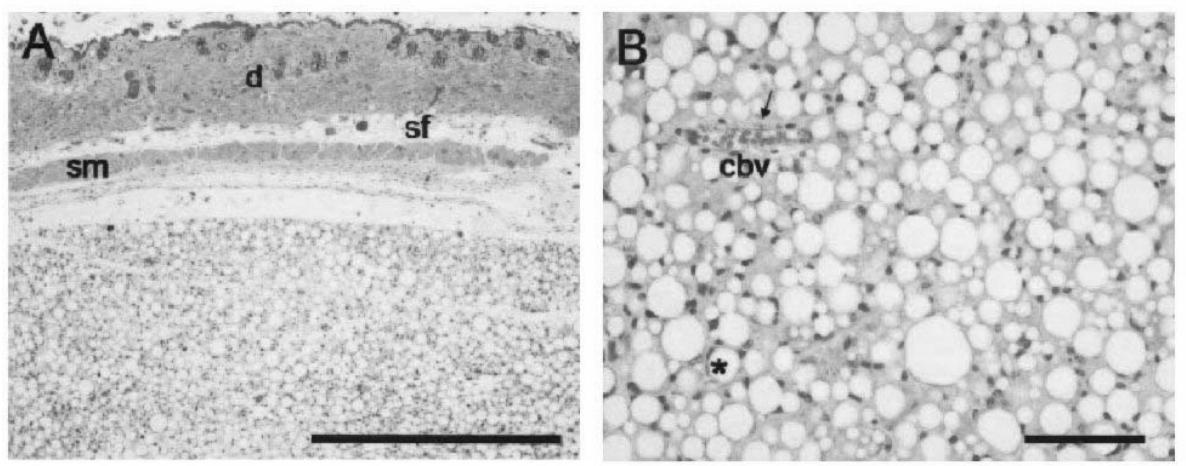

Figure 3. Light micrographs of subcutaneous microspheres after 3 months of follow-up. (A) $d=$ dermis; sf = subcutaneous fat cells; and sm = subcutaneous muscle layer. The microspheres are seen in the lower half of this micrograph; scale bar $=1 \mathrm{~mm}$. (B) Part of the microspheres in (A) shown at larger magnification; $c b v=$ capillary blood vessel; the arrow points to an endothelial cell in the capillary's wall. The asterisk indicates a microsphere surrounded by a giant cell. Scale bar $=100 \mu m$

Invaded macrophages are seen throughout the entire implant site. Most macrophages are apart, although in some cases they fused to form a giant cell. The asterisks in Figure 3(B) mark such giant cells; they consist of several nuclei and surround an entire microsphere in an apparent attempt to engulf it. This is an example of frustrated phagocytosis. Some invaded fibroblast cells were spotted as well.

Histology after 8 days and 3 months was different in two subtle respects: 1) granulocytes were found only after 8 days and 2) capillary blood vessels were found only after 3 months (Figure 3 ). Red blood cells are seen in the lumen, the small arrow points at an endothelial cell. Angiogenesis is not manifest during the 1st week of implantation.

Figure 4 shows a light micrograph of microspheres after intramuscular injection (follow-up of 3 months). The microspheres are closely packed, and no polymer degradation is seen. All microspheres were found close to the injection site (low magnification) (i.e., there is no evidence of particle migration). This is noteworthy because these microspheres resided in musculature tissue, which is highly dynamic. Macrophages invaded the space in between the microspheres. 


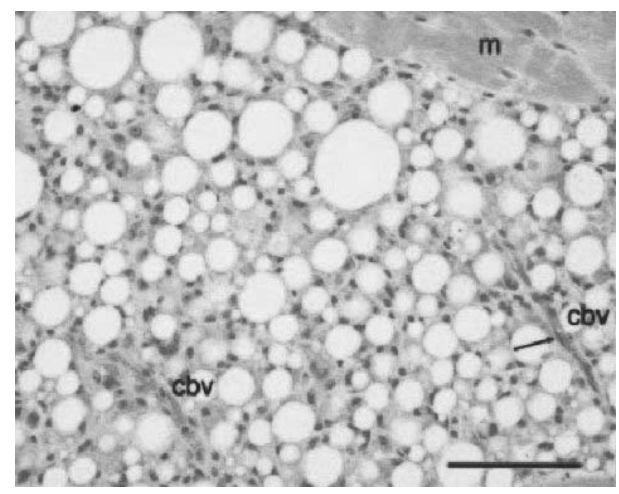

Figure 4. Light micrograph of intramuscular microspheres after 3 months of follow-up; $m=$ muscular tissue; $c b v=$ capillary blood vessel. The arrow points to an endothelial cell in the capillary's wall. Scale bar $=100 \mu \mathrm{m}$.

Several giant cells were found; these always surrounded an entire microsphere, in an apparent attempt to engulf and degrade that microsphere. Capillary blood vessels were present throughout the entire bed of microspheres, which reveals that angiogenesis can proceed close to and in between the microspheres.

We attempted to quantify the migratory aptitude of the injected microspheres on the basis of the X-ray images. For each image, we determined the ratio area occupied by microspheres: area occupied by the entire animal, as an estimate of the volume fraction of the particle-rich tissue. Immediately after injection, the ratio was found to be $0.021 \pm$ $0.004(\mathrm{n}=18)$. After 8 days, the ratio was $0.020 \pm 0.005$ (subcutaneous, $\mathrm{n}=4$ ) and $0.019 \pm 0.006$ (intramuscular, $\mathrm{n}=5$ ). After 3 months, the ratio was $0.022 \pm 0.007$ (subcutaneous, $\mathrm{n}=5$ ) and $0.023 \pm 0.009$ (intramuscular, $\mathrm{n}=4$ ). These data do not show a statistically significant increase of the area that is occupied with microspheres. By no means, however, can this be taken as proof for nonmigration of the particles: the X-ray images provide merely vague contours of the injected ensembles of particles, and our data sets are far too small for a proper statistical analysis. It is clear, however, that the volume of particle-rich tissue never expanded by $>10 \%$.

Finally, it should be noted that we are uncertain about the fate of the collagen that was injected with the microspheres. Most likely, it was resorbed quickly, without causing any adverse effects. This would explain why the microspheres were found to be closely packed already after 8 days. Moreover, we consistently failed at retrieving collagen 


\section{Chapter3}

samples that were injected as contra-lateral controls (both subcutaneously and intramuscularly). This could also be explained by rapid degradation and removal of the collagen from site of the injection.

\section{Concluding Remarks}

The radiopaque microspheres described here have the potential to become an attractive alternative to silicone and PTFE microspheres, which are used clinically as bulking agents in, for instance, SUI treatment. Our microspheres bring the benefit of clear X-ray fluoroscopic visibility in situ. The data generated in this study provide further support for this idea. Microspheres injected into mice showed clear X-ray contrast, and they were well tolerated in the subcutaneous tissue as well as in the hamstrings. After 3 months, capillary blood vessels penetrated the implants, macrophages and fibroblasts invaded the space in between microspheres, and giant cells were found only occasionally. The presence of the giant cells points at a mild inflammatory response. This is considered to be normal (i.e., the microspheres typically behave as a passive implant that is not engaged in any interaction with the surrounding tissue). No granuloma was observed, and there was no evidence of significant particle migration. The histopathological data are reminiscent of our previous study on long-term biocompatibility and stability of related iodine-containing radiopaque biomaterials, albeit that these were studied as bigger, more massive samples (cylinders with 3-mm diameter and 10-mm length) [25]. Taken together, the data reinforce the idea that radiopaque polymeric microspheres have potential use as new bulking agents. We realize that the mouse model has only little predictive value with respect to the actual application, which involves periurethral injection around the bladder neck in humans. Current experiments are aimed at further increasing the size of these microspheres. Finally in vivo experiments with larger animals, which may provide more realistic models, are required to evaluate these radiopaque microspheres as bulking agent.

\section{References}

1. Hoffart V, Ubrich N, Lamprecht A, Bachelier K, Vigneron C, Lecompte T, Hoffman M, Maincent P. Microencapsulation of low molecular weight heparin into polymeric particles designed with biodegradable and nonbiodegradable polycationic polymers. Drug Deliv. 2003;10:1-7.

2. Chandy T, Rao GH, Wilson RF, Das GS. Delivery of LMW heparin via surface coated chitosan/PEG-alginate microspheres prevents thrombosis. Drug Deliv. 2002;9:87-96. 


\section{Biocompatibility of radiopaque polymeric microspheres in a mouse model}

3. De Rosa G, Bochot A. Quaglia F, Besnard M, Fattal E. A new delivery system for antisense therapy: PLGA microspheres encapsulating oligonucleotide/polyethyleneimine solid complexes. Int. J. Pharm. 2003;18:89-93.

4. Liu Z, Ballinger JR, Rauth AM, Bendayan R, Wu XY. Delivery of anticancer drug and a chemosensitizer to murine breast sarcoma by intratumoral injection of sulfopropyl dextran microspheres. J. Pharm. Pharmacol. 2003;55:3441-3447.

5. Wang J, Ng CW, Win KY, Shoemakers, Lee TK, Feng SS, Wang CH. Release of paclitaxel from polylactide-co-glycolide (PLGA) microparticles and discs under irradiation. J. Microencapsul. 2003;20:317-327.

6. Umamaheswari RB, Jain S, Tripathi PK, Agrawal GP, Jain NK. Floating-bioadhesive microspheres containing acetohydroxamic acid for clearance of Heliobacter pylori. Drug Deliv. 2002; 9:223-231.

7. Wang J, Tauchi Y, Deguchi Y, Morimoto K, Tabata Y, Ikada Y. Positively charged gelatin microspheres as gastric mucoadhesive drug delivery system for eradication of H. pylori. Drug Deliv. 2000;7:237-243.

8. Jerry N, Anitha Y, Sharma CP, Sony P. In vivo absorption studies of insulin from an oral delivery system. Drug Deliv. 2001;8:19-23.

9. Pokorova D, Reschova S, Franz J, Hampl J, Dittrich M. Antigenic and adjuvant activities of branched aliphatic oligoester (M-DLLA) microspheres with incorporated bovine rotavirus. Drug Deliv. 2002;9:105-111.

10. Herrero-Vanrell R, Ramirez L, Fernandez-Carballido A, Refojo MF. Biodegradable PLGA microspheres loaded with ganciclovir for intraocular administration. Encapsulation technique, in vitro release profiles, and sterilization process. Pharm. Res. 2000;17:1323-1328.

11. Jordan DR. Soft-tissue Fillers for wrinkles, folds and volume augmentation. Can. J. Ophthalmol. 2003;38:285-288.

12. van Kerrebroeck P, ter Meulen PH, Farrelly E, Larsson G, Edwall L, Fianu-Honasson A. Treatment of stress urinary incontinence: recent developments in the role of urethral injection. Urol. Res. 2003;30:356-362.

13. Dmochovski RR, Appell RA. Delivery of injectable agents for treatment of stress urinary incontinence in women: evolving techniques. Tech. Urol. 2001;7:110 -117.

14. Duckett JRA. The use of periurethral injectables in the treatment of genuine stress incontinence. $\mathrm{Br}$. J. Obstet. Gynaecol. 1998;105:390-396.

15. Murless BC. The injection treatment of stress incontinence. J. Obstet. Gynaecol. 1938;45:67-71.

16. Berg S. Polytef augementation urethroplasty. Correction of surgically incurable urinary incontinence by injection technique. Arch. Surg. 1973;107:379-385.

17. Ferro MA, Smith JH, Smith PJ. Periurethral granuloma: unusual complication of Teflon periurethral injection. Urology 1988;31:422-423.

18. Claes H, Stroobants D, van Meerbeek J, Knockaert D, Baert L. Pulmonary migration following periurethral polyfluoroethylene injection for urinary incontinence. J. Urol. 1989;142:821-822.

19. ter Meulen PH, Berghmans LC, van Kerrebroeck P. Systematic review: efficacy of silicone microimplants (Macroplastique ${ }^{\circledR}$ ) therapy for stress urinary incontinence in adult women. Eur. Urol. 2003;44:573-582.

20. Herschorn S, Radomski SB. Collagen injections for genuine stress urinary incontinence: patient selection and durability. Int. Urogynecol. 1997;8:18-22.

21. Pannek J, Brands FN, Senge T. Particle migration after transurethral injection of carbon-coated beads for stress urinary incontinence. J. Urol. 2001;166:1350-1353. 


\section{Chapter3}

22. Saralidze K, Aldenhoff YBJ, Knetsch MLW, Koole LH. Injectable polymeric microspheres with Xray visibility. Preparation, properties and potential utility as new traceable bulking agents. Biomacromolecules 2003;4:793-798.

23. Malizia AA, Reiman HM, Myers RP, Sande JR, Barham SS, Benson RC, Dewanjee MK, Utz WJ. Migration and granulomatous formation after periurethral injection of polyTef (Teflon). JAMA 1984;251:3277-3281.

24. Henly DR, Barrett DM, Weiland TL, O’Connor MK, Malizia AA, Wein AJ. Particulate silicone for use in periurethral injections: local tissue effects and search for migration. J. Urol. 1995;153:2039 2043.

25. Aldenhoff YBJ, Kruft MAB, Pijpers AP, van der Veen FH, Bulstra SK, Kuijer R, Koole LH. Stability of radiopaque iodine containing biomaterials. Biomaterials 2002;23:881-886. 


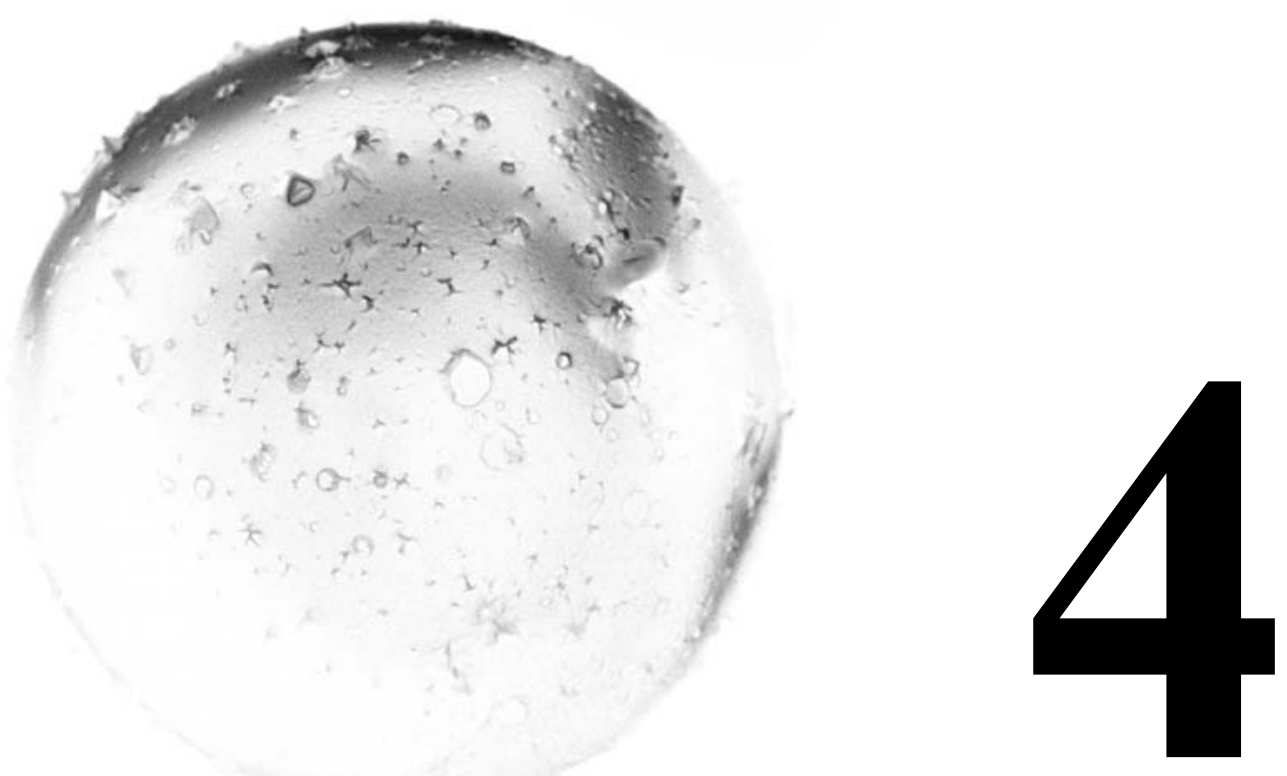

Radio-Opaque and Surface-Functionalized Polymer Microparticles: Potentially Safer Biomaterials for Different Injection Therapies

Ketie Saralidze, Menno L.W. Knetsch, Catharina S. J. van HooyCorstjens and Leo H. Koole

Biomacromolecules 7 (2006), 2991-2996 


\title{
Chapter 4
}

\begin{abstract}
Injectable polymer particles with a diameter in the range $30-300 \mu \mathrm{m}$ find applications as a biomaterial in different clinical fields, such as cosmetic surgery, reconstructive surgery and urology. However, clinical effects tend to disappear after several months, either due to migration of the particles away from the injection site (caused by weak adherence with the surrounding soft tissues), or due to fibrosis (caused by excessive encapsulation of the particles by fibrous tissue). Little is known about the fate of injected microparticles, due to the fact that they are extremely difficult to trace in a noninvasive manner. Design, synthesis and characterization of new polymeric microspheres with two additional features that can enhance safety and can help to overcome drawbacks of existing products are reported. First, the new microparticles feature clear radio-opacity (X-ray visibility) as they are prepared on the basis of a reactive methacrylic monomer that contains covalently bound iodine. Model experiments reveal that the level of X-ray contrast is sufficient for clinical monitoring; they can be visualized both during the injection and afterwards. The particles feature excellent cytocompatibility in vitro and in vivo. Secondly, a method is explored to functionalize the surface of the particles, e.g., through immobilization of collagen. Other extracellular matrix proteins can also be immobilized, and this provides mechanism to control anchoring of the particles in soft tissue. The results are briefly discussed in the context of improved biomaterials, contemporary X-ray imaging, and control over biomaterial soft tissue interactions in vivo.
\end{abstract}

\section{Introduction}

Several medical treatments are based on local injection of polymeric particles with a diameter in the $30-300 \mu \mathrm{m}$ range. Augmentation of soft tissues (e.g., correction of lips [1], reduction of wrinkles [2],) can be achieved through local injection of a "filler agent", which is a suspension of non-degradable synthetic microparticles in a biodegradable solution or dispersion [3]. Another example is found in urology: stress urinary incontinence in women (SUI) -defined as the complaints of involuntary leakage of urine on effort or exercise, sneezing or coughing- can be treated through precise periurethral injection of polymeric particles [4].

There are concerns, however, about possible complications and long-term effects of injected polymeric microspheres [5]. Cosmetic fillers can induce the formation of 
granulomatous tissue, or they may migrate away from the site of injection [6]. Zullo et al. have reported that peri-urethral injection of poly(dimethylsiloxane) (PDMS) particles to treat SUI had a high initial success rate (90\% after 1 month), which decreased to $75 \%$ after 3 months and 57\% after 60 months [7]. This pattern was confirmed in a series of other publications [8]. These disappointing long-term effects have been attributed, quite generally, to the migratory aptitude of injected microparticles. Indeed, poly(tetrafluoroethylene) (PTFE) particles can migrate from the injection site into lungs and brain [9]. Analogously, carbon-coated $\mathrm{ZrO}_{2}$ microbeads (Durasphere ${ }^{\circledR}$ ) [10], injected to treat SUI in patients, were found to migrate into local and distant lymph nodes, and into urethral mucosa [11]. The marginal long-term results have prompted the industry to introduce a variety of new bulking agents, especially with respect to SUI treatment. Most of these agents actually consist of a classic inert biomaterial with a well-established record of safety and durability, albeit in totally different applications. The most important examples, after PTFE, PDMS and Durasphere ${ }^{\circledR}$ are: glutaraldehyde crosslinked bovine collagen (GAX collagen) [12], calcium hydroxylapatite [13], dextranomer/hyaluronic acid copolymer (Dx/HA) [14] and autologous fat [15]. Claims of improved performance in SUI treatment were usually unsubstantiated. Some new agents even led to complications, such as pulmonary embolism (autologous fat) [16], or a severe local inflammatory response (GAX collagen) [17].

Migration of injected or implanted microparticles has been studied in animal models, but - to the best of our knowledge- only scarcely in humans [6a]. This may be explained, in part, by the fact that commercial particles are extremely difficult to trace in vivo. The only exception is Durasphere ${ }^{\circledR}$, for which the particles have a core of $\mathrm{ZrO}_{2}$, a notoriously radio-opaque material $[10,11]$. However, Durasphere ${ }^{\circledR}$ particles are not particularly suitable for long-term model studies in animals; the high density of $\mathrm{ZrO}_{2}$ $\left(5.89 \times 10^{3} \mathrm{~kg} / \mathrm{m}^{3}\right)$ may lead to movement of the particles due to gravitation. Here, we report on new polymeric microspheres that combine soft-tissue-like density with intrinsic radio-opacity; one of the building blocks is $\mathbf{1}$, a methacrylate monomer that contains three covalently bound iodine atoms [18]. The iodine-containing microparticles are stable in vivo, and they feature a high level of biocompatibility, both in vitro and in vivo. Their radio-opacity allows for accurate non-invasive monitoring through $\mathrm{X}$-ray fluoroscopy and micro-CT techniques. 


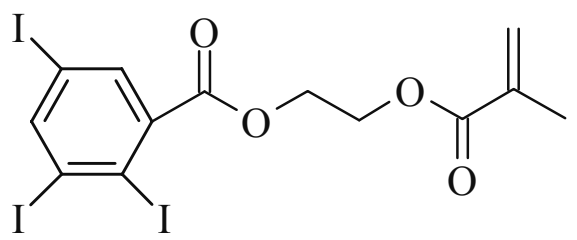

1

Furthermore, our microspheres have a reactive surface, which can be used to immobilize a plethora of compounds, such as collagen and other proteins. First, the new particles are useful vehicles to study the problem of injected-particle migration in animal models. Secondly, the pertaining question whether the anchoring of injected particles in soft-tissues can be improved through surface-tethering of molecules that are recognised biologically, can be addressed. Ultimately, the use of radio-opaque and surface-modified polymeric microparticles as described here, may open the way to safer and improved methods to treat SUI or to achieve safer and more long-lasting therapies in cosmetic surgery.

\section{Materials and Methods}

\section{Materials}

Chemicals were purchased from Sigma/Aldrich/Fluka, Acros, or Invitrogen. Methylmethacrylate (MMA) was distilled at atmospheric pressure and stored at $-20^{\circ} \mathrm{C}$. 2-Hydroxyethyl methacrylate (HEMA) was distilled in vacuo and stored at $-20{ }^{\circ} \mathrm{C}$. The monomer 2-[2',3',5'-triiodobenzoyl]-oxo-ethyl methacrylate (1) was prepared as described previously [18d,f]. All other commercially available chemicals were used as received. Porcine alkaline phosphatase and FITC-labelled collagen (type I, bovine) were from Sigma. Buffer solutions were prepared as follows: MES buffer: 2-(NMorpholino)ethanesulfonic acid (MES, $9.76 \mathrm{~g}, 50 \mathrm{mmol}$ ) was dissolved in $1 \mathrm{~L}$ of water and the $\mathrm{pH}$ was set to 5.5 with $\mathrm{NaOH}$. Tris buffer: Tris(hydroxyl-methyl)aminomethane (Tris, $6.06 \mathrm{~g}, 50 \mathrm{mmol}$ ) was dissolved in $1 \mathrm{~L}$ of water and the $\mathrm{pH}$ was set to 9.0 with $\mathrm{HCl}$. Carbonate buffer: two solutions were made: $\mathrm{NaHCO}_{3}(4.20 \mathrm{~g}, 50 \mathrm{mmol})$ in 500 $\mathrm{mL}$ water, and $\mathrm{Na}_{2} \mathrm{CO}_{3}(5.27 \mathrm{~g}, 50 \mathrm{mmol})$ in $500 \mathrm{~mL}$ water. These were mixed in the ratio $100 \mathrm{~mL}: 285 \mathrm{~mL}\left(\mathrm{Na}_{2} \mathrm{CO}_{3}: \mathrm{NaHCO}_{3}\right)$, which gave $\mathrm{pH}=9.6$. 


\section{Microscopy}

Scanning electron micrographs were recorded with a RJ Lee Personal SEM system (Goffin-Meyvis, Etten-Leur, The Netherlands). Microspheres were sprinkled onto an aluminium stub with double-faced carbon tape. Samples were sputter-coated with gold (2 min.) and examined at an accelerating voltage of $20 \mathrm{kV}$. Approximately 500 microspheres were included in the analysis of size and size distribution of each batch. Light microscopy was performed on a Leica DM-IL inverted microscope, equipped with a Sony DSC-70 digital camera. Fluorescence microscopy was performed with Nikon Eclipse E800, equipped with an RS Photometrics CoolSNAP camera.

\section{Preparation of microspheres}

A solution of poly(vinylalcohol) (PVA, Mw 86,000; 99-100\% hydrolyzed; $1.25 \mathrm{~g}$ ), poly(ethylene glycol) (PEG, Mw 1,000; $1.50 \mathrm{~g}$ ), and poly(N-vinyl-pyrrolidinone) (PVP, Mw 58,000; $250 \mathrm{mg}$ ) in $100 \mathrm{~mL}$ distilled water was mechanically stirred and heated to $75{ }^{\circ} \mathrm{C}$. MMA (5.00 g, $\left.49.93 \mathrm{mmol}\right)$, monomer 1 (1.00 g, $\left.1.63 \mathrm{mmol}\right)$, benzoyl peroxide (125 mg, $0.52 \mathrm{mmol}$ ) and tetra-ethylene glycol dimethacrylate (TEGDMA, $340 \mathrm{mg}$, $1.03 \mathrm{mmol}$ ) were mixed, and this mixture was added dropwise to the stirred aqueous PVA-PEG-PVP solution [19]. After the addition, stirring at $75{ }^{\circ} \mathrm{C}$ was continued for $3 \mathrm{~h}$. The microspheres precipitated immediately as stirring was stopped, and the supernatant was decanted carefully. The microspheres were allowed to cool to room temperature, and washed (water $(3 x)$, ethanol $(3 x)$, water $(3 x)$ ). The microspheres were then taken up in boiling water $(1 \mathrm{~h})$, decanted, frozen $\left(-180{ }^{\circ} \mathrm{C}\right.$, liquid nitrogen), and lyophilized. Yield: $5.04 \mathrm{~g}(84 \%)$.

\section{Surface hydrolysis}

Microspheres (1.00 g), ethylene glycol $(50 \mathrm{~mL})$, and $\mathrm{KOH}(2.80 \mathrm{~g})$ were transferred into a $100-\mathrm{mL}$ round bottom flask [20]. The flask was immersed in an oil bath $\left(180{ }^{\circ} \mathrm{C}\right)$, and the reaction was allowed to proceed for 5 min. Two identical batches were prepared, and these were reacted for 15 and 30 min, respectively. The flask was removed from the oil bath, and allowed to cool to room temperature. Microspheres were decanted, washed (water, ethanol, water, vide supra), frozen, and lyophilized. 


\section{Chapter 4}

\section{Titration of carboxylic groups on microspheres}

Microspheres $(100 \mathrm{mg}$ ) were resuspended in $100 \mu \mathrm{L} 0.100 \mathrm{M} \mathrm{NaOH}$ and $10 \mu \mathrm{L}$ of phenophtalein (400mg in $40 \mathrm{~mL} \mathrm{96 \%} \mathrm{ethanol).} \mathrm{Carefully} \mathrm{small} \mathrm{amounts} \mathrm{of} 0.010 \mathrm{M} \mathrm{HCl}$ were added until the colour changed from bright purple to colourless [21]. Untreated spheres that do not contain carboxylic groups needed the same amount of $\mathrm{HCl}$ to neutralize the solution without spheres. The hydrolyzed spheres were neutralized with less $\mathrm{HCl}$. The difference in added volume of $\mathrm{HCl}$ is a direct measure for the amount of carboxylic groups generated on the spheres by surface hydrolysis.

\section{Cytocompatibility of microspheres}

Mouse fibroblasts (3T3 cells) were grown in DMEM/F12 medium containing Glutamax and supplemented with $10 \%$ fetal bovine serum and antibiotics $(10 \mathrm{U} / \mathrm{mL}$ penicillin, 10 $\mu \mathrm{g} / \mathrm{mL}$ streptomycin, $0.25 \mu \mathrm{g} / \mathrm{mL}$ amphotericin B). Cells were harvested with $0.05 \%$ Trypsin/0.53 mM EDTA and seeded in a 24 well plate at a density of 25,000 cells per well. The cells were allowed to attach for 16 hours at $37^{\circ} \mathrm{C} / 5 \% \mathrm{CO}_{2}$. Microspheres were added in such amount that approximately $20 \%$ of the surface was covered by microspheres. The cells were allowed to grow for a further 48 hours and subsequently photographs were taken with a Leica DM-IL inverted microscope equipped with a Sony DSC-70 digital camera. In order to quantify cell viability, after the 48 hour incubation, medium was exchanged for medium containing $0.5 \mathrm{mg} / \mathrm{mL}$ MTT. The cells were incubated for a further 1.5 hours at $37^{\circ} \mathrm{C}$. MTT is converted into an insoluble blue/purple formazan by intact mitochondria, meaning incubation with non-viable cells will not result in staining. The medium was aspirated, the formazan was dissolved in isopropanol and absorbance at $550 \mathrm{~nm}$ was determined as a direct measure for viability.

\section{Surface coupling of coumarin}

Surface-hydrolyzed microspheres $(100 \mathrm{mg})$ were transferred to a 1-mL Eppendorf tube, and washed with MES buffer for $30 \mathrm{~min}$ [22]. Then, the supernatant was removed. A stock solution of reactants was prepared as follows: 1-ethyl-3-(3-dimethylaminopropyl) carbodiimide (EDC) $(191.5 \mathrm{mg}, 0.999 \mathrm{mmol})$, N-hydroxysuccinimide (NHS) $(46.5 \mathrm{mg}$, $0.404 \mathrm{mmol})$, and 7-amino-4-methylcoumarin $(5.0 \mathrm{mg}, 0.029 \mathrm{mmol})$ were dissolved in 5 $\mathrm{mL}$ of MES buffer. Then, $1 \mathrm{~mL}$ of the stock solution was mixed with the washed microspheres, and the reaction was allowed to proceed for $2 \mathrm{~h}$. The tube was mounted 
on a carousel that rotated at a slow speed. After $2 \mathrm{~h}$, the supernatant was removed, the microspheres were washed with MES buffer, and examined by fluorescence microscopy. The reaction was run for different batches of $\mathrm{KOH}$-treated microspheres $(5$, 15 or 30 minutes treated), and for microspheres that did not receive $\mathrm{KOH}$ treatment (control).

\section{Protein immobilization}

KOH-treated microspheres (100 mg) were transferred to a 1-mL Eppendorf tube, and washed with MES buffer for 30 minutes [23]. The supernatant was removed. A new stock solution was made, as follows: EDC (191.5 mg, $0.999 \mathrm{mmol})$, and NHS (46.5 mg, $0.404 \mathrm{mmol}$ ) were dissolved in $5.0 \mathrm{~mL}$ of MES buffer. Then, $0.5 \mathrm{~mL}$ of the stock solution and $0.5 \mathrm{~mL}$ of MES buffer were added to the washed microspheres. The Eppendorf tube was mounted on the carousel and rotated for 30 minutes. The supernatant was discarded, and the microspheres were briefly washed with MES buffer. As proteins we used: (i), porcine alkaline phosphatase (2 $\mathrm{mg} / \mathrm{mL}$ in MES buffer); (ii), heat-denatured FITC-labeled bovine collagen I $(0.8 \mathrm{mg} / \mathrm{mL})$ in carbonate buffer. In each case, microspheres pre-treated with EDC and NHS, were incubated with $1 \mathrm{~mL}$ of the protein solution for $2 \mathrm{~h}$, while the vial was rotated on the carousel. Subsequently, microspheres were washed repeatedly with MES buffer.

Microspheres, to which alkaline phosphatase was coupled, were incubated with p-nitrophenylphosphate (PNPP). A solution of PNPP (26.3 mg, $0.1 \mathrm{mmol})$ and $\mathrm{MgCl}_{2}(9.5 \mathrm{mg}$, $100 \mu \mathrm{mol})$ in $10 \mathrm{~mL}$ Tris buffer was made. $1 \mathrm{~mL}$ of this solution was added to the microspheres. For all different microspheres, control measurements (microspheres incubated with alkaline phosphatase but without EDC and NHS) were performed, to subtract the contribution of non-specific adsorbed alkaline phosphatase. Aliquots were taken regularly, and extinction at $405 \mathrm{~nm}$ was determined. Increase in extinction at 405 $\mathrm{nm}$ in time is a direct measure for the amount of converted PNPP and thus of the amount of alkaline phosphatase. By comparing conversion rates of the microspheres with the rates of known amounts of alkaline phosphatase, the amount of covalently bound alkaline phosphatase could be estimated. Collagen-FITC-labeled microspheres were examined directly by fluorescence microscopy. Part of the microspheres was treated with collagenase $(0.5 \mathrm{mg} / \mathrm{mL})$ in $10 \mathrm{mM}$ phosphate buffered saline. Fluorescence (ex $485 \mathrm{~nm} / \mathrm{em} 520 \mathrm{~nm}$ ) was determined with a Gemini XS fluorometer. 


\section{Chapter 4}

\section{X-ray visibility}

$\mathrm{X}$-ray contrast of the microspheres was assessed under routine hospital conditions, using a digital mammography imaging system (ThermoTrex Corporation, San Diego, CA).

\section{Results and Discussion}

\section{Microspheres}

Iodine-containing radio-opaque cross-linked polymer microspheres readily formed within $3 \mathrm{~h}$ during suspension polymerization of the mixture MMA + 1 + TEGDMA.
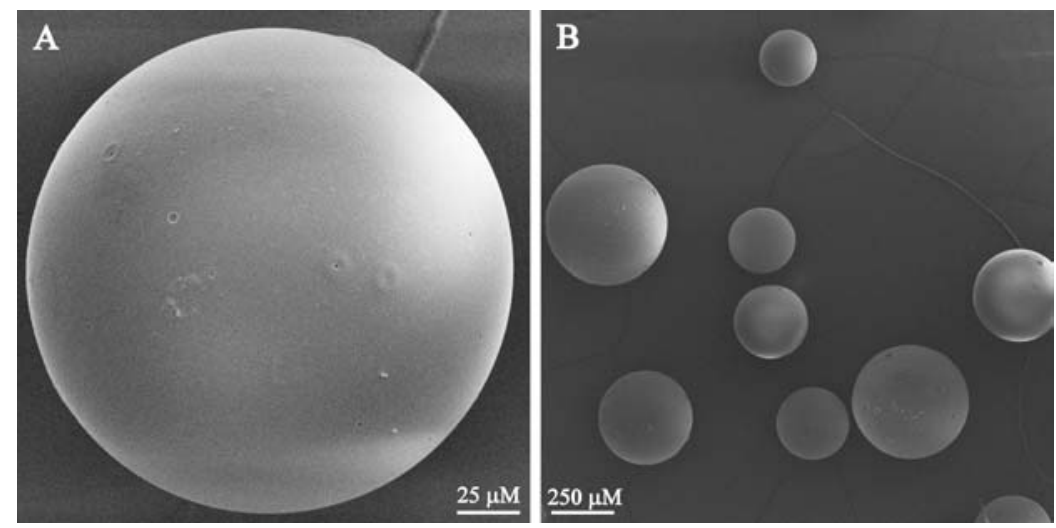

Figure 1. Scanning electron micrographs showing the radio-opaque microspheres at two different magnifications (see bars).

The yield was $84 \%$ after work-up and lyophilization. Monomer 1 was prepared from 2,3,5-triiodobenzoic acid and HEMA as described previously [18d,f]. The beads were washed thoroughly, in order to remove traces of unreacted monomers, which would otherwise exert a cytotoxic effect on contacting cells.SEM analysis revealed that the beads are smooth, perfectly spherical, and non-porous (Figure 1). Of a typical batch, the average diameter was $333 \mu \mathrm{m}$, with a standard deviation of $112 \mu \mathrm{m}$. Size and size distribution were reproducible, although the exact stirring parameters (speed, depth of the rotating paddle, flask geometry) influenced the outcome substantially.

The reaction conditions represent a delicate balance: saponification proceeds very slowly at lower temperatures, and higher temperatures or longer reaction times were found to result in structural deterioration of the particles. The reaction was run in three different batches, one for $5 \mathrm{~min}$, one for $15 \mathrm{~min}$, and one for or $30 \mathrm{~min}$. We anticipated 
that a longer reaction time would result in an increased surface density of - $\mathrm{COOH}$ groups. After treatment, the microspheres were washed thoroughly, in order to remove the last traces of ethylene glycol. Inadequate washing resulted in coalescence of the particles during lyophilization, and loss of the spherical shape. Figure 2 shows SEM micrographs of microspheres after $\mathrm{KOH}$ treatment and work-up. The smooth surface was preserved in the 5-min treatment $(\mathrm{A})$, while the 15 -min treatment led to some surface spots (B). After $30 \mathrm{~min}$ of $\mathrm{KOH}$ treatment (C), the surface became rough with incrustations and some flakes.
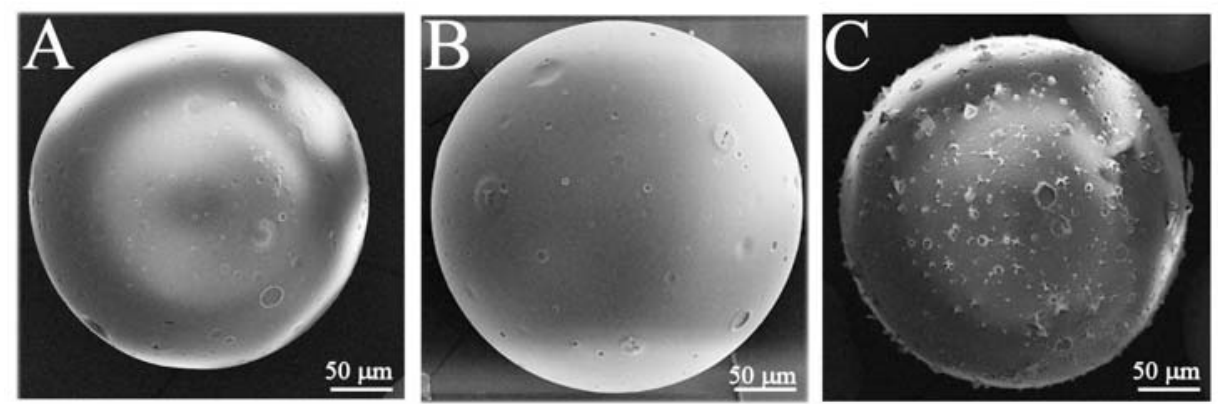

Figure 2. Scanning electron micrograph showing the effect of the incubation with $\mathrm{KOH}\left(180^{\circ} \mathrm{C}\right)$ on the surface of the microspheres. A: 5 min; B: 15 min; C: 30 min.

The amount of - $\mathrm{COOH}$ groups on the surface was determined by titration. The results given in Table 1 demonstrate that with increasing time of $\mathrm{KOH}$ treatment an increasing amount of carboxylic groups were generated on the surface of the microspheres.

Table 1. Results of titration of hydrolysed microspheres.

\begin{tabular}{|c|c|}
\hline $\begin{array}{c}\text { Time of KOH treatment } \\
(\mathrm{min})\end{array}$ & $\begin{array}{c}-\mathrm{COOH} \text { groups } \\
(\mu \mathrm{mol} / \mathrm{gr} \text { spheres })\end{array}$ \\
\hline 0 & $0.96 \pm 0.27$ \\
\hline 5 & $1.61 \pm 0.41$ \\
\hline 15 & $10.26 \pm 1.80$ \\
\hline 30 & \\
\hline
\end{tabular}




\section{Chapter 4}

The large increase of carboxylic groups between 15 and 30 minutes may indicate that the surface of the microspheres starts disintegrating, as can also be seen in Figure $2 \mathrm{C}$. The presence of $-\mathrm{COOH}$ groups was also confirmed using a fluorescent chromophore. The dye 7-amino-4-methylcoumarin was coupled to the $-\mathrm{COOH}$ through an activated ester (NHS) + EDC protocol.
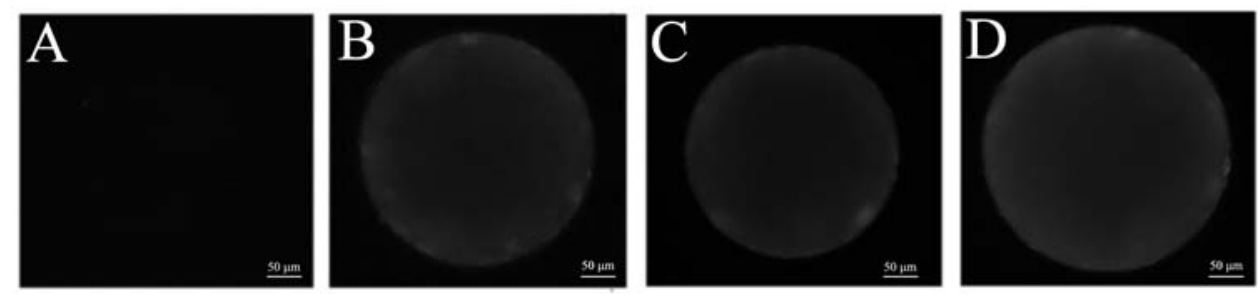

Figure 3. Fluorescence micrographs revealing the presence of immobilized coumarin. B: typical microsphere incubated with $\mathrm{KOH}$ for $5 \mathrm{~min}\left(180^{\circ} \mathrm{C}\right)$, prior to reaction with coumarin; $\mathrm{C}:$ idem, but incubated with $\mathrm{KOH}$ for $15 \mathrm{~min}$; D: idem, but incubated with $\mathrm{KOH}$ for $30 \mathrm{~min}$. A: control, i.e., this particle was not treated with $\mathrm{KOH}$, but treated with NHS, EDC and coumarin in an identical manner, as for $B-D$.

This one-step procedure was straightforward; $2 \mathrm{~h}$ reaction time was sufficient for clear labelling. Figure 3 shows fluorescence micrographs for the untreated control (A), and $\mathrm{KOH}$-reaction times of 5, 15 and $30 \mathrm{~min}$, respectively (B-D). Differences in fluorescence intensity due to the labelling (A vs. B-D), and due to the density of $\mathrm{COOH}$ groups at the surface (within the series $\mathrm{B}-\mathrm{D}$ ), are clearly visible.

\section{X-ray visibility}

A model set-up was used to test whether our particles feature an adequate level of X-ray visibility. First, we dispersed microspheres from 4 different batches (untreated, treated with $\mathrm{KOH}$ for 5,15 or $30 \mathrm{~min}$ ) in molten gelatine, which served to mimic the filler agent. After cooling, the samples were implanted in the soft tissue part of a chicken leg; the bones served as a qualitative internal standard for the X-ray contrast of the particles [18d]. Figure 4 shows the X-ray image. The particles are clearly visible, especially in the expansion (B). Noteworthy, not only conglomerated particles are seen; some of the larger particles can also be discerned individually. The images do not reveal any effect 
of the $\mathrm{KOH}$ treatment on the X-ray contrast. This is expected, since the saponification only affects the surface of the particles. We believe, based on Figure 4, and based on comments of an experienced radiologist, that the particles exhibit sufficient X-ray visibility for clinical use, e.g., most likely they would be traceable if injected in periurethral tissue to treat SUI in human patients.
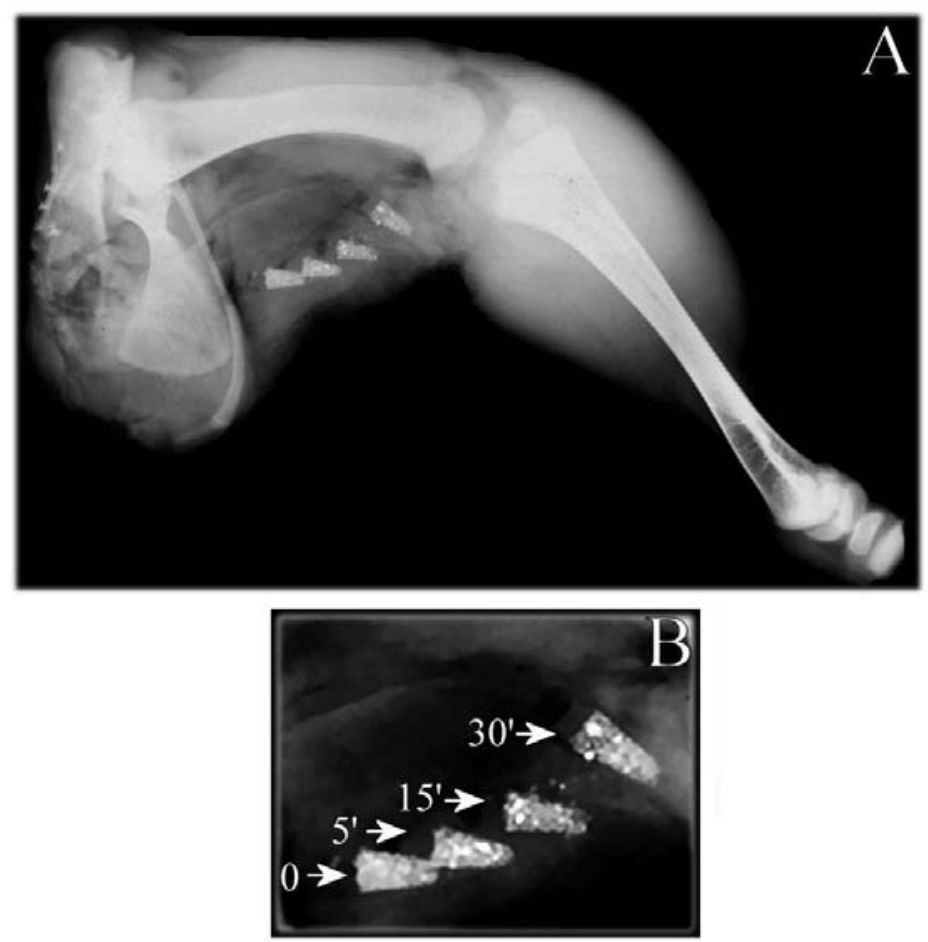

Figure 4. A: X-ray of the chicken leg with 4 different samples of the radio-opaque microparticles, embedded in gelatin as a mimic for the filler agent used clinically, implanted in the soft tissue part (see text). B: Expansion of the soft-tissue containing the four samples.

\section{Cytocompatibility in vitro}

Growth of cells (mouse 3T3 fibroblasts) in direct contact with our particles was examined in vitro. Figure 5 shows light micrographs, taken after 4 days of incubation. 

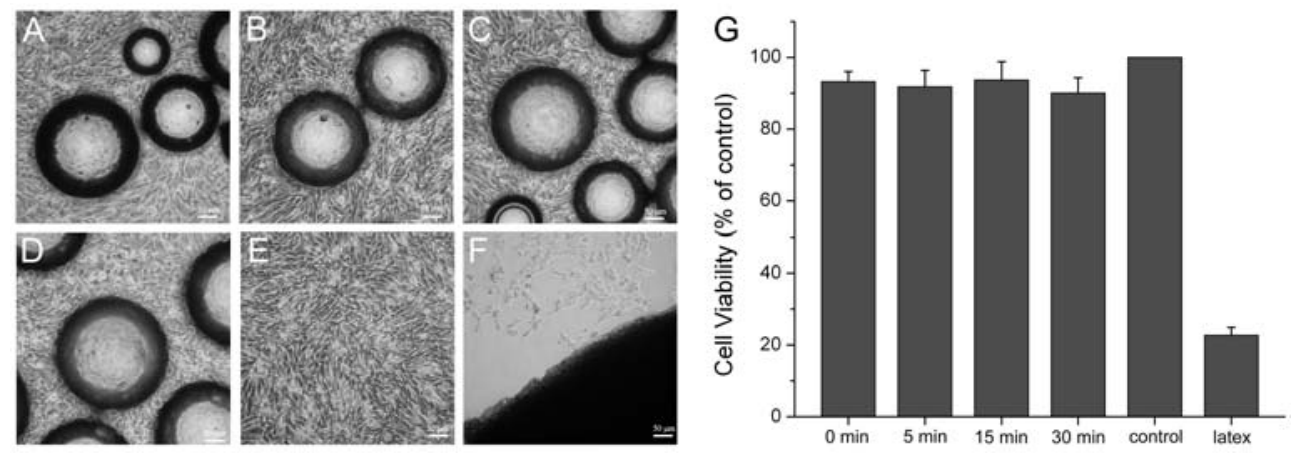

Figure 5. Light microscopic images, taken during the direct-contact cytocompatibility assay. The images were recorded after 4 days of incubation with mouse 373 fibroblast cells. A: fibroblasts in contact with microspheres that were not incubated with $\mathrm{KOH}$ (control); B: fibroblasts in contact with microspheres that were incubated with $\mathrm{KOH}$ for $5 \mathrm{~min}$; $\mathrm{C}$ : idem, but $\mathrm{KOH}$ treatment lasted $15 \mathrm{~min}$; D: idem, but KOH treatment lasted $30 \mathrm{~min}$; E: fibroblasts proliferating in the absence of any biomaterial (control); F: $3 T 3$ cells in the presence of Latex, which is a toxic control biomaterial (control); G: Quantification of cytocompatibility with the MTT conversion assay.

Figures $5 \mathrm{~A}-\mathrm{D}$ reveal that the fibroblasts cells grow readily in the presence of the untreated microspheres $(5 \mathrm{~A})$, and in the presence of $\mathrm{KOH}$-treated microspheres $(\mathrm{B}-\mathrm{D})$. Note that cells lie adjacent to the biomaterial's surface in all 4 cases, which indicates that their affinities for the iodine-containing biomaterial and for the tissue-culture poly(styrene) (TCPS) of the culture plate are comparable. Apparently, the presence of $\mathrm{COOH}$ groups does not affect cytocompatibility of the surfaces. Figures 5E and $\mathrm{F}$ represent controls: 5E shows the fibroblasts cultured on TCPS in the absence of any biomaterial, and 5F shows the effect of a toxic biomaterial (latex): much less cells are found in near the material's surface, and the morphology of the cells is clearly distorted. Cell viability of the cells was determined using a MTT assay in order to quantitatively confirm these results. Figure $5 \mathrm{G}$ clearly demonstrates that the microspheres are completely non-toxic.

\section{Immobilization of proteins}

Our first attempt to couple a protein to the surface - $\mathrm{COOH}$ groups on the microspheres was performed with the enzyme alkaline phosphatase (porcine). An activated ester (NHS) / carbodiimide (EDC) protocol was used, exactly in the same manner as for the 
coupling of 7-amino-4-methylcoumarin. Spheres were thoroughly washed after the reaction, in order to remove adsorbed, uncoupled enzyme as much as possible. Incubation of the modified spheres with p-nitrophenylphosphate led to conversion; formation of p-nitrophenol could be monitored spectrophotometrically. The occurrence of the reaction implies that the spheres have active enzyme molecules on their surface. Figure 6 shows the increase of the optical density as a function of time, for the microspheres that received 5,15 or $30 \mathrm{~min} \mathrm{KOH}$ treatment prior to the reaction with alkaline phosphatase.

The data indicate that prolonged $\mathrm{KOH}$ treatment first resulted in higher $-\mathrm{COOH}$ surface density, and later in higher surface density of active enzyme (Figure 6B). Microspheres that were not treated with $\mathrm{KOH}$ served as a control. Furthermore, all spheres were also treated with alkaline phosphatase but without the cross-linking agents EDC and NHS to correct for non-specific adsorption of alkaline phosphatase (adsorption controls).
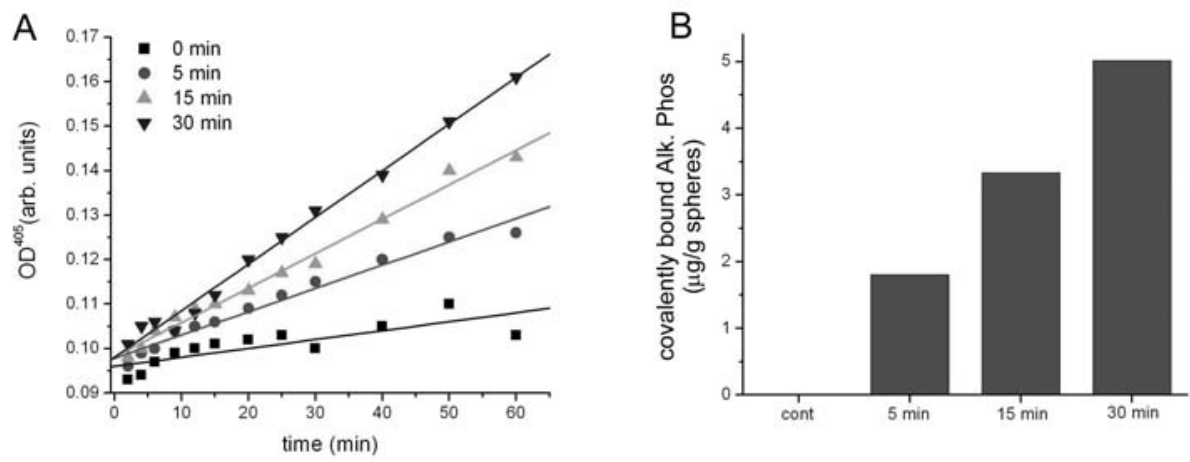

Figure 6. A) Para-nitrophenol formation over time followed by absorbance at $405 \mathrm{~nm}$, in the presence of the different spheres with surface coupled alkaline phosphatase. Note that the rate of the reaction, i.e., the surface density of the enzyme molecules, correlates with the duration of $\mathrm{KOH}$ treatment. B) Amount of covalently coupled alkaline phosphatase to the different spheres, determined by comparing rates of para-nitrophenol formation with those of a standard curve of alkaline phosphatase. These data are representative for three independent experiments using different batches of spheres.

Upon incubation with PNPP all control spheres, both the non-KOH treated spheres as well as the adsorption control, demonstrated virtually the same slight p- 


\section{Chapter 4}

nitrophenylphosphate conversion. The total amount of covalently surface-linked alkaline phosphatase increases with longer $\mathrm{KOH}$ treatment (Figure 6B).

The carbodiimide protocol was also used to bind fluorescently labelled collagen to our particles, as was verified through fluorescence microscopy (Figure 7A-D). Note that the fluorescence intensity again correlates with the time of $\mathrm{KOH}$ treatment. To quantify collagen coupling, the microspheres were incubated with collagenase. This rendered the supernatant fluorescent and this fluorescence could be compared to known concentrations of fluorescent collagen (Figure 7E). Up to approximately $190 \mu \mathrm{g}$ per gram spheres could be covalently coupled. The apparent possibility to bind collagen to the surface of the microspheres is of great interest with respect to the aim of this study: to explore new methods to prevent migration of injected microparticles in vivo.
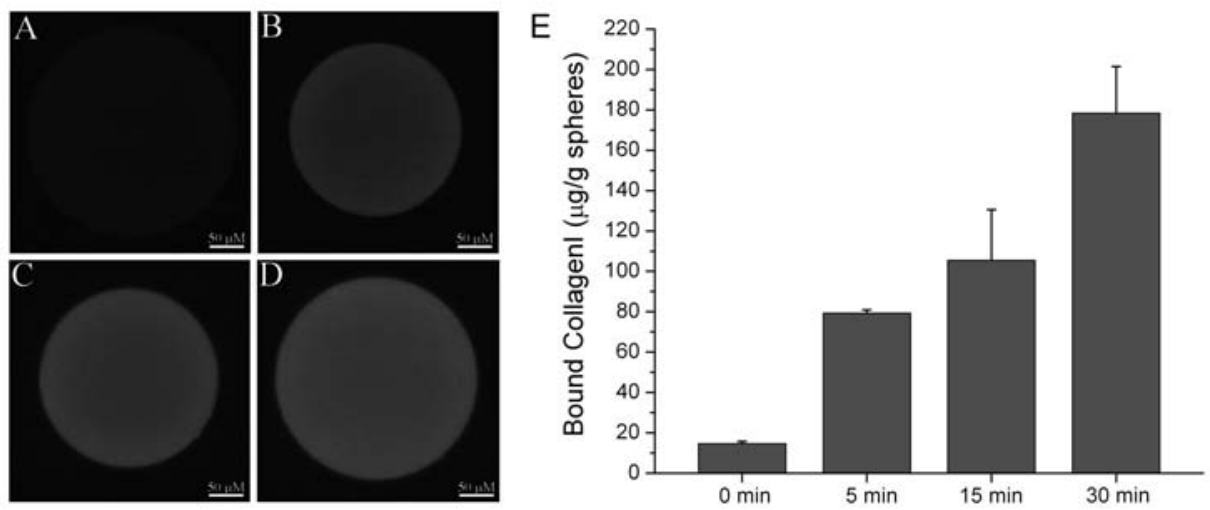

Figure 7. Fluorescence micrographs, showing immobilized fluorescent collagen at the surface of the microspheres $(B-D)$. B: microspheres that were incubated with $\mathrm{KOH}$ for 5 min prior to reaction with NHS, EDC and labeled collagen. C: idem, but incubation with KOH lasted 15 min; D: idem, but incubation with $\mathrm{KOH}$ lasted $30 \mathrm{~min}$. A: control, i.e., this particle was not treated with $\mathrm{KOH}$, but treated with NHS, EDC and labeled collagen in an identical manner as for B-D.

There are numerous studies that describe strongly increased cell adhesion on surfaces coated with collagen type I leading to the frequent use of collagen matrices for tissue engineering purposes [24]. Our ongoing research is directed toward the question whether immobilized collagen molecules will bind to extracellular matrix proteins (e.g., collagen) that are present in soft tissues. If such molecular recognition and binding 
occurs, then it must be expected that the microparticles have a decreased tendency to migrate. We will address this question in a series of in vitro and in vivo model studies.

\section{Concluding remarks}

Injectable synthetic polymer microparticles that are currently used in the clinic, e.g., in cosmetic/reconstructive surgery, or to treat SUI, all consist of passive biomaterials. Their primary function inside the body is to fill space. Usually, they are surrounded by a fibrous capsule and there is no interaction whatsoever with surrounding tissues. This study makes clear that polymeric microspheres with several different and potentially useful functionalities can be manufactured. Firstly, radio-opacity can be introduced through incorporation of covalently bound iodine in the polymer's structure, without affecting the density of the biomaterial and without compromising the cytocompatbility of the biomaterial. Clinically, it is important that injected biomaterials can be visualised through X-ray fluoroscopy. Moreover, a method to engineer the surface of the particles is described. Attachment of proteins, especially those that are recognized and bound by the extracellular matrix proteins in soft tissues, may turn out to be an effective strategy to prevent migration of injected microparticles away from the site of injection.

\section{References}

1. (a) Perenack J. J. Oral. Maxillofac. Surg. 2005;63:1634-1641. (b) Byrne PJ, Hilger PA. Facial Plast. Surg. 2004;20:31-38. (c) Wall SJ, Adamson PA. Otolaryngol. Clin. North. Am. 2002;35:87102.

2. (a) Jordan DR. Can. J. Ophthalmol. 2003;38:285-288. (b) Sclafani AP, Romo T III. Facial Plast. Surg. 2000;16:29-34.

3. (a) Homicz MR, Watson D. Facial Plast. Surg. 2004;20:21-29. (b) Carruthers A, Carruthers JD. Dermatol. Surg. 2005;31:1561-1564. (c) Haneke E. Semin. Cutan. Med. Surg. 2004;23:227-232. (d) Lemperle G, Romano JJ, Busso M. Dermatol. Surg. 2003;29:573-587.

4. (a) ter Meulen H, van Kerrebroeck E. Expert Rev. Med. Devices 2004;1:205-213. (b) Lightner DJ, Itano NB, Sweat SD, Chrouser KL, Fick F. Curr. Urol. Rep. 2002;3;408-413. (c) Lightner DJ. Curr. Opin. Urol. 2002;12:333-338. (d) Hershorn S. Can. J. Urol. 2006;13:5-12.

5. (a) Requena C, Izquierdo MJ, Navarro M, Martinez A, Vilata JJ, Botella R, Amorrortu J, Sabater V, Aliaga A, RequenaL. Am. J. Dermatopathol. 2001;23:197-202. (b) Lemperle G, Morhenn V, Charrier U. Aesthetic. Plast. Surg. 2003;27:354-366. (c) Christensen L, Breiting V, Janssen M, Vuust J, Hogdall E. Aesthetic. Plast. Surg. 2005;29:34-48. (d) Rubin JP, Yaremchuk MJ. Plast. Reconstr. Surg. 1997;100:1336-1353.

6. (a) Lemperle G, Morhenn VB, Pestonjamasp V, Gallo RL. Plast. Reconstr. Surg. 2004;113:13801390. (b) Morhenn VB, Lemperle G, Gallo RL. Dermatol. Surg. 2002;28:484-490.

7. Zullo MA, Plotti F, Bellati F, Muzii L, Angioli R, Panici PB. J. Urol. 2005;173:898-902. 


\section{Chapter 4}

8. (a) Sheriff MK, Foley S, Mcfarlane J, Nauth-Misir R, Shah P. J. Eur. Urol. 1997;32:284-288. (b) Guys JM, Breaud J, Hery G, Camerlo A, Le Hors H, De Lagausie P. J. Urol. 2006;175:1106-1110. (c) Halachmi S, Farhat W, Metcalfe P, Bagli DJ, McLorie GA, Khoury AE. J. Urol. 2004;171:1287-1290.

9. (a) Malizia AAJr, Reiman HM, Myers RP, Sande JR, Barham SS, Benson RCJr, Dewanjee MK, Utz WJ. JAMA 1984;251:3277-3281. (b) Claes H, Stroobants D, van Meerbeek J, Verbeken E, Knockaert D, Baert L. J. Urol. 1989;142:821-822. (c) Kiilholma PJ, Chancellor MB, Makinen J, Hirsch IH, Klemi PJ. Neurourol. Urodyn. 1993;12:131-137.

10. (a) Madjar Sh, Covington-Nichols C, Secrest ChL. J. Urol. 2003;170:2327-2329. (b) Lightner D, Calvosa C, Andersen R, Klimberg I, Brito CG, Snyder J, Gleason D, Killion D, Macdonald J, Khan AU, Diokno A, Sirls LT, Saltzstein D. Urology 2001;58:12-15.

11. Pannek J, Brands FH, Senge T. J. Urol. 2001;166:1350-1353.

12. (a) Bent AE, Foote J, Siegel S, Faerber G, Chao R, Gormley EA. J. Urol. 2001; 166:1354-1357.

(b) Corcos J, Fournier C. Urology 1999;54:815-818. (c) Monga AK, Robinson D, Stanton SL. Br. J. Urol. 1995,76:156-160.

13. (a) Mayer R, Lightfoot M, Jung I. Urology 2001;57:434-438. (b) Bos SD, Ypma AF, Timmermans CJ. Br. J. Urol. 1995;76:275-276.

14. (a) Stenberg AM, Larsson G, Johnson P. Int. Urogynecol. J. Pelvic Floor Dysfunct. 2003;14:335338. (b) van Kerrebroeck P, ter Meulen F, Larsson G, Farrelly E, Edwall L, Fianu-Jonasson A. Urology 2004;64:276-281.

15. (a) Palma PC, Riccetto CL, Herrmann V, Netto NRJr. J. Endourol. 1997;11:67-70. (b) Kanchwala SK, Holloway L, Bucky LP. Ann. Plast. Surg. 2005;55:30-35.

16. (a) Sweat SD, Lightner DJ. J. Urol. 1999;161:93-96. (b) Currie I, Drutz HP, Deck J, Oxorn D. Int. Urogynecol. J. Pelvic Floor Dysfunct. 1997;8:377-380. (c) Thaunat O, Thaler F, Loirat P, Decroix JP, Boulin A. Plast. Reconstr. Surg. 2004;113:2235-2236.

17. (a) McLennan MT, Bent AE. Obstet. Gynecol. 1998;92:650-652. (b) Echols KT, Chesson RR, Breaux EF, Shobeiri SA. Int. Urogynecol. J. Pelvic Floor Dysfunct. 2002;13:52-54.

18. (a) Boelen EJ, van Hooy-Corstjens CSJ, Bulstra SK, van Ooij A, van Rhijn LW, Koole LH. Biomaterials 2005;26:6674-6683. (b) van Hooy-Corstjens CSJ, Aldenhoff YBJ, Knetsch MLW, Govaert LE, Arin E, Erli H, Koole LH. J. Mater. Chem. 2004;14:3008-3013. (c) van HooyCorstjens CSJ, Govaert LE, Spoelstra AB, Bulstra SK, Wetzels GM, Koole LH. Biomaterials 2004;25:2657-2667. (d) Saralidze K, Aldenhoff YBJ, Knetsch MLW, Koole LH. Biomacromolecules 2003; 4:793-798. (e) Aldenhoff YBJ, Kruft MA, Pijpers AP, van der Veen FH, Bulstra SK, Kuijer R, Koole LH. Biomaterials 2002;23:881-886. (f) Benzina A, Kruft MA, van der Veen FH, Bar FH, Blezer R, Lindhout T, Koole LH. J. Biomed. Mater. Res. 1996;32:459-466.

19. Sivakumar M, Panduranga Rao K. J. Appl. Pol. Sci. 2002;83:3045-3054.

20. Jayakrishnan A, Chitambara Thanoo B, Rathinam K, Ravi Mandalam K, Rao VRK, Lal AV, Mohanty M. Bull. Mater. Sci. 1989;12:17-25.

21. Lewandowski K, Svec F, Fréchet JM. J. Chem. Mater. 1998;10:385-391.

22. Buttafoco L, Engbers-Buijtenhuijs P, Poot AA, Dijkstra PJ, Daamen WF, van Kuppevelt TH, Vermes I, Feijen J. J. Biomed. Mater. Res. B Appl. Biomater. 2005;77:357-368.

23. Puleo DA, Kissling RA, Sheu MS. Biomaterials 2002;23:2079-2087.

24. (a) Dewez JL, Lhoest JB, Detrait E, Berger V, Dupont-Gillain CC, Vincent LM, Schneider YJ, Bertrand P, Rouxhet PG. Biomaterials 1998;19:1441-1445. (b) McCarthy JB, Vachhani B, Lida J. Biopolymers 1996;40:371-381. (c) Garcia AJ, Reyes CD. J. Dent. Res. 2005;84:407-413. 

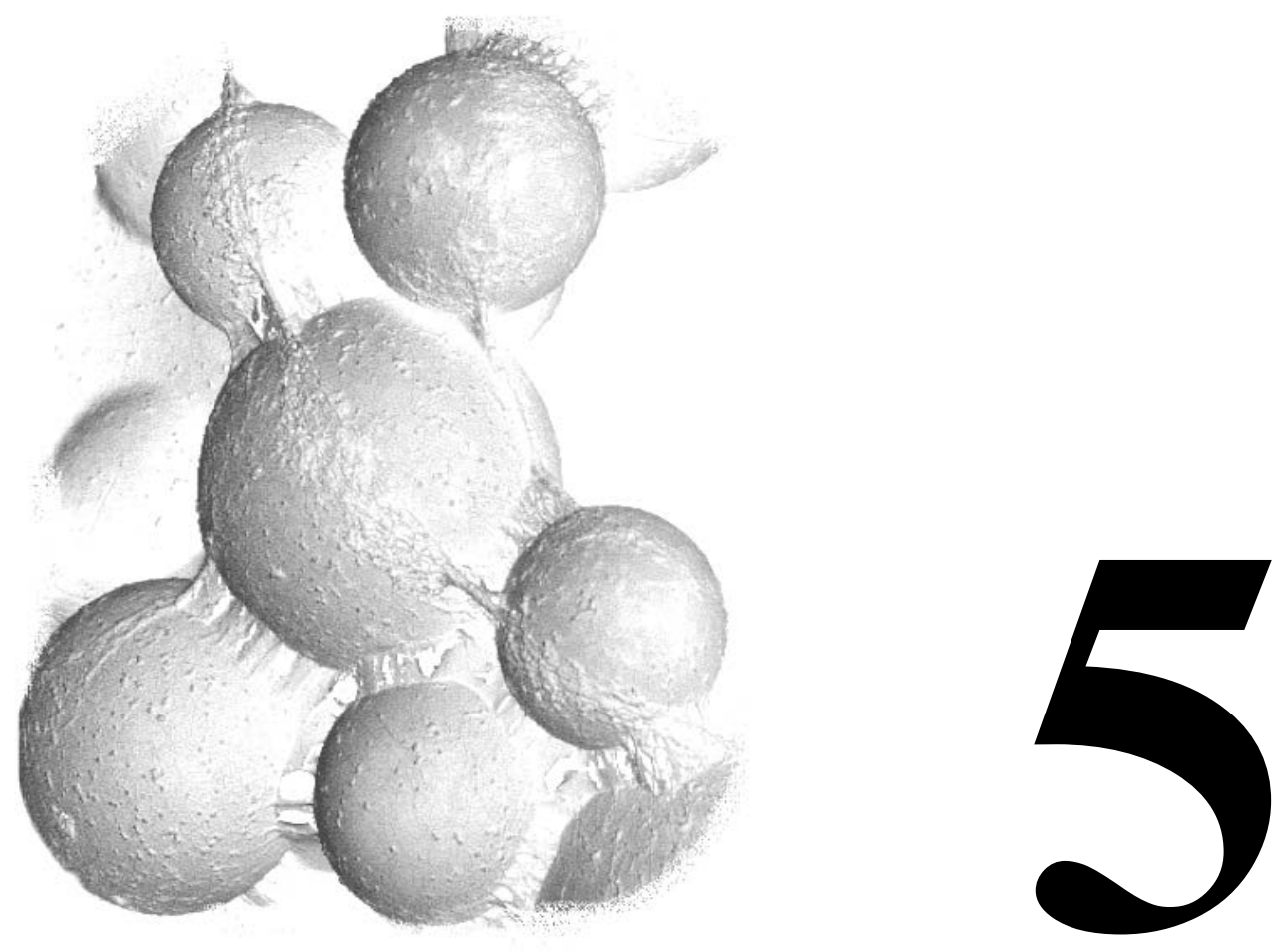

New acrylic microspheres for arterial embolization: combining radiopacity for precise localization with immobilized thrombin to trigger local blood coagulation.

Ketie Saralidze, Catharina S. J. van Hooy-Corstjens, Leo H. Koole and Menno L.W. Knetsch

Biomaterials 28 (2007), 2457-2464. 


\title{
Chapter 5
}

\begin{abstract}
Particles currently used in arterial embolization therapy have several disadvantages, most importantly their radiolucency. This means the radiologist can not precisely asses the fate of embolization particles. Microspheres that combine two additional features have been designed. By incorporating an iodine-containing monomer, radiopaque microspheres were obtained that display good visibility under standard X-ray conditions. Incorporation of methacrylic acid makes the surface of the spheres suitable for surface functionalization. Here, thrombin was covalently attached to the surface of the radiopaque microspheres. By induction of a thrombus, improved anchoring of the embolization spheres in the blood vessel can be obtained. The immobilized thrombin induced a biphasic response of the blood namely: (1) fast deposition of fibrin on the surface resulting in sphere aggregation and (2) additional thrombin generation in the surrounding blood and a subsequent local thrombus formation. These microspheres with both intrinsic X-ray visibility and a biofunctionalized surface can potentially improve embolization therapies.
\end{abstract}

\section{Introduction}

Polymeric microspheres are employed in a wide variety of medical applications. They are used as bulking agents in plastic surgery to fill up subcutaneous defects $[1,2]$ and to treat stress urinary incontinence $[3,4]$. Microspheres are also used in interventional radiology, especially for embolization therapy [5-7]; by injecting particles in a feeding blood vessel occlusion occurs and as a result shrinkage of a lesion, e.g., a tumor, is obtained [8]. Embolization has emerged as a highly effective technique in a wide variety of diseases. Since 1995, more than 50,000 cases of uterine fibroid embolizations (UFEs), which are the most common tumors in the female genital tract, were performed worldwide [9-11]. Embolization is also used for treatment of inoperable tumors [12], arterio-venous malformations (AVMs) [8] and haemoptysis (excessive bleeding) $[13,14]$.

While polyvinyl alcohol particles are probably the most widely used particulate embolic agents, microspheres, e.g., trisacryl gelatin microspheres, are also emerging as valuable tool in therapeutic embolization [15]. The advantage of microspheres over irregularly shaped particles is that the former have a uniform geometrical shape, which allows precise location of the embolic material. 
A shortcoming of commercially available embolic agents is that they are radiolucent, which means that they cannot be visualized radiographically. Consequently, complications such as 'reflux with non-target embolization' and 'through embolization' are essentially undetectable. Currently, prior to the injection particles are dispersed in saline that has been enriched with contrast medium [12,15]. This indirect method of introducing radiopacity has the disadvantage that in case of improper dispersion of the particles in the medium, the liquid can pass more distal into the tumor than the particles and as a result fluoroscopic exploration provides incorrect information about the position of the particles. The challenge is therefore to render the embolic agents, preferably microspheres, themselves radiopaque.

This unique feature of intrinsic radiopacity has been introduced about one decade ago for polymeric biomaterials [16-20]. Since then, several applications have emerged [2024]. Recently, we started the development of intrinsically radiopaque microspheres, in first instance for use in stress urine incontinence [22]. Also, in embolization therapies these types of spheres can be of great importance. It will enable the interventional radiologist to determine precisely the amount and location of the injected microspheres. Further improvement of the microspheres can be obtained by biofunctionalization of the surface. By immobilization of a coagulation factor, like thrombin, on the surface, blood coagulation can be triggered. The advantage for embolization therapies can be that in this way the spheres get anchored. We therefore have developed a range of microspheres that combine the unique traits of intrinsic radiopacity, i.e., X-ray visibility, with controllable modification of the surface. The microspheres were synthesized from methyl methacrylate (MMA), methacrylic acid (MAA) and a radiopaque building block, i.e., 2-[4-iodobenzoyloxy]-ethyl methacrylate (4IEMA, 1) by a suspension polymerization technique. The covalently bound iodine is responsible for X-ray visibility. The methacrylic acid provides carboxylic groups at the particles' surface. These can be used to couple proteins and peptides to the surface. In this study, thrombin was coupled to the spheres.

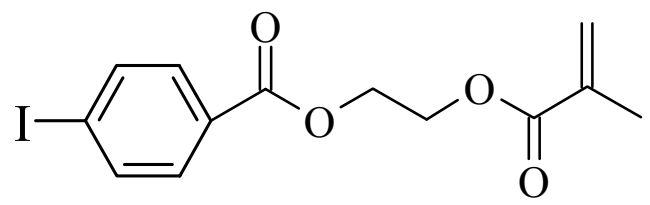




\section{Chapter 5}

It was hypothesized that the thrombin modified spheres will induce local thrombus formation and thereby anchor the spheres. By varying the ratio of the different monomers, the radiopacity and the surface modification of the spheres can be tuned to the needs of the interventional radiologist.

In this article, the synthesis of microspheres with dual functionality will be described. The spheres have been characterized for their X-ray visibility, cytocompatibility and thrombus-inducing capacities.

\section{Materials and Methods}

\section{Materials}

Chemicals were purchased from Sigma/Aldrich/Fluka (Zwijndrecht, The Netherlands) and Acros (Landsmeer, The Netherlands). Methylmethacrylate (MMA) was distilled at atmospheric pressure and stored at $-20^{\circ} \mathrm{C}$. The monomer 4IEMA (1) was synthesized from 4-iodobenzoyl chloride as described previously [16]. Methacrylic acid (MAA), benzoyl peroxide (BPO), tetraethylene glycol dimethacrylate (TEGDMA), poly(vinyl alcohol) (PVA; M.W. 86,000; 99-100\% hydrolyzed), poly(ethylene glycol (PEG; M.W. 1,000) and poly(vinyl pyrrolidone) (PVP; K-23-32; M.W. 58,000) were used as purchased. Cell culture medium (DMEM/F12), fetal bovine serum, and antibiotics were from Invitrogen (Breda, The Netherlands). The fluorescent thrombin-specific substrate Z-Gly-Gly-Arg-AMC was from Bachem (Weil am Rhein, Germany). Thrombin with high specificity $(>2,000 \mathrm{U} / \mathrm{mg}$ solid) was purchased from Synapse (Maastricht, The Netherlands) and thrombin with low specificity (43 U/mg solid) was from Sigma.

\section{Preparation of microspheres}

A solution of PVA (1.25 g), PEG (1.50 g) and PVP (0.25 g) in $100 \mathrm{~mL}$ distilled water was magnetically stirred and heated to $85{ }^{\circ} \mathrm{C}$. MMA, 4IEMA, MAA, BPO and TEGDMA were mixed, and this mixture was added drop wise to the stirred aqueous PVA-PEG-PVP solution [25]. After the addition, stirring at $85{ }^{\circ} \mathrm{C}$ was continued for 6 h. The microspheres precipitated immediately as stirring was stopped, and the supernatant was decanted carefully. The microspheres were allowed to cool to room temperature, and washed several times in water. In the end, microspheres were frozen ($196{ }^{\circ} \mathrm{C}$, liquid nitrogen), and lyophilized. Two types of spheres were prepared: (i) $10 \% \mathrm{I}$, containing 10\%w/w iodine, consisting of MMA (2.312 g, $23.09 \mathrm{mmol})$, 4IEMA (1.700 
g, $4.72 \mathrm{mmol})$, MAA (1.988 g, $23.09 \mathrm{mmol}), 1 \mathrm{~mol} \%$ BPO and 2 mol\% TEGDMA; and (ii) $20 \% \mathrm{I}$, containing $20 \% \mathrm{w} / \mathrm{w}$ iodine, consisting of MMA (1,26 g, 12,55 mmol), 4IEMA (3.402 g, $9.45 \mathrm{mmol})$, MAA (1.54 g, $17.95 \mathrm{mmol}), 1 \mathrm{~mol} \% \mathrm{BPO}$ and $2 \mathrm{~mol} \%$ TEGDMA. Microspheres were examined by scanning electron microscopy using a Philips XL30 SEM system.

\section{Cytocompatibility}

Mouse 3T3 fibroblasts were grown in Dulbecco's modification of Eagle medium/F-12 nutrient mix containing Glutamax-I and supplemented with $10 \%$ fetal bovine serum and antibiotic/antimycotic solution $(100 \mathrm{U} / \mathrm{mL}$ penicillin, $100 \mu \mathrm{g} / \mathrm{mL}$ streptomycin, 0.25 $\mu \mathrm{g} / \mathrm{mL}$ amphotericin B). Cells were harvested and 25,000 cells were inoculated in each well of a 24-well plate. The cells were cultured at $37{ }^{\circ} \mathrm{C} / 5 \% \mathrm{CO}_{2}$ for $20 \mathrm{~h}$ before microspheres were added. Microspheres were sterilized with UV light for $15 \mathrm{~min}$ and subsequently were added to the cells in such a way that estimated $20 \%$ coverage of the total area by the spheres was achieved. Latex was used as a positive, toxic, control. After 5 days of incubation, photographs of the cells were taken using a Leica DM-IL inverted microscope. From a separate plate, the medium was removed and replaced with culture medium containing $0.5 \mathrm{mg} / \mathrm{mL}$ MTT to measure cell viability [26]. The cells were incubated for $1 \mathrm{~h}$ at $37^{\circ} \mathrm{C}$, the medium was removed, and the precipitated formazan was dissolved in isopropanol. The absorbance at $550 \mathrm{~nm}$ of the samples was determined using a micro-plate reader.

\section{X-ray visibility}

For demonstration of radiopacity of the microspheres, a realistic model under routine hospital conditions was used. Microspheres were inserted into a rabbit cadaver in two ways: 1) $25 \mathrm{mg}$ loose spheres were inserted into the back muscle and 2) $75 \mathrm{mg}$ spheres were resuspended in 3\% gelatin and inserted into the back leg. X-ray pictures were taken using a digital mammography imaging system (Bennet Trex Medical).

\section{Immobilization of thrombin}

The microspheres were washed in $50 \mathrm{mM}$ MES buffer, pH 5.5 for $30 \mathrm{~min}$, resuspended in $20 \mathrm{mM}$ 1-ethyl-3-(3-dimethylaminopropyl)carbodiimide (EDC) and $50 \mathrm{mM} \mathrm{N}$ hydroxysuccinimide (NHS) in $50 \mathrm{mM}$ MES, and incubated at room temperature for 30 


\section{Chapter 5}

min under continuous mixing [27]. Then microspheres were washed once with $50 \mathrm{mM}$ MES and $700 \mu \mathrm{L}$ thrombin solution was added. For determining the optimal composition of the microspheres, $2.5 \mathrm{mg} / \mathrm{mL}$ thrombin with low specific activity was used because of economical reasons. For the following experiments, thrombin of a high quality, $>2,000 \mathrm{U} / \mathrm{mg}$, was used at a concentration of $0.4 \mathrm{mg} / \mathrm{mL}$. The thrombin was dissolved in thrombin-coupling buffer (50 mM Hepes, $150 \mathrm{mM} \mathrm{NaCl} \mathrm{pH} \mathrm{8.2).} \mathrm{After} 2$ hours incubation at room temperature, spheres were washed at least 6 times in thrombin-coupling buffer. $10 \mathrm{mg}$ microspheres (in triplo) were put into a 96-well plate. $120 \mu \mathrm{L}$ thrombin-assay buffer (20 mM Hepes, $150 \mathrm{mM} \mathrm{NaCl}, 5 \mathrm{mM} \mathrm{CaCl}_{2} \mathrm{pH}$ 7.4) was added to each well with spheres. The plate was warmed to $37{ }^{\circ} \mathrm{C}$ and $80 \mu \mathrm{L} 1 \mathrm{mM}$ fluorescent thrombin-substrate, in thrombin-assay buffer, was added to start the quantification of thrombin. Fluorescence increase (ex $485 \mathrm{~nm} / \mathrm{em} 520 \mathrm{~nm}$ ) was determined with a Gemini XS fluorometer. The increase in fluorescence is directly related to thrombin activity. The amount of coupled thrombin could be estimated by comparison to a standard curve with known amounts of thrombin.

\section{Microsphere induced fibrin formation}

Blood was obtained from a healthy donor by venipuncture and mixed with $0.13 \mathrm{M} \mathrm{Na}-$ citrate ( 9 parts blood: 1 part Na-citrate). Platelet rich plasma (PRP) was prepared by centrifugation of blood at $180 \mathrm{~g}$ for $15 \mathrm{~min}$. PRP was recalcified by addition of 40 $\mu \mathrm{L} / \mathrm{mL} 0.5 \mathrm{M} \mathrm{CaCl}_{2}$. Microspheres were incubated at room temperature with recalcified platelet rich plasma (PRP) in a $35 \mathrm{~mm}$ Petri-dish. The dishes were gently shaken and photographs were taken at regular intervals on a Nikon Eclipse 800 microscope equipped with a RS Photometric CoolSnap digital camera. Aggregates of microspheres that were formed after 2-3 min of incubation in PRP were fixed in 2.5\% glutaraldehyde in phosphate buffered saline $(\mathrm{pH} 7.4)$ at $4{ }^{\circ} \mathrm{C}$. The samples were extensively washed and dried, attached on a stub with double-sided carbon tape, sputter-coated with gold and examined by SEM.

\section{Microsphere induced thrombin generation}

To test the ability of the covalently coupled thrombin to induce blood coagulation, microspheres were mixed with recalcified whole blood, PRP, or platelet poor plasma (PPP) that was prepared by centrifugation of blood at $1,800 \mathrm{~g}$ for $10 \mathrm{~min}$. Recalcified 
blood, PRP, or PPP was added to $10 \mathrm{mg}$ microspheres to start the reaction, which was allowed to proceed at $37^{\circ} \mathrm{C}$. Samples $(17.5 \mu \mathrm{L})$ were taken every minute and added to 282.5 $\mu \mathrm{L}$ thrombin-stop buffer (20 mM Hepes pH 7.4, $140 \mathrm{mM} \mathrm{NaCl,} 20 \mathrm{mM}$ EDTA, 1 $\mathrm{mg} / \mathrm{mL}$ BSA, $200 \mu \mathrm{M} \mathrm{S} 2238$ ). EDTA was used to directly abolish any further thrombin formation by binding all available calcium, S2238 is a chromogenic thrombin-specific substrate. Sampling was stopped upon complete clotting of the blood, PRP or PPP. In the case of incubation with whole blood, erythrocytes were removed by short centrifugation $(5 \mathrm{sec})$ and the supernatant was pipetted into a 96-well microplate. The plate was heated to $37{ }^{\circ} \mathrm{C}$ and increase in extinction at $405 \mathrm{~nm}$ could be directly converted to thrombin concentration. For PRP and PPP samples, no centrifugation was needed, and so the samples could be measured directly in a 96-well microplate. Also spheres without coupled thrombin (control spheres) were used as well as the empty tube. The concentration of thrombin was plotted against time.

\section{Results and discussion}

We set out to design microspheres for embolization purposes that combine multiple characteristics: (i) uniform shape, (ii) radiopacity, and (iii) biofunctionalized surface. SEM was used to confirm the shape and size of the $10 \% \mathrm{I}$ and $20 \% \mathrm{I}$ microspheres. From Figure 1 it is clear that the spheres are solid and perfectly spherical. The size of at least 500 microspheres was determined and average sizes of $150 \pm 42 \mu \mathrm{m}$ and $113 \pm 54 \mu \mathrm{m}$ for $10 \% \mathrm{I}$ and $20 \% \mathrm{I}$ respectively were obtained.
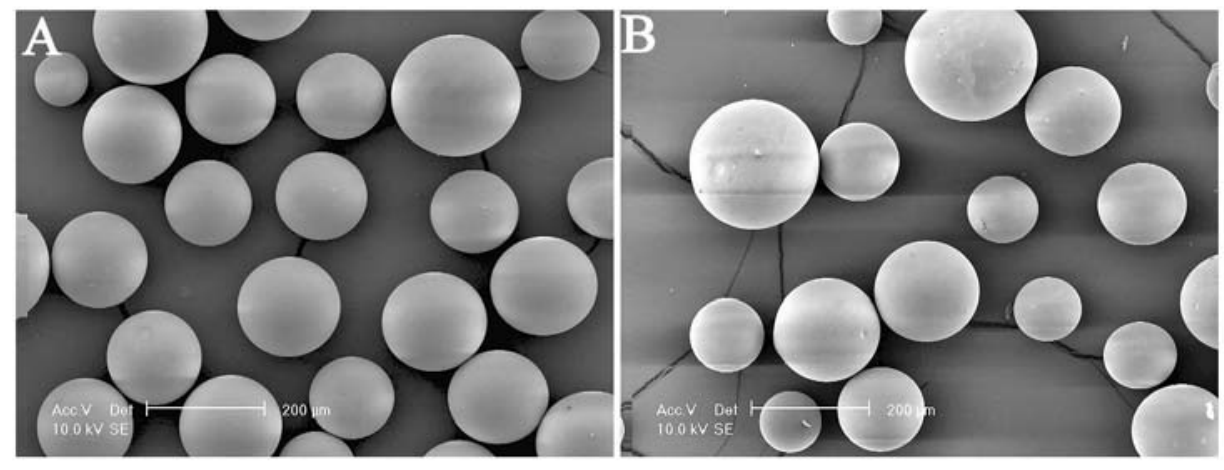

Figure 1. Scanning electron micrographs of $10 \% \mathrm{I}(\mathrm{A})$ and $20 \% \mathrm{I}(\mathrm{B})$ microspheres. The scale bar represents $200 \mu \mathrm{m}$. 


\section{Chapter 5}

When these microspheres are to be used in animals or human patients, the spheres must be safe and non-toxic. Therefore, cytocompatibility of the microspheres was determined in vitro in two ways: (1) by a direct contact assay and (2) by a MTT cell viability assay.
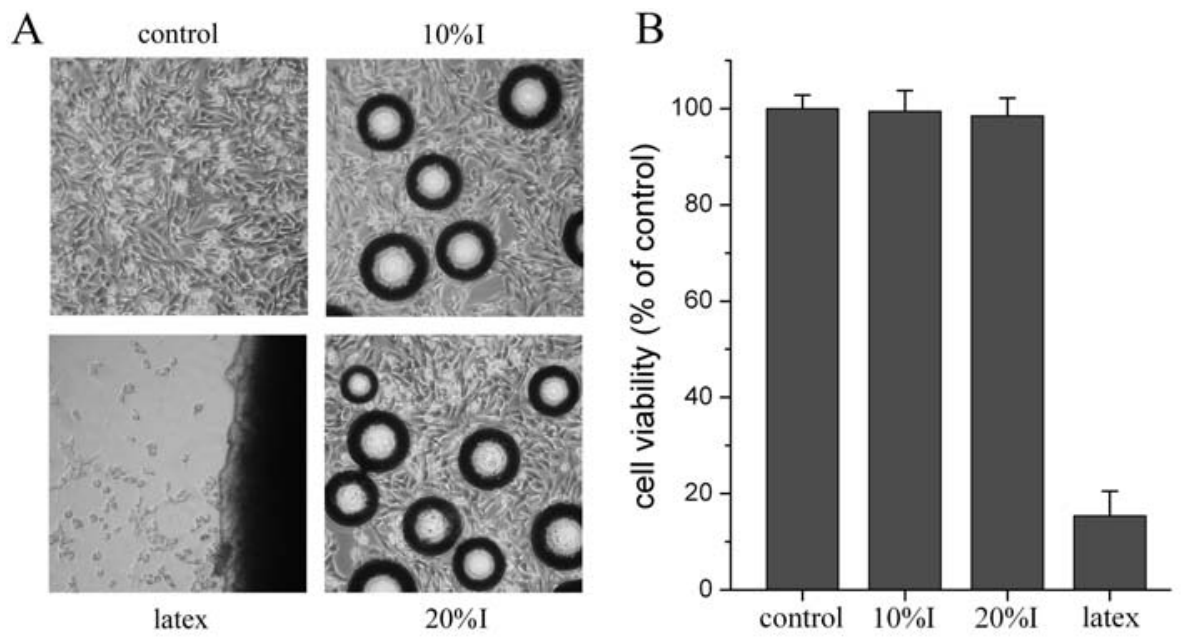

Figure 2. Cytocompatibility of microspheres. (A) Photographs of direct contact between microspheres and mouse fibroblasts. Latex was taken as a toxic control. (B) Viability assay (MTT) of the cells in contact with microspheres for 5 days. Note that the microspheres have no adverse effect on the cells.

Mouse fibroblasts were incubated with microspheres and photographs were taken after 2 days of incubation (Figure 2A). No adverse effect of the spheres on the morphology of the cells could be observed. To quantify cytocompatibility, viability of cells in contact with spheres was determined using MTT (Figure 2B). No toxic effect of the spheres could be measured, which is in line with an earlier work on the biosafety of iodinecontaining microspheres [22,28]. The cytocompatibility of our current spheres is supported by the biosafety of iodine-containing polymers in general [29,30]. Therefore one can assume that our microspheres will be safe for in vivo use, although animal experiments should still be performed.

In order to confirm radiopacity, $10 \% \mathrm{I}$ and $20 \% \mathrm{I}$ microspheres were implanted in two different ways in a rabbit cadaver (Figure 3). First, loose spheres were inserted into the back (Figure 3 right bottom panel). 

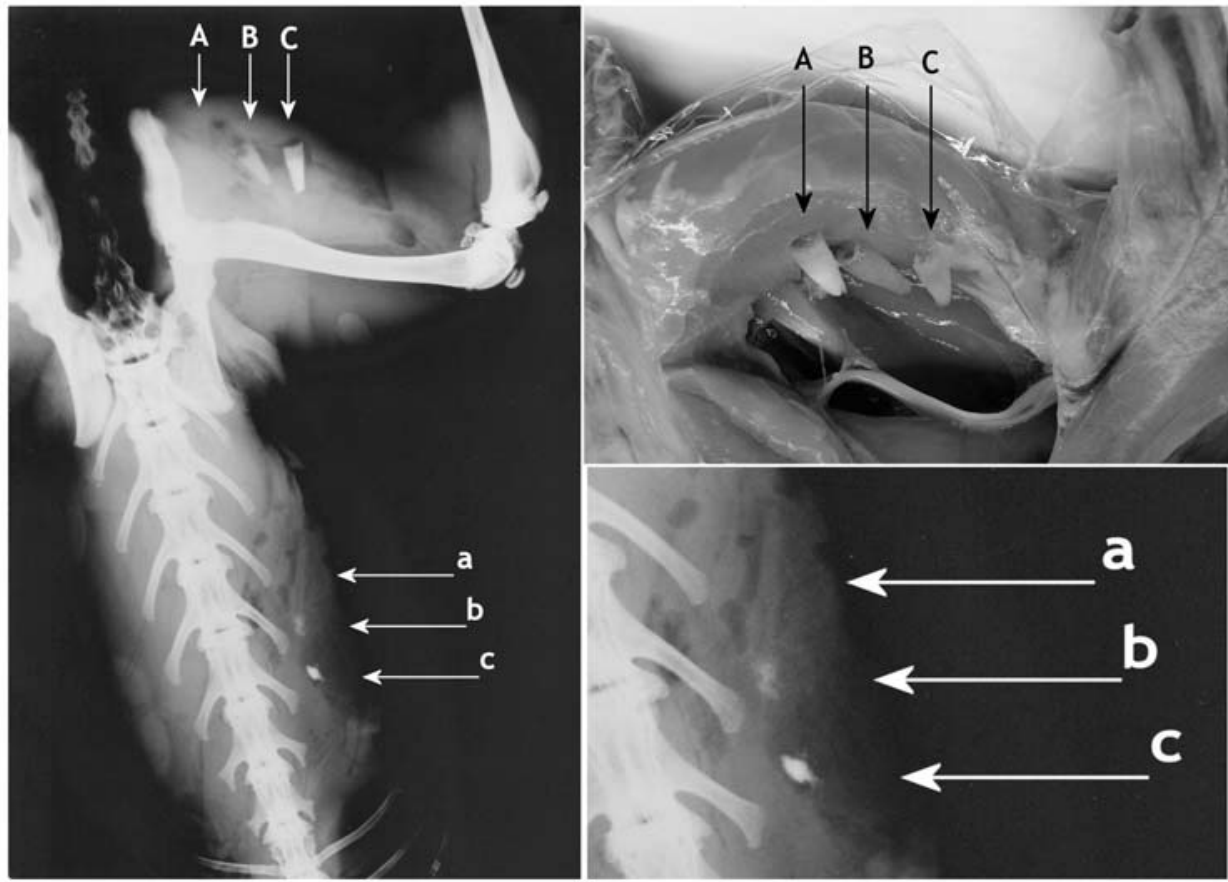

Figure 3. X-ray radiography of the microspheres inserted into a rabbit cadaver. The left panel shows the X-ray image. $A$ and a represent radiolucent microspheres (without iodine), $B$ and $b$ indicate 10\%I spheres, $C$ and c 20\%I microspheres. The upper right panel photograph shows how spheres were inserted in the back leg. The lower right panel is an enlargement of the spheres inserted in the back muscle of the rabbit.

The spheres are nicely visible under standard X-ray conditions and it is also clear that the $20 \% \mathrm{I}$ spheres are better visible, i.e., more radiopaque, than the $10 \% \mathrm{I}$ spheres. Radiolucent spheres, that do not contain iodine, were not visible under these X-ray conditions. Alternatively, approximately $75 \mathrm{mg}$ spheres were suspended in $3 \%$ gelatin and inserted into the back leg of the rabbit (Figure 3 right upper panel). Again, the spheres are clearly visible under X-ray and again the $20 \% \mathrm{I}$ is more radiopaque than the $10 \% \mathrm{I}$ spheres. The difference seems to be somewhat less than for the microspheres implanted in the back, but this is caused by saturation of the X-ray signal by the larger amount of spheres.

The surface of the microspheres was biofunctionalized by covalently coupling a coagulation inducing agent, in this case thrombin, but in fact any desired protein can be 


\section{Chapter 5}

coupled to the surface of these spheres. Thrombin is the key enzyme in thrombus formation [31]. Fibrinogen is cleaved by thrombin and multimerizes subsequently to form a fibrin network which will capture erythrocytes and platelets, forming the final thrombus [32]. To immobilize protein onto the microspheres, we attempted to induce carboxylic groups on copolymer spheres derived from 4IEMA and MMA, by treatment with strong base [33,34]. Although successful, this method was difficult to control, resulting in batch to batch variation, as well as disintegration of spheres after prolonged treatment [34]. Therefore we chose to produce terpolymer microspheres containing MAA. Proteins can readily be coupled to the carboxylic groups on the surface of these spheres by cross-linking chemistry based on the use of EDC and NHS [27]. In this way $\mathrm{X}$-ray visible microspheres are obtained that not only mechanically block blood vessels, but also improve blocking and anchoring by inducing blood coagulation. The protein linked to the surface, in this case thrombin, will anchor the spheres in a blood clot.

In order to determine the optimal composition of the microspheres for coupling of thrombin, a range of $10 \% \mathrm{I}$ spheres, that differ in the content of MAA, was prepared. The data presented in Figure 4A demonstrate that spheres with $45 \mathrm{~mol} \%$ MAA have the highest thrombin activity on their surface.
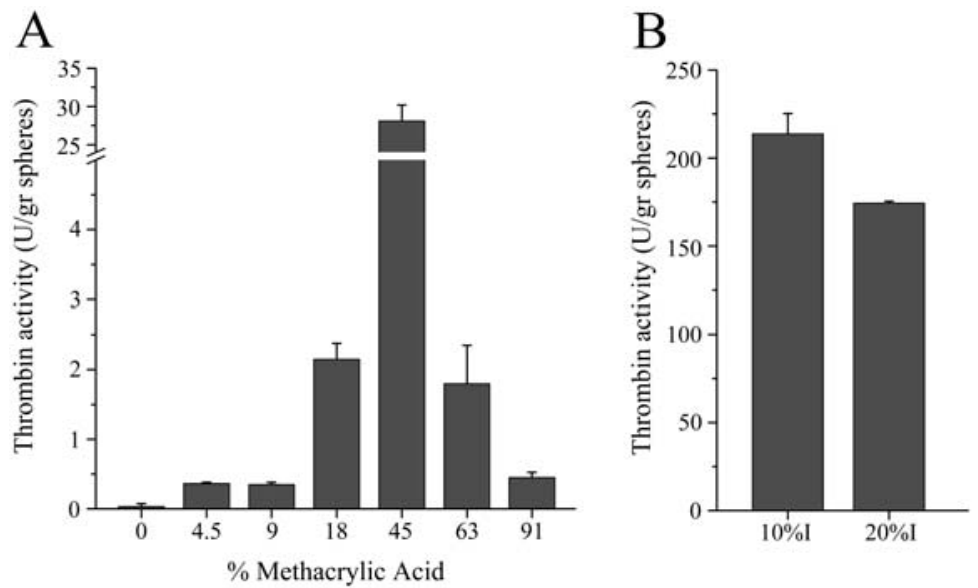

Figure 4. (A) Thrombin activity of 10\%I spheres with varying methacrylic acid content. Thrombin was coupled to these spheres and activity was determined using a fluorescent peptide substrate. (B) Thrombin activity of $10 \%$ I and $20 \%$ I spheres with $45 \%$ methacrylic acid. 
The spheres with less MAA show much lower thrombin activity, which can be explained by lower number of carboxylic groups on their surface, and thus less chance of forming a bond with thrombin in solution. The fact that a peak of thrombin activity was found may be explained by the possibility that on the surface of spheres with higher MAA content, multiple cross-links per thrombin molecule may occur, rendering thrombin inflexible and subsequently inactive. To improve radiopacity (Figure 3), 20\%I spheres with 45\% MAA were prepared, and compared to $10 \% \mathrm{I}$ spheres (Figure 4B). For this experiment thrombin with a very high specific activity $(>2,000 \mathrm{U} / \mathrm{mg})$ was used. Therefore a higher thrombin activity, 213 and $174 \mathrm{U} / \mathrm{g}$ spheres for the $10 \% \mathrm{I}$ and $20 \% \mathrm{I}$ spheres respectively, was achieved, when compared to the $10 \% \mathrm{I}$ spheres $(28 \mathrm{U} / \mathrm{g}$ spheres) in Figure 4A. Thus, increasing the iodine content had little effect on the coupling efficiency of thrombin to the sphere surface.

The microspheres with immobilized thrombin were tested for their ability to induce thrombus formation in blood. Upon contact of blood with our thrombin-carrying spheres, a sequence of events will be initiated. First, a fast deposition of fibrin on the surface will occur. The immobilized thrombin will cleave fibrinogen, resulting in fibrin network formation. This fibrin can act as a procoagulant surface, especially when activated platelets are enclosed in the fibrin clot [35,36]. In a second phase, free thrombin will be generated in the surrounding blood.

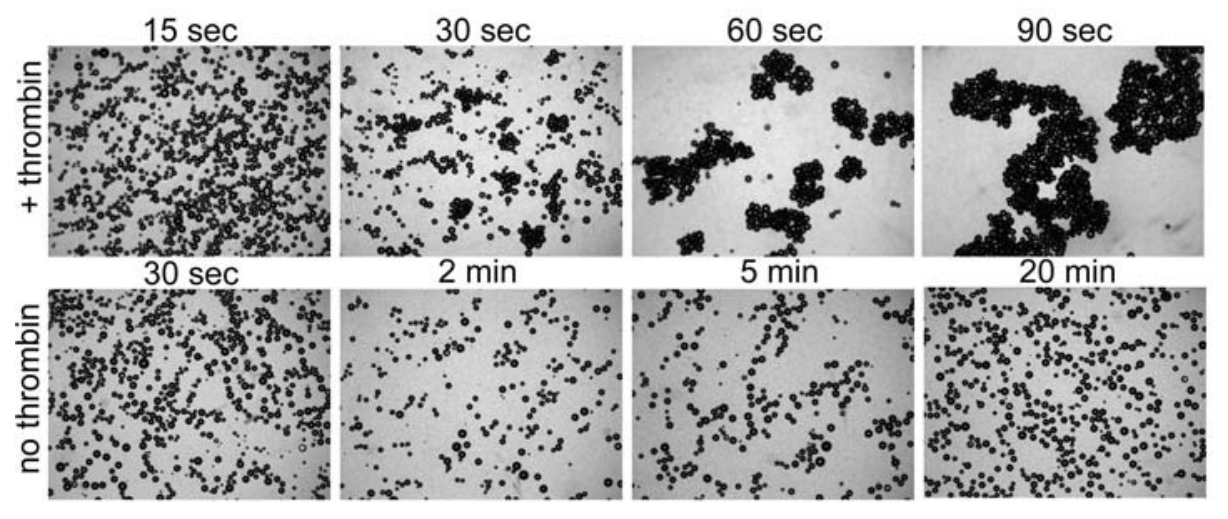

Figure 5. Thrombin-induced microsphere aggregation. 20\%I spheres with (upper) or without (bottom) coupled thrombin were mixed with recalcified platelet rich plasma. The samples were gently shaken at room temperature and pictures were taken. Microspheres with thrombin form stable aggregates within 1 min while the control spheres do not. 


\section{Chapter 5}

Feed-back activation of factor XI or factor VIII by the immobilized thrombin will result in generation of free thrombin in the surrounding blood and subsequent thrombus formation [31]. Additionally, the procoagulant surface on the spheres (fibrin with activated platelets) will accelerate the conversion of prothrombin to thrombin and thus result in faster thrombus formation [35,36]. Result will be a biphasic formation of thrombus on and near the thrombin-modified-spheres.

First, we investigated the fibrin formation on the surface of the $10 \% \mathrm{I}$ and $20 \% \mathrm{I}$ spheres with immobilized thrombin. When these spheres were mixed with whole blood or PRP, an aggregate/clot formed directly around the spheres within a minute at room temperature (Figure 5). Only thrombin carrying microspheres aggregated, suggesting the formation of a fibrin network entrapping the spheres in a clot.

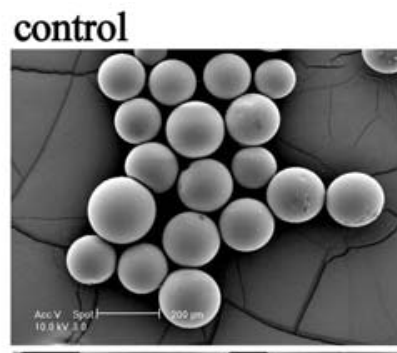

$10 \% \mathrm{I}$
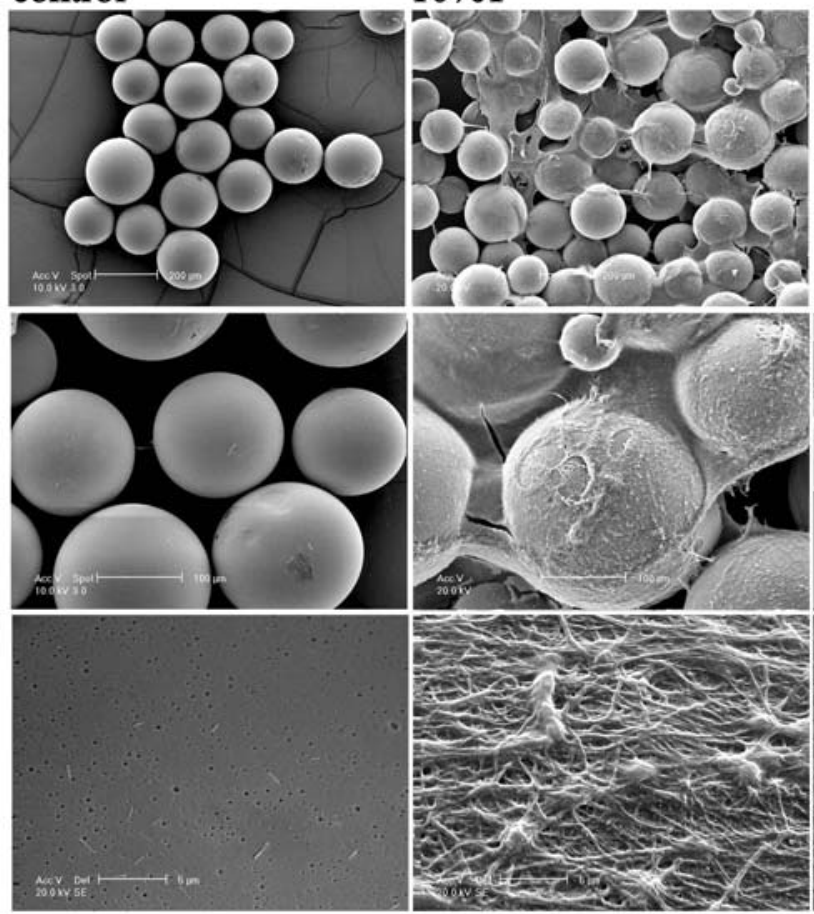

\section{$20 \%$ I}
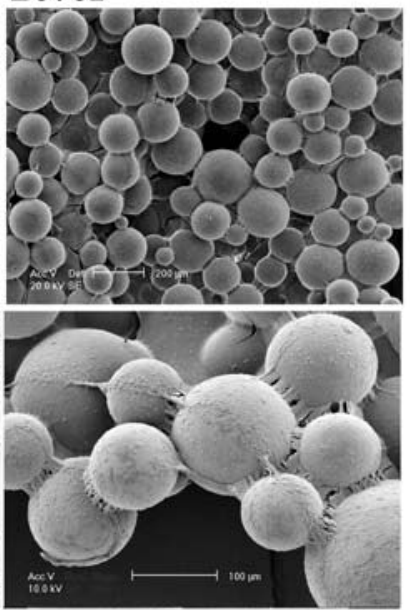

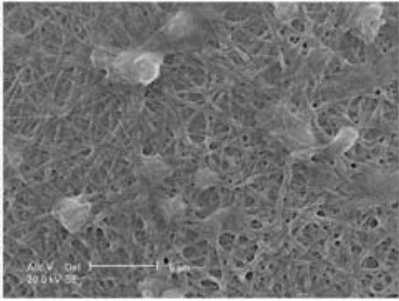

Figure 6. Scanning electron micrographs of microspheres treated with platelet rich plasma for 3 minutes. The control spheres show no fibrin network on their surface, while the $10 \%$ I and $20 \%$ I microspheres carrying thrombin do induce fibrin network on their surface. Scale bars represent $200 \mu m$ (upper), $100 \mu m$ (middle), and $5 \mu m$ (bottom). 
To visualize the fibrin network on the surface of the spheres, we fixed spheres that had been shortly incubated in PRP and observed the aggregates/clots by scanning electron microscopy (Figure 6). Surface-linked thrombin will not only directly induce fibrin formation but can also induce additional thrombin generation in the surrounding blood via a feed back loop involving platelets [31,35].
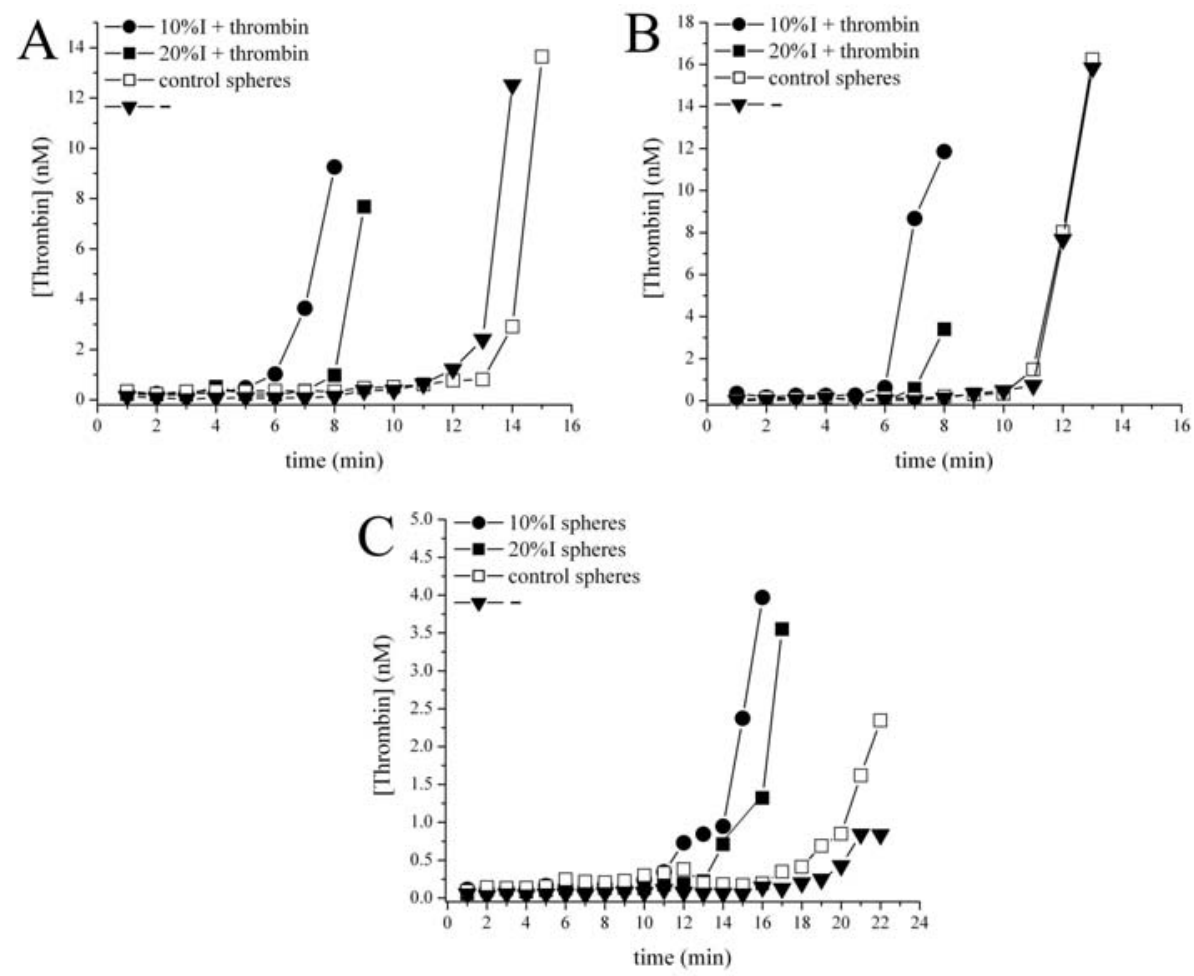

Figure 7. Microsphere-induced thrombin generation in whole blood (A), platelet rich plasma (B), and platelet poor plasma $(C)$. Microspheres were mixed with recalcified blood, PRP, or PPP and samples were taken every minute. Thrombin concentration was determined by the conversion of the chromogenic thrombin substrate S2238. Sampling was stopped upon complete clotting of the blood, PRP, or PPP. Control spheres were 20\%I spheres without coupled thrombin. The control was the empty tube used for this experiment.

In addition, the fast formation of a pro-coagulant surface on the spheres can accelerate thrombin generation. To determine the thrombin generation by modified microspheres, they were incubated with whole blood (Figure 7A), platelet rich plasma (PRP, Figure 


\section{Chapter 5}

7B) and platelet poor plasma (PPP, Figure 7C). Both $10 \% \mathrm{I}$ and $20 \% \mathrm{I}$ spheres with thrombin induced an accelerated burst in free thrombin, and subsequent full clotting of the blood and PRP by 6-8 minutes while the control needed 12-14 minutes. In PPP slower thrombin generation was observed, confirming the hypothesis that platelets play an important role in thrombin generation and subsequent thrombus formation. The microspheres with immobilized thrombin can thus induce anchoring by formation of a fibrin network as well as by inducing a local thrombus. This process of thrombin formation can also be initiated by coupling of other coagulation factors that are upstream in the coagulation cascade like factor Xa or XIIa, but these sorts of spheres have not been investigated yet.

In this study, a maximum loading with thrombin was pursued. The optimal extent of surface modification for in vivo use can only be determined with animal experiments. Too much thrombin will induce too rapid thrombus formation and cause the spheres to clot prematurely, in the worst case even blocking the tip of the catheter. The level of surface modification can be tuned either by using spheres with less MAA or by diluting the protein solution with an inactive protein like albumin. Additionally, virtually any protein, or combination of proteins, can be linked to the surface of the microspheres, making these microspheres a flexible system with numerous possible applications.

\section{Conclusion}

Microspheres that combine uniform shape, radiopacity and biofunctionality were successfully made. These spheres may be used in different interventions as for instance embolization therapy or management of excessive bleeding. The intrinsic radiopacity of our microspheres can be of great help to the interventional radiologist. Using standard X-ray fluoroscopy, the fate of the spheres can be observed. This means the radiologist can easily observe if enough spheres have been injected and if these remain at the intended site. The surface modification with active proteins is also of great importance for use of the spheres. Biofunctionalization of X-ray visible microspheres with proteins of choice opens a wide variety of possible applications.

\section{References}

1. Jordan DR. Soft-tissue fillers for wrinkles, folds and volume augmentation. Can. J. Ophthalmol. 2003;38:285-288. 
2. Sclafani AM. Soft tissue fillers for management of the aging perioral complex. Facial. Plast. Surg. 2005;21:74-78.

3. Herschorn S. Current role of injectable agents for female stress urinary incontinence. Can. J. Urol. 2006;13:5-12.

4. Chapple CR, Wein AJ, Brubaker L, Dmochowski R, Pons ME, Haab F, Hill S. Stress incontinence injection therapy: what is best for our patients? Eur. Urol. 2005;48:552-565.

5. Lookstein RA, Guller J. Embolization of complex vascular lesions. The Mount. Sinai J. of Med. 2004;71(1):17-28.

6. Matsumaru Y, Hyodo A, Nose T, Hirano T, Ohashi S. Embolic materials for endovascular treatment of cerebral lesions. J. of Biomat. Sci: Pol. Ed. 1997;8(7):555-569.

7. Qureshi AI. Endovascular treatment of cerebrovascular diseases and intracranial neoplasms. The Lancet 2004;363:804-813.

8. $\quad$ Fleetwood I, Steinberg GK. Arteriovenous malformations. The Lancet 2002;359:863-873.

9. Baakdah H, Tulandi T. Uterine fibroid embolization. Clin. Obstet. and Gynec. 2005;48:361-368.

10. Siskin GP, Englander M, Stainken BF, Ahn J, Dowling K, Dolen EG. Embolic agents used for uterine fibroid embolization. AJR 2000;175:767-773.

11. Lupattelli T, Basile A, Garaci FG, Simonetti G. Percutaneous extraluminal recanalization: usefulness of false channel balloon dilation and heparin administration before true lumen reentry. EJR 2005;54:136-47.

12. Bendszus M, Martin-Schrader I, Warmuth-Metz M, Hofmann E, Solymosi L. MR-Imaging - and MR spectroscopy - revealed changes in Meningiomas for which embolization was performed without subsequent surgery. Am. J. Neuroradiol. 2000;21:666-669.

13. Yoon W. Embolic agents used for bronchial artery embolization in massive haemoptysis. Expert Opin. Pharmacothe. 2004;5(2):361-367.

14. Vinaya KN, White RI Jr, Sloan JM. Reassessing bronchial artery embolotherapy with newer spherical embolic materials. J. Vasc. Interv. Radiol. 2004;15(3):304-305.

15. Bendszus M, Klein R, Burger R, Warmuth-Metz M, Hofmann E, Solymosi L. Efficacy of Trisacryl gelatin microspheres versus polyvinyl alcohol particles in the preoperative embolization of meningiomas. Am. J. Neuroradiol. 2000;21:255-261.

16. Benzina A, Kruft MA, Bar F, van der Veen FH, Bastiaansen CW, Heijnen V, Reutelingsperger C, Koole LH. Studies on a new radiopaque polymeric biomaterial. Biomaterials 1994;15:1122-1128.

17. Kruft MA, Benzina A, Bar F, van der Veen FH, Bastiaansen CW, Blezer R, Lindhout T, Koole LH. Studies on two new radiopaque polymeric biomaterials. J. Biomed. Mater. Res. 1994;28:1259-1266.

18. Benzina A, Kruft MA, van der Veen FH, Bar FH, Blezer R, Lindhout T, Koole LH. A versatile threeiodine molecular building block leading to new radiopaque polymeric biomaterials. J. Biomed. Mater. Res. 1996;32:459-466.

19. Davy KWM, Anseau MR, Odlyha M, Foster GM. X-ray opaque methacrylate polymers for biomedical applications. Pol. Int. 1997;43:143-154.

20. Jayakrishnan A, Thanoo BC, Rathinam K, Mohanty M. Preparation and evaluation of radiopaque hydrogel microspheres based on PHEMA/iothalamic acid and PHEMA/iopanoic acid as particulate emboli. J. Biomed. Mater. Res. 1990;24:993-1004.

21. van Hooy-Corstjens CSJ, Govaert LE, Spoelstra AB, Bulstra SK, Wetzels GMR, Koole LH. Mechanical behaviour of a new acrylic radiopaque iodine-containing bone cement. Biomaterials 2004;25:2657-2667.

22. Saralidze K, Aldenhoff YB, Knetsch ML, Koole LH. Injectable polymeric microspheres with X-ray visibility. Preparation, properties, and potential utility as new traceable bulking agents. Biomacromolecules 2003;4:793-798. 


\section{Chapter 5}

23. Boelen EJ, van Hooy-Corstjens CS, Bulstra SK, van Ooij A, van Rhijn LW, Koole LH. Intrinsically radiopaque hydrogels for nucleus pulposus replacement. Biomaterials 2005;26:6674-6683.

24. Horak D, Metalova M, Rypacek F. New radiopaque polyHEMA-based hydrogel particles. J. Biomed. Mater. Res. 1997;34:183-188.

25. Sivakumar M, Panduranga Rao K. Synthesis, characterization, and in vitro release of ibuprofen from poly(MMA-HEMA) copolymeric core-shell hydrogel microspheres for biomedical applications. J. of Appl. Pol. Sci. 2002;83;3045-3054.

26. Vistica DT, Skehan P, Scudiero D, Monks A, Pittman A, Boyd MR Tetrazolium-based assays for cellular viability: a critical examination of selected parameters affecting formazan production. Cancer Res. 1991;51(10):2515-2520.

27. Staros JV, Wright RW, Swingle DM. Enhancement by N-hydroxysulfosuccinimide of water-soluble carbodiimide-mediated coupling reactions. Anal. Biochem. 1986;156(1):220-222.

28. Emans PJ, Saralidze K, Knetsch ML, Gijbels MJ, Kuijer R, Koole LH. Development of new injectable bulking agents: biocompatibility of radiopaque polymeric microspheres studied in a mouse model. J. Biomed. Mater. Res. A 2005;73(4):430-436.

29. Aldenhoff YB, Kruft MA, Pijpers AP, van der Veen FH, Bulstra SK, Kuijer R, Koole LH. Stability of radiopaque iodine-containing biomaterials. Biomaterials 2002;23(3):881-886.

30. Boelen EJH, van Hooy-Corstjens CSJ, Gijbels MJJ, Bulstra SK, van Ooij A, van Rhijn LW and, Koole LH. Preliminary evaluation of new intrinsically radiopaque hydrogels for replacing the nucleus pulposus J. Mater. Chem. 2006;16 (9):824-828.

31. Spronk HM, Govers-Riemslag JW, ten Cate H. The blood coagulation system as a molecular machine. Bioessays 2003;25(12):1220-1228.

32. Mosesson MW. Fibrinogen and fibrin structure and functions. J. Thromb. Haemost. 2005;3(8):18941904.

33. Shivakumar K, Nair RR, Jayakrishnan A, Thanoo BC, Kartha CC Synthetic hydrogel microspheres as substrata for cell adhesion and growth. In Vitro Cell Dev. Biol. 1989;25(4):353-357.

34. Saralidze K, Knetsch ML, van Hooy-Corstjens CS, Koole LH. Radio-opaque and surfacefunctionalized polymer microparticles: potentially safer biomaterials for different injection therapies. Biomacromolecules 2006;7(11):2991-6.

35. Heemskerk JW, Bevers EM, Lindhout T. Platelet activation and blood coagulation. Thromb. Haemost. 2002;88(2):186-193.

36. Monroe DM, Hoffman M, Roberts HR. Platelets and thrombin generation. Arterioscler. Thromb. Vasc. Biol. 2002;22(9):1381-1389. 

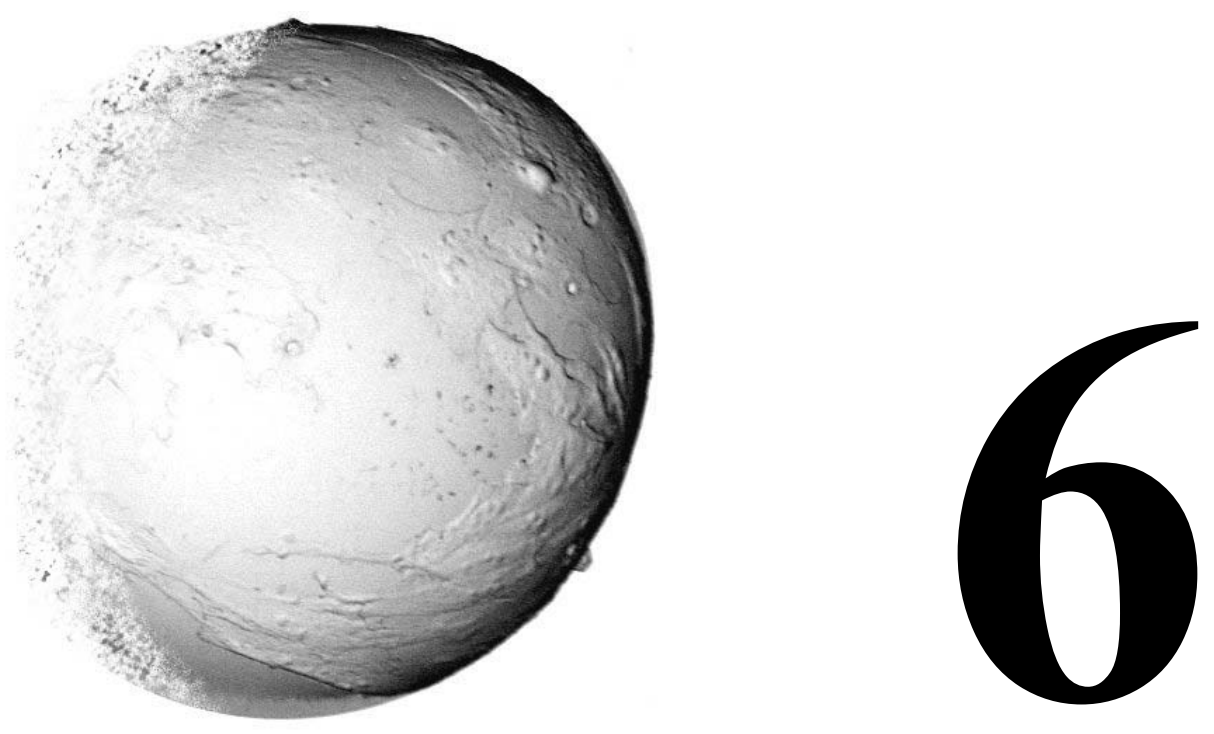

Radiopaque Microspheres containing Acrolein for Protein Attachment to improve Cell Adhesion

Ketie Saralidze, Menno L.W. Knetsch and Leo H. Koole

Submitted for publication 


\title{
Chapter 6
}

\begin{abstract}
Polymeric microspheres find use in minimally invasive treatments as fillers and bulking agents. A frequently encountered problem of currently used microspheres is migration away from the injection site. Also many polymeric microspheres are invisible for Xradiation and are difficult to detect with MRI. Here we present the synthesis of polymeric microspheres that are composed of methylmethacrylate (MMA), acrolein (2propenal), and the iodine-containing monomer 4IEMA. The aldehyde groups that are introduced by the addition of acrolein were used to covalently couple protein to the spheres. The microspheres were demonstrated to be non-toxic in vitro. The optimal composition of the microspheres for coupling of albumin and collagen type I was determined to be 10-20 weight $\%$ acrolein. Microspheres decorated with collagen I were shown to support the migration and growth of cells on their surface, which leads to anchoring of the spheres to a cell layer. These collagen modified spheres may improve anchoring in the surrounding tissue and thereby prevent migration of the microspheres from the injection site. The here presented microspheres combine intrinsic radiopacity with the possibility of surface bio-functionalization, and present an improvement for use of microspheres as filler or bulking agent.
\end{abstract}

\section{Introduction}

Polymeric microspheres have attracted attention in a wide array of medical and pharmacological applications. A widespread utilization of polymeric microspheres is their use as fillers, for soft tissue augmentation, or as bulking agent. Soft tissue augmentation is the most effective and least invasive treatment of acne scars $[1,2]$, wrinkles [3], facial lypoathropy, which is associated with human immunodeficiency virus(HIV)-infected individuals [4,5], and aesthetical lip augmentation [6]. Additionally, polymeric microspheres can be employed as injectable bulking agent everywhere in the body to improve open-closing systems. In 1911 the first injection laryngoplasty was performed [7], a procedure that aims to support to a vocal fold during unilateral vocal fold paralysis (UVFP). UVFP is a disorder that occurs when one or both of vocal cords do not open or close properly because nerve impulses to the muscles of the voice box are interrupted. Another example is vesico-ureteral reflux [8], the backflow of urine from the bladder into the ureters and often even into the kidneys, which is increasingly managed by periurethral injection of different bulking agents [8]. The use 
of injectable bulking agents to improve intrinsic sphincter deficiency, which is the major cause of stress urinary incontinence, has become more prevalent in recent years as a minimally invasive alternative for surgical procedures $[9,10]$. Since 1911 , various synthetic or biologic materials were used for unilateral vocal fold paralysis augmentation and other minimally invasive procedures [11]. It is remarkable, that the same injectables found use in urology and plastic surgery. All these injectables can be separated in two groups: (i) injectable agents with temporary effect, such as xenograft (bovine collagen, hyaluronic acid), autograft (autologous fat, fascia, autologous collagen) and homograft; and (ii) permanent synthetic injectable agents, such as carboncoated zirconium oxide beads, PDMS (polydimethylsiloxane paste), calcium hydroxylapatite, PTFE (polytetrafluoroethylene paste), silicone, PMMA (polymethylmethacrylate microspheres). The shortcoming of the first group materials is that, the initial volume is not conserved, resulting in repetitive injections, which causes high expenses. Also allergic reactions of these materials are frequently observed. One study demonstrated that $13 \%$ of patients developed calcification, surrounded by chronic inflammation, after of glutaraldehyde cross-linked collagen injections for incontinence treatment in children [12]. Ophthalmic artery occlusion, after a paranasal injection of autologous fat, can result in visual loss [13]. In a significant number of cases a suburethral mass develops and urinary retention occurs after dextranomer/hyaluronic acid copolymer urethral injection [14]. The second group of materials showed better results in durability, but, concerns regarding the side effects of these materials have limited general acceptance of their use. PTFE paste [15-17], pyrolitic carbon-coated zirconium oxide beads [18,19] and calcium hydroxylapatite microspheres [20] all have been shown to migrate away from the site of implantation to distant organs and tissues. Micropsheres have been demonstrated to migrate far away from the site of application, e.g., as the antecubital fossa, to the upper arm, chest and shoulder, along the chest and abdominal walls, as far away as the groin [21]. Finally, the development of granulomas or cutaneous sarcoids were frequently described for certain microspheres [22,23].

The "ideal" bulking agent has to be non-immunogenic, hypoallergenic, biocompatible, non-carcinogenic, non-migratory, and somehow traceable for surgeons after injection into the patient. In earlier reports synthesis of microspheres with intrinsic X-ray visibility was described [24-26]. These microspheres contained an iodine-containing building block, e.g., 2-[4-iodobenzoyloxy]-ethyl methacrylate (4IEMA, 1) that is 


\section{Chapter 6}

responsible for intrinsic radiopacity. Furthermore, the microspheres were designed with reactive groups on their surface, e.g., carboxylic groups, to facilitate attachment of protein. Coupling of thrombin to the surface of microspheres that were designed for embolotherapy, resulted in a dramatically increased fibrin deposition on the spheres as well as accelerated blood coagulation [26]. In this manuscript microspheres are described that combine intrinsic radiopacity with surface aldehyde groups for protein attachment under mild conditions.

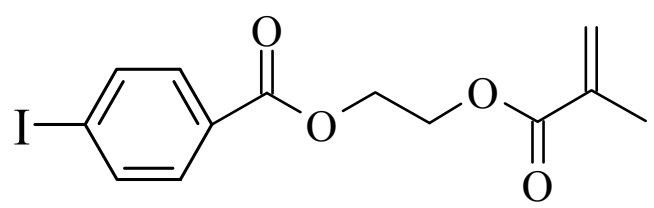

1

For this, acrolein (2-propenal) was combined with methylmethacrylate (MMA) and 1 (4-IEMA) to produce microspheres by suspension polymerization. The covalent attachment of especially collagen was studied in relation to improved cell adhesion, to enhance anchoring of the spheres into the surrounding tissue upon implantation into patients. In this way the chance of migration of microspheres after injection into the patient can be reduced.

\section{Materials and Methods}

\section{Materials}

Chemicals were purchased from Sigma/Aldrich/Fluka (Zwijndrecht, The Netherlands), Acros (Landsmeer, The Netherlands), or Invitrogen (Breda, The Netherlands). Methylmethacrylate (MMA) was distilled at atmospheric pressure and stored at $-20{ }^{\circ} \mathrm{C}$. The monomer 4IEMA was synthesized from 4-iodobenzoyl chloride as described previously [27]. Acrolein (2-propenal), benzoyl peroxide (BPO), tetraethylene glycol dimethacrylate (TEGDMA), poly(vinyl alcohol) (PVA; M.W. 86,000; 99-100\% hydrolyzed), poly(ethylene glycol (PEG; M.W. 1,000), poly(vinyl pyrrolidone) (PVP; K-23-32; M.W. 58,000) were used as purchased. Cell culture medium (DMEM-F12), foetal bovine serum (FBS), and antibiotics were purchased Invitrogen (Breda, The Netherlands). MTT and dinitrophenyl-hydrazine were from Acros, Cyquant reagent from Invitrogen. The FITC labelled forms of collagen and albumin were from Sigma. 
Buffers composition are: $0.2 \mathrm{M}$ carbonate buffer was prepared from $0.2 \mathrm{M} \mathrm{Na}-$ bicarbonate and 0.2 M Na-Hydrogencarbonate, mixed to $\mathrm{pH}$ 9.6. Phosphate buffered saline (PBS) is $8.0 \mathrm{~g} \mathrm{NaCl}, 0.2 \mathrm{~g} \mathrm{KCl}, 1.44 \mathrm{~g} \mathrm{Na}_{2} \mathrm{HPO}_{4}, 0.24 \mathrm{~g} \mathrm{KH}_{2} \mathrm{PO}_{4}$ in 11 distilled water and set to $\mathrm{pH} 7.4$.

\section{Production of microspheres}

The method of preparation of spheres was described previously [26]. Briefly, solution of PVA (1.25 g), PEG (1.50 g) and PVP (0.25 g) in $100 \mathrm{~mL}$ distilled water was magnetically stirred and heated to $85^{\circ} \mathrm{C}$. Microspheres were synthesized in batches of 6 grams. The amount of monomer 1 used (here $1.7 \mathrm{~g}, 4.72 \mathrm{mmol}$ ) was such that the final iodine content is 10 weight $\%$. The rest of the monomers, MMA and acrolein were divided so that different weight percentages of acrolein were obtained (Table 1). The cross-linking agent TEGDMA was used at a $2 \mathrm{~mol} \%$, BPO was used at $1 \mathrm{~mol} \%$. For microspheres with high acrolein content more BPO was needed to get successful suspension polymerization. In this way 8 different acrolein containing microspheres were obtained (Table 1).

Table 1. Composition of the range of acrolein containing microspheres.

\begin{tabular}{|c|c|c|c|c|c|}
\hline & MMA & Acrolein & Monomer 1 & BPO & TEGDMA \\
\hline $0 \%$ acrolein & $\begin{array}{c}4.3 \mathrm{~g} \\
42.95 \mathrm{mmol}\end{array}$ & & $\begin{array}{c}1.7 \mathrm{~g} \\
4.72 \mathrm{mmol}\end{array}$ & $\begin{array}{c}0.11 \mathrm{~g} \\
0.45 \mathrm{mmol}\end{array}$ & $\begin{array}{c}0.32 \mathrm{~g} \\
0.97 \mathrm{mmol}\end{array}$ \\
\hline $2 \%$ acrolein & $\begin{array}{c}4.21 \mathrm{~g} \\
42.04 \mathrm{mmol} \\
\end{array}$ & $\begin{array}{c}0.086 \mathrm{~g} \\
1.534 \mathrm{mmol} \\
\end{array}$ & $\begin{array}{c}1.7 \mathrm{~g} \\
4.72 \mathrm{mmol} \\
\end{array}$ & $\begin{array}{c}0.11 \mathrm{~g} \\
0.45 \mathrm{mmol} \\
\end{array}$ & $\begin{array}{c}0.32 \mathrm{~g} \\
0.97 \mathrm{mmol} \\
\end{array}$ \\
\hline $5 \%$ acrolein & $\begin{array}{c}4.09 \mathrm{~g} \\
40.85 \mathrm{mmol} \\
\end{array}$ & $\begin{array}{c}0.22 \mathrm{~g} \\
3.92 \mathrm{mmol} \\
\end{array}$ & $\begin{array}{c}1.7 \mathrm{~g} \\
4.72 \mathrm{mmol} \\
\end{array}$ & $\begin{array}{c}0.11 \mathrm{~g} \\
0.45 \mathrm{mmol} \\
\end{array}$ & $\begin{array}{c}0.33 \mathrm{~g} \\
0.99 \mathrm{mmol} \\
\end{array}$ \\
\hline $10 \%$ acrolein & $\begin{array}{c}3.87 \mathrm{~g} \\
38.65 \mathrm{mmol} \\
\end{array}$ & $\begin{array}{c}0.43 \mathrm{~g} \\
7.67 \mathrm{mmol} \\
\end{array}$ & $\begin{array}{c}1.7 \mathrm{~g} \\
4.72 \mathrm{mmol} \\
\end{array}$ & $\begin{array}{c}0.12 \mathrm{~g} \\
0.49 \mathrm{mmol} \\
\end{array}$ & $\begin{array}{c}0.34 \mathrm{~g} \\
1.03 \mathrm{mmol} \\
\end{array}$ \\
\hline $20 \%$ acrolein & $\begin{array}{c}3.44 \mathrm{~g} \\
34.36 \mathrm{mmol} \\
\end{array}$ & $\begin{array}{c}0.86 \mathrm{~g} \\
15.34 \mathrm{mmol} \\
\end{array}$ & $\begin{array}{c}1.7 \mathrm{~g} \\
4.72 \mathrm{mmol} \\
\end{array}$ & $\begin{array}{c}0.13 \mathrm{~g} \\
0.54 \mathrm{mmol} \\
\end{array}$ & $\begin{array}{c}0.36 \mathrm{~g} \\
1.09 \mathrm{mmol} \\
\end{array}$ \\
\hline $30 \%$ acrolein & $\begin{array}{c}3.01 \mathrm{~g} \\
30.06 \mathrm{mmol} \\
\end{array}$ & $\begin{array}{c}1.29 \mathrm{~g} \\
23.01 \mathrm{mmol} \\
\end{array}$ & $\begin{array}{c}1.7 \mathrm{~g} \\
4.72 \mathrm{mmol} \\
\end{array}$ & $\begin{array}{c}0.14 \mathrm{~g} \\
0.58 \mathrm{mmol} \\
\end{array}$ & $\begin{array}{c}0.38 \mathrm{~g} \\
1.16 \mathrm{mmol} \\
\end{array}$ \\
\hline $50 \%$ acrolein & $\begin{array}{c}2.15 \mathrm{~g} \\
21.47 \mathrm{mmol} \\
\end{array}$ & $\begin{array}{c}2.15 \mathrm{~g} \\
38.35 \mathrm{mmol} \\
\end{array}$ & $\begin{array}{c}1.7 \mathrm{~g} \\
4.72 \mathrm{mmol} \\
\end{array}$ & $\begin{array}{c}0.16 \mathrm{~g} \\
0.66 \mathrm{mmol} \\
\end{array}$ & $\begin{array}{c}0.43 \mathrm{~g} \\
1.29 \mathrm{mmol} \\
\end{array}$ \\
\hline $70 \%$ acrolein & $\begin{array}{c}1.29 \mathrm{~g} \\
12.88 \mathrm{mmol} \\
\end{array}$ & $\begin{array}{c}3.01 \mathrm{~g} \\
53.69 \mathrm{mmol} \\
\end{array}$ & $\begin{array}{c}1.7 \mathrm{~g} \\
4.72 \mathrm{mmol} \\
\end{array}$ & $\begin{array}{c}0.52 \mathrm{~g} \\
2.15 \mathrm{mmol} \\
\end{array}$ & $\begin{array}{c}0.47 \mathrm{~g} \\
1.43 \mathrm{mmol} \\
\end{array}$ \\
\hline $100 \%$ acrolein & & $\begin{array}{c}4.3 \mathrm{~g} \\
76.70 \mathrm{mmol}\end{array}$ & $\begin{array}{c}1.7 \mathrm{~g} \\
4.72 \mathrm{mmol}\end{array}$ & $\begin{array}{c}0.59 \mathrm{~g} \\
2.44 \mathrm{mmol}\end{array}$ & $\begin{array}{c}0.54 \mathrm{~g} \\
1.62 \mathrm{mmol}\end{array}$ \\
\hline
\end{tabular}




\section{Chapter 6}

The mix of monomers and BPO was added drop-wise to the aqueous PVA-PEG-PVP solution. After the addition, stirring at $85{ }^{\circ} \mathrm{C}$ was continued for $6 \mathrm{~h}$. The microspheres precipitated immediately after stirring was stopped, and the supernatant was decanted carefully. The microspheres were allowed to cool to room temperature, and washed several times in water. Finally microspheres were freeze-dried. Yields varied between $50 \%$ and $78 \%$. Microspheres were inspected by phase-contrast and scanning electron microscopy (SEM) using a Philips XL30 SEM system.

\section{Analysis of surface aldehyde groups}

The number of aldehyde groups on the surface of the microspheres was determined by quantifying the coupling of dinitrophenyl-hydrazine (DNPH) to free aldehyde groups. For this a $20 \mu \mathrm{g} / \mathrm{mL}$ solution of DNPH in ethanol was mixed with approximately 100 mg spheres and the reaction was allowed to run for 20 hours. The absorbance of the remaining ethanol at $348 \mathrm{~nm}$ was determined. From this the amount of soluble DNPH left and subsequently the amount of DNPH coupled to the microspheres could be determined. The spheres with bound DNPH turned bright yellow, but this coloration was not suited for quantification.

\section{Coupling of fluorescently labelled albumin or collagen to microspheres}

$100 \mathrm{mg}$ of microspheres (all percentages of acrolein) were washed twice with $50 \mathrm{mM}$ carbonate buffer $\mathrm{pH}$ 9.6. The washed spheres were incubated with 1) $10 \mathrm{mg} / \mathrm{mL}$ FITCBSA; or 2) $0.8 \mathrm{mg} / \mathrm{mL}$ FITC-Collagen I in $50 \mathrm{mM}$ carbonate buffer $\mathrm{pH} 9.6$ for 16 hours at room temperature. In the case of FITC-collagen, the protein solution was first heat treated at $80{ }^{\circ} \mathrm{C}$ for 10 minutes and rapidly cooled to room temperature. After 3 hours of incubation, the microspheres were washed until no more significant fluorescence was present in the wash. First, the microspheres were analyzed by fluorescence microscopy using a Nikon Eclipse 3600, equipped with a Coolsnap CCD camera. Thereafter microspheres with FITC albumin were digested with trypsin $(0.5 \mathrm{mg} / \mathrm{mL}$ in PBS with $0.53 \mathrm{mM}$ EDTA) for 16 hours at $37{ }^{\circ} \mathrm{C}$. The liberated protein was quantified by determining release fluorescence using a Gemini XS fluorometer, and comparison to a standard curve of trypsin digested FITC-BSA. Microspheres with covalently attached FITC-Collagen I were digested with collagenase $(1 \mathrm{mg} / \mathrm{mL}$ in PBS $\mathrm{pH} 7.4)$ for 16 hours 
at $37^{\circ} \mathrm{C}$. Quantification of digested collagen was performed similarly to FITC-BSA from microspheres as described above.

\section{Coupling of Collagen I}

To $500 \mathrm{mg}$ of washed microspheres, $0.8 \mathrm{mg} / \mathrm{mL}$ bovine collagen I in $50 \mathrm{mM}$ carbonate buffer $\mathrm{pH} 9.6$ was added. The collagen solution was heated to $80{ }^{\circ} \mathrm{C}$ for 10 minutes prior to incubation with microspheres. After 16 hours incubation the spheres were treated with $10 \mathrm{mg} / \mathrm{mL} \mathrm{NaCNBH}_{3}$ for at least 2 hours at room temperature. The microspheres were washed extensively in carbonate buffer and PBS and subsequently stored in PBS at $4{ }^{\circ} \mathrm{C}$ until further use.

\section{Cytotoxicity of microspheres}

Mouse fibroblasts (3T3) were inoculated in 96-wells plates at a density of 1,000 cells/well After incubation for 1 day at $37{ }^{\circ} \mathrm{C}$ extracts of microspheres in culture medium were added. The cells were allowed to proliferate for 3 days and the number of viable cells was determined by addition of $0.5 \mathrm{mg} / \mathrm{mL}$ MTT in culture medium. After a further incubation of 1 hour, the medium was aspirated and the formed blue formazan crystals were dissolved in isopropanol, and the absorbance at $570 \mathrm{~nm}$ was determined. For a direct contact cytotoxicity assay, cells were grown in 24-wells plates up to approximately $50 \%$ confluency. Then microspheres shortly soaked in culture medium were added. After 5 days of incubation at $37{ }^{\circ} \mathrm{C}$ photographs were taken using a standard digital camera on a Leica DM-IL microscope.

\section{Cell Adhesion to collagen coupled microspheres.}

3 T3 cells were grown to confluency in 24-wells plates. Microspheres with or without covalently coupled collagen were shortly soaked in culture medium and added to the cell layers and incubated at $37{ }^{\circ} \mathrm{C}$ for times indicated. In this set-up, cells have to actively migrate onto the spheres and attach to them. For quantification, microspheres were carefully removed from the cell layers (microscopic evaluation of the cell layer showed no significant damage of the remaining cell layer) and washed twice in culture medium. The last bit of medium was removed using a syringe equipped with a cut of 0.5 $\mathrm{mm}$ needle, and the "dry" spheres were frozen at $-80^{\circ} \mathrm{C}$. The amount of attached cells was determined using the CyQuant reagent according to the manufacturer's instructions. 


\section{Chapter 6}

Alternatively, cells were grown on coverslips (12 mm diameter) and microspheres were carefully placed on the semi-confluent layers. After 24 or 48 hours of incubation on the cell layers, the medium was aspirated and the coverslips could be removed from the culture dishes. The coverslips with microspheres lying on the cells were put on a microscope slide and put at an angle of approximately 45 degrees. Medium was flushed over the coverslips to study the adherence of the microspheres to the cells. The resulting coverslip were (i) photographed macroscopically, (ii) observed microscopically, and (iii) fixated in $2.5 \%$ glutaraldehyde in PBS for more than 1 hour at $4{ }^{\circ} \mathrm{C}$, dehydrated with an ethanol series, airdried, and prepared for observation with a scanning electron microscope (Philips XL30 SEM system).

\section{Results and discussion}

\section{Radiopaque microspheres}

Microspheres containing the iodine-monomer 4IEMA and the aldehyde carrying acrolein were obtained without too many complications. Scanning electron microscopy shows nice microspheres with average sizes between 100-200 $\mu \mathrm{m}$ (Figure 1).
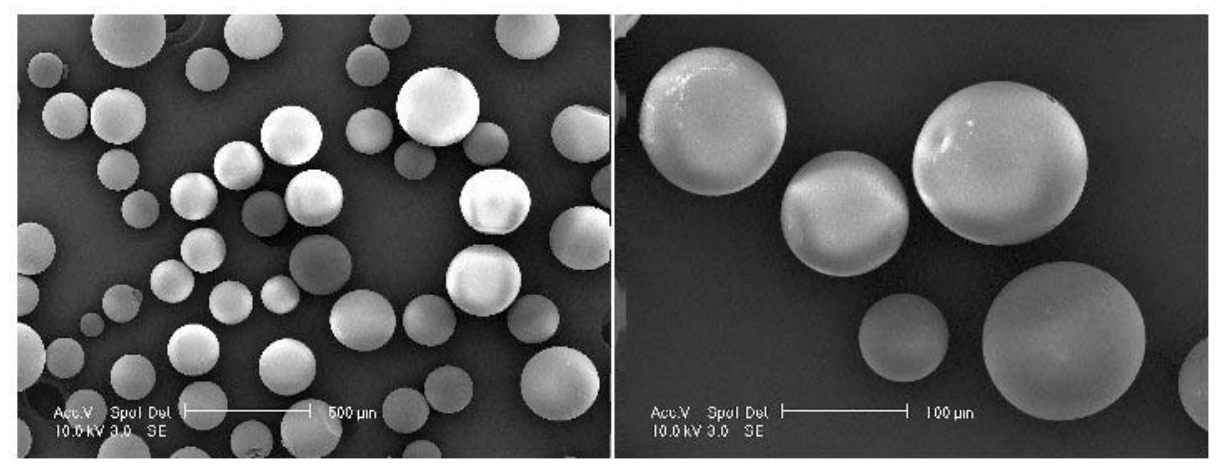

Figure 1. SEM photographs of acrolein containing microspheres with $10 \%$ (A) and $20 \%(B)$ acrolein.

The inclusion of iodine is responsible for the visibility of these spheres under standard $\mathrm{X}$-ray condition. We have extensively reported on the X-ray visibility of iodinecontaining polymers and the stability of the radiopacity. Implantation in rats for 2 years [28], boiling of iodine-containing microspheres at $180^{\circ} \mathrm{C}$ for 30 minutes did not result 
in reduction of radiopacity [25]. With NMR we could confirm the presence of the iodine-containing monomer in the microspheres and therefore one can assume that the acrolein containing microspheres will be nicely X-ray visible (data not shown). To obtain microspheres that can be bio-functionalized, aldehyde groups were designed on the surface by addition of acrolein.

These aldehyde groups can be easily modified with for instance proteins or peptides by a reaction with free amino groups that will yield covalent attachment via a Shiff base, which can be subsequently reduced to yield an amide bond [29]. The production of microspheres with high percentage acrolein $(\geq 70 \%)$ was only successful when an increased percentage of the initiator BPO was used. This may be caused by the relatively good solubility of acrolein in water, meaning that when the polymerization with the standard 1\% BPO proceeds too slow, a large part of the acrolein will dissolve. By increasing the initiator (BPO) concentration, the reaction velocity will increase, less acrolein will be lost in solution, and yields will increase to acceptable levels. Consequently it is reasonable to assume that the average chain length of these spheres will be shorter than in the low acrolein $(<50 \%$ acrolein $)$ microspheres. This will however not pose any problems since microspheres are cross-linked with TEGDMA that carries two methacrylate functions.

Table 2 Aldehyde content of the range of acrolein microspheres as determined by the coupling of dinitrophenylhydrazine.

\begin{tabular}{|c||c||}
\hline $\begin{array}{c}\text { \% acrolein in } \\
\text { microspheres }\end{array}$ & $\begin{array}{c}\text { Dinitrophenylhydrazine binding } \\
\text { (nmol/g spheres) }\end{array}$ \\
\hline 0 & $0 \pm 0$ \\
\hline 2 & $68.8 \pm 0.5$ \\
\hline 5 & $100.8 \pm 5.4$ \\
\hline 10 & $182.2 \pm 13.1$ \\
\hline 20 & $303.5 \pm 32.0$ \\
\hline 30 & $343.6 \pm 25.4$ \\
\hline 50 & $406.5 \pm 16.3$ \\
\hline 70 & $437.5 \pm 3.6$ \\
\hline 100 & $435.9 \pm 5.6$ \\
\hline
\end{tabular}




\section{Chapter 6}

To further analyse the surface of the microspheres, aldehyde groups on the surface of the microspheres were analyzed by reaction with dinitrophenyl-hydrazine (DNPH) [29]. After this reaction the microspheres were stained bright yellow, but this staining could not be quantified (data not shown). Therefore the decrease of dissolved DNPH in the reaction was determined. The decrease of the DNPH concentration is directly proportional to the density of aldehyde groups on the surface. The data presented in Table 2 show that the density of the aldehyde groups increased with increasing acrolein content. For microspheres with high acrolein feed $(>50 \%)$, the amount of coupled DNPH, does not increase anymore. One explanation is that the aldehyde groups on the surface are so densely packed that steric hindrance avoids the coupling of additional DNPH to the surface. Therefore, addition of more than $50 \%$ acrolein to the polymerization reaction seems pointless, since no higher surface modification can be achieved.

\section{Cytotoxicity of microspheres}

Since the microspheres are intended for injection into tissue as a bulking agent, they should be non-toxic to cells in vitro and in vivo. The set of acrolein microspheres was tested for cytotoxicity by incubating 1) the extract of microspheres or 2) the microspheres directly with mouse fibroblasts (3T3). Microspheres containing less than $50 \%$ acrolein were non-toxic (Figure 2A). Also when these spheres were incubated in direct contact with mouse fibroblasts, no toxicity could be determined (Figure 2B).
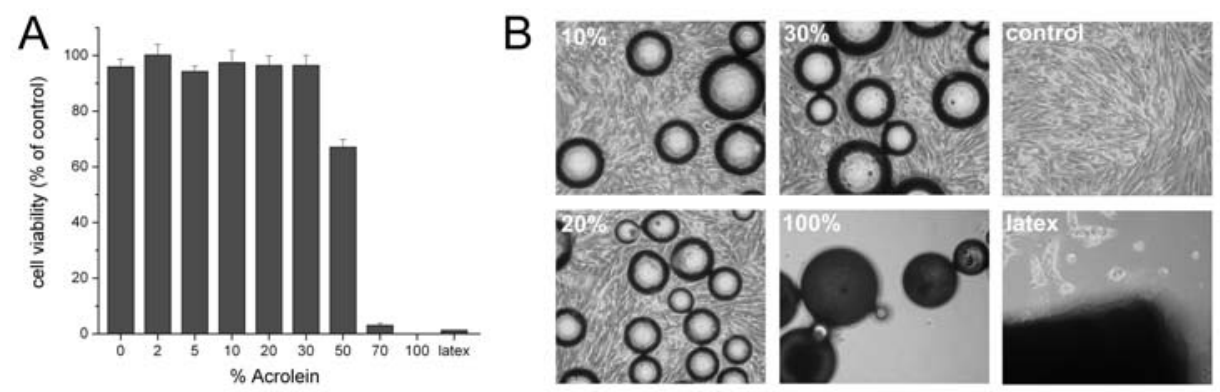

Figure 2. (A) Cell viability of cells incubated with extracts from the range of microspheres. (B) cells cultures in direct contact with microspheres with 10, 20, 30, and 100\% acrolein. Control incubations were without any material or with cytotoxic latex. 
Microspheres with 70 or $100 \%$ acrolein released substances that were toxic to the mouse fibroblasts. These could be unreacted acrolein, which is known to be highly toxic $\left(\mathrm{LD}_{50}=46 \mathrm{mg} / \mathrm{kg}\right)$, or BPO that was used in an increased concentration for the production of these spheres. The radiopaque microspheres that contain $50 \%$ acrolein or less are non toxic and potentially safe for in vivo use. Because the microspheres with more acrolein are toxic in vitro and additionally did not yield in increased binding sites, these microspheres will not be of use in the future.

\section{Coupling of fluorescently labelled proteins}

A frequent problem of currently used bulking agents is that they have a tendency to migrate away from the site of implantation [15-20]. This is caused by poor anchoring of the spheres in the surrounding tissue. To avoid migration and improve anchoring of the microspheres in tissue, attachment of protein, e.g., extra-cellular matrix protein like collagen, can be advantageous. First the attachment of FITC-labelled albumin was attempted. From Figure 3 can be seen that the binding succeeded and a strong increase in fluorescence on the surface could be observed by fluorescence microscopy.
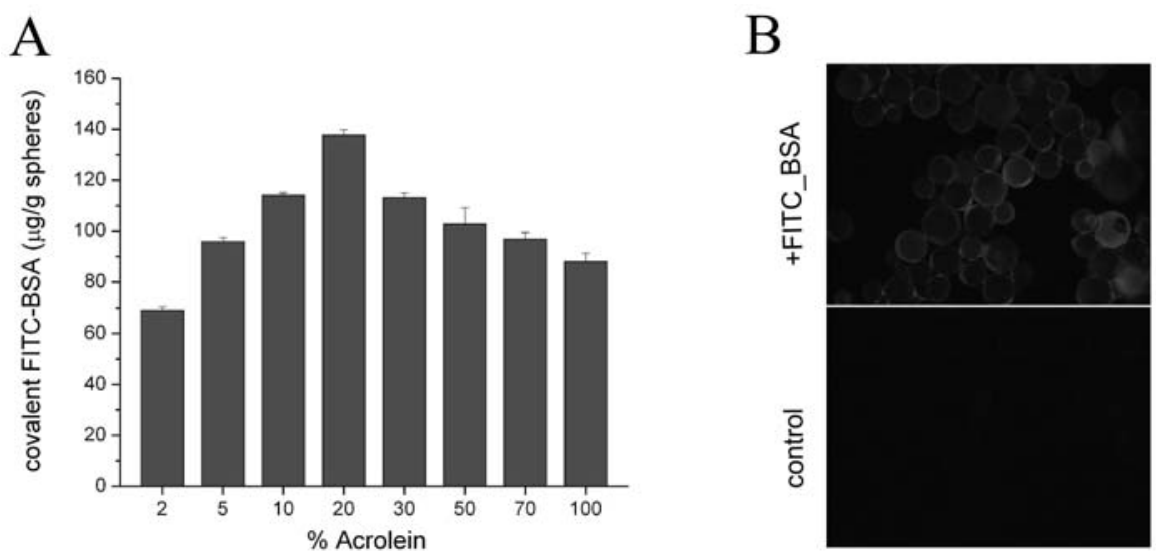

Figure 3. (A) Quantification of attachment of FITC labelled bovine serum albumin (BSA) to acrolein microspheres. (B) Fluorescence micrographs from microspheres with (top) and without (bottom) FITC-BSA.

Treatment of these spheres with trypsin resulted in cleavage of the albumin and release of fluorescent protein fragments of the surface of the spheres. Quantification of the proteolysis products showed that an optimal composition of the spheres, for albumin 


\section{Chapter 6}

attachment, could be observed. Microspheres with 10-30\% acrolein had most FITClabelled albumin on their surface. The fact that more acrolein, and thus higher density of aldehyde groups on the surface did not result in increased albumin binding may be somewhat surprising. This could be explained by the fact that multipoint attachment of albumin on the surface is more likely than attachment of additional protein from solution. The reaction of a soluble protein on the solid surface is less likely than the reaction of the free amino groups of an already coupled protein already in the vicinity of the aldehyde groups on the surfaces. Also the space for additional protein molecules on the surface may become too small, causing steric hindrance for additional albumin molecules.

When studying the coupling of FITC-labelled collagen, a very similar result was obtained. The data presented in Figure 4 show a narrower distribution of covalent protein coupling to the different acrolein microspheres. But again the spheres with 10$20 \%$ acrolein turned out to have the most suitable composition for protein attachment. Collagen was cleaved from the microspheres with collagenase, demonstrating that the bound collagen still had a more or less native conformation that could be recognized by this specific protease. Several experiments were attempted to couple active enzymes to the surface, e.g., alkaline phosphatase or thrombin.
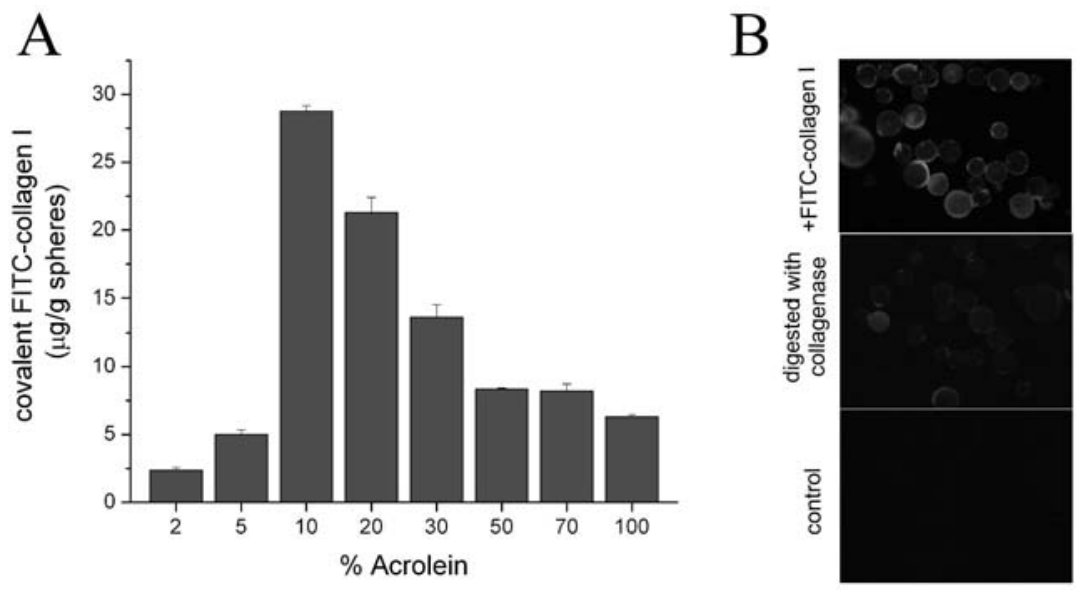

Figure 4. (A) Quantification of FITC labelled collagen type I to acrolein microspheres.(B) fluorescence micrographs of microspheres with FITC-collagen (top), after treatment with collagenase (middle), and the control spheres (bottom). 
No significant amounts of active phosphatase or thrombin could be detected at the microsphere surface. This may be explained by coupling of multiple amino groups of lysine residues from each protein molecule to the surface of the microspheres. Because the aldehyde groups are stable in aqueous, binding of a second lysine residue to the surface is likely, more likely than the binding of an additional protein molecule. This will result in an immobilized protein that is catalytically inactive. So this may be why we have not been able to attach active protein to the acrolein microspheres. Decreasing the acrolein even further than in this study could improve the activity of attached protein, but the attachment to such spheres is far from optimal, as can be seen from the binding optimums for albumin and collagen (Figure 3 and 4). For use as bulking agents however, we do not need attachment of active protein but solely protein that enhances cell attachment and proliferation, e.g., collagen, laminin or fibronectin [30].

\section{Cell attachment to microspheres with collagen}

The anchoring of microspheres in tissue may be obtained by the attachment of the extracellular matrix protein collagen I. This protein has been reported to enhance the attachment of cells to synthetic biomaterials [31,32]. This phenomenon has been extensively exploited in tissue engineering to avoid detachment of cells from polymeric scaffolds when growing cells under flow conditions. For this, non-labelled collagen I was attached to microspheres with 10,20 , and $30 \%$ acrolein. These were the microspheres with best protein binding characteristics.
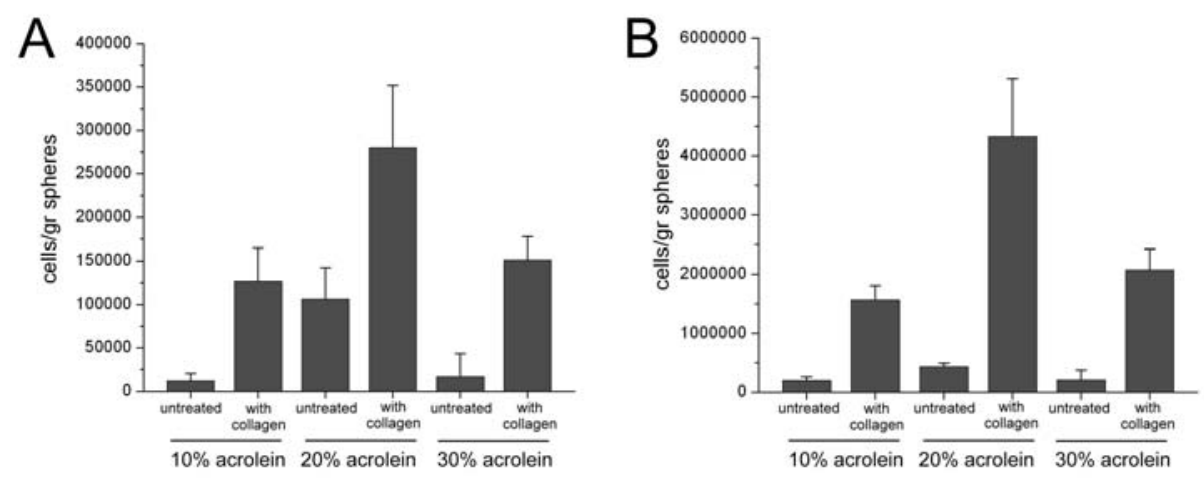

Figure 5. Number of cells on microspheres with 10, 20, or $30 \%$ acrolein after 8 hours (A) or 24 hours (B) incubation. 


\section{Chapter 6}

From Figure 5 can be seen that indeed cells attached rapidly and more efficiently to the collagen modified microspheres. In the used experimental set-up the cells have to migrate onto and subsequently attach to the surface of the spheres. This closely resembles the situation that can be expected shortly after implantation of these spheres in a patient. Already after 8 hours significant numbers of cells are already on the microspheres with collagen while the non-modified microspheres did not accommodate cells.
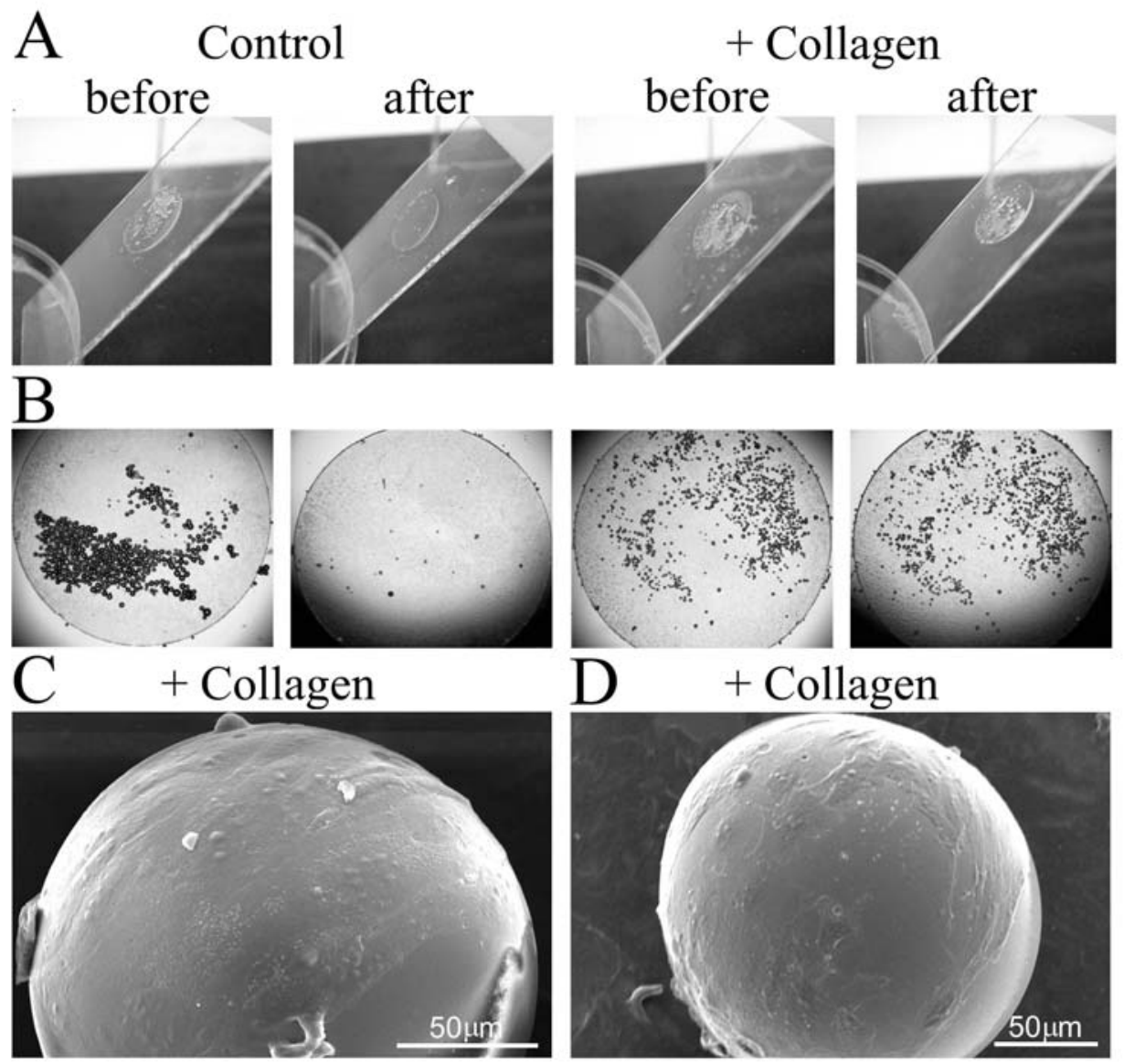

Figure 6. (A) Photograph and (B) Micrograph of microspheres on a cell layer before and after flushing with medium. Note that the collagen modified microspheres remain attached to the cells. (C,D) SEM pictures of collagen modified microspheres on top of a cell monolayer, demonstrating cells that migrated onto the spheres in 24 hours. 
The difference between modified and non-modified microspheres was even more pronounced after 24 hours, when the spheres with collagen were coated with a nice layer of cells. Subsequently the attachment of the collagen microspheres on the cell layer was demonstrated by the experiment depicted in Figure 6. Cells without collagen were almost directly flushed off the cell layer, while the collagen modified spheres remained attached to the cells, also after extensive flushing with medium. The microscopically analysis demonstrated that cells grew onto the microspheres (Figure 6 $\mathrm{C}$ and D). No control microspheres were analyzed by SEM in this experiment because none of these spheres remained attached on the cell layer during the flushing with medium and all the washing and dehydration procedures that were necessary to prepare the samples for SEM analysis.

The data presented here clearly demonstrate that the chosen strategy of covalently coupling collagen to microspheres will result in a rapid and efficient attachment of cells. In earlier reports from our group, we reported protein attachment to microspheres that carry carboxylic groups on their surface $[25,26]$. To these spheres, proteins were attached using 1-ethyl-3-(3-dimethylaminopropyl)carbodiimide (EDC) and Nhydroxysuccinimide (NHS) chemistry. The disadvantage is that these toxic chemicals may persist in the spheres. Also it is more difficult to perform protein attachment to carboxylic groups, since reaction time, concentration of the reactants, and the density of surface groups are much more critical and more difficult to control. The attachment of proteins to the aldehyde groups is relatively simple since the only requirement is that protein has to be dissolved in a buffer of alkaline $\mathrm{pH}(>9.0)$ and no additional reactants are required. The reaction time has not been determined exactly, but merely several hours are required for efficient protein attachment. The reduction of the formed Shiff base by borohydride is the only addition of a potential toxic chemical. The borohydride is easily washed away and can be degraded by heating, so no more borohydride will be left after the incubation. The MTT analysis clearly shows that the microspheres are nontoxic. Also some pilot experiments with protein attachment without the borohydride treatment were performed and no significant difference was observed (data not shown). All the results demonstrate that microspheres containing acrolein are easy to produce and that attachment of protein to the surface is straightforward and can be performed under mild conditions. 


\section{Chapter 6}

\section{Concluding remarks}

The here synthesized iodine-containing microspheres combine radiopacity and possible surface biofunctionalization. The currently used polymeric microspheres are radiolucent and also have a tendency to migrate throughout the patient after injection. Attachment of proteins to the acrolein containing radiopaque microspheres can be performed under easily controlled mild conditions. Covalent coupling of the extra-cellular matrix component collagen I strongly enhanced the interaction of the microspheres with a cell layer in vitro. The collagen-spheres attached strongly to a monolayer of fibroblasts grown on a glass cover slip. Furthermore, cells migrated rapidly onto these microspheres when compared to non-modified polymeric microspheres. A careful extrapolation of these results may indicate that the microspheres with coupled collagen will show improved anchoring in the tissue after injection. These bifunctional microspheres may therefore present a significant improvement in polymeric particles that can be used as filler or bulking agent.

\section{References}

1. Hirsch RJ, Lewis AB Treatment of acne scarring. Semin. Cutan. Med. Surg. 2001;20(3):190-8.

2. Goodman G. Post acne scarring: a review. J. Cosmet. Laser. Ther. 2003;5(2):77-95.

3. Johl SS, Burgett RA. Dermal filler agents: a practical review. Curr. Opin. Ophthalmol. 2006;17(5):471-9.

4. Jones D. HIV facial lipoatrophy: causes and treatment options. Dermatol. Surg. 2005;31(11 Pt 2):1519-29.

5. Moyle GJ. Plastic surgical approaches for HIV-associated lipoatrophy. Curr. HIV/AIDS Rep. 2005;2(3):127-31.

6. Clymer MA . Evolution in techniques: lip augmentation. Facial Plast. Surg. 2007;23(1):21-6.

7. Bruening W. Uber eine Behandlungsmethode der Rekurrenslahmung. Verh Dtsch Laryngol $1911 ; 18 ; 23$

8. Lorenzo AJ, Khoury AE. Endoscopic treatment of reflux: management pros and cons. Curr. Opin. Urol. 2006;16(4):299-304.

9. Starkman JS, Scarpero H, Dmochowski RR. Emerging periurethral bulking agents for female stress urinary incontinence: is new necessarily better? Curr. Urol. Rep. 2006;7(5):405-13.

10. Appell RA, Dmochowski RR, Herschorn S. Urethral injections for female stress incontinence. BJU Int. 2006;98 Suppl 1:27-30.

11. Kwon TK, Buckmire R. Injection laryngoplasty for management of unilateral vocal fold paralysis. Curr. Opin. Otolaryngol. Head Neck Surg. 2004;12(6):538-42.

12. Knudson MJ, Cooper CS, Block CA, Hawtrey CE, Austin JC. Calcification of glutaraldehyde crosslinked collagen in bladder neck injections in children with incontinence: a long-term complication. $J$. Urol. 2006;176(3):1143-6.

13. Danesh-Meyer HV, Savino PJ, Sergott RC. Case reports and small case series: ocular and cerebral ischemia following facial injection of autologous fat. Arch. Ophthalmol. 2001;119(5):777-8. 


\section{Radiopaque microspheres containing acrolein}

14. Abdelwahab HA, Ghoniem GM. Obstructive suburethral mass after transurethral injection of dextranomer/hyaluronic acid copolymer. Int. Urogynecol. J. Pelvic Floor Dysfunct. 2007;18(11):1379-80.

15. Malizia AA, Reiman HM, Myers RP, Sande JR, Barham SS, Benson RC, Dewanjee MK, Utz WJ. Migration and granulomatous reaction after periurethral injection of polytef (Teflon). JAMA 1984;251: 3277-3281.

16. Claes H, Stroobants D, Van Meerbeek J, Verbeken E, Knockaert D, Baert L. Pulmonary migration following periurethral polytetrafluoroethylene injection for urinary incontinence. J. Urol. 1989;142:821-822.

17. Aaronson IA, Rames RA, Greene WB, Walsh LG, Hasal UA, Garen PD. Endoscopic treatment of reflux: Migration of polytetrafluoroethylene into the lungs and brain. Eur. Urol. 1993;23:394-399.

18. Lemperle G, Morhenn VB, Pestonjamasp V, Gallo RL. Migration studies and histology of injectable microspheres of different sizes in mice. Plast. Reconstr. Surg. 2004;113(5):1380-90.

19. Pannek J, Brands FH, Senge T. Particle migration after transurethral injection of carbon coated beads for stress urinary incontinence. J. Urol. 2001;166(4):1350-3.

20. Onol FF, Tarcan T, Tinay I, Kotiloglu E, Simsek F. Kidney loss due to periureteral fibrosis and ureteral obstruction secondary to migration of subureterically injected calcium hydroxylapatite. $J$. Pediat. Urol. 2006;2:503-508.

21. Wang J, Shih TT, Chang KJ, Li YW. Silicone migration from silicone-injected breasts: magnetic resonance images. Ann. Plast. Surg. 2002;48(6):617-21.

22. Kim KJ, Lee HW, Lee MW, Choi JH, Moon KC, Koh JK. Artecoll granuloma: a rare adverse reaction induced by microimplant in the treatment of neck wrinkles. Dermatol. Surg. 2004;30(4 Pt 1):545-7.

23. Sidwell RU, McL Johnson N, Francis N, Bunker CB. Cutaneous sarcoidal granulomas developing after Artecoll facial cosmetic filler in a patient with newly diagnosed systemic sarcoidosis. Clin. Exp. Dermatol. 2006;31(2):208-11.

24. Saralidze K, Aldenhoff YB, Knetsch ML, Koole LH. Injectable polymeric microspheres with X-ray visibility. Preparation, properties, and potential utility as new traceable bulking agents. Biomacromolecules 2003;4(3):793-8.

25. Saralidze K, Knetsch ML, van Hooy-Corstjens CS, Koole LH. Radio-opaque and surfacefunctionalized polymer microparticles: potentially safer biomaterials for different injection therapies. Biomacromolecules 2006;7(11):2991-6.

26. Saralidze K, van Hooy-Corstjens CS, Koole LH, Knetsch ML. New acrylic microspheres for arterial embolization: combining radiopacity for precise localization with immobilized thrombin to trigger local blood coagulation. Biomaterials 2007;28(15):2457-64.

27. Benzina A, Kruft MA, Bär F, van der Veen FH, Bastiaansen CW, Heijnen V, Reutelingsperger C, Koole LH. Studies on a new radiopaque polymeric biomaterial. Biomaterials 1994;15:1122-1128.

28. Aldenhof YB, Kruft MA, Pijpers AP, van der Veen FH, Bulstra SK, Kuijer R, Koole LH. Stability of radiopaque iodine-containing biomaterials. Biomaterials 2002;23(3):881-6.

29. Slomkowski S. Polyacrolein containing microspheres: synthesis, properties and possible medical applications. Prog. Polym. Sci. 1998;23:815-874.

30. Reyer CD, Garcia AJ. A centrifugation cell adhesion assay for high-throughput screening of biomaterial surfaces. J. Biomed. Mater. Res. 2003;67A:328-333.

31. McCarthy JB, Vachhani B, Iida J. Cell adhesion to collagenous matrices. Biopolymer 1996;40(4):371380 .

32. Dewez JL, Lhoest JB, Detrait E, Berger V, Dupont-Gillain CC, Vincent LM, Schneider YJ, Bertrand P, Rouxhet PG. Adhesion of mammalian cells to polymer surfaces: from physical chemistry of surfaces to selective adhesion on defined patterns. Biomaterials 1998;19(16):1441-1445. 


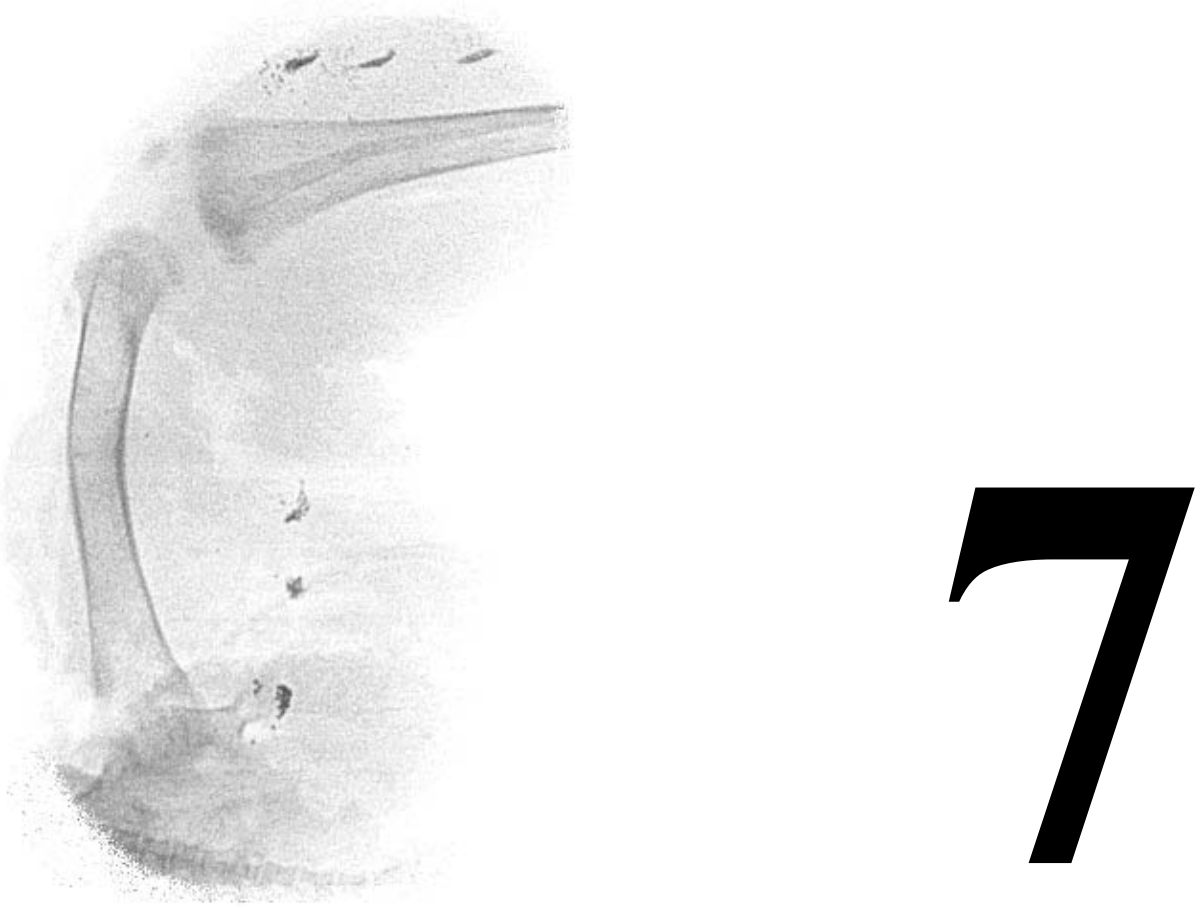

New intrinsically radiopaque hydrophilic microspheres for embolization: synthesis and characterisation

Catharina S.J. van Hooy-Corstjens, Ketie Saralidze, Menno L.W. Knetsch, Pieter J. Emans, Michiel W. de Haan, Pieter C.M.M. Magusin, Brahim Mezari and Leo H. Koole Biomacromolucules; in press 


\title{
Chapter 7
}

\begin{abstract}
Polymeric particles currently used for embolization procedures have the disadvantage that they are radiolucent, i.e., invisible on X-ray images, and consequently the interventional radiologist has to resort to angiography to (indirectly) monitor the fate of the particles. Here, we introduce intrinsically radiopaque hydrophilic microspheres. Since these microspheres can directly be visualised on X-ray images, using these microspheres for embolization purposes will allow super-precise location of the embolic material, both during and after the procedure. The microspheres, which are prepared by suspension polymerisation, are based on the radiopaque monomer 2-[4-iodobenzoyl]oxo-ethylmethacrylate and hydroxyethylmethacrylate and/or 1-vinyl-2-pyrrolidinone as hydrophilic component. It has been shown that for clinically relevant X-ray visibility the spheres should contain at least $20 \mathrm{wt} \%$ iodine. At this iodine content, copolymerisation with HEMA results in spheres that hardly imbibe water $(\mathrm{EQ}=1.08)$. By replacing HEMA by NVP, the volume swelling ratio can be significantly increased (to 1.33 ).
\end{abstract}

\section{Introduction}

Artificial emboli are used by interventional radiologists in minimally invasive procedures to occlude vascular malformations (AVM's) and tumour-feeding blood vessels [1-3]. Commercially, liquid or particulate emboli, both natural and synthetic, are used to obtain vascular occlusion [4]. The choice for a specific material depends on many factors, like the type of lesion to be treated and the kind of catheter to be used. The focus of this article is on a new type of synthetic particulate embolization material. Hydrogels, e.g., polyvinylalcohol (PVA), are a very commonly used example of this type of emboli. Because of their hydrophilic nature, PVA particles are soft and compressible, and as a result they perform better in vascular occlusions than rigid particles [5]. Originally, PVA particles were irregular in shape, but over the years preparation methods have improved, leading to the synthesis of spherical particles. The advantage of a sphere is that it is uniform in shape, which implies that the size is much better calibrated than that of a three-dimensional irregularly shaped particle. The combined benefit of particles that are both hydrophilic and spherical in shape is that they allow a simple transcatheteral introduction without aggregation of particles, and a geometrically better blocking of the vascular lumen is obtained [6,7]. 
A disadvantage of PVA microspheres and all other commercially available artificial particulate emboli is that they are radiolucent, i.e., they are invisible on X-ray images. However, to prevent incorrect positioning of the spheres, resulting in complications such as 'reflux with non-target embolization' and 'through embolization', permanent surveillance of the embolization procedure is necessary. A solution that is clinically applied is monitoring by angiography, which implies that the radiolucent spheres are dispersed in contrast medium [7]. This indirect method of visualisation has the disadvantage that in case of inhomogenous dispersion of the particles, the contrast medium passes more distally into the vascular bed than the particles and as such does not provide information about the position of the particles. Another disadvantage is that the contrast medium is cleared quickly from the place of injection, so postoperatively no information about the position of the particles can be obtained.

Based on these shortcomings, the challenge is to prepare hydrophilic microspheres that are intrinsically radiopaque, which will allow exact location of the embolic material, not only during the embolization procedure, but also afterwards.

The unique feature of intrinsic radiopacity has been introduced more than one decade ago [8-13]. Since then, several applications of these types of polymers have been suggested and studied [12-22]. Different syntheses of intrinsically radiopaque microspheres have been described in literature. For embolization purpose, both hydrophobic [20-22] and hydrophilic microspheres [12-14] have been proposed. For the latter, two types of microspheres are described: (i) polyhydroxyethylmethacrylate (PHEMA) microspheres for which the surface has been modified with an iodinecontaining radiopaque compound [12,13], (ii) porous radiopaque microspheres, prepared via copolymerisation of hydroxyethylmethacrylate (HEMA) and an iodinecontaining monomer [14]. The disadvantage of (i) is that desired properties like hydrophilicity and softness are largely lost due to the surface modification. The disadvantage of (ii) is that due the porosity of the microspheres, relatively high amounts of iodine are required to render the particles radiopaque and these results in the formation of some irregular particles and agglomerates during polymerisation [14]. Furthermore, the required high amount of iodine also diminishes the hydrophilic character of the material.

Recently, we started the development of intrinsically radiopaque non-porous microspheres, which are based on the iodine-containing methacrylic monomer (2-[4- 


\section{Chapter 7}

iodobenzoyl]-oxo-ethylmethacrylate (4IEMA)). This monomer was copolymerised with HEMA and/or 1-vinyl-2-pyrrolidinone (NVP) to render the microspheres hydrophilic. This article describes the preparation of this new type of intrinsically radiopaque microspheres and their most relevant physical-chemical properties, such as composition, size and size distribution, swelling capacity, cytocompatibility and X-ray contrast.

\section{Materials and Methods}

\section{Preparation of radiopaque hydrogel microspheres}

All microspheres were based on the radiopaque iodine-containing monomer 2-[4iodobenzoyl]-oxo-ethylmethacrylate (4IEMA, Figure 1). As published previously, this monomer was prepared from 4-iodobenzoylchloride and distilled HEMA in a one-step esterification reaction [23].

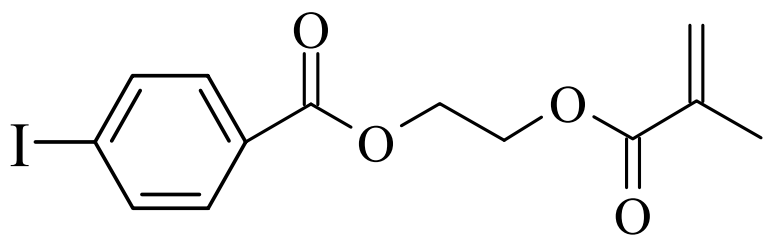

Figure 1. Structural formula of 4IEMA.

To obtain hydrophilic microspheres, this hydrophobic monomer was reacted with HEMA, NVP or a combination of HEMA and NVP. Both HEMA and NVP were purchased from Acros (Landsmeer, the Netherlands) and purified by distillation under reduced pressure before use.

A range of microspheres with an iodine content of 10,15 or $20 \mathrm{wt} \%$ has been prepared via suspension polymerisation, following a recipe of Jayakrishnan et al [24]. The dispersion medium, consisting of $70 \mathrm{~mL}$ distilled water, $14.64 \mathrm{~g}$ sodium chloride $(\mathrm{NaCl})$ and $2.00 \mathrm{~g}$ magnesium chloride hexahydrate, was heated in a $250-\mathrm{mL} 3$-neck round bottom flask to $70{ }^{\circ} \mathrm{C}$. At this temperature $0.78 \mathrm{~g}$ sodium hydroxide dissolved in $15 \mathrm{~mL}$ water was added dropwise under mechanical stirring (200 rpm), resulting in clouding of the solution by precipitation of magnesium hydroxide $\left(\mathrm{Mg}(\mathrm{OH})_{2}\right)$, the suspension stabiliser. The dispersion medium thus contained $17 \mathrm{wt} \% \mathrm{NaCl}$ and $0.67 \mathrm{wt} \% \mathrm{Mg}(\mathrm{OH})_{2}$. 
For the preparation of HEMA/4IEMA spheres with $20 \mathrm{wt} \%$ iodine, $[\mathrm{NaCl}]$ was lowered to $11.6 \mathrm{wt} \%$ and $\left[\mathrm{Mg}(\mathrm{OH})_{2}\right]$ was increased to $1.2 \mathrm{wt} \%$.

After complete addition of the sodium hydroxide solution, the temperature was further raised to $75-80{ }^{\circ} \mathrm{C}$. At this temperature, a homogeneous mixture of $20 \mathrm{~g}$ monomers and $80 \mathrm{mg}$ initiator (2,2'-azobis(isobutyronitrile)) was added dropwise. Subsequently, the temperature was increased to $85{ }^{\circ} \mathrm{C}$ and the reaction mixture was kept at this temperature for $4.5 \mathrm{~h}$, while stirring was maintained at $200 \mathrm{rpm}$. In case of NVPcontaining microspheres, the reaction was further continued overnight at $55{ }^{\circ} \mathrm{C}$. For spheres containing solely NVP as hydrophilic component, $3 \mathrm{~mol} \%$ crosslinker (allylmethacrylate) was added to the homogeneous mixture of monomers.

Table 1. Coding, composition, yield of synthesis and equilibrium volume swelling ratio (EQ) of radiopaque microspheres.

\begin{tabular}{|c|l|c|c|c|}
\hline Code & Monomer ratio (wt/wt) & wt\% iodine & $\begin{array}{c}\text { Yield } \\
\text { Synthesis }\end{array}$ & EQ $^{(2)}$ \\
\hline H100_10 & HEMA/4IEMA 71.6/28.4 & 10 & $84 \%$ & $1.27 \pm 0.03$ \\
\hline H100_15 & HEMA/4IEMA 57.4/42.6 & 15 & $82 \%$ & $1.18 \pm 0.03$ \\
\hline H100_20 & HEMA/4IEMA 43.2/56.8 & 20 & $81 \%$ & $1.08 \pm 0.01$ \\
\hline H50_N50_10 & HEMA/NVP/4IEMA 35.8/35.8/28.4 & 10 & $84 \%$ & $1.99 \pm 0.14$ \\
\hline H50_N50_15 & HEMA/NVP/4IEMA 28.7/28.7/42.6 & 15 & $86 \%$ & $1.33 \pm 0.02$ \\
\hline H50_N50_20 & HEMA/NVP/4IEMA 21.6/21.6/56.8 & 20 & $86 \%$ & $1.16 \pm 0.02$ \\
\hline N100_10 & NVP/4IEMA 71.6/28.4 & 10 & $81 \%$ & $2.16 \pm 0.07$ \\
\hline N100_15 & NVP/4IEMA 57.4/42.6 & 15 & $82 \%$ & $1.87 \pm 0.07$ \\
\hline N100_20 & NVP/4IEMA 43.2/56.8 & 20 & $81 \%$ & $1.33 \pm 0.03$ \\
\hline
\end{tabular}

Note (1) Coding of the samples HxNy_z: $x$ and $y$ denote the weight percentage HEMA and NVP respectively of the hydrophilic part of the microspheres; $z$ denotes the weight percentage iodine of the microspheres. (2) per composition 8 spheres were measured to determine EQ.

In all cases, diluted hydrochloric acid was added to the reaction mixture after cooling to room temperature to dissolve the stabiliser. The spheres were washed five times with distilled water and dried under vacuum.

Table 1 depicts the composition of the different spheres that have been prepared. 


\section{Chapter 7}

\section{Size distribution}

Photomicrographs of the spheres were taken using a Nikon optical microscope. Per composition, the diameter of at least 500 spheres was measured to determine the number-averaged sphere size. Afterwards, the beads were sieved in fractions of welldefined sizes $(<90 \mu \mathrm{m}, 90-200 \mu \mathrm{m}, 200-300 \mu \mathrm{m}, 300-425 \mu \mathrm{m}, 425-600 \mu \mathrm{m}, 600$ $-800 \mu \mathrm{m}, 800-1000 \mu \mathrm{m},>1000 \mu \mathrm{m})$.

\section{Swelling}

The volume swelling ratio $(\mathrm{Q})$ of the spheres was determined as follows: A single sphere was immersed in water and at fixed time points an image of the sphere was taken with the fluorescent microscope. Subsequently, the diameter of the sphere was measured and the volume was calculated, assuming perfect spherical geometry. (E)Q was calculated according to [25]:

$$
\mathrm{Q}=\frac{\mathrm{V}_{\mathrm{sw}}}{\mathrm{V}_{\mathrm{p}}}
$$

where $\mathrm{V}_{\mathrm{sw}}$ and $\mathrm{V}_{\mathrm{p}}$ are the volume of the swollen and dry sphere respectively.

\section{Solid state NMR}

${ }^{1} \mathrm{H}$-decoupled ${ }^{13} \mathrm{C}$-NMR spectra were recorded on a Bruker DMX500 spectrometer with a ${ }^{13} \mathrm{C}-\mathrm{NMR}$ frequency of $125.13 \mathrm{MHz}$. A 4-mm magic-angle-spinning (MAS) probe head was used with sample rotation rates of 4-8 $\mathrm{kHz}$. The radio-frequency power was adjusted to obtain $5 \mu$ s 90-degree pulses both for the ${ }^{1} \mathrm{H}$ and ${ }^{13} \mathrm{C}$ nuclei. ${ }^{13} \mathrm{C}$-NMR spectra were recorded by use of a Hahn-echo pulse sequence on swollen samples in $\mathrm{CDCl}_{3}$ with an interscan delay of 40-80 sec to obtain quantitative spectra for the copolymers and with an interscan delay of $5 \mathrm{sec}$ to obtain qualitative spectra for both homopolymers.

\section{Cytotoxicity}

20,000 human microvascular endothelial cells (HMEC-1) were inoculated in each well of a 24-well plate. The cells were cultured at $37{ }^{\circ} \mathrm{C} / 5 \% \mathrm{CO}_{2}$ for $24 \mathrm{~h}$ before the microspheres were added. Microspheres were sterilised with UV light for $15 \mathrm{~min}$ and 
subsequently added to the cells in such a way that estimated $20 \%$ coverage of the total area by spheres was achieved. Latex (Het Rubberhuis, Maastricht) was used as positive, toxic control and the negative control was a well with only cells and no spheres. After 3 days of incubation, photographs of the cells were taken with a Leica DM-IL inverted microscope.

\section{In vitro $\mathrm{X}$-ray visibility}

X-ray contrast of the spheres was determined on two different machines. The first was an Integris V5000, which is normally used in the hospital for angiography. The advantage of this machine is that the distance between the X-ray source and the detector can be varied, which increases the contrast of the X-ray image. For the current experiments, the machine was operated at $70-80 \mathrm{kV}$. The X-ray contrast of the spheres was also determined at a Philips BV Pulsera (C-bow), which is operated at $48 \mathrm{kV}$. This machine has a fixed (relatively) big distance (approx. $75 \mathrm{~cm}$ ) between X-ray source and detector and is normally used for animal experiments.

First, clusters of 5 spheres of defined size and iodine content were recorded on the Integris V5000. The next experiment was that $10 \mathrm{mg}$ of spheres was placed in the soft tissue of a cadaveric chicken leg and images were recorded on both X-ray machines. The chicken leg was used as a model, to mimic a realistic situation, where surrounding tissue will also influence the X-ray visibility of the spheres.

\section{In vivo $\mathrm{X}$-ray visibility}

A pilot study with a Yorkshire land race pig $(30 \mathrm{~kg})$ has been performed. This experiment was approved by the Maastricht University Experimental Animal Committee and the European and Dutch laws on animal experimentation were followed strictly. After anaesthetising by an intravenous injection of Pentothal, the pig was insufflated with a mixture of $\mathrm{O}_{2}, \mathrm{~N}_{2} \mathrm{O}$ and isoflurane. A midline incision was made in the abdomen, the skin was opened and the fascia was carefully incised. A catheter was inserted in the aorta under the artery renali. Subsequently, the tip of the catheter was positioned in the renal artery and the skin and fascia were carefully closed again to ensure realistic absorption of X-ray by the surrounding tissue. Then the microspheres, dispersed in water, were injected via the catheter. During injection, the radiopacity of the spheres was tested with the C-bow. 


\section{Chapter 7}

\section{Results and Discussion}

\section{Synthesis of P(HEMA/4IEMA) microspheres}

A common technique for the preparation of microspheres is suspension polymerisation, with water as dispersion medium. Here, a concentrated salt solution is used as dispersed phase, to prevent dissolution of the hydrophilic monomers [24].

In first instance, microspheres are prepared based on the radiopaque monomer 4IEMA and HEMA. Suspension polymerisation of the two monomers results for mixtures with 28.4 or $42.6 \mathrm{wt} \%$ 4IEMA (i.e., 10 and $15 \mathrm{wt} \%$ iodine) in the formation of spherical particles and the yield of the reaction is always larger than $80 \%$.
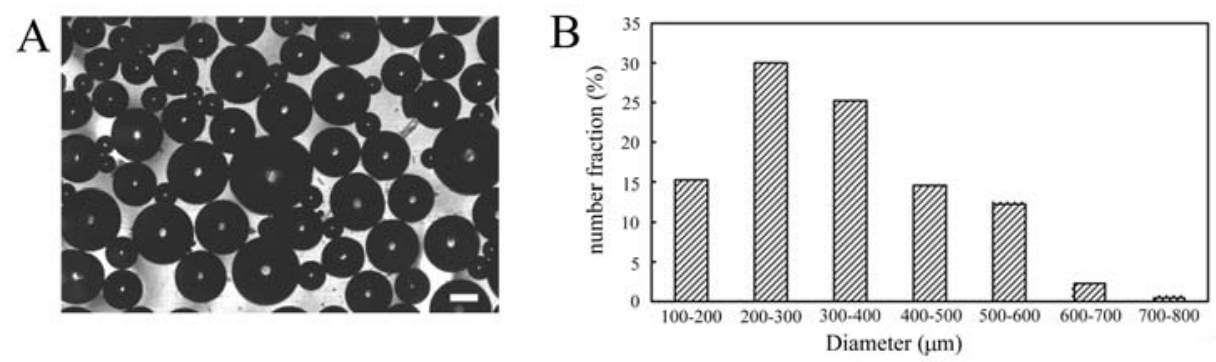

Figure 2. HEMA/4IEMA microspheres containing $10 \mathrm{wt} \%$ iodine (H100_10): (a) optical micrograph, scale bar $=250 \mu \mathrm{m}$; (b) size distribution.

Figure 2a depicts an example of such spheres (H100_10; see Table 1 for an explanation of the codes), while in Figure $2 b$ the size distribution of these spheres is given. The average size of the spheres is $336 \mu \mathrm{m}$ with a standard deviation of $132 \mu \mathrm{m}$. It is observed that with increasing 4IEMA content, the average sphere size increases (H100_15: average size $468 \pm 130 \mu \mathrm{m})$.

For spheres with $56.8 \mathrm{wt} \%$ 4IEMA (H100_20), the dispersion medium containing 17 $\mathrm{wt} \% \mathrm{NaCl}$ and $0.67 \mathrm{wt} \% \mathrm{Mg}(\mathrm{OH})_{2}$ even results in the formation of agglomerates and big, non-spherical particles. Therefore, the $[\mathrm{NaCl}]$ is lowered to $11.6 \mathrm{wt} \%$ and the $\left[\mathrm{Mg}(\mathrm{OH})_{2}\right]$ is increased to $1.2 \mathrm{wt} \%$. Both changes induce smaller sphere sizes in case of PHEMA microspheres [24]. For H100_20, these reaction conditions result in the formation of spherical particles, with a large fraction $>600 \mu \mathrm{m}$ in diameter. For all compositions, a relatively broad size distribution of spheres is obtained. For use in embolization however, spheres of well-defined size are preferred, since this allows 
selective embolization. Ultimately, embolization can be performed with a series of microspheres of well-defined size in such a way that first the capillaries at the periphery can be occluded, followed by occlusion of the larger feeding vessels. The broad size distribution obtained during suspension polymerisation gives the advantage that many different sizes of spheres are obtained. By sieving the spheres subsequently, narrow size distributions can be obtained. This method of sphere preparation thus results in a range of microspheres with different and well-defined sizes.

\section{Swelling of P(HEMA/4IEMA) microspheres}

Figure 3 shows a representative swelling curve for H100_10. Equilibrium in swelling is assumed when the diameter of the sphere maintains constant for at least $2 \mathrm{~h}$. For this typical example, equilibration is reached in $2 \mathrm{~h}$. It should be noted that the time to equilibrium swelling (EQ) is dependent on the initial sphere diameter, which varies for all experiments. Therefore, only EQ of the different spheres will be compared and the time to reach EQ is not taken into account. For H100_10, H100_15 and H100_20, EQ decreases from 1.27 to 1.18 and 1.08 respectively (see also Table 1).

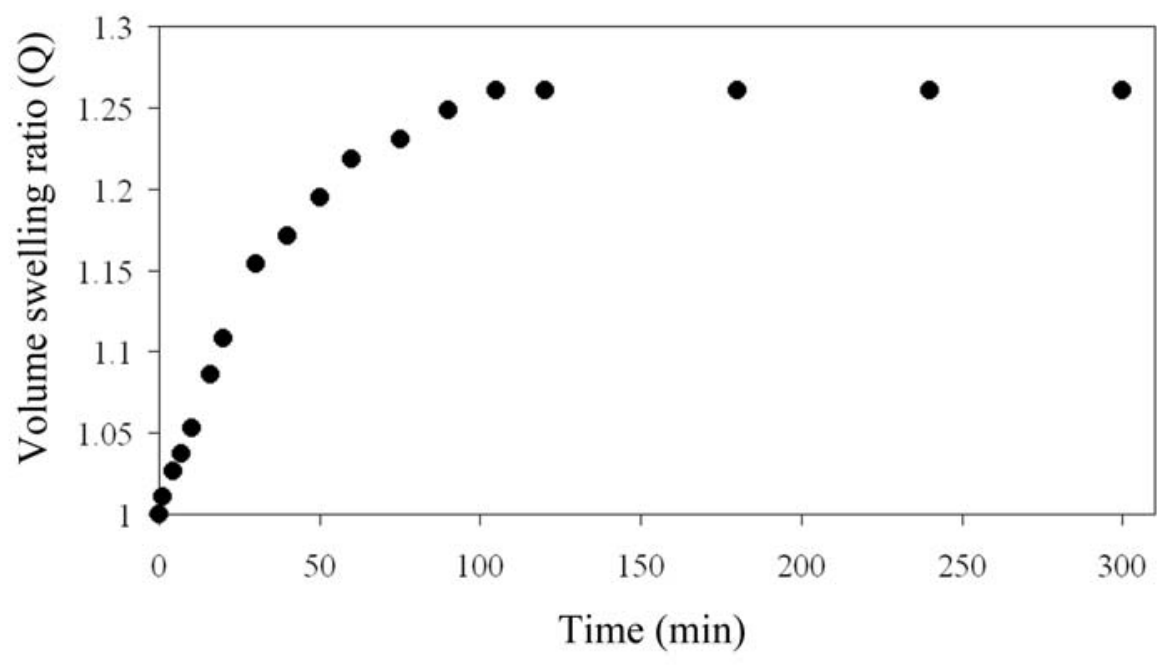

Figure 3. Volume swelling ratio $Q$ of H100_10 (initial sphere diameter $=573 \mu \mathrm{m}$ ).

\section{Synthesis and swelling of P(HEMA/NVP/4IEMA) microspheres}

In an attempt to obtain higher EQs, also microspheres containing a combination of HEMA and NVP as hydrophilic component have been prepared. NVP, which is also 


\section{Chapter 7}

used already in biomedical applications, is more hydrophilic than HEMA and therefore microspheres based on a combination of both monomers are anticipated to be more hydrophilic.

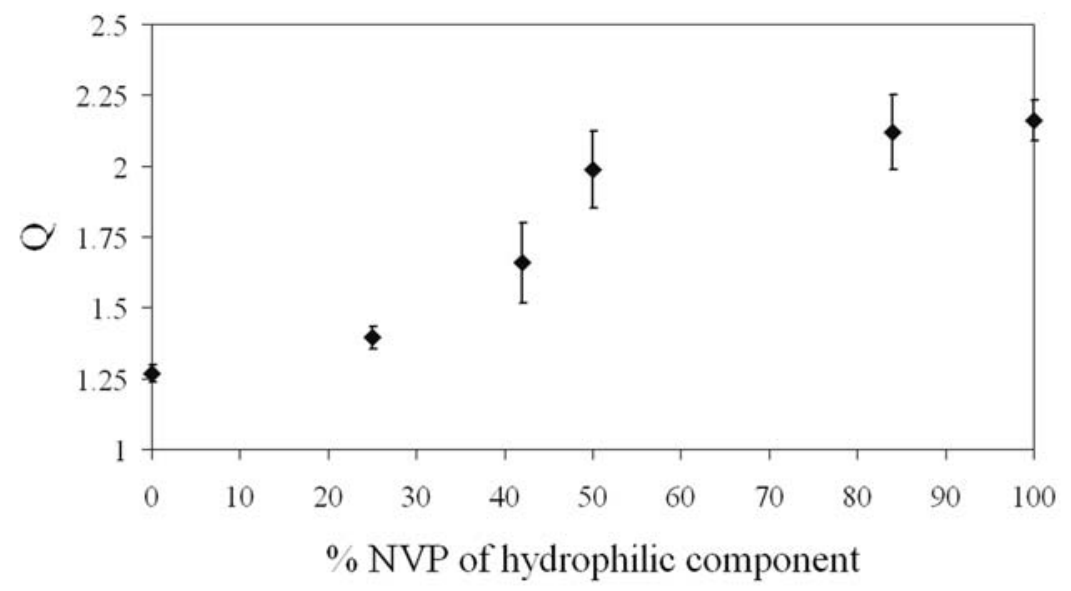

Figure 4. EQ dependence as function of the composition of the hydrophilic component of microspheres.

Figure 4 depicts EQ as function of the composition of the hydrophilic component, i.e., the ratio NVP/HEMA, for spheres with $10 \mathrm{wt} \%$ iodine. From this figure it is clear that changing the hydrophilic component from pure HEMA to a mixture of HEMA and NVP significantly increases EQ. Also spheres with 15 and $20 \mathrm{wt} \%$ iodine are prepared and their equilibrium swelling ratio is compared tot that of spheres with $10 \mathrm{wt} \%$ Iodine in Table 1. From this table it is clear that for all iodine contents a significant increase in EQ is obtained by (partially) replacing HEMA by NVP.

\section{Solid state NMR of P(NVP/4IEMA) microspheres}

Previous work in our group on intrinsically radiopaque hydrogels for nucleus pulposus replacement has demonstrated that the reactivity of 4IEMA and HEMA is comparable, resulting in the formation of random copolymers. It has also been shown that 4IEMA is far more reactive than NVP (e.g., for the copolymerisation of 4IEMA with NVP we found $r_{4 \text { IEMA }}=5.4$ and $r_{\mathrm{NVP}}=0.04$ ) [19]. As a result, copolymerisation of NVP with 4IEMA results in the formation of PVP oligomers at the end of the polymerisation reaction, which dissolve upon immersing the xerogel in water. By using a few mol\% 
allylmethacrylate, which couples vinyl to methacrylate monomers, as crosslinker, this problem could largely be overcome [26]. Based on this knowledge, we use $3 \mathrm{~mol} \%$ allylmethacrylate for the preparation of NVP/4IEMA microspheres Magic-angle spinning ${ }^{13} \mathrm{C}$ NMR has been performed on the materials swollen in $\mathrm{CDCl}_{3}$ to determine the ratio of the built-in monomers. First, spectra of the homopolymers PVP and P4IEMA are measured for qualitative information about peak positions (Figure 5).

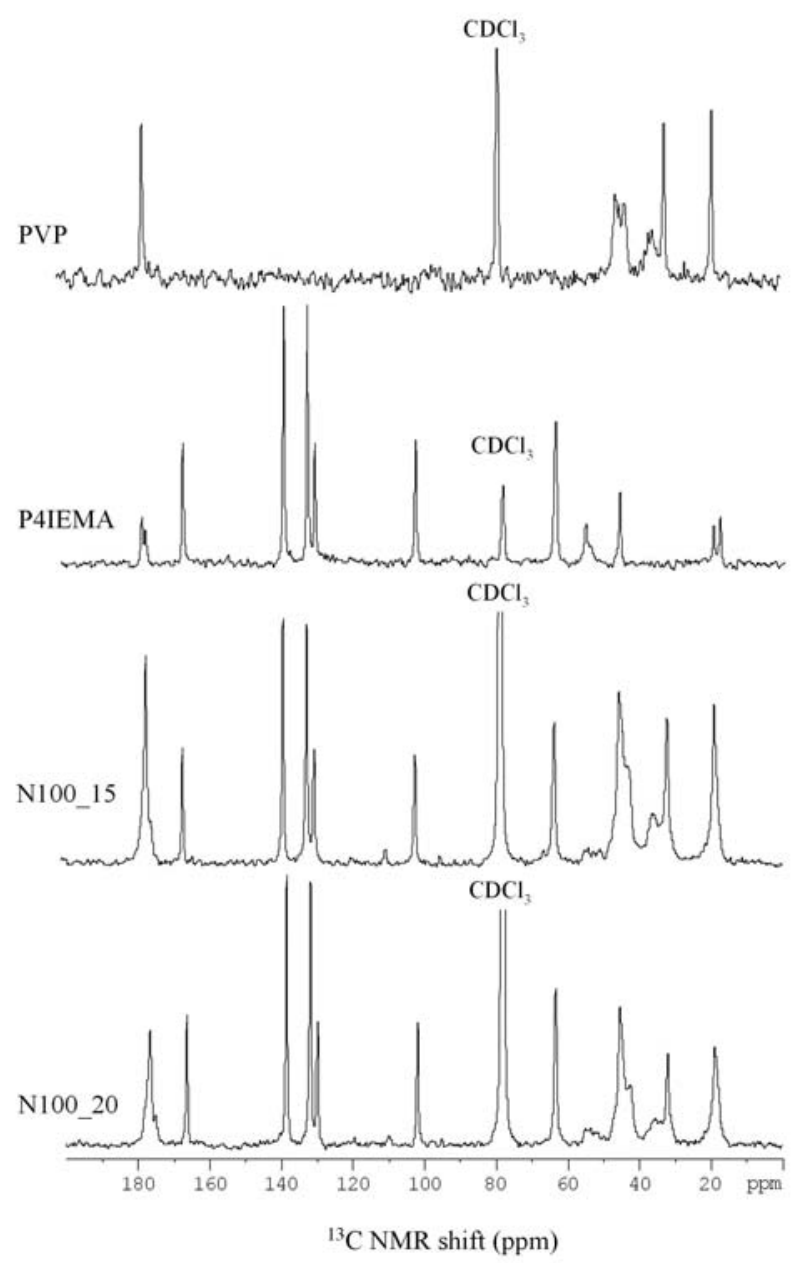

Figure 5. MAS ${ }^{13}$ C NMR Hahn-echo spectra.

Reasoning that single, narrow peaks are preferably used for composition calculations, the ratio of the carbonylic peaks at $167 \mathrm{ppm}$ (solely 4IEMA) and $177 \mathrm{ppm}$ (both NVP 


\section{Chapter 7}

and 4IEMA) will be used to calculate the fraction built-in 4IEMA in the copolymers. Figure 5 also displays the Hahn-echo spectra of N100_15 and N100_20. The ratio of the peaks at 167 and $177 \mathrm{ppm}$ is 0.25 and 0.38 respectively. These values reveal a mass $\%$ of built-in 4IEMA of 52.3 and 66.5 respectively. The mass\% of 4IEMA in the monomer mixtures of both microspheres is 42.5 and 56.8 respectively. Assuming that all 4IEMA of the monomer mixture is built-in (due to its higher reactivity) and some NVP dissolved during synthesis and/or washing of the microspheres, it can be calculated that for both types of microspheres approx. $65 \%$ of the NVP in the monomer mixture is incorporated in the microspheres. This confirms our previous findings that some of the NVP dissolves in the water phase during synthesis and/or washing of the microspheres.

\section{Cytotoxicity}

To establish the cytotoxicity of the microspheres, endothelial cells are incubated with three different types of microspheres and after 3 days of incubation photographs are taken (Figure 6).

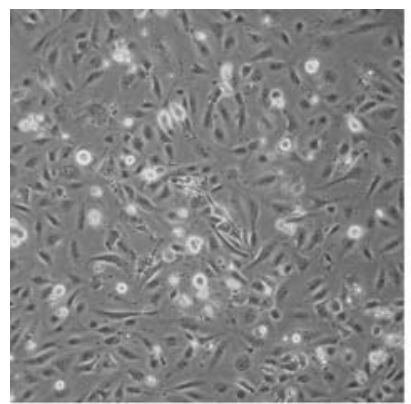

control

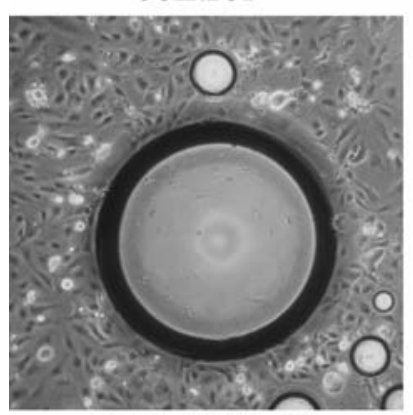

H50_N50_10
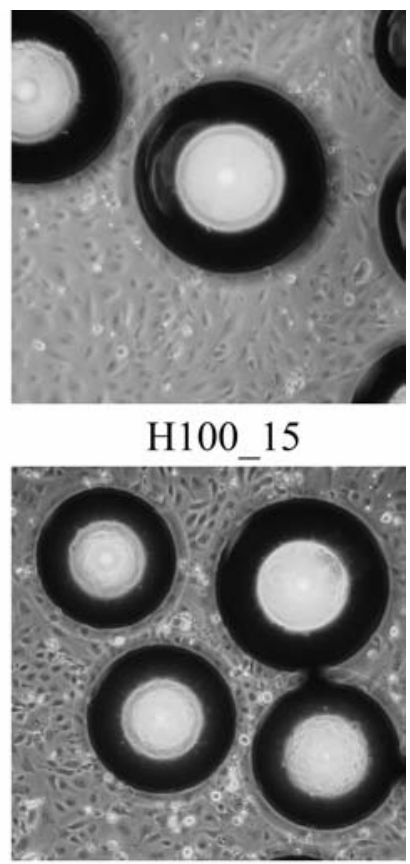

N100_20

Figure 6. Cytotoxicity of microspheres: direct contact with endothelial cells. 
Around the surface of all microspheres no inhibition layer of cells can be observed; i.e., the microspheres do not effect cell proliferation. Also by comparing the morphology of the cells in presence of spheres to that of the control sample no adverse effect on the morphology of the cells can be observed. The cytocompatibility of these microspheres is corroborated by earlier studies of our group, where discs of comparable hydrogels have been implanted subcutaneous in mice [27]. These studies showed that the hydrogels were well tolerated and no signs of severe adverse reactions of the surrounding tissue were observed.

\section{In vitro $\mathrm{X}$-ray contrast}

Reasoning that a high water content is good for compressibility, spheres with a high fraction of hydrophilic monomers would be the preferable choice for use in embolization. However, these spheres also have the lowest content of iodine, which implies that they will be the least visible on the X-ray image. So, a compromise between compressibility and X-ray visibility will have to be made. First, the X-ray visibility of single spheres is studied. By comparing the X-ray contrast of the different clusters of spheres as depicted in Figure 7a, it is clear that, as expected, the contrast increases with sphere size and iodine content. Subsequently, the X-ray visibility of the different radiopaque microspheres after injection in a chicken leg, purchased at a local supermarket, is studied. The chicken leg provides a cheap model which enables us to examine the particles under conditions that also allow imaging of soft tissue. Moreover, the contrast of the particles can be compared immediately to that of bone. Finally we use the chicken leg model to compare the X-ray images of the Integris V5000 system that is normally used for clinical angiography to that of the C-bow instrument (in our animal facility). For the images taken with the clinical X-ray machine (Integris V5000), clusters of spheres of all sizes and iodine content can be distinguished clearly, as is shown in Figure $7 \mathrm{~b}$ and $7 \mathrm{c}$, and the contrast of spheres with high iodine content (20 and $15 \%$ ) is superior to that of bone.

When checking single spheres, which are lying slightly apart from the clusters, it can be concluded that for sphere sizes of $600 \mu \mathrm{m}$ and larger, single spheres can be distinghuised for all three iodine content. For spheres in the range of 425-600 $\mu \mathrm{m}$, it becomes more difficult to observe single spheres: only for H100_20, separate spheres are visible on the X-ray image. In the size-range of 300-425 $\mu \mathrm{m}$, single spheres cannot 


\section{Chapter 7}

be distinghuised. By comparing the X-ray contrast of the spheres in the chicken leg to that of plain single spheres (Figure 7a), it can be concluded that the surrounding soft tissue of the chicken leg has not much influence on the contrast of the spheres.
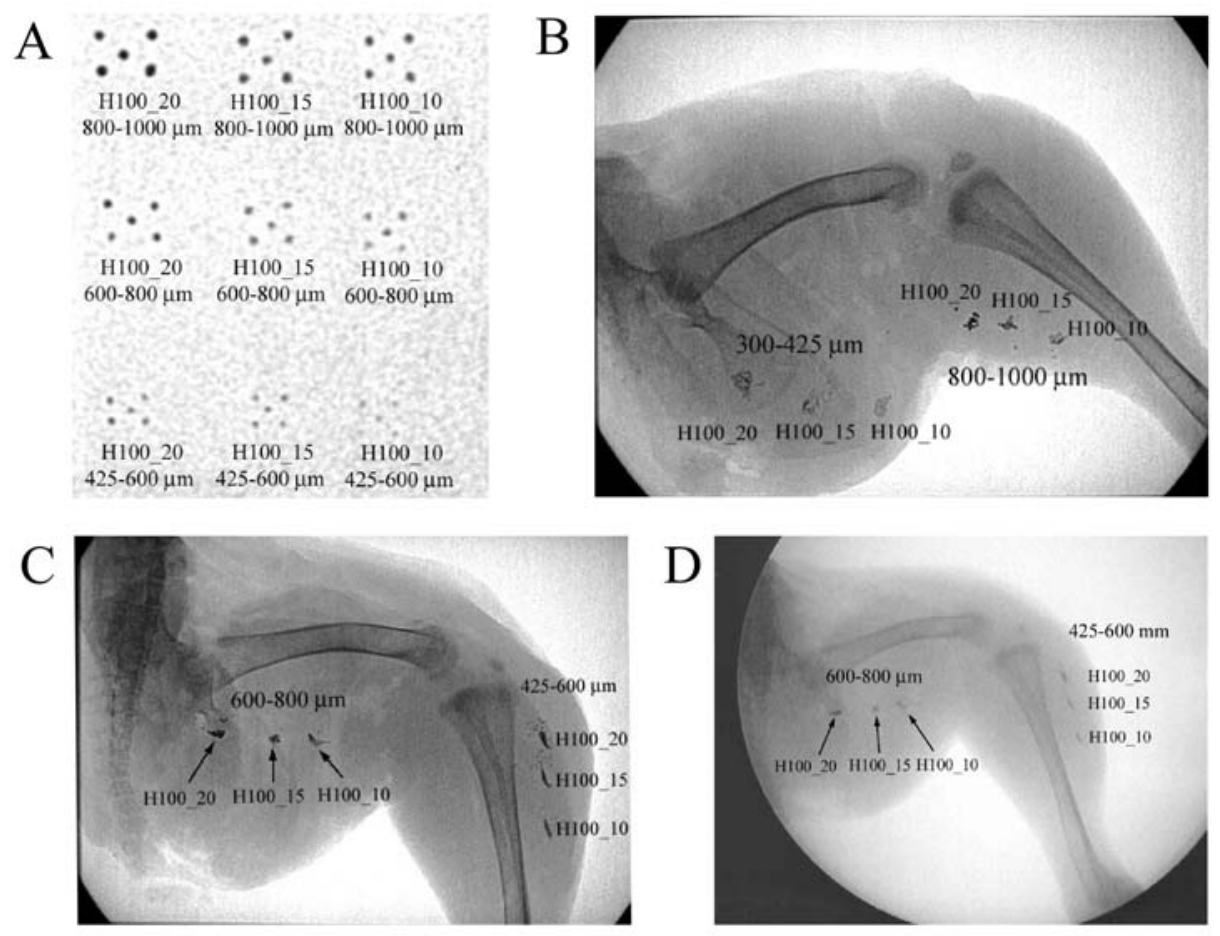

Figure 7. X-ray images of radiopaque microspheres: (a) single spheres, recorded at clinical conditions; (b),(c) $10 \mathrm{mg}$ of spheres in a chicken leg, recorded at clinical conditions; (d) $10 \mathrm{mg}$ of spheres in a chicken leg, recorded on the C-bow at $48 \mathrm{kV}$.

Figure $7 \mathrm{~d}$ demonstrates that on the X-ray images recorded with the C-bow, clusters of spheres can be distinguished, but for all sphere sizes single spheres are not visible. In other words, the resolution of the C-bow is lower than that of the Integris system. This is important to know since the in vivo experiments are evaluated with the C-bow instrument. 


\section{In vivo $\mathrm{X}$-ray contrast}

Next, spheres of H100_20 are injected in the renal artery of a Yorkshire land pig. The injection is performed in 2 steps: First spheres in the size range 425-600 $\mu \mathrm{m}$ are injected and at a certain place in the artery they get stuck and as such block the blood supply to the tissue behind.

Figure 8a shows the X-ray image (taken with the C-bow) of part of the kidney, where the spheres are assembled. The spheres can well be distinguished. Subsequently spheres with a diameter between 600 and $800 \mu \mathrm{m}$ are injected in the same artery and they get blocked just behind the introduced occlusion. Figure $8 \mathrm{~b}$ shows that the spheres line up, causing further occlusion of the artery. This preliminary experiment reveals that it is possible to induce blockage of an artery and follow this process in-situ by using intrinsically radiopaque microspheres. It is noted that these spheres can definitely be utilised in clinical conditions as well, where the resolution of the X-ray machine is even higher (vide supra).
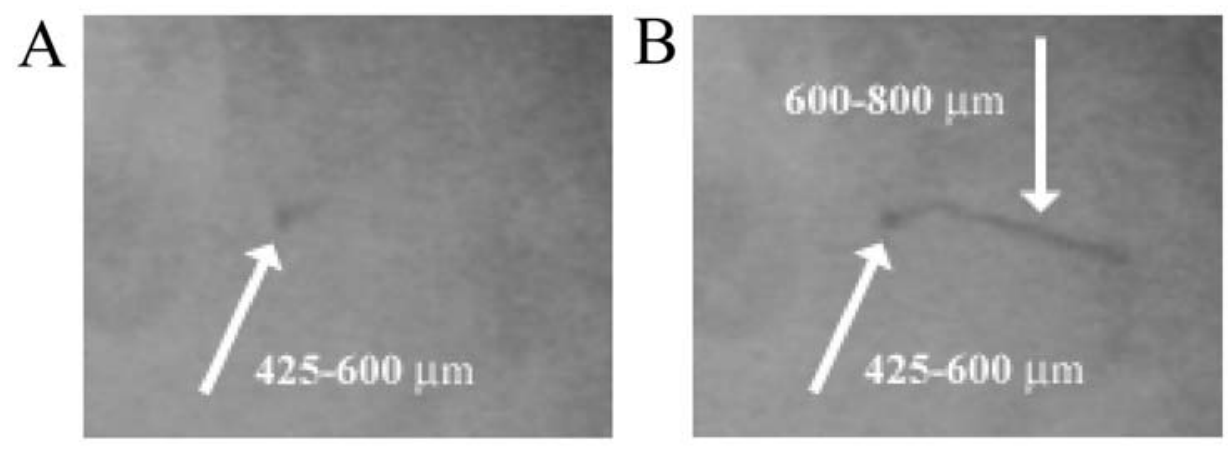

Figure 8. X-ray image of H100_20 spheres injected in a kidney of a pig, recorded on the C-bow at $48 \mathrm{kV}$ : (a) spheres of 425-600 $\mu \mathrm{m}$; (b) spheres of 600-800 $\mu \mathrm{m}$.

\section{Discussion}

A variety of microspheres have been proposed for use as embolization material, but most of the spheres are not widely used or commercially available. The ones that are commercially available all lack radiopacity and clinically only indirect routes are used to overcome this problem (vide supra). The current research clearly demonstrates that the use of intrinsically radiopaque microspheres enables visualisation of the 


\section{Chapter 7}

embolization material itself and the X-ray visibility of single spheres increases with iodine-content and sphere size. In case of clusters (of equal weight) of spheres, the iodine content is the only determining factor for X-ray visibility.

The question whether clusters of spheres or single spheres should be distinguishable is determined by the intended application. Also the size of spheres that are used is very much dependent on the type of lesion. In cases where distal embolization is desirable, e.g., the preoperative treatment of meningiomas, small spheres will be the most effective and in clinical practice mostly spheres in the range of 50-300 $\mu \mathrm{m}$ are used $[7,28,29]$. For more proximal embolization, as is e.g., the case in the treatment of uterine fibroids, larger particles $(500-900 \mu \mathrm{m})$ are mostly applied [30].

The first pilot experiments with a pig indicate that for clinically relevant X-ray visibility of individual spheres, the microspheres should at least contain $20 \mathrm{wt} \%$ iodine, though it should be remembered that the visibility is also very much dependent on the X-ray machine that is used.

\section{Conclusions}

Intrinsically radiopaque hydrophilic microspheres have been successfully prepared via suspension polymerisation. It has been shown that for clinically relevant X-ray visibility the spheres should contain at least $20 \mathrm{wt} \%$ iodine. Spheres from $425 \mu \mathrm{m}$ and larger can then be distinguished as single spheres. At this iodine content, copolymerisation with HEMA results in spheres that hardly imbibe water $(E Q=1.08)$. By replacing HEMA by NVP, the water content of the spheres can be significantly increased to 1.33.

The advantage of the new microspheres over commercially available embolization particles is that the fate of spheres can be monitored using X-ray fluoroscopy, which provides an important improvement over commercially available microspheres. It enables the interventional radiologist to determine precisely the site of injection and the amount of spheres that he/she wants to inject to obtain sufficient occlusion without the risk of migration as would be the case when too many spheres would be injected. A further advantage is that also post-operatively the position of the spheres can be determined radiographically.

During the last decades, techniques for imaging have improved significantly (in particular CT), while the materials used for embolization have hardly refined. Here we 
introduced a new, improved type of embolization material, which creates freedom for design and application: radiopacity, swelling and sphere size can all be varied.

\section{References}

1 Lookstein RA, Guller J. Embolization of complex vascular lesions. Mt. Sinai J. Med. 2004;71:1728.

2 Matsumaru Y, Hyodo A, Nose T, Hirano T, Ohashi S. Embolic materials for endovascular treatment of cerebral lesions. J. Biomater. Sci. Polym. Ed. 1997;8:555-569.

3 Qureshi AI. Endovascular treatment of cerebrovascular diseases and intracranial neoplasms. Lancet 2004;363:804-813.

4 Kunstlinger F, Brunelle F, Chaumont P, Doyon D. Vascular occlusive agents. Am. J. Roentgenol. 1981;136:151-156.

5 Phadke RV, Venkatesh SK, Kumar S, Tandon V, Pandey R, Tyagi I, Jain VK, Chhabra DK. Embolization of cranial/spinal tumours and vascular malformations with hydrogel microspheres. An experience of 69 cases. Acta Radiol. 2002;43:15-20.

6 Laurent A., Beaujeux R, Wassef M, Rufenacht D, Boschetti E, Merland JJ. Trisacryl gelatin microspheres for therapeutic embolization, I: development and in vitro evaluation. Am. J. Neuroradiol. 1996;17:533-540.

7 Bendszus M, Klein R, Burger R, Warmuth-Metz M, Hofmann E, Solymosi L. Efficacy of trisacryl gelatin microspheres versus polyvinyl alcohol particles in the preoperative embolization of meningiomas. Am. J. Neuroradiol. 2000;21:255-261.

8 Benzina A., Kruft MA, Bär F, van der Veen FH, Bastiaansen CW, Heijnen V, Reutelingsperger C, Koole LH. Studies on a new radiopaque polymeric biomaterial. Biomaterials 1994;15:1122-1128.

9 Kruft MA, Benzina A, Bär F, van der Veen FH, Bastiaansen CW, Blezer R, Lindhout T, Koole LH. Studies on two new radiopaque polymeric biomaterials. J. Biomed. Mater. Res. 1994;28:12591266.

Benzina A, Kruft MA, van der Veen FH, Bar FH, Blezer R, Lindhout T, Koole LH. A versatile three-iodine molecular building block leading to new radiopaque polymeric biomaterials. $J$. Biomed. Mater. Res. 1996;32:459-466.

11 Davy KWM, Anseau MR, Odlyha M, Foster GM. X-Ray Opaque Methacrylate Polymers for Biomedical Applications. Pol. Int. 1997;43:143-154.

12 Jayakrishnan A., Thanoo BC, Rathinam K, Mohanty M. Preparation and evaluation of radiopaque hydrogel microspheres based on PHEMA/iothalamic acid and PHEMA/iopanoic acid as particulate emboli. J. Biomed. Mater. Res. 1990;24:993-1004.

Horak D, Metalova M, Svec F, Drobnik J, Kalal J, Borovicka M, Adamyan AA, Voronkova OS, Gumargalieva KZ. Hydrogels in endovascular embolization. III. Radiopaque spherical particles, their preparation and properties. Biomaterials 1987;8:142-145.

Horak D, Metalova M, Rypacek F. New radiopaque polyHEMA-based hydrogel particles. $J$ Biomed. Mater. Res. 1997;34:183-188.

15 van Hooy-Corstjens CSJ, Aldenhoff YBJ, Knetsch MLW, Govaert LE, Arin E, Erli H, Koole LH. Radiopaque polymeric spinal cages: a prototype study. Journal of Materials Chemistry 2004; 14:3008-3013. Mechanical behaviour of a new acrylic radiopaque iodine-containing bone cement. Biomaterials 2004;25:2657-2667. 


\section{Chapter 7}

17 Lewis G, van Hooy-Corstjens CSJ, Bhattaram A, Koole LH. Influence of the radiopacifier in an acrylic bone cement on its mechanical, thermal, and physical properties: barium sulfate-containing cement versus iodine-containing cement. J. Biomed. Mater. Res. B Appl. Biomater. 2005;73:77-87.

Saralidze K, Aldenhoff YBJ, Knetsch MLW, Koole LH. Injectable polymeric microspheres with $\mathrm{X}$-ray visibility. Preparation, properties, and potential utility as new traceable bulking agents. Biomacromolecules 2003;4:793-798.

Boelen EJH, van Hooy-Corstjens CSJ, Bulstra SK, van Ooij A, van Rhijn LW, Koole LH. Intrinsically radiopaque hydrogels for nucleus pulposus replacement. Biomaterials 2005;26:66746683.

Saralidze K, van Hooy-Corstjens CS, Koole LH, Knetsch MLW. New acrylic microspheres for arterial embolization: combining radiopacity for precise localization with immobilized thrombin to trigger local blood coagulation. Biomaterials 2007;28:2457-2464.

Galperin A, Margel S. Synthesis and characterization of new micrometer-sized radiopaque polymeric particles of narrow size distribution by a single-step swelling of uniform polystyrene template microspheres for X-ray imaging applications. Biomacromolecules 2006;7:2650-2660.

Galperin A, Margel D, Margel S. Synthesis and characterization of uniform radiopaque polystyrene microspheres for X-ray imaging by a single-step swelling process. J. Biomed. Mater. Res. A 2006;79:544-551.

Kruft MA, Benzina A., Blezer R, Koole LH. Studies on radio-opaque polymeric biomaterials with potential applications to endovascular prostheses. Biomaterials 1996;17:1803-1812.

Jayakrishnan A, Thanoo BC. Suspension polymerization of 2-hydroxyethyl methacrylate in the presence of polymeric diluents: a novel route to spherical highly porous beads for biomedical applications. J. Biomed. Mater. Res. 1990;24:913-927.

Peppas NA. Hydrogels in medicine and pharmacy; CRC Press: Boca Raton, Fl, 1987.

Boelen EJH, van Hooy-Corstjens CSJ, van Rhijn LW, Koole LH. Journal of Biomedical Material Research, Part B Applied Biomaterials 2007;83:440-450.

Boelen EJH, van Hooy-Corstjens CSJ, Gijbels MJJ, Bulstra SK, van Ooij A, van Rhijn LW, Koole LH. Preliminary evaluation of new intrinsically radiopaque hydrogels for replacing the nucleus pulposus. Journal of Materials Chemistry 2006;16:824-828.

Bendszus M, Martin-Schrader I, Warmuth-Metz M, Hofmann E, Solymosi L. MR imaging- and MR spectroscopy-revealed changes in meningiomas for which embolization was performed without subsequent surgery. AJNR Am. J. Neuroradiol. 2000;21:666-669.

Bendszus M, Martin-Schrader I, Schlake HP, Solymosi L. Embolization of intracranial meningiomas without subsequent surgery. Neuroradiology 2003;45:451-455.

Siskin GP, Englander M, Stainken BF, Ahn J, Dowling K, Dolen EG. Embolic agents used for uterine fibroid embolization. AJR Am. J. Roentgenol .2000;175:767-773. 


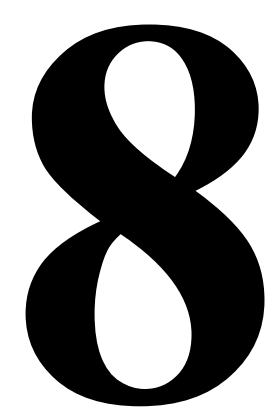

Summary

Samenvatting

Краткое обозрение

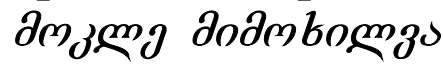




\section{Chapter 8}

\section{Summary}

A variety of minimally invasive therapies was introduced during the last 2 decades. The most prominent example may be endovascular stenting, e.g., coronary or carotid arteries. Other developments are: (i) catheter-based specific embolization of solid tumors or aterio-venous malformations, or (ii), use of synthetic bulking agents to augment soft tissues, e.g., in cosmetic surgery or as a treatment of stress urinary incontinence (SUI). In fact, marked improvements in imaging methods, notably X-ray fluoroscopy and X-ray based computed tomography, have opened the ways to these new therapies. Besides, equipment and methods for catheterizations improved dramatically. This led, for instance, to novel guidewires with excellent steerability, and improved catheters with excellent properties such as flexibility, lubricity, etc.

In 2003, at the onset of this research project, it seemed obvious that some of the new minimally invasive injection therapies were actually based on the use of archaic polymeric biomaterials. This was most certainly the case in embolotherapy which was (and in many cases still is) largely based on injection of irregular particles of poly (vinyl alcohol). Furthermore, it appeared that the biomaterial particles, used to treat SUI (such as microspheres from PTFE, silicone rubber, or carbon-coated zirconium dioxide) were far from ideal, as they showed either migration away from the site of injection, or excessive formation of granuloma.

We reasoned that it should be possible to develop improved and more sophisticated microspheres for minimally invasive therapies, notably for SUI treatment and for different embolotherapies. First, we focused on radiopacity, i.e., microspheres were prepared from biocompatible and stable polymeric biomaterials that feature intrinsic radiopacity, due to incorporation of covalently bound iodine. This approach was in line with previous work from this laboratory, in which it was shown that iodine-containing poly(methacrylates) can be used in novel radiopaque implant materials, such as bone cements or biomimetic prostheses for the nucleus pulposus. Secondly, we focused on surface modification of the radiopaque microspheres, with the aim to either achieve improved anchorage in soft tissues (relevant for SUI treatment, since migration of injected bulking agent is unacceptable), or to impart bioactivity in the surface of the microspheres through immobilization of functional proteins. The thesis describes the preparation of new injectable microspheres with three functionalities: (i) they can be injected in soft tissues without inciting an inflammatory response, which is the basis for 
soft-tissue augmentation, or they can be injected through a catheter in the arterial bloodstream leading to obstruction in a target blood vessel bed; (ii) the particles can be seen real-time on X-ray images, i.e., during injection but also afterwards; (iii) the particles can be decorated with functional proteins, such as collagen (which presumably will lead to improved anchoring of the particles in soft tissues), or thrombin, which turns on fibrin formation in blood almost immediately after injection of embolic particles.

The data presented in chapter 2 demonstrate the possibility to create biocompatible microspheres that are intrinsically radiopaque. For this 2-[2',3',5',-triiodobenzoyloxy] ethyl methacrylate (2,3,5-TIEMA) was copolymerized with methylmethacrylate (MMA) in bulk. Subsequently the copolymer was dissolved and added drop-wise to an aqueous solution containing detergent to create microspheres. These were shown to contain sufficient intrinsic radiopacity under standard clinical conditions in a chicken leg model. Also the spheres were shown to be injectable suspended in collagen and loaded in a syringe. A disadvantage of the solvent evaporation method used in this chapter may be that it is relatively inefficient for making microspheres that are larger than approx. $100 \mu \mathrm{m}$. It is however the best method to obtain spheres in the range of 10$100 \mu \mathrm{m}$.

The in vivo biocompatibility was studied by injection of the microspheres, suspended in collagen, into mice. The microspheres did not incite toxic or significant inflammatory responses. This result confirmed the data of an implant study in which rods of iodinecontaining copolymer were inserted subcutaneously into mice or rats. The microspheres however represent much more surface area and also the microspheres might migrate away from the site of injection. In chapter 3 it is shown that no obvious migration of the microspheres could be distinguished by X-ray 3 months after implantation.

To fully avoid the problem of microsphere migration, the incorporation of spheres in the surrounding tissue would be the best strategy. For this, microspheres were prepared by suspension polymerization, so that larger spheres were obtained (chapter 4). These spheres were subsequently incubated under strong alkaline conditions at high temperatures. The surface ester groups slowly converted into carboxylic groups, which were used for chemical cross-linking of proteins. In chapter 4, cross-linking of an active enzyme, in this case alkaline phosphatase, is described. Also collagen could be linked to the surface of the microspheres. The possibility of linking proteins in their native, 


\section{Chapter 8}

active, conformation to the radiopaque microspheres demonstrated the bi-functionality of these spheres combining intrinsic X-ray visibility with surface bioactivity that can be tailored. In chapter 5 methacrylic acid (MAA) was added to the copolymer feed, so that a terpolymer containing 2-[4-iodobenzoyl]-oxo-ethylmethacrylate (4IEMA), MMA, MAA was obtained. The MAA content is of critical importance for the efficiency of protein coupling to the surface of these terpolymer microspheres. With low density of carboxylic groups, the coupling efficiency will be low because of low chance of a free amino group of the protein coming in close enough proximity of an activated carboxylic group on the sphere surface. In case of very high carboxylic density the chance of multiple point attachment of a single protein molecule to the surface is more likely than binding of a second protein molecule. Proteins that are bound to the surface by multiple links are most likely unable to change their conformation and are thus rendered inactive. It is therefore vital to closely control the monomer feed prior to the suspension polymerization and invest time into the optimization of microsphere composition.

For application of radiopaque microspheres in embolization therapy, the functionalization of the surface with coagulation enzymes might lead to a more rapid and complete blockage of the artery (chapter 5). For this purpose thrombin, the central enzyme of the coagulation cascade, was linked to the microspheres. These thrombinspheres rapidly induced the formation of a fibrin clot and also accelerated additional generation of thrombin in the surrounding blood. Microspheres carrying active enzymes may have a range of possible applications in minimally invasive treatments. Also they may help in setting up models for occlusive diseases like stroke. In the near future microspheres carrying thrombin will be tested for their ability to induce stroke in a rat model, especially to induce strokes reliably and of a constant size and severity. Also for haemoptysis, i.e., severe bleedings after trauma or infection, these microspheres that induce rapid blood clotting may be of use to manage the bleeding and reduce blood loss. In chapter 6 microspheres are described that eliminate the need for cross-linking chemicals. The chemicals that are required for protein cross-linking (EDC and NHS) can be toxic since they may still be active upon activation. Although this risk is very small with the microspheres presented here, terpolymer microspheres were produced that contain surface aldehyde groups that react with free amino-groups (lysine residues) under mild alkaline conditions. The data clearly demonstrate that this strategy can work, however the linking of active enzymes was not successful yet. Cross-linking collagen I 
to the surface greatly improved the interaction of cells with the surface of the spheres. These collagen coated microspheres are therefore well suited as bulking agent and filler, because the chance of migration is much reduced, since cells of the surrounding tissue will grow onto the spheres and cover these with extra-cellular matrix. The collagen linked to the microspheres will get entangled with collagen from the extra-cellular matrix, preventing migration of the spheres.

The microspheres described in the chapters 2-6 are all hard and stiff. In chapter 7 the synthesis of hydrogel microspheres is described. These spheres are designed to take up water so that the spheres are compressible. This makes the microspheres especially well suited for injection into the blood stream via a catheter. Also swelling of the microspheres in situ will diminish the chance of the spheres dislodging. One could state that these microspheres first get stuck in the artery, block blood flow, swell and anchor themselves tightly into the vessel wall. The prospect of such hydrogel spheres with proteins attached to their surface is exciting. For instance collagen coated microspheres may result in rapid coagulation. Especially platelets can get activated on the surface of such spheres, inducing the normal formation of a blood clot, further stabilizing the block of the artery.

This thesis research work shows that substantial technical improvements in injectable polymeric microspheres were realized. Further experimentation in large representative animal models is mandatory to precisely investigate the potential utility of such particles. It seems that the feature of intrinsic radiopacity is a valuable asset, in view of the existing X-ray based methods for (real-time) in vivo imaging. Moreover, it is now obvious that particles for use in different injection therapies can be decorated with active proteins. This enables us to translate basic knowledge in physiological mechanisms, such as blood coagulation, into improved therapeutical tools, which is the objective of what is currently known as translational medicine. 



\section{Samenvatting}

Gedurende de afgelopen decennia zijn er verschillende nieuwe minimaal-invasieve operatie- en behandelmethoden ontwikkeld. Het meest in het oog springende voorbeeld is wel het plaatsen van endovasculaire stents in de kransslagader, via een kleine ingang in de bovenbeenslagader. Andere ontwikkelingen op dit gebied zijn: (i) specifieke embolisatie van tumoren of aterio-veneuze malformaties met behulp van catheterisatie technieken, of (ii) het verstevigen van zachte weefsels door injectie van opvulmiddelen in de cosmetische chirurgie (opspuiten van rimpels of acne littekens) of ter behandeling van stress incontinentie. De grote verbeteringen in imaging technieken zoals Röntgen diagnostiek en computertomografie (CT scan) hebben de opkomst van deze nieuwe, minimaal-invasieve methoden mogelijk gemaakt. Daarnaast heeft de sterke verbetering van instrumenten bijgedragen om catheterisatie technieken te optimaliseren. Dit heeft onder meer geleid tot betere voerdraden, en tot verbeterde catheters met uitstekende eigenschappen betreffende flexibiliteit, gladheid, enz.

Toen in 2003 begonnen werd met dit onderzoeks-project, was het duidelijk dat sommige van de nieuwe minimaal-invasieve methoden nog steeds gebruik maken van archaische polymere biomaterialen. Dit was het meest duidelijk voor embolisatie-therapie waarbij destijds (en vaak nog steeds) onregelmatig gevormde poly(vinyl alcohol)-deeltjes werden geinjecteerd in patiënten. Bovendien bleek dat de deeltjes die gebruikt werden als opvulmiddel om bijvoorbeeld stress incontinentie te behandelen (zoals microbolletjes van Teflon (poly(tetrafluoretheen); PTFE), siliconen rubber, of met koolstof bedekte zirconium-dioxide bolletjes) verre van ideaal zijn, omdat ze na injectie kunnen migreren of granulomas induceren.

Onze hypothese was dat het mogelijk moest zijn om betere en meer geavanceerde microbolletjes te ontwikkelen voor minimaal-invasieve methoden, zoals de behandeling van stress-incontinentie en verschillende vormen van embolotherapie. Allereerst richtten we ons op Röntgenzichtbaarheid. Dit betekent dat bolletjes werden gemaakt van polymeren die stabiel en biocompatibel zijn en tegelijk intrinsieke Röntgenzichtbaarheid bezitten, doordat er covalent gebonden jodium in het polymeer werd ingebouwd. Deze aanpak sloot naadloos aan bij eerder werk van onze onderzoeksgroep. Hierin was reeds aangetoond dat jodium-houdende polymethacrylaten gebruikt kunnen worden als nieuwe Röntgenzichtbare implanteerbare materialen zoals botcement. Een ander voorbeeld betreft materialen die dienen ter vervanging van de 


\section{Chapter 8}

nucleus pulposus, de zachte kern van de tussenwervelschijf. Vervolgens richtten we ons op de modificatie van het oppervlak van deze Röntgenzichtbare microbolletjes, met als doel: (1) betere verankering in zacht weefsel te verkrijgen, dit is van belang wanneer de bolletjes als opvulmiddel bij de behandeling van stress incontinentie worden gebruikt aangezien migratie van de bolletjes onacceptabel is, of (2) specifieke bio-activiteit op het oppervlak te verkrijgen door middel van het koppelen van actieve eiwitten. In dit proefschrift is de ontwikkeling beschreven van nieuwe, injecteerbare microbolletjes met drie verschillende eigenschappen: (i) ze kunnen geinjecteerd worden in zacht weefsel en worden daarin goed geaccepteerd. Dit is een vereiste om succesvolle versteviging van het zachte weefsel te verkrijgen. Ook kunnen de bolletjes gericht door een catheter ingebracht worden in de arteriële bloedstroom om vervolgens een slagader te blokkeren; (ii) ze zijn zichtbaar op Röntgen beelden, zowel tijdens het injecteren als naderhand; (iii) hun oppervlak kan worden geactiveerd door het koppelen van actieve en functionele eiwitten, zoals collageen (wat zou kunnen leiden tot een betere verankering van de bolletjes in zachte weefsels), of trombine, wat zorgt voor vorming van bloedstolsels bijna direct na injectie in de bloedbaan.

De resultaten beschreven in hoofdstuk 2 laten zien dat het mogelijk is om biocompatibele microbolletjes te maken die intrinsiek Röntgenzichtbaar zijn. Hiervoor lieten wij het zelf gesynthetiseerde 2-[2',3',5'-triiodobenzoyl]oxoethyl methacrylaat (2,3,5-TIEMA) reageren met methylmethacrylaat (MMA) in een bulk polymerisatie reactie. Het resulterende polymeer werd opgelost in chloroform en druppelsgewijs toegevoegd aan een oplossing van een detergent (zeep) in water om bolletjes te vormen. Men zou als nadeel van deze "solvent-evaporation" (oplosmiddel-verdampings) techniek kunnen aanmerken dat het relatief inefficient is om met deze methode microbolletjes te maken groter dan $100 \mu \mathrm{m}$. Het is naar onze ervaring de beste techniek om microbolletjes te verkrijgen tussen 10 en $100 \mu \mathrm{m}$. De hier verkregen microbolletjes bleken voldoende intrinsieke Röntgenzichtbaarheid te bezitten. Dit kon worden geïllustreerd met behulp van een realistisch model. Bovendien was het mogelijk om de bolletjes met een collageen suspensie te mengen zodat injectie met een normale injectiespuit werd vergemakkelijkt.

De in vivo biocompatibiliteit van microbolletjes, gesuspendeerd in collageen, werd bestudeerd door deze te injecteren in muizen. De bolletjes bleken geen significante onstekingsreactie te induceren. Dit resultaat bevestigde eerdere bevindingen betreffende 
implantatie van jodium-houdende polymere biomaterialen in muizen en ratten. De microbolletjes representeren echter een veel groter oppervlak en tevens kunnen ze (potentieel) weg migreren van de plaats van injectie. In hoofdstuk 3 laten we zien dat er geen tekenen van migratie van de microbolletjes konden worden waargenomen, noch via een Röntgen onderzoek, noch via histologie.

Om het probleem van mogelijke migratie van microbolletjes te ondervangen, is de beste strategie om deze aan het omringende weefsel te binden. Hiertoe werden bolletjes gemaakt met zogenaamde suspensie-polymerisatie, zodat grotere bolletjes werden verkregen (hoofdstuk 4). Deze bolletjes werden vervolgens behandeld met base (KOH) bij hoge temperatuur $\left(180{ }^{\circ} \mathrm{C}\right)$. Onder deze omstandigheden verzepen de ester groepen op het oppervlak tot $\mathrm{COOH}$-groepen, welke voor het covalent koppelen van eiwitten kunnen worden gebruikt. In hoofdstuk 4 staat beschreven hoe een actief enzym, in dit geval het alkalische fosfatase, werd gekoppeld aan de microbolletjes. Ook werd het eiwit collageen covalent aan het oppervlak van de bolletjes gekoppeld. De mogelijkheid om actieve eiwitten in hun natieve en ook actieve conformatie aan het oppervlak van deze Röntgenzichtbare bolletjes te koppelen toont de bi-functionaliteit aan, namelijk een combinatie van Röntgenzichtbaarheid en bioactief oppervlak dat naar wens kan worden aangepast. In hoofdstuk 5 werd methacrylzuur (MAA) aan de polymerisatie-reactie toegevoegd, zodat een terpolymeer van 2-[4-iodobenzoyl]-oxo-ethylmethacrylaat (4IEMA), MMA, en MAA werd verkregen. Het gehalte aan MAA bleek van cruciaal belang voor de efficientie van eiwit koppeling aan het oppervlak van deze polymere bolletjes. In het geval van een lage dichtheid carboxyl groepen op het oppervlak (laag MAA gehalte in de polymerisatie reactie), bleek de eiwitkoppeling niet erg efficiënt vanwege de kleine kans dat een vrije aminogroep van het eiwit een geactiveerde carboxyl groep op het oppervlak dicht genoeg zal benaderen. In het geval van een (te) hoge dichtheid van carboxyl groepen op het oppervlak zal de kans op meer-punts koppeling van het eiwit toenemen. Wanneer een eiwit eenmaal aan het oppervlak is gekoppeld, wordt de vorming van een tweede koppeling veel waarschijnlijker. Eiwitten die op meerdere punten aan het oppervlak vast zitten, zullen zeer waarschijnlijk geen mogelijkheid hebben hun conformatie te veranderen en zijn dientengevolge inactief. Het is dus belangrijk om de relatieve hoeveelheden van de monomeren (speciaal die van MAA) in de polymerisatie nauwkeurig te bepalen. 


\section{Chapter 8}

De koppeling van thrombine op het oppervlak van Röntgenzichtbare microbolletjes kan gunstig zijn m.b.t. embolisatie-therapie. Om dit te bestuderen werd trombine, het centrale enzym in de bloedstolling, aan de bolletjes gekoppeld (Hoofdstuk 5). Deze trombine-bolletjes induceerden een snelle aanmaak van fibrine op het oppervlak en versnelden ook de aanmaak van trombine in het omringende bloed. Microbolletjes met actieve enzymen op hun oppervlak zouden een reeks van mogelijke toepassingen in minimaal-invasieve behandelingen kunnen krijgen. Ook kunnen dit type bolletjes nuttig zijn bij het ontwikkelen van goede modellen voor trombotische aandoeningen. In de nabije toekomst zullen de trombine-bolletjes worden getest om te kijken of ze een gecontroleerde beroerte in ratten kunnen induceren. Ook voor hevige bloedingen, bijvoorbeeld na trauma of bij bepaalde longinfecties (tuberculose), kunnen dit soort microbolletjes, zeer nuttig zijn om de bloeding snel en lokaal te stelpen.

In hoofdstuk 6 zijn microbolletjes gemaakt met aldehyde groepen op het oppervlak. Deze aldehyde groepen kunnen reageren met vrije amino-groepen (bijv. van lysine residuen van een eiwit) onder milde basische condities. De resultaten laten duidelijk zien dat deze strategie succesvol kan zijn, hoewel het koppelen van actieve enzymen nog niet gelukt is. Het koppelen van collageen type I aan deze bolletjes bevorderde adhesie en groei van cellen. Deze collageen-bolletjes lijken zeer geschikt als opvulbiomateriaal omdat de kans op migratie sterk verminderd wordt. Dit komt omdat de cellen van het omliggende weefsel over de bolletjes heen groeien en ze zo met extracellulaire matrix eiwitten zullen bedekken. Het collageen van de bolletjes zal zich verstrengelen met het collageen van de extracellulaire matrix van het weefsel, en zo migratie van bolletjes voorkomen.

De microbolletjes die worden beschreven in de hoofdstukken 2-6 hebben gemeen dat ze hard en hydrofoob zijn. In hoofdstuk 7 is de synthese van volledig nieuwe radiopaque hydrogel microbolletjes beschreven. Deze bolletjes zijn speciaal ontwikkeld om in situ water op te nemen zodat ze zwellen en samendrukbaar, worden. Dit maakt ze dan uitermate geschikt voor injectie in de arteriële bloedbaan via een catheter. Bovendien zal opzwelling van de microbolletjes in situ er toe leiden dat ze beter vast komen te zitten in het bloedvat. Hydrogel bolletjes die tevens actieve eiwitten exponeren op het oppervlak zullen een hele nieuwe klasse van uitermate interressante microbolletjes gaan vormen. Microbolletjes met een oppervlak van collageen zouden bijvoorbeeld ook kunnen leiden tot versnelde stolling via activatie van bloedplaatjes. 
Het werk beschreven in dit proefschrift laat zien dat aanmerkelijke verbeteringen aan injecteerbare polymere microbolletjes gemaakt konden worden. Verdere experimenten in representatieve proefdier modellen zijn nodig om te onderzoeken wat de precieze toepasbaarheid van deze Röntgenzichtbare microbolletjes is. Het lijkt erop dat Röntgenzichtbaarheid een belangrijke toevoeging is. Bovendien is nu duidelijk dat aan de bolletjes (actieve) eiwitten gekoppeld kunnen worden, afhankelijk van de specifieke toepassing. Dit maakt het mogelijk om de kennis van fysiologische mechanismen, zoals bloedstolling, te vertalen naar betere en meer bruikbare therapeutische oplossingen. Dit is de primaire doelstelling van wat tegenwoordig bekend staat als translationele geneeskunde. 



\section{Краткое обозрение}

Широкий спектр минимально-инвазийных методов лечения нашел свое применение в практической медицине в последние годы. Наиболее ярким примером служит эндоваскулярное стентирование, например коронарных или сонных артерий. Другими разработками в этой области являются: (a) специфическая эмболизация опухолей или артериовенозных мальформаций; или (б) использование синтетических веществ для заполнения мягких тканей, например, в косметической хирургии или в урологии, для лечения стрессового недержания мочи (CHM). В значительной мере совершенствование методов визуализации, в особенности рентгенологической флюороскопии и рентгеновской компьютерной томографии (КТ), способствовало развитию указанных новых методов лечения. Кроме того, произошло значительное улучшение оснащения и методов катетеризации, что в свою очередь привело к появлению лучше управляемых новых катетеров, а так же к улучшению таких качеств, как эластичность, скольжение и т.д.

В 2003 году, когда наш проект только начинался, часть новых минимальноинвазийных инъекционных методик была фактически основана на использовании архаичных полимерных биоматериалов. Этот подход находил наиболее широкое применение в случае эмболотерапии, которая в значительной степени была (и зачастую есть) основана на инъекции ассиметричных частиц поливинилалкоголя. Кроме того, частицы биоматериала, которые использовались при лечении СНМ (такие, как микросферы из Тефлона (политетрафторэтиле́н, ПТФЭ), силикона или покрытые углеродом частицы диоксида циркония) были далеки от совершенства, т.к. наблюдалась либо их миграция с места инъекции, либо формирование гранулемы.

Мы предположили возможность создания более совершенных микросфер для минимально-инвазийных методов лечения, в особенности для различных эмболотерапий или лечения СНМ. В первую очередь мы сконцентрировались на улучшении рентгеноконтрастности микросфер. Так, микросферы были изготовлены из биосопоставимых и устойчивых полимерных биоматериалов, которые обладают внутренней рентгеноконтрастностью, благодаря наличию ковалентно-связанного йода. Этот подход был основан на предшествующих разработках нашей лаборатории, которые показали что йод-содержащие 


\section{Chapter 8}

поли(метакрилаты) могут быть использованы в новом рентгеноконтрастном имплантантном материале, таком как костный цемент или биомиметические протезы. Далее мы модифицировали поверхность рентгеноконтрастных микросфер с целью достижения улучшенной фиксации в мягких тканях (т.к. например, при лечении СНМ недопустима миграция инъецированного заполняющего вещества с места инъекции); или, достижения биоактивности микросфер путем фиксации функциональных протеинов на их поверхности.

В данной дисертации описано изготовление новых микросфер с тремя функциями: 1) они могут быть инъецированы в мягкие ткани с целью их (тканей) укрепления не вызывая воспаления; или они могут быть введены с помощью катетера, в просвет кровеносного сосуда для его облитерации; 2) частицы можно идентифицировать рентгеновским лучом во время инъекции и в дальнейшем; 3) поверхность частиц может содержать функциональные белки, такие как коллаген (который предположительно повлечет за собой улучшение фиксирования частиц в мягкой ткани), или тромбин, который мгновенно индуцирует образование тромба в просвете сосуда, подвергнутого эмболизации.

Представленные во 2 главе данные, показывают возможность создания биосовместимых рентгеноконтрастных микросфер. Для этого была произведена полимеризация 2-[2',3',5',- трийодобензоилокси]этил метакрилата (2,3,5-ТЙЭМА) с метилметакрилатом (ММА) в массе. Микросферы были образованы путем капельного добавления предварительно растворенного сополимера к раствору детергента в воде. Рентгеноконтрастность микросфер в стандартных клинических условиях была показана экспериментально в реальной модели. Микросферы также могли быть инъецированы после смешения с коллагеном и перенесения в специальный шприц. Недостатком этого метода (метода выпаривания растворителя), может быть то, что он сравнительно неэффективен для создания микросфер, размер которых более $100 \mu$ м. Однако, этот метод является лучшим для получения сфер размером 10-100 $\mu$ м.

Биосовместимость микросфер in vivo была изучена после инъекции суспензированных в коллагене микросфер мышам. Микросферы не вызвали токсических или других значительных инфекционных реакций. Эти данные подтвердили результаты исследований, в которых йод-содержащие полимерные стержни были имплантированы подкожно крысам или мышам. Микросферы, 
однако, имеют большую площадь поверхности и могут перемещаться с места инъекции. В главе 3 показано отсутствие миграции микросфер на рентгеновских снимках, сделанных 3 месяца после имплантации.

Лучшим решением проблемы миграции микросфер будет их интегрирование в окружающие мягкие ткани. Для достижения этой цели, микросферы большего размера были изготовлены суспензионным методом полимеризации (глава 4) и далее обработаны в сильной щелочной среде при высокой температуре. Находящиеся на поверхности эфирные группы были медленно преобразованны в карбоксильные, которые, в свою очередь, образовали химическую связь с белками. В 4-ой главе описано связывание активного энзима с микросферами. Коллаген так же может соединяться с поверхностью микросфер. Возможность связывания протеинов в их природной активной форме с микросферами указывает на биофункциональность этих сфер в частности, на комбинацию рентгенноконтрастности и наличия активной поверхности.

В 5-ой главе метакриловая кислота (МАК) была добавлена к сополимеру, что привело к образованию терполимера содержащего 2-[4-йодобензоил]-оксоэтилметакрилат (4ЙЭМА), ММА, МАК. Наличие МАК играет важную роль в успешном связывании протеина с поверхностью сфер. При низкой плотности карбоксильных групп, эффективность связывания с протеином низкая, т.к. вероятность того, что свободная аминогруппа протеина приблизится достаточно близко к карбоксильной группе на поверхности сферы, очень мала. В случае слишком высокой плотности карбоксильных групп, многоразовое связывание одной молекулы протеина на поверхности более ожидаемо, чем связывание нескольких молекул протеина. Формирование множественных связей протеина с поверхностью микросферы приводит к фиксации структуры протеина и потере его активности. Потому определение точного состава полимера важно для получения оптимальных микросфер.

Возможность связывания энзимов, инициирующих свёртывание крови, с поверхностью рентгенноконтрастных микросфер, может стать преимуществом в эмболотерапии, т.к. возможна более быстрая и полная блокада артерии (глава 5). Для этого тромбин, являющийся центральный энзим свёртывающей системы, был связан с поверхностью микросфер. Полученные тромбо-сферы ускоряют генерацию тромбина, а так же образование сгустка фибрина в крови. Микросферы 


\section{Chapter 8}

- носители активных энзимов могут иметь широкое применение в минимальноинвазийных методиках. Так же они могут быть полезны для воссоздания экспериментальных моделей заболеваний, развивающихся в результате закупорки сосудов, например инсульта. В ближайшем будущем тромбин - содержащие микросферы будут проверены на способность вызывать контролируемый инсульт у крыс. Другим применением этих микросфер может стать их использование при гемоптизисе, или кровотечениях во время травмы или инфекций, для скорейшей остановки кровотечения и предотвращения значительной кровопотери.

В главе 6 описаны микросферы, не нуждающиеся в специфичных химикалиях для связывания с протеинами. Для этого были созданы микросферы с альдегидными группами на поверхности, которые могут реагировать со свободными аминогруппами протеина в слабой щелочной среде. Полученные результаты демонстрируют успешность выбранной стратегии, хотя осуществить связь с активными энзимами пока не удалось. Связанный с поверхностью микросфер коллаген I улучшил взаимосвязь клеток с поверхностью сфер. Такие покрытые коллагеном микросферы могут быть успешно использованы как заполнители, т.к. шанс их миграции мал, ввиду того что, клетки окружающей ткани будут расти на поверхности сфер, и покроют их внеклеточным матриксом. Связанный с поверхностью микросфер коллаген переплетется с коллагеном внеклеточного матрикса и предотвратит миграцию микросфер.

Описанные в главах 2-6 микросферы твердые и неэластичные. В 7-ой главе описан синтез так называемых гидрогелевых микросфер. Эти сферы, впитывая воду in situ, приобретают эластичность и сжимаемость. Эти свойства делают микросферы подходящими для инъекции через катетер в артериальное русло. Разбухание микросфер in situ также уменьшит шанс смещения сфер. Микросферы, попадая в артерию, блокируют поток крови, разбухают и фиксируют друг друга в просвете кровеносного сосуда. Перспектива, создания таких гидрогелевых микросфер с привязанными к их поверхности протеинами, захватывающа. Так, покрытые коллагеном микросферы могут вызвать активацию тромбоцитов, что вызовет формирование тромба, и дальнейшее блокирование артерии.

В тезисах этой исследовательской работы показано достижение существенного технического улучшения полимерных микросфер. Дальнейшие более масштабные 
эксперименты на животных точно исследуют потенциал использования таких частиц. Предположительно, внутренняя рентгеноконтрастность является ценным свойством этих микросфер, с учетом существующих рентгеноскопических методов изображения. Более того, очевидно, что частицы, используемые при различных инъекционных терапиях, могут связываться с активными протеинами. Это дает возможность, используя знания физиологических механизмов, таких как свертывание крови, улучшить доступные терапевтические инструменты, что является целью, так называемой, транслативной медицины. 



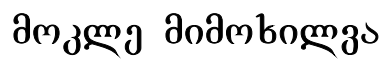

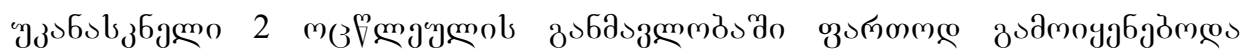

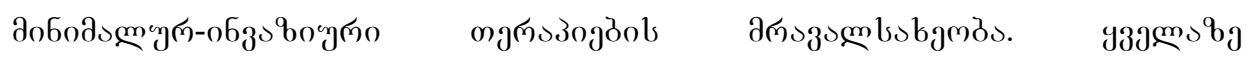

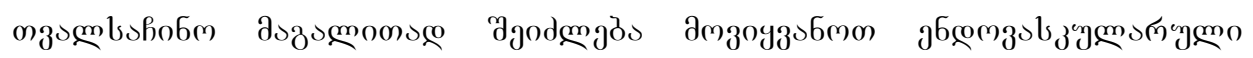

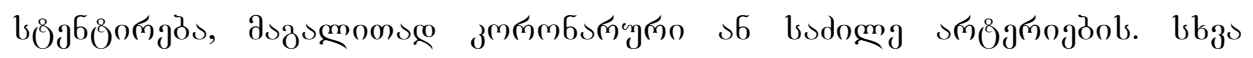

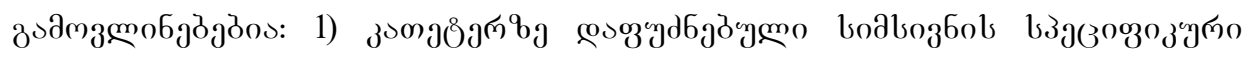

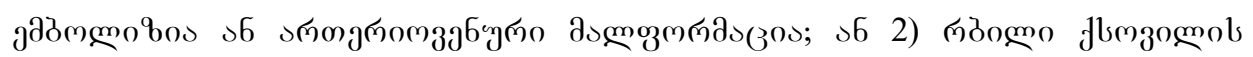

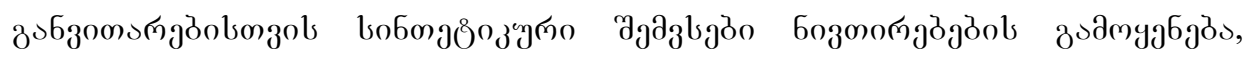

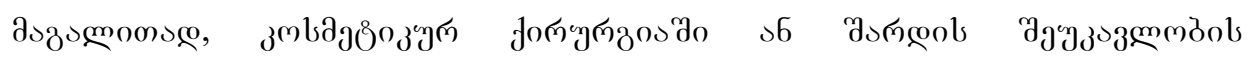

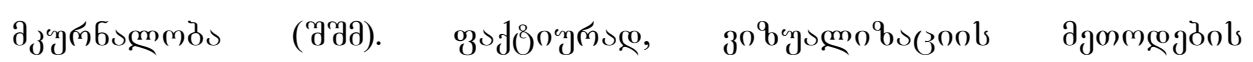

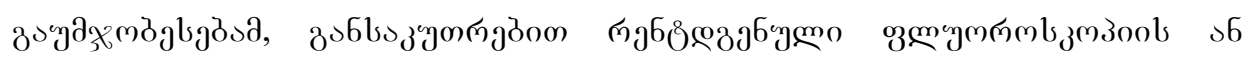

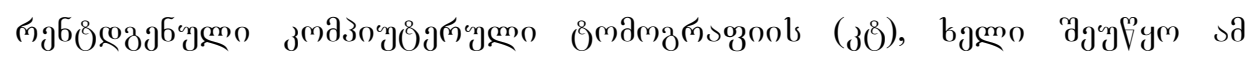

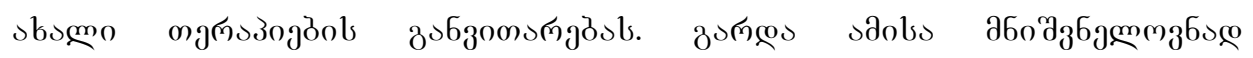

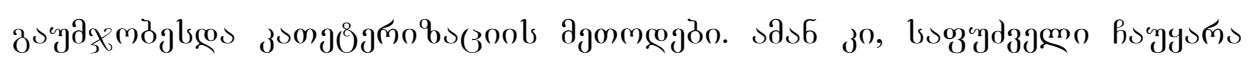

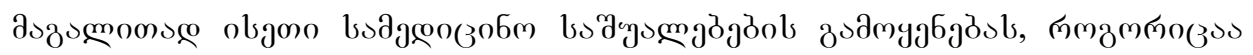

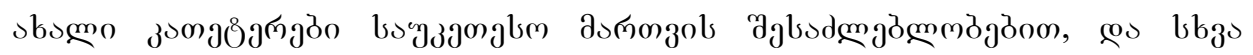

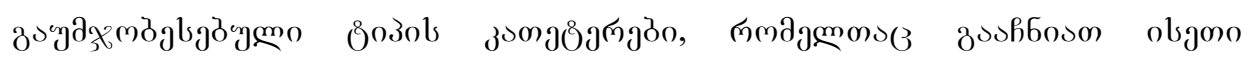

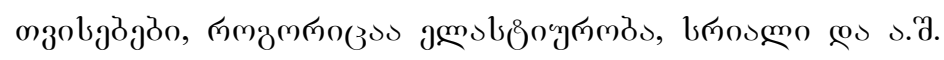

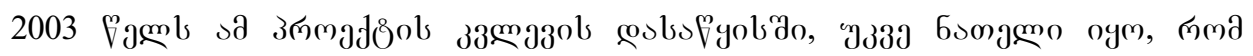

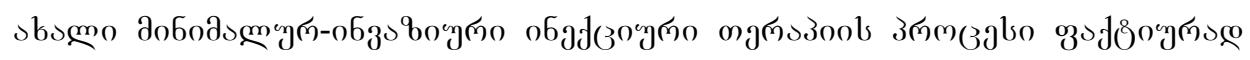

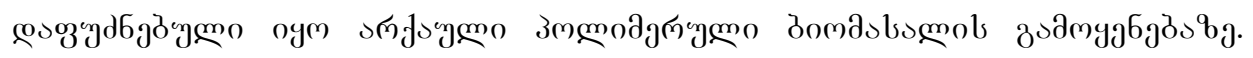

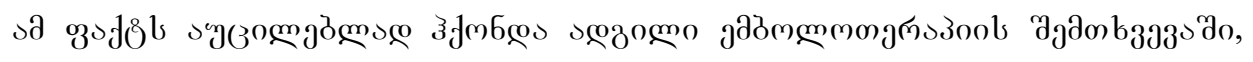

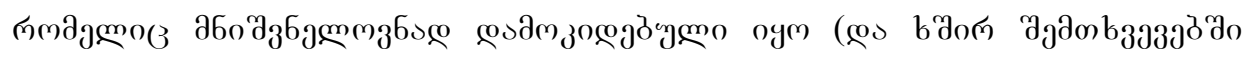

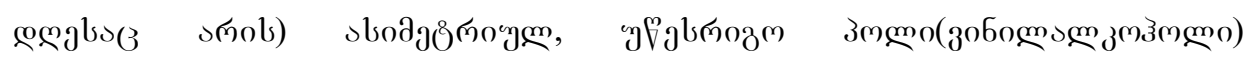

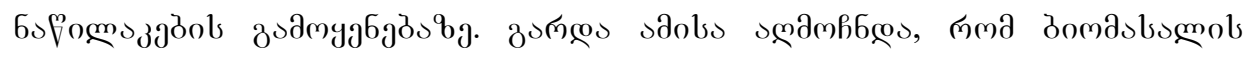

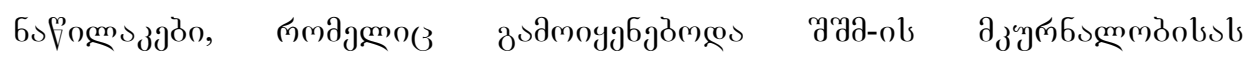

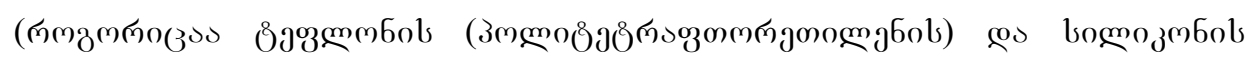

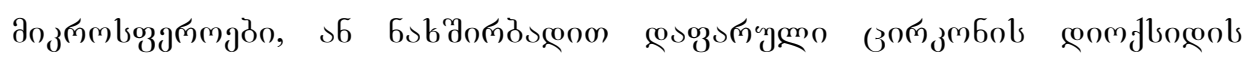

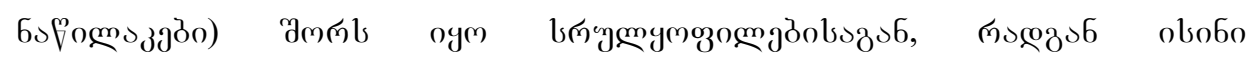

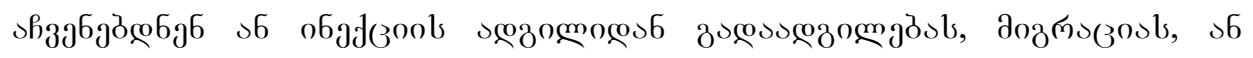

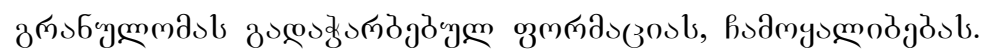

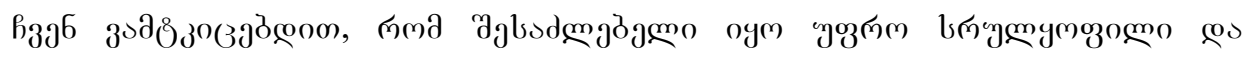

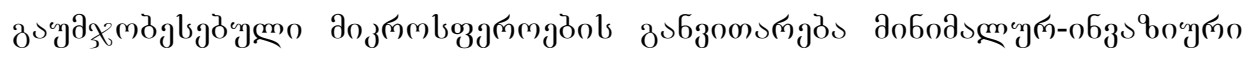




\section{Chapter 8}

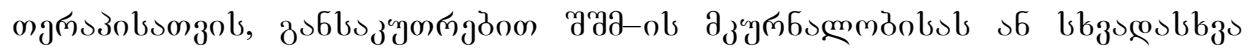

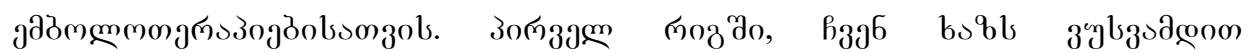
пуб

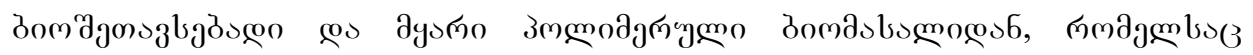

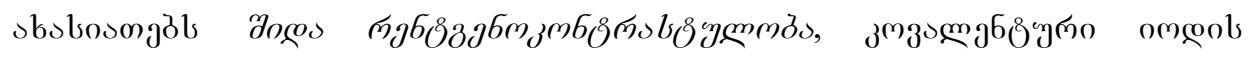

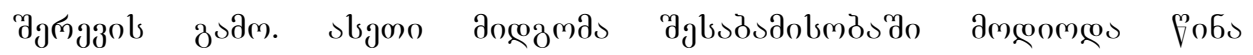

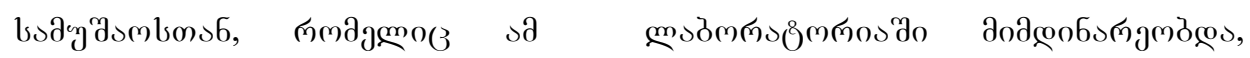

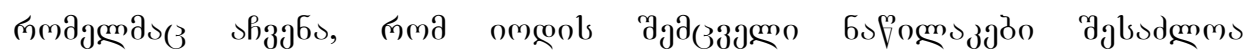

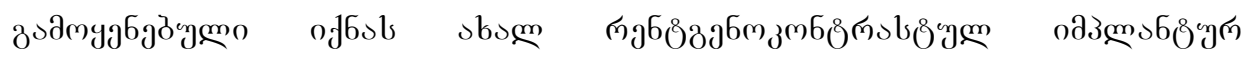

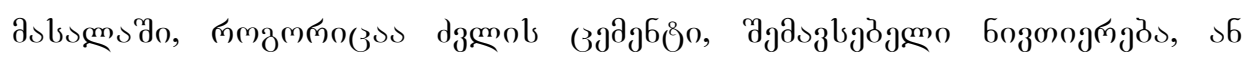

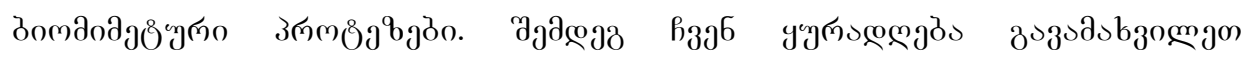

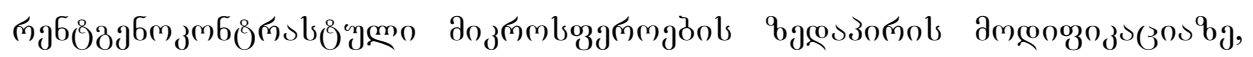

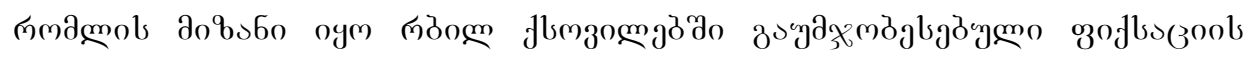

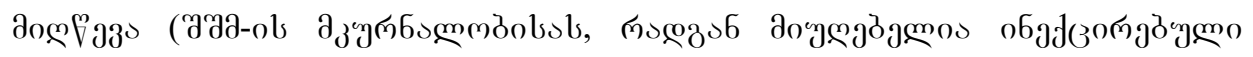

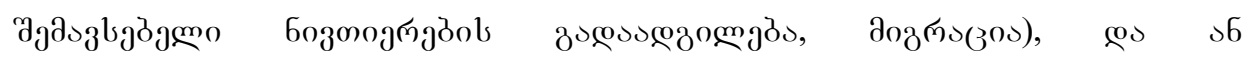

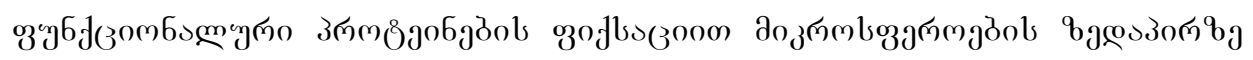

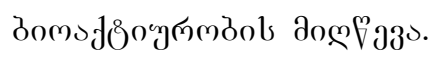

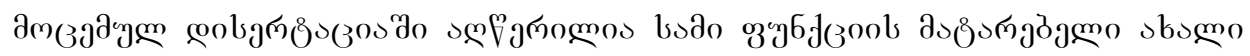

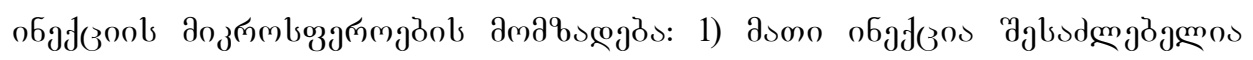

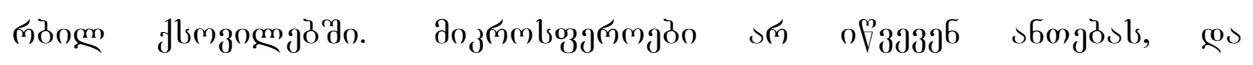

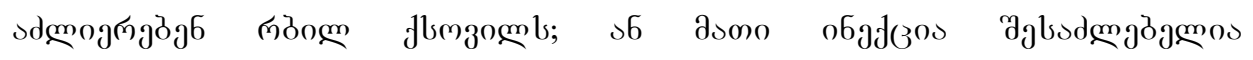

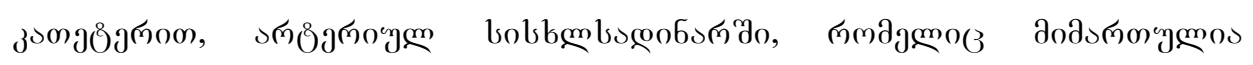

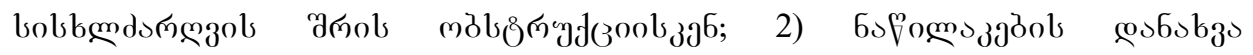

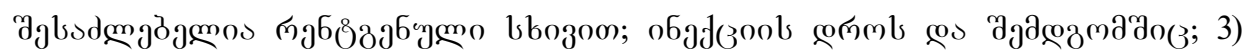

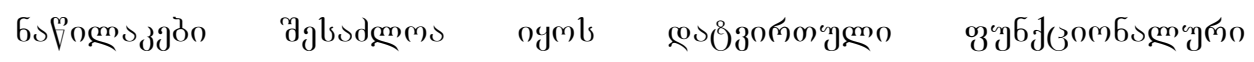

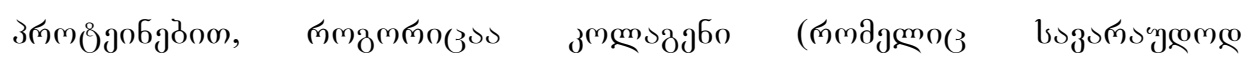

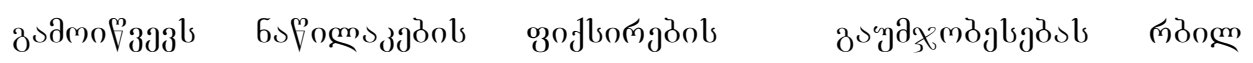

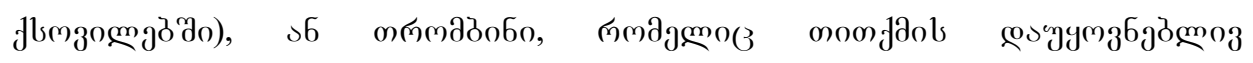

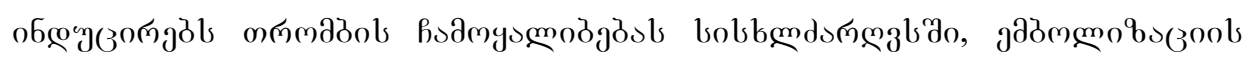
conml.

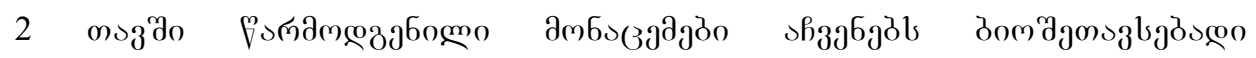

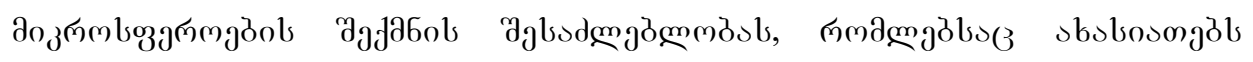
доко плб 


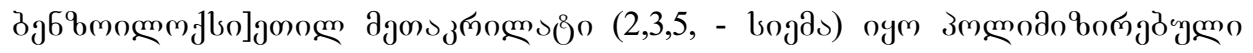

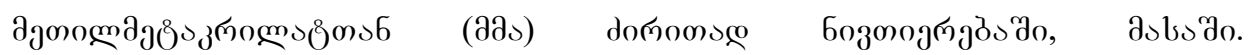

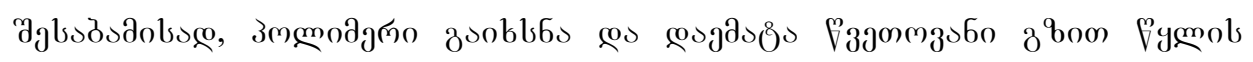

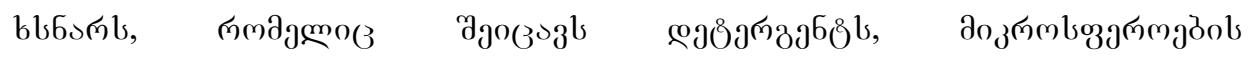

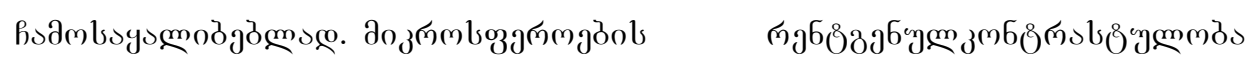

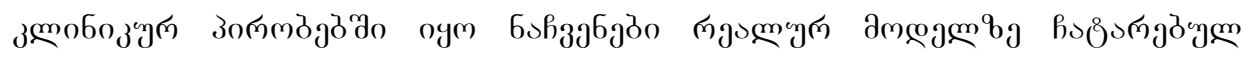

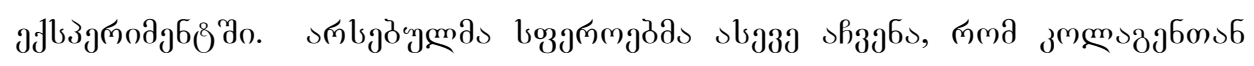

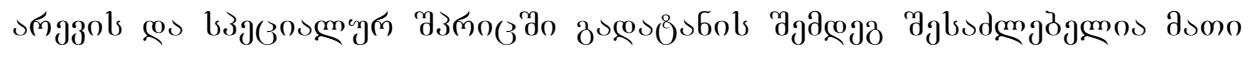

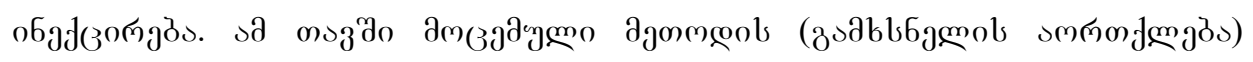

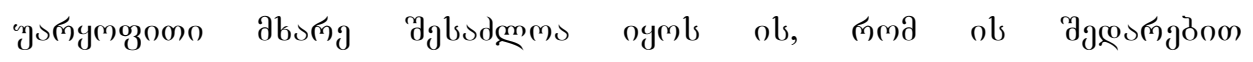

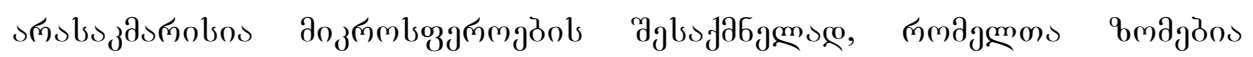

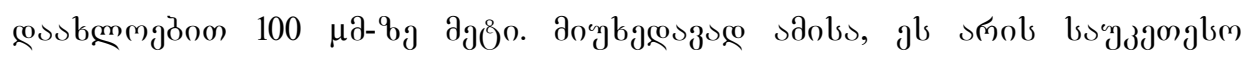

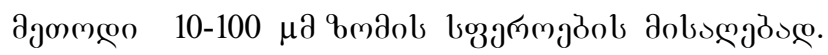

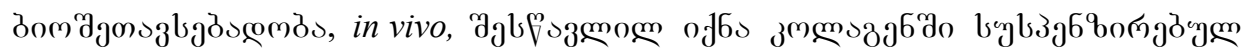

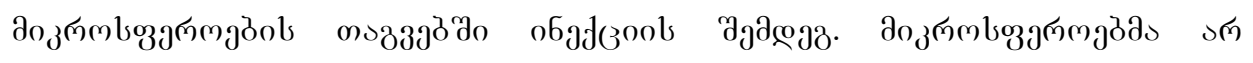

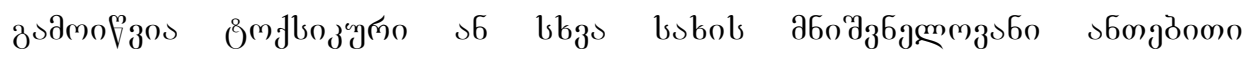

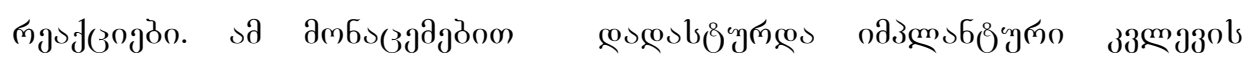

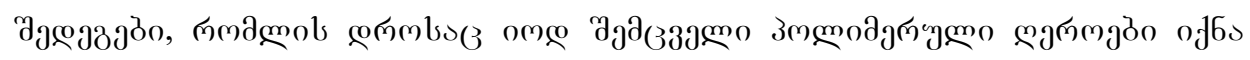

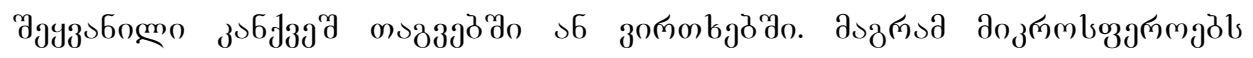

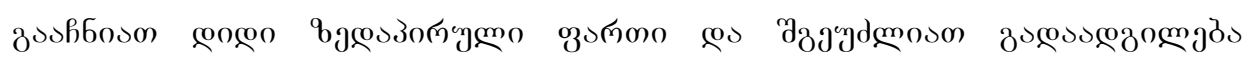

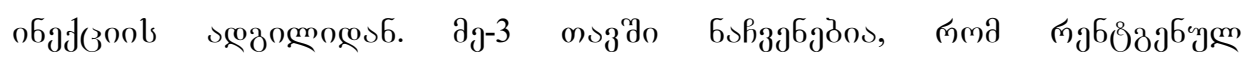

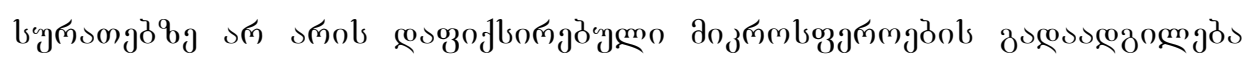

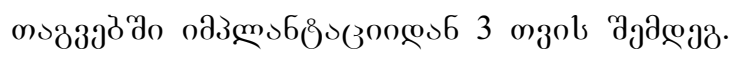

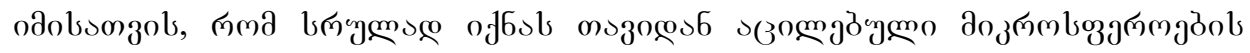

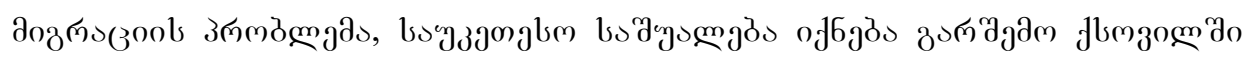

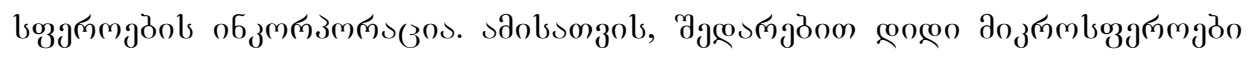

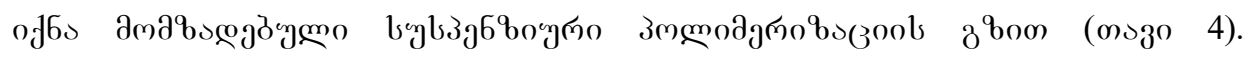

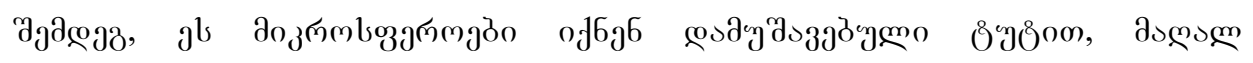

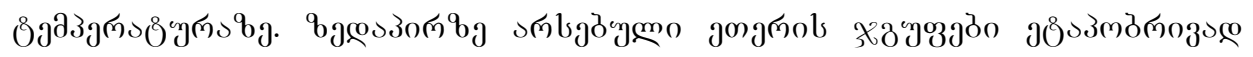

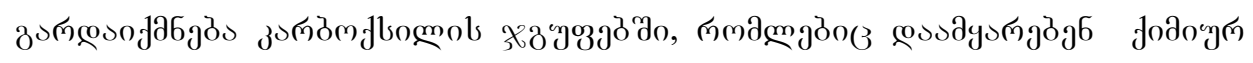

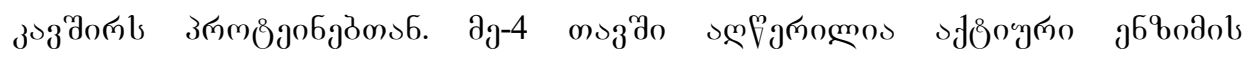

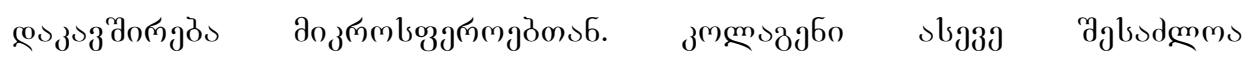

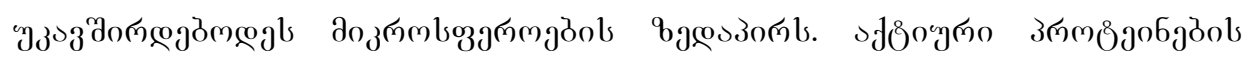




\section{Chapter 8}

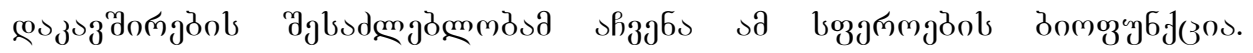

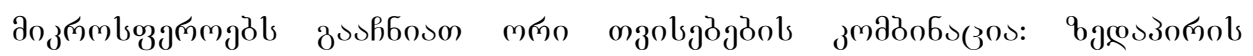

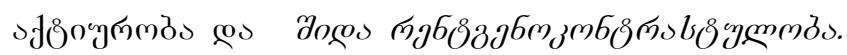

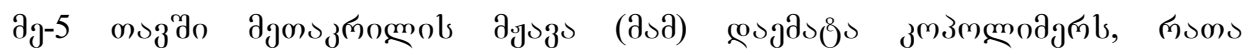

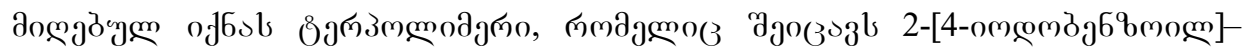

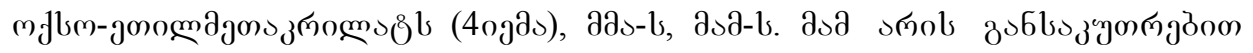
дбодаб

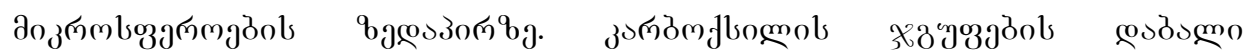

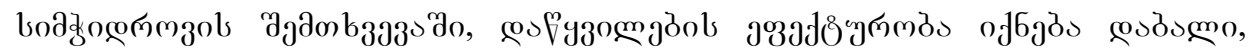

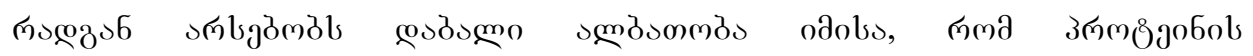

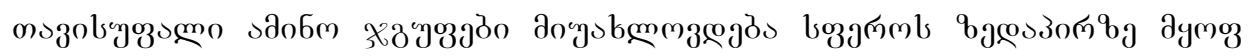

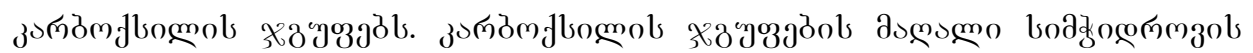

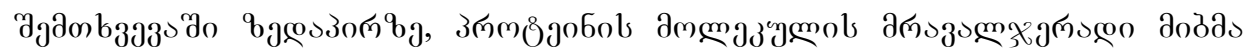

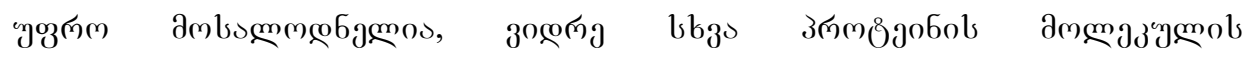

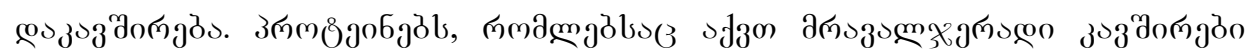

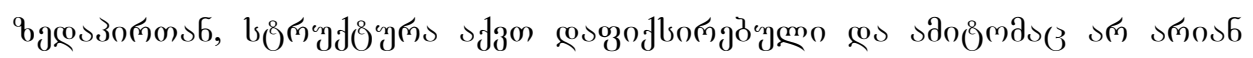

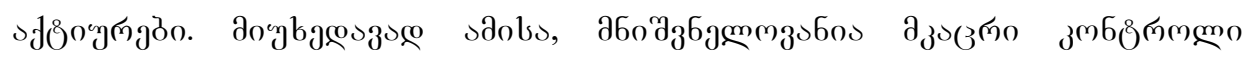

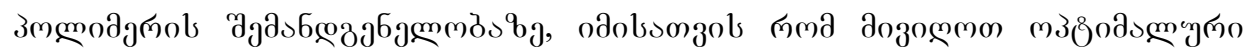

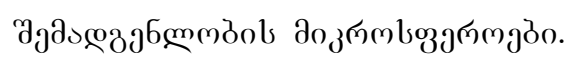

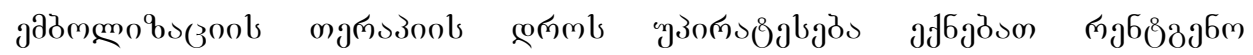

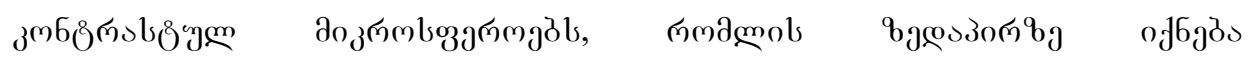

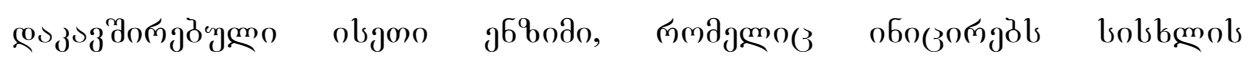

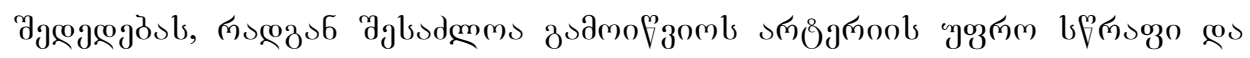

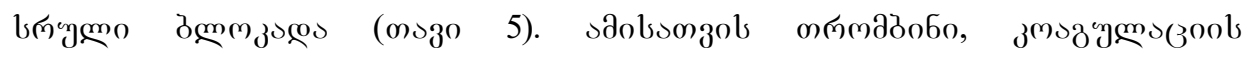

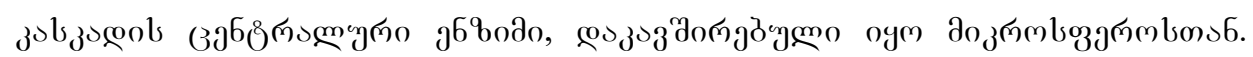

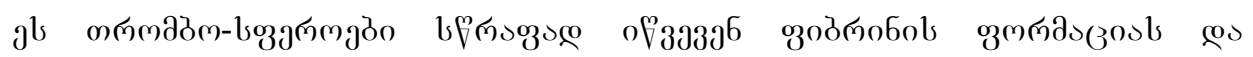

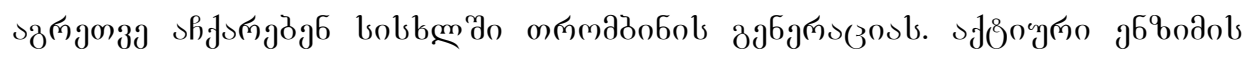

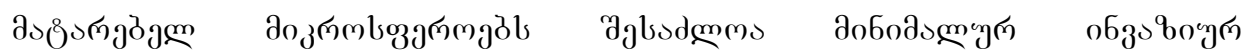

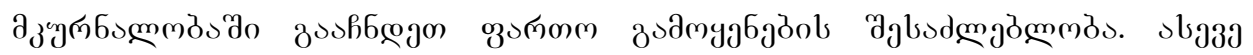

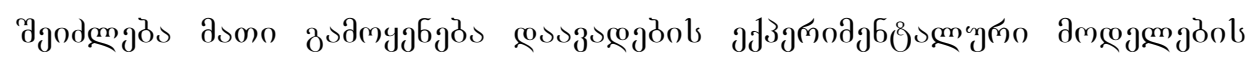

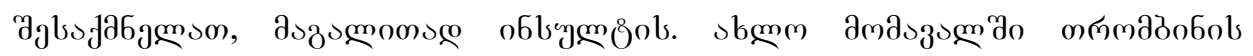

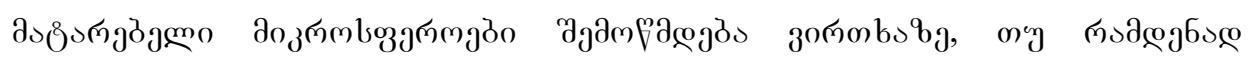

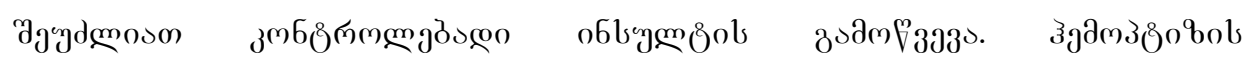




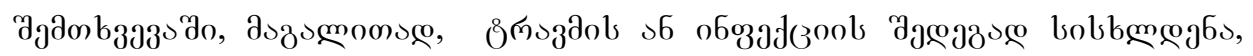

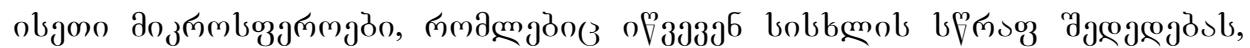

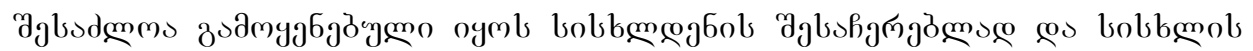

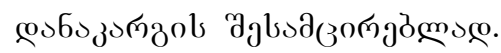

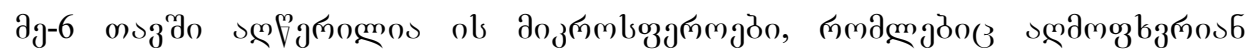

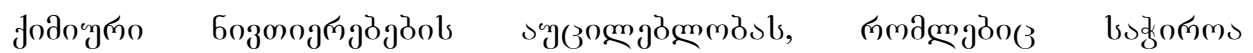

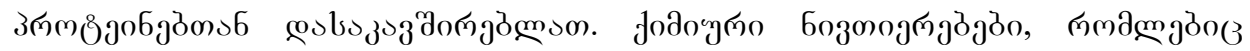

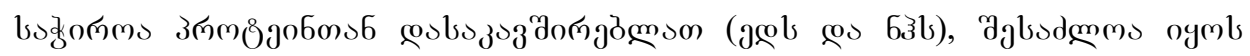

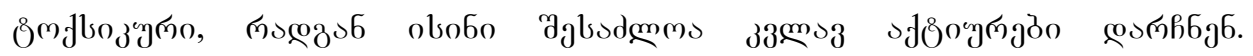
догу

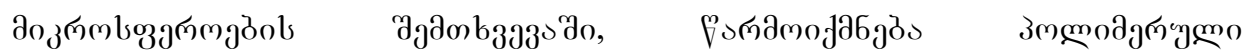

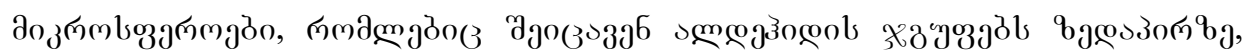

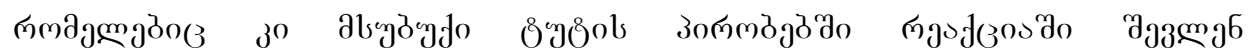

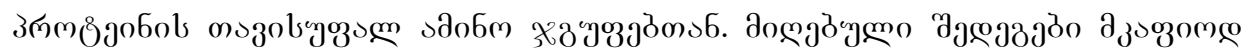

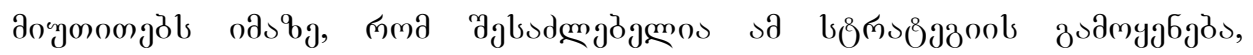

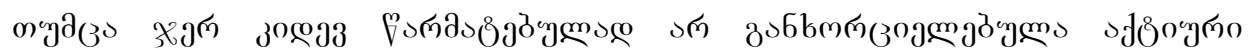

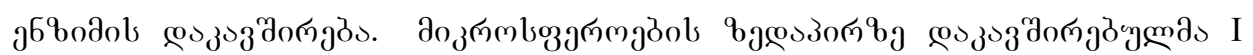

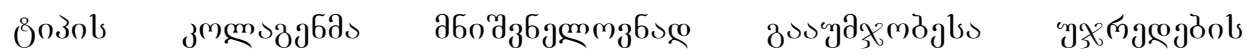

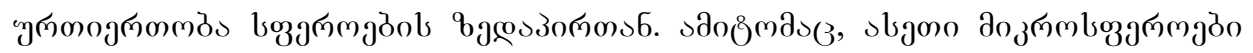

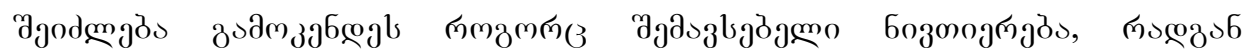

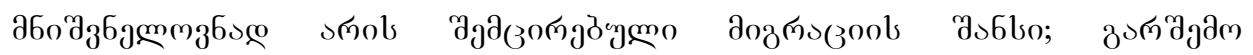

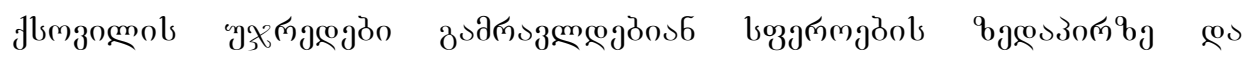

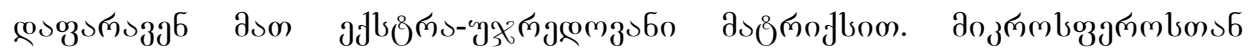

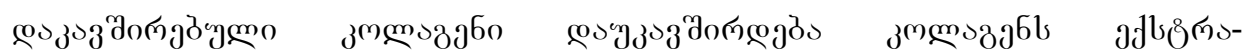

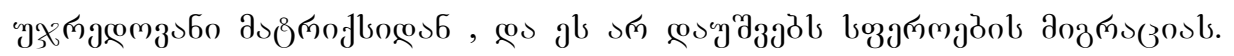

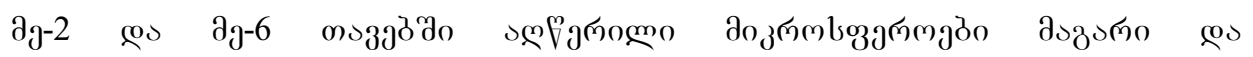

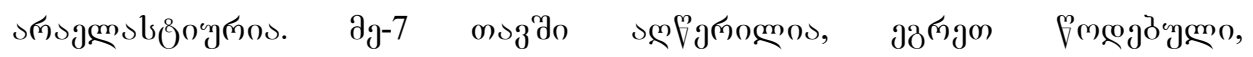

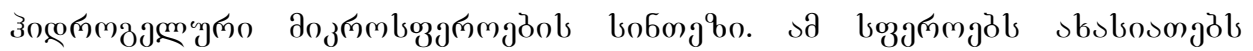

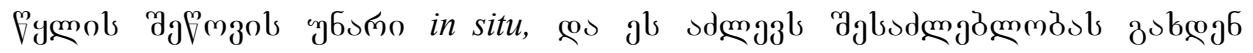

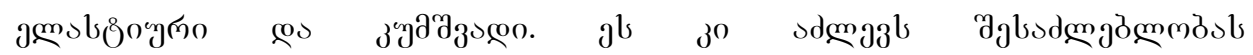

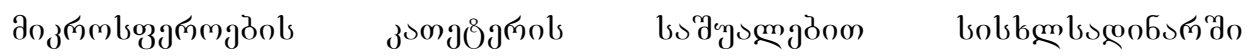

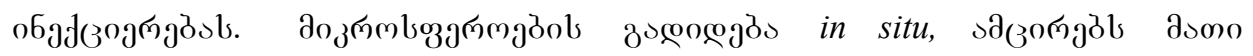

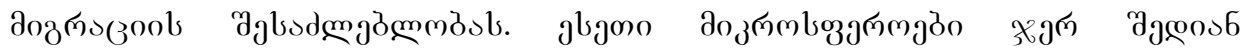




\section{Chapter 8}

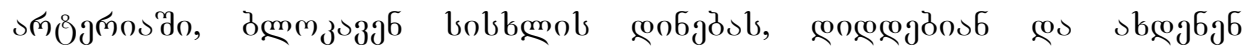

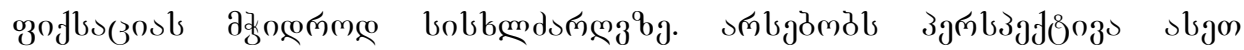

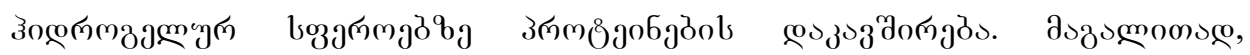
змщх

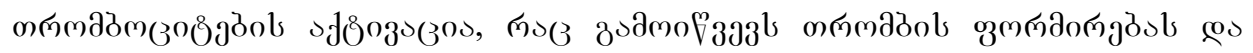

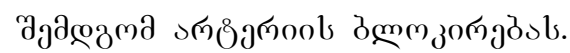

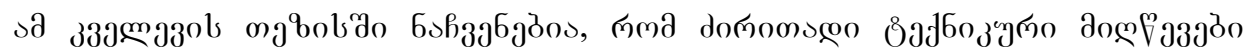

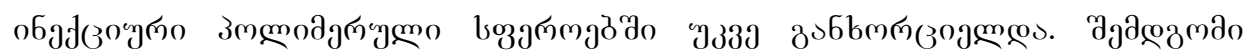

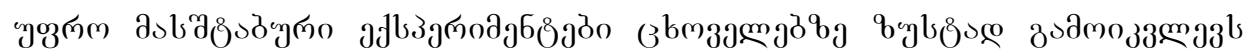

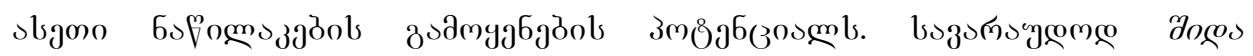

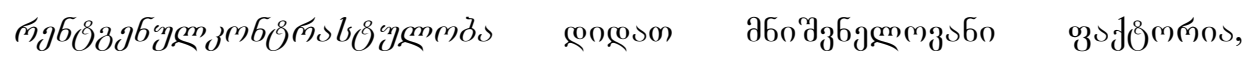
пуб

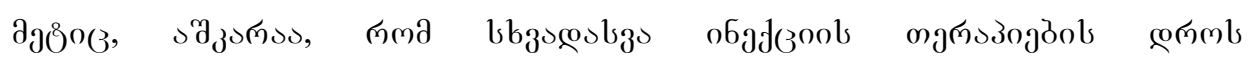

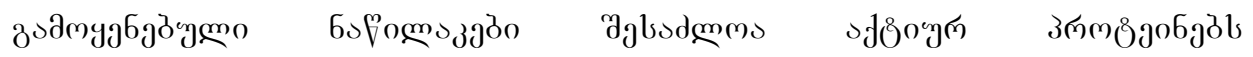

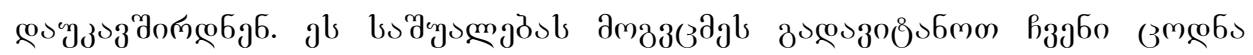

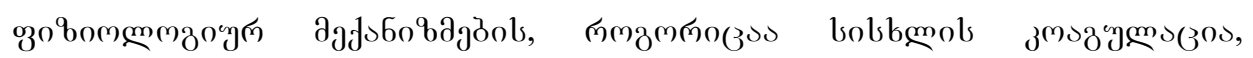

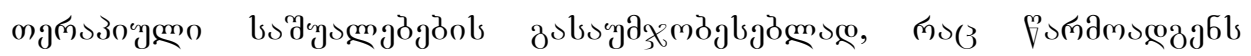

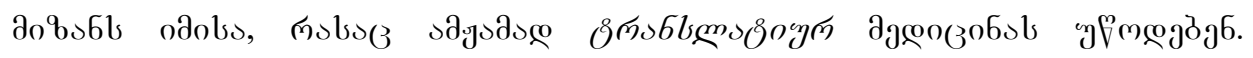




\section{List of Publications}

\section{Manuscripts}

Saralidze K, Aldenhoff YBJ, Knetsch MLW, Koole LH.

Injectable polymeric microspheres with X-ray visibility. Preparation, properties, and potential utility as new traceable bulking agents.

Biomacromolecules. 2003 May-Jun;4(3):793-8.

Emans PJ, Saralidze K, Knetsch MLW, Gijbels MJJ, Kuijer R, Koole LH.

Development of new injectable bulking agents: biocompatibility of radiopaque polymeric microspheres studied in a mouse model.

Journal of biomedical materials research. Part A. 2005 Jun 15;73(4):430-6.

Saralidze K, Knetsch MLW, van Hooy-Corstjens CSJ, Koole LH.

Radio-opaque and surface-functionalized polymer microparticles: potentially safer biomaterials for different injection therapies.

Biomacromolecules. 2006 Nov;7(11):2991-6.

Saralidze K, van Hooy-Corstjens CSJ, Koole LH, Knetsch MLW.

New acrylic microspheres for arterial embolization: Combining radiopacity for precise localization with immobilized thrombin to trigger local blood coagulation.

Biomaterials. 2007 May;28(15):2457-64.

van Hooy-Corstjens CSJ, Saralidze K, Knetsch MLW, Emans PJ, de Haan MW, Magusin PCMM, Mezari B, Koole LH.

New intrinsically radiopaque hydrophilic microspheres for embolization: synthesis and characterisation.

Biomacromolecules, in press.

Saralidze K, Knetsch MLW, Koole LH.

Radiopaque Microspheres containing acrolein for protein attachment to improve cell adhesion. Submitted. 


\section{Abstracts (oral contributions only)}

Saralidze K, Aldenhoff YBJ, van Hooy-Corstjens CSJ, Knetsch MLW, Koole LH. Annual meeting of the Dutch Society for Biomaterials and Tissue Engineering (NBTE) 2003, 2004, 2005, 2006.

Saralidze K, Aldenhoff YBJ, van Hooy-Corstjens CSJ, Knetsch MLW, Koole LH. Integrated Biomedical Engineering for restoration of Human Function (iBME) Conference. 2003, 2004, 2005.

Saralidze K, Aldenhoff YBJ, Hackeng T, Knetsch MLW, Koole LH.

Protein Immobilization on the surface of the injectable radiopaque polymeric microspheres.

Transaction of the $7^{\text {th }}$ World Biomaterials Congress, Sydney, Australia (2004), 1057.

Saralidze K, Aldenhoff YBJ, Knetsch MLW, Koole LH.

Injectable radiopaque polymeric microspheres as new traceable bulking agent.

Transaction of the $7^{\text {th }}$ World Biomaterials Congress, Sydney, Australia (2004), 1826.

Saralidze K, Emans PJ, Kuijer R, Aldenhoff YBJ, Koole LH.

In-vivo biocompatibility of new radiopaque polymeric microspheres.

Transaction of the $7^{\text {th }}$ World Biomaterials Congress, Sydney, Australia (2004), 1875.

Saralidze K, Knetsch MLW, Koole LH.

Radiopaque microspheres for treatment of female stress urinary incontinence: protein attachment to enhance tissue incorporation.

The $19^{\text {th }}$ European Conference on Biomaterials (ESB), Sorrento, Naples, Italy, 2005.

Saralidze K, Knetsch MLW, van Hooy-Corstjens CSJ, Koole LH.

Radiopaque bioactive microspheres for improved embolization therapy and treatment of aneurysms.

First IDEA League Summer School, Biotechnology and Bioengineering Applications in Medicine, Monte Verita, Ascona, Switzerland, 2006. 
Saralidze K, Knetsch MLW, van Hooy-Corstjens CSJ, Koole LH.

Radiopaque bioactive microspheres for improved embolization therapy.

First Dutch Conference on Bio-Medical Engineering (BME) Conference, Egmond aan Zee, The Netherlands, 2007.

Saralidze K, Knetsch MLW, van Hooy-Corstjens CSJ, Koole LH.

Radiopaque bioactive microspheres as injectable biomaterials.

First International Symposium on Surface and Interface of Biomaterials, Chengdu,

China, 2007.

Saralidze K, Knetsch MLW, van Hooy-Corstjens CSJ, Koole LH.

Radiopaque bioactive microspheres as injectable biomaterials.

Colloquium of the Graduiertenkolleg BIOINTERFACE. Abdij Rolduc, Kerkrade, The Netherlands, 2007. 



\section{Acknowledgements}

At the end of this thesis, I finally have the opportunity to thank all those people that have made my years at the University of Maastricht a very enjoyable and remarkable experience. The fact remains that the work underlying a doctoral thesis is to some extent a group effort, which means that I have had support from a number of people. Without them, this thesis would have been so much more difficult to put together.

First of all, I have to express my deep and sincere gratitude to my promotor Leo Koole. Leo, you gave me the opportunity to work in your group. Your encouragement, enthusiasm and continuous support were the basis for this thesis. You were always interested in the progress of my work as well as in non-scientific matters. You always encouraged me to go out and present my work at international meetings, for which I am very grateful.

Also, I owe my most sincere appreciation to Menno. I'm very grateful for your patience, enthusiasm, motivation, that, taken together, makes you a good mentor for me. Your support was far beyond duty. Thank you doesn't seem sufficient but it is said with appreciation and respect. I can't forget that during the trip to Chengdu a Taoist monk made clear you are from the "down-level" (for me he saw the "up-level"), demonstrating that also the ancient art of fortune telling is not always correct.

I also want to thank Tosca for working with me on the microspheres project. You let me participate in the Veni-project on hydrophilic microspheres, and although the preparation of these spheres was sometimes a frustrating business, we always came up with a more-or-less "perfect" method for microsphere-production. Also the optimalisation of radiopacity of the spheres succeeded, although it took a lot of tri-iodo, and boiling water from the lab kettle to get there.

Dear Yvette, you were my first contact and tutor in Maastricht and the biomaterials group. You introduced me to the ins and outs of biomaterials research and you showed me a lot of tricks about organic chemistry and chemical synthesis, which were of 
invaluable importance for the work described in this thesis. And for which I can not thank you enough.

For the in vivo experiments I am extremely thankful the continuous support of Pieter. The first injections of radiopaque microspheres in mice we performed already some years ago, and still you are always enthusiastic about the project. I hope you continue to be involved in the testing of exciting new radiopaque microspheres.

I want to thank some of the other Biomaterials-folks namely Erik, Rachel, Miriam, Peter, Hans for all their support and interest in my research, and for providing a great working environment in the lab. Erik, I hope you will keep enjoying your work although it is in far-away Belgium (nothing is perfect...). Rachel, I am sure you will find the eyeopener of a job soon and wish you all the best. The Eindhoven students Miriam, Peter, and Hans were responsible for bringing the necessary life and fun into the lab. For all of you I can only hope that you remain biomedical wizards even after your trips to Oz.

The research described in this thesis was, for a major part, supported by a grant from the Graduiertenkolleg Biointerface, from the RWTH Aachen. I owe my thanks to Prof. dr. Doris Klee who made me feel at home in the grad-kolleg and always was very supportive. I learned a lot during the Friday-afternoon meetings in Aachen. It sometimes was a nuisance for the speakers to have to change their talk to English, just because of me, but I thank all of them and my colleague "Stipendiaten" for their consideration. During this time, I met a number of "Stips" with which I had some memorable times. The "low sleep-much fun and party" meeting in Ascona (Switzerland) together with Jenny, Birgit, Daniela, Nora, and many others, will be always engraved in my mind. The Graduiertenkolleg has been a nice and comforting environment for me and the regular meetings all over the Euregion were always a pleasure to visit.

Also the assistance from all the people at the central animal facility (CPV) and the Mammography Department of the academic hospital Maastricht (AZM) is greatly acknowledged. This was of critical importance for my work. 
Furthermore, I want to thank the Tchaikovski family, Svetlana and Vadim, for being prepared to support me as paranimfs, also reading and providing me with valuable comments on the Russian version of summary.

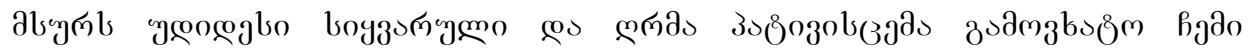

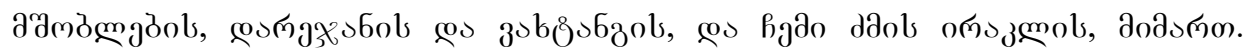

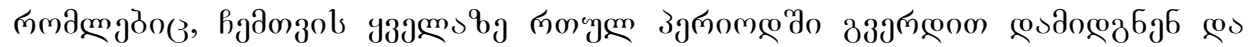

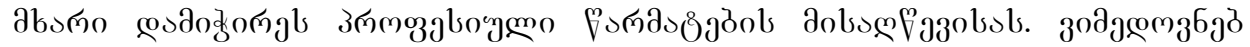

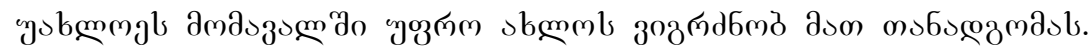

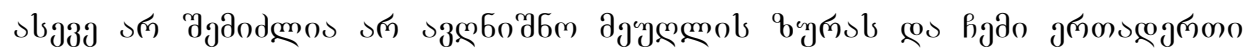

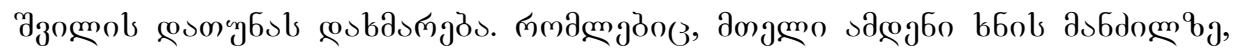

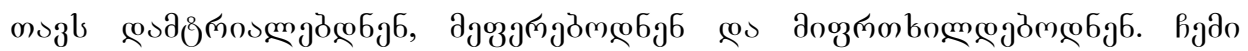

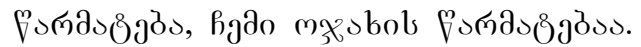

And also many, many sincere thanks to all people I have not named personally.

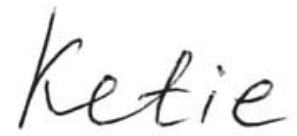




\section{Curriculum vitae}

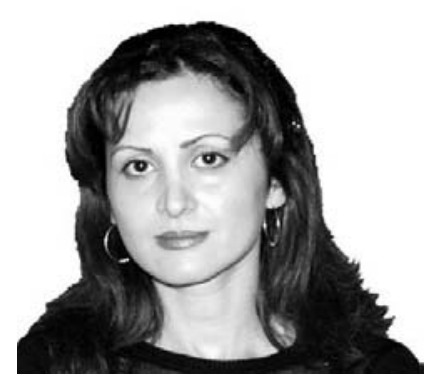

Ketie Saralidze was born on September $5^{\text {th }}, 1970$ in Tbilisi, Georgia. After finishing her secondary education in Tbilisi she studied chemistry at the Ivane Javakhishvili Tbilisi State University, specializing in organic chemistry. In 1992 she obtained her master degree with specialization organic chemistry. Directly thereafter, she started a $\mathrm{PhD}$ project at the P.Melikishvili Institute of Physical and Organic Chemistry at the Georgian Academy of Science, Tbilisi. After coming to the Netherlands she studied chemistry and organic chemistry at the Hogeschool Zuyd, from which she obtained her degree in 2001. During her final project she worked at the Centre for Biomaterials Research of the University of Maastricht under guidance of Prof. Dr. Ir. L.H. Koole on a project on radiopaque microspheres. After finishing the study at the Hogeschool Zuyd, she worked at the Biomaterials group in Maastricht as a research assistant on an industry-funded project concerning bulking agents for plastic surgery purposes and for treatment of SUI. From October 2004 to august 2007 she worked as AIO at the Biomaterials groups of the University of Maastricht on the research project that led to this thesis. As an AIO she was part of the graduiertenkolleg Biointerface in which the RWTH-Aachen, Univeristé de Liège, and the University of Maastricht cooperate. 